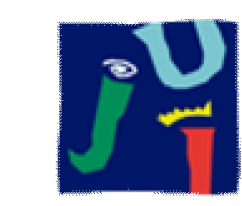

UNIVERSITAT

JAUME-I

TESIS DOCTORAL

Coger el toro por los cuernos vs. den Stier bei den Hörnern packen:

Análisis contrastivo de la competencia fraseológica

de los jóvenes españoles y alemanes

María Isabel Andúgar Andreu

Dirigida por:

DRA. ROSA AGOST CANÓS

DR. JOSÉ LUIS BLAS ARROYO

Castelló de la Plana, noviembre de 2015 



A mis padres 




\section{AGRADECIMIENTOS}

El presente proyecto de investigación se inició con ilusión y ha podido llevarse a cabo con tesón y esfuerzo, a pesar de las dificultades encontradas en el camino. Esto no hubiera sido posible sin el apoyo de las personas que, de un modo u otro, han colaborado a la finalización del mismo y a quienes quiero mostrar mi agradecimiento.

En primer lugar, deseo expresar mi más sincero agradecimiento a los directores José Luis Blas Arroyo y Rosa Agost Canós, por dirigir, aconsejar y animar: a José Luis, por haber estado desde el inicio del proyecto y acompañar en todo momento, y a Rosa, por aportar el entusiamo necesario para acabarlo. En segundo lugar, quiero agradecer la colaboración en el proceso de recogida de datos a los profesores Pedro Tejada, en Castellón, y Jens Kappelhoff, en Hamburgo, y a este último también por su amistad. Agradezco también a Pilar Jara la inestimable ayuda prestada en los momentos finales, agradecimiento que hago extensivo a otras personas de la UJI que sería muy prolijo mencionar pero que también han ayudado o colaborado con diversos gestos.

A mis amigos, por su apoyo incondicional, en especial a Vicente, Carmen N., Ma Antonia, Ana Z., Pablo, Benjamin, Ana V., Manolo M. y Carmen H.; agradecimiento que hago extensivo a Paqui, Marta, Alfredo, Pilar, Xavi, Manolo N., Carol, Sara, Diego, Patxi y a tantos otros a los que me resulta imposible mencionar aquí, pero que han estado en todo el camino, in praesentia o in absentia. A todos ellos, gracias.

Mi agradecimiento final es para mi familia: a ellos dedico este trabajo. 



Lista de abreviaturas, siglas y signos

Adj. Adjetivo

Adv. Adverbio

Atr. Atributo

cf./ Cf. Cónfer, véase

Conj. Conjunción

ed./ eds. Editor, editores

N. Nombre

P. Partícula

p. ej. Por ejemplo

pl. Plural

sg. Singular

Sig. $\quad$ Significación (estadística)

Sust. Sustantivo

UF Unidad/es fraseológica/s (término de uso general)

UF1 Unidad fraseológica del corpus del presente trabajo

V. Verbo

CD Complemento directo

$\mathrm{Cl} \quad$ Complemento indirecto

CC Complemento circunstancial

CN Complemento del nombre

C Pred. Complemento predicativo

C Reg. Complemento de régimen

CV Complementos verbales de rección

C prep. Complemento preposicional

Suj. Sujeto

$\approx \quad \quad$ Equivalencia entre dos UF

$\neq \quad \quad$ No significa lo mismo

$\S \quad$ Capítulo 

ÍNDICE

1. INTRODUCCIÓN 25

2. MARCO TEÓRICO 29

2.1. LA DISCIPLINA: LA FRASEOLOGÍA 29

2.2. LA FRASEOLOGÍA EN LAS DIFERENTES TRADICIONES 32 FILOLÓGICAS

2.2.1. LA FRASEOLOGÍA RUSA 33

2.2.1.1. FASES 34

2.2.1.2. UNIDADES 37

2.2.1.3. LÍNEAS DE INVESTIGACIÓN

2.2.2. LA FRASEOLOGÍA GERMÁNICA 49

2.2.2.1. PRINCIPALES ETAPAS Y LÍNEAS DE INVESTIGACIÓN 50

2.2.2.1.1. PREFASE: HASTA 1970

2.2.2.1.2. FASE DE INICIO: 1970-1980 (1982) 52

2.2.2.1.3. FASE DE CONSOLIDACIÓN: 1980-1990 (1983-1992) 53

2.2.2.1.4. FASE DE AFIANZAMIENTO: 1992-2003 55

2.2.3. LA FRASEOLOGÍA HISPÁNICA 58

2.2.3.1. UNIDADES 60

2.2.3.2. PRINCIPALES APORTACIONES 62

2.3. FRASEOLOGIA ACTUAL 68

2.3.1. PRINCIPALES LÍNEAS DE INVESTIGACIÓN 68

2.3.2. DIVULGACIÓN CIENTÍFICA Y ACADÉMICA 69

2.3.2.1. CONGRESOS 69

2.3.2.2. INVESTIGACIÓN: TESIS/ PROYECTOS/REVISTAS 72

2.3.2.3. OTRAS CONTRIBUCIONES 74

2.4. LA FRASEOLOGÍA CONTRASTIVA 76

2.4.1. INTRODUCCIÓN $\quad 76$

2.4.2. ÁMBITO DE ESTUDIO

2.4.3. ESTADO DE LA CUESTIÓN

2.4.3.1. INTRODUCCIÓN 78

2.4.3.2. ESTUDIOS INTERLINGÜÍSTICOS 80 
2.4.3.2.1. ESTUDIOS DEL ESPAÑOL OTRAS LENGUAS 81

2.4.3.2.2. ESTUDIOS DEL ALEMÁN CON OTRAS LENGUAS 81

2.4.3.2.3. ESTUDIOS INTERLINGÜÍSTICOS ESPAÑOL-ALEMÁN 83

2.4.3.3. ESTUDIOS INTRALINGÜÍSTICOS 85

2.4.3.3.1. ESTUDIOS DEL ESPAÑOL 85

2.4.3.3.2. ESTUDIOS DEL ALEMÁN 86

3. OBJETO DE ESTUDIO 87

3.1. DEFINICIÓN

3.2. RASGOS DELIMITADORES 89

3.2.1. PLURIVERBALIDAD 91

3.2.2. FIJACIÓN 93

3.2.2.1.VARIANTES 93

3.2.2.2.VARIACIONES 94

3.2.3. IDIOMATICIDAD 95

3.2.4. INSTITUCIONALIZACIÓN 97

3.2.5. ESTRUCTURA ORACIONAL 98

3.2.6. FRECUENCIA 99

3.2.7. NOMINACIÓN 100

3.2.8. ANOMALÍAS 100

3.2.9. FIGURAS DE REPETICIÓN 102

3.2.10. RASGOS PRAGMÁTICO-DISCURSIVOS 105

3.3. TIPOS DE UNIDADES 105

3.3.1. UNIDAD FRASEOLÓGICA 109

$\begin{array}{ll}\text { 3.3.2. LOCUCIÓN } & 109\end{array}$

3.3.3. EXPRESIÓN PLURIVERBAL 110

3.3.4. EXPRESIÓN FIJA 111

3.3.5. PAREMIA, REFRÁN, FRASE PROVERBIAL 111

3.3.6. COLOCACIÓN 112

4. LA EQUIVALENCIA FRASEOLÓGICA 115

4.1. DEFINICIÓN 115

4.2. INTERPRETACIONES TRADICIONALES DE LA EQUIVALENCIA 116

4.2.1. CLASIFICACIÓN TRIPARTITA 116

4.2.1.1. EQUIVALENCIA TOTAL 117 
4.2.1.2. EQUIVALENCIA PARCIAL 118

4.2.1.3. EQUIVALENCIA NULA 119

4.2.2. CLASIFICACIÓN CUATRIPARTITA 119

4.2.2.1. EQUIVALENTES EXACTOS 119

4.2.2.2. EQUIVALENTES PARCIALES 120

4.2.2.3. PARALELISMOS FRASEOLÓGICOS 121

4.2.2.4. NO-EQUIVALENTES 122

4.3. ALGUNAS INTERPRETACIONES SOBRE LA NO- 123 EQUIVALENCIA

4.3.1. FALSOS AMIGOS IDIOMÁTICOS 124

4.3.2. CASI-SINÓNIMOS INTERLINGÜÍSTICOS 125

4.3.3. POLISEMIA ASIMÉTRICA $\quad 125$

5. METODOLOGÍA 128

5.1. HIPÓTESIS DE TRABAJO 128

5.2. EL CORPUS 129

5.3. PROCESO DE RECOGIDA DE DATOS 138

5.3.1. LA ENCUESTA 138

5.3.2. FACTORES SOCIALES 152

5.3.3. DESCRIPCIÓN DE LAS MUESTRAS 153

5.3.3.1. EDAD 153

5.3.3.2. SEXO 154

5.3.3.3. BILINGÜISMO 155

5.3.3.4. ENTORNO FAMILIAR 155

5.3.4. LOS ENCUESTADORES 157

5.3.5. HERRAMIENTAS ESTADÍSTICAS 158

6. ANÁLISIS DE LOS DATOS 162

6.1. FASE I: NIVEL LINGÜÍSTICO 162

6.1.1. HIPÓTESIS 1: La competencia fraseológica global de los 162 jóvenes de las comunidades lingüísticas española y alemana presenta diferencias significativas

6.1.2. HIPÓTESIS 2: Determinadas UF son más conocidas en una 163 lengua que en otra

6.1.3. HIPÓTESIS 3: Hay diferencias en el grado de competencia 
activa y pasiva

6.1.4. HIPÓTESIS 4: El tipo de ejercicio condiciona la competencia que 203 muestran los jóvenes

6.1.5. HIPÓTESIS 5: La adscripción temática de las UF determina diferencias en la competencia

Hipótesis 5.1: Las UF del par no adscrito al mismo grupo temático en

ambas lenguas presentan un nivel de competencia diferente en las dos lenguas

Hipótesis 5.2: Los zoologismos presentan un nivel de competencia diferente en las dos lenguas

Hipótesis 5.3: El grupo de UF denominadas somatismos presentan un nivel de competencia diferente en las dos lenguas

Hipótesis 5.4: Las UF referidas a la experiencia humana presentan un nivel de competencia diferente en las dos lenguas

Hipótesis 5.5: Las UF que se refieren a la herencia cultural presentan 216 un nivel de competencia diferente en las dos lenguas

6.2. FASE II: NIVEL SOCIOLINGÜÍSTICO

6.2.1. HIPÓTESIS 6: La competencia fraseológica está condicionada por diversos factores sociales

Hipótesis 6.1: Las diferencias de edad se reflejan en la competencia 222 fraseológica de los jóvenes

Hipótesis 6.2: Chicos y chicas muestran diferencias significativas en el conocimiento de las UF

Hipótesis 6.3: La competencia fraseológica está condicionada por la adscripción lingüística y el grado de bilingüismo de los hablantes

Hipótesis 6.4: El entorno familiar de los jóvenes influye en el nivel de competencia fraseológica

6.2.2. HIPÓTESIS 7: La interacción entre algunas variables son significativas para explicar la competencia fraseológica

Hipótesis 7.1: La interacción entre las variables edad y sexo son significativas para explicar la competencia Hipótesis 7.2: La interacción entre las variables edad y bilingüismo es significativa para explicar la competencia 
Hipótesis 7.3: La interacción entre las variables edad y entorno familiar es significativa para explicar la competencia

Hipótesis 7.4: La interacción entre las variables sexo y bilingüismo es significativa para explicar la competencia

Hipótesis 7.5: La interacción entre las variables sexo y entorno familiar es significativa para explicar la competencia

Hipótesis 7.6: La interacción entre las variables bilingüismo y entorno familiar es significativa para explicar la competencia

7. CONCLUSIONES

8. BIBLIOGRAFÍA

9. ANEXOS

ANEXO I. DOCUMENTACIÓN FRASEOGRÁFICA DEL CORPUS

ANEXO II. ENCUESTAS

ANEXO III. DOCUMENTACIÓN ESTADÍSTICA 





\section{INTRODUCCIÓN}

La presente investigación ofrece un análisis de la competencia fraseológica de los jóvenes de dos comunidades de habla diferentes: la española y la alemana. Las lenguas comparadas son, por tanto, el español y el alemán.

Entendemos por competencia lingüística la disponibilidad activa o pasiva de determinadas estructuras que poseen los hablantes de una lengua: es decir, no solo qué unidades lingüísticas son capaces de usar (competencia activa), sino también aquellas que conocen, aunque no suelan utilizar (competencia pasiva). ${ }^{1}$ En el caso que nos ocupa, nuestro objetivo es medir cuantitativa y cualitativamente el conocimiento de expresiones fraseológicas que poseen los jóvenes.

Las expresiones fraseológicas en cualquiera de sus formas (colocaciones, locuciones, refranes, etc. $)^{2}$ suponen un componente muy importante de las lenguas, principalmente por dos motivos: en primer lugar, por su frecuencia de aparición, ya que están muy presentes en todo tipo de textos y en cualquier soporte; en segundo lugar, por su complejidad, pues a diferencia de lo que ocurre con las palabras, los términos más simples de las lenguas, la consulta de las unidades fraseológicas en los diccionarios no resulta tarea fácil. Es de suponer que el conocimiento exacto y, como consecuencia de ello, la correcta utilización de la Fraseología, no es ni siquiera sencillo para los propios hablantes de una lengua; mucho más difícil, por tanto, será dominar el sistema fraseológico de una segunda lengua, que no solo presentará esquemas lingüísticos diferentes, sino también culturales.

$\mathrm{Si}$ bien es frecuente encontrar estudios lingüísticos que investigan la competencia lingüística en cuanto a la disponibilidad léxica en general, tanto en español como en alemán, es decir, el caudal de vocabulario que activa o

\footnotetext{
${ }^{1}$ Yaguello (1983: 79-80) se refiere a la competencia pasiva como la «aptitud para reconocer», y la competencia activa a la «capacidad de reproducir».

${ }^{2}$ Más adelante (cf. § 3.3.1) se hace una descripción pormenorizada de estas expresiones, objeto de estudio del presente trabajo.
} 
pasivamente conoce un grupo de hablantes, no podemos decir lo mismo de la competencia o disponibilidad fraseológica en general, que cuenta con un número de trabajos especializados sensiblemente menor. ${ }^{3}$

Tal vez esto se deba a que la misma investigación fraseológica es relativamente joven comparada con la lingüística en general, pues debemos remontarnos apenas a las últimas décadas para presenciar un desarrollo importante de los estudios fraseológicos, no solo desde una perspectiva teórica, sino también aplicada, de manera que actualmente podemos considerar la situación de la disciplina como más boyante.

Como se ha mencionado, a pesar de la reciente eclosión de los estudios fraseológicos, la competencia fraseológica ha sido poco estudiada, especialmente en expresiones fraseológicas distintas a los refranes. También es escasa la investigación de la competencia que relaciona los sistemas fraseológicos de lenguas diferentes, ${ }^{4}$ como se propone en el presente estudio, aspecto sobre el que no conocemos la existencia de investigaciones previas. Precisamente la ausencia de trabajos de esta índole, es decir, que midan la competencia de sistemas fraseológicos equivalentes, ${ }^{5}$ nos animó a intentar suplir esta laguna con la presente investigación.

Así pues, la inquietud que motivó el presente estudio era doble: en primer lugar, deseábamos averiguar si la competencia de los hablantes respecto a las expresiones equivalentes era similar en ambas lenguas contrastadas, el español y el alemán; y, en segundo lugar, si algunos factores sociológicos podían influir en esa competencia, y en qué medida determinaban los resultados en cada una de las dos poblaciones. Para obtener los datos de la investigación se ha elaborado una encuesta ad hoc con dos partes diferenciadas, una lingüística, en la que se presentan cincuenta expresiones equivalentes en ambas lenguas y se investiga la competencia que poseen los

\footnotetext{
${ }^{3}$ No obstante, se han realizado algunos estudios en lo que respecta a refranes, por ejemplo, las investigaciones realizadas por Sevilla para el español (Sevilla, 2010).

${ }^{4}$ Los estudios contrastivos de fraseología abordan generalmente aspectos sobre la lengua literaria, el análisis de corpus y sus traducciones (López Roig, 2002), o las equivalencias entre las lenguas (Tarnovska, 2004).

${ }^{5}$ Sobre el concepto de equivalencia fraseológica, cf. § 4 .
} 
hablantes, y otra sociológica, en la que se obtienen datos de los sujetos por medio de un breve cuestionario sociológico.

Del mismo modo que un estudio sobre disponibilidad léxica ofrece datos interesantes sobre el uso del idioma por parte de la población que lo sustenta, entendemos que este tipo de estudios en el campo fraseológico pueden también ser de gran ayuda, pues no solo arrojarán luz sobre el uso real de fraseología en las comunidades lingüísticas respectivas y se comprobará si las expresiones más usadas en una comunidad coinciden en la otra, sino que, además, verificará si esa competencia es socialmente homogénea o por el contrario depende de ciertos factores sociales.

El objetivo perseguido con este tipo de investigaciones no acaba con la descripción de la situación, sino que la información lingüística obtenida puede utilizarse también en posteriores estudios, como el establecimiento de mínimos fraseológicos, ${ }^{6} \tan$ útiles para trabajar en situaciones de interacción lingüística, como pueden ser la docencia de lenguas extranjeras o la traducción; y, por supuesto, en la elaboración de herramientas para estas dos disciplinas lingüísticas, como los diccionarios fraseológicos con criterios de uso efectivo, tan necesarios para contrastar estas expresiones ( $\mathrm{y}$ tan escasos al mismo tiempo).

La presente tesis doctoral presenta la siguiente estructura. Tras esta breve introducción (cf. $\S 1$ ), iniciamos la investigación, como no podía ser de otra manera, con el marco teórico (cf. $\S 2$ ), que ofrece una revisión de lo que han sido los estudios fraseológicos desde sus inicios hasta la actualidad: los inicios de la disciplina en la filología rusa (cf. § 2.2.1) y el desarrollo de esta materia en las tradiciones filológicas que son objeto de nuestro estudio: la alemana (cf. $\S$ 2.2.2) y la española (cf. $\S 2.2 .3$ ). Teniendo en cuenta el enfoque contrastivo de nuestro trabajo, también abordamos esta vertiente de los estudios fraseológicos (cf. § 2.4), y hacemos hincapié especialmente en las

\footnotetext{
${ }^{6}$ Un mínimo fraseológico sería un conjunto de expresiones fraseológicas que son relevantes por la frecuencia de uso en una lengua. El concepto ya ha sido muy usado en paremiología (Tarnovska, 2004: 3), pero muy poco en fraseología en general.
} 
investigaciones contrastivas de la combinación lingüística español-alemán. Continuamos esta parte teórica con la revisión terminológica tanto del objeto de estudio (cf. § 3) como de los rasgos definitorios. Posteriormente, llevamos a cabo una revisión de la noción de equivalencia, centrada en el campo fraseológico (cf. § 4). Seguimos con la exposición de la metodología (cf. § 5), en la que planteamos las hipótesis de nuestra investigación, explicamos el desarrollo de nuestra investigación, tanto a nivel lingüístico como sociológico, así como los pasos metodológicos seguidos. A continuación, sigue el análisis de los datos (cf. § 6), la exposición de los resultados obtenidos cuantitativa y cualitativamente y las interpretaciones que nos sugieren. Procedemos después a presentar las principales conclusiones a las que ha llevado el análisis de los datos (cf. § 7) y consignamos las fuentes documentales utilizadas en el capítulo dedicado a la bibliografía (cf. $\S 8$ ). Para concluir, aportamos un anexo con la información adicional. 


\section{MARCO TEÓRICO}

\subsection{LA DISCIPLINA: LA FRASEOLOGÍA}

La palabra fraseología remite etimológicamente a dos términos griegos: el verbo $\varphi \rho a ́ \zeta \omega$, que significa 'dar a entender, mostrar, anunciar' y el sustantivo

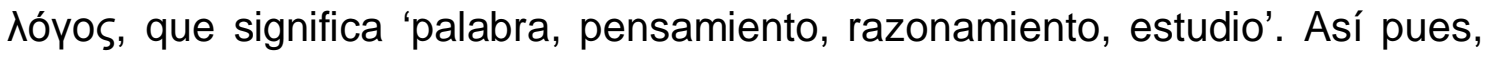
se podría definir la fraseología como el estudio de lo que se da a entender, añadiendo un sentido más amplio a lo que simplemente se dice de una manera objetiva y sencilla. En alemán se utiliza igualmente el término Phraseologie para definir la disciplina, atendiendo al mismo origen culto. El uso del término fraseología se registra ya en la época del Humanismo, en la que se hacía referencia con él al estudio de expresiones idiomáticas. Pero su difusión como denominación de la disciplina autónoma es bastante más reciente, y ha corrido en paralelo al auge de los estudios en este campo.

No obstante, el término fraseología puede ser utilizado con dos acepciones: por un lado, como genérico o hiperónimo, englobando en él todo el conjunto de expresiones fraseológicas; ${ }^{7}$ y por otro lado, como término específico o hipónimo, denominando así una disciplina que solo se ocuparía de aquellas expresiones descritas como unidades fraseológicas ${ }^{8}$ y diferenciándolas en este caso de otras como los refranes.

Como en cualquier otra disciplina científica, se intenta llegar a un consenso terminológico sobre la denominación de la disciplina en sí misma y la de su objeto de estudio, el cual abordaremos con más profundidad en apartados posteriores. Tradicionalmente, hay dos puntos de vista o concepciones desde los que se ha intentado definir la materia fraseológica y que han dado origen a la extendida controversia entre la concepción ancha y la concepción estrecha de la fraseología.

\footnotetext{
${ }^{7}$ Incluso refranes (en alemán Sprichwörter), estudiados específicamente por la Paremiología (en alemán Parömiologie), considerada habitualmente como una subdisciplina de la primera.

${ }^{-}$En adelante utilizaremos la abreviatura UF para unidad fraseológica tanto en singular, como en plural. Además, es el término utilizado mayoritariamente en el presente trabajo.
} 
La distinción entre la concepción estrecha y concepción ancha de la fraseología se enmarca en el ámbito de la disciplina fraseológica y, de alguna manera, con ella se intenta explicar el alcance de las unidades que en cada caso son objeto de estudio. Como recuerda Carneado (1985: 68), ya en 1957, el lingüista ruso Ozhegov planteaba la existencia de dos fraseologías: la fraseología en sentido estrecho y la fraseología en sentido amplio. Ozhegov mantenía que ambas poseen una característica común, como es la estabilidad, pero que, como contrapartida, presentan una gran heterogeneidad de estructuras y funcionalidad. De acuerdo con este autor, la fraseología en sentido estrecho estaría formada por combinaciones de palabras que poseen características estructurales aptas para construir oraciones o ser ellas mismas elementos oracionales; por ejemplo, expresiones del tipo coger el toro por los cuernos, susceptible de formar parte de una oración, tal y como se puede apreciar en el siguiente contexto: 'la situación en el equipo era desastrosa: el entrenador cogió el toro por los cuernos y puso a cada cual en su sitio'. En la fraseología en sentido amplio entrarían, por ejemplo, las anteriormente señaladas, y las que no poseen esas características, como los refranes, que son textos independientes pues constituyen ellos mismos oraciones: 'El hombre dijo: No es oro todo lo que reluce'. Ambas concepciones continúan teniendo vigencia hoy en día y cuentan con defensores y detractores. A continuación, pasamos a delimitarlas con más detalle.

La concepción ancha de la fraseología es la más extendida actualmente, no solo en el ámbito hispánico, sino también en otras tradiciones filológicas. Esta concepción considera como objeto de estudio de la fraseología toda expresión lingüística que puede definirse como expresión fija, sean cuales sean sus características. Así, englobaría grandes grupos como colocaciones, locuciones y enunciados fraseológicos. Por tanto, esta concepción aunaría bajo uno mismo enfoque expresiones tan dispares como colocaciones del tipo regalo envenenado, locuciones como encontrar una aguja en un pajar y paremias o refranes como $A$ buen entendedor, sobran palabras. ${ }^{9}$

\footnotetext{
${ }^{9}$ En el caso de refranes, utilizamos la mayúscula al inicio.
} 
García-Page (2008: 20) menciona algunos de los seguidores en el ámbito español de la concepción ancha de la fraseología, entre los que destacamos a Carneado (1985), Corpas (1996), Ruiz Gurillo (1997), Sancho Cremades (1999), Iñesta y Pamies (2002), López Roig (2002) y Mena Martínez (2002).

En el ámbito europeo también es la concepción que tiene más adeptos, y entre ellos se encuentran numerosos eslavistas, germanistas o hispanistas, como Burger (1973), Thun (1978), Gläser (1978), Fleischer (1982), Gréciano (1983), Dobrovol'skij (1988), B. Wotjak (1992), Mel'čuk (1995), Korhonen y G. Wotjak (2001).

A diferencia de la anterior, mantener una concepción estrecha de la fraseología supone liberarla de carga, excluir muchas de las unidades susceptibles de ser su objeto por tener características peculiares frente a otras unidades.. En definitiva, la concepción estrecha reduce la variedad del objeto de estudio, centrándolo en unas clases de expresiones determinadas y dejando para otras disciplinas aquellas que no considera su objeto de estudio.

El máximo representante autoproclamado de la concepción estrecha es Casares, aunque a juicio de García-Page (2008: 20), no puede considerarse muy estrecha si acoge locuciones, frases proverbiales y enunciados con verbo soporte. En ocasiones, también Ruiz Gurillo defiende una visión estrecha de la fraseología:

Resulta más acertado para nuestros propósitos partir de una concepción estrecha que tenga en cuenta, fundamentalmente, las locuciones, las frases proverbiales del tipo I y las unidades sintagmáticas (Ruiz Gurillo, 1997: 72). ${ }^{10}$

A pesar de su concepción estrecha, Ruiz Gurillo considera que la fraseología «parece estar estructurada como un continuum difícil de segmentar» (1997: 71). En cualquier caso, la concepción descrita por Ruiz Gurillo es aglutinadora.

\footnotetext{
${ }^{10}$ Ruiz Gurillo define las frases proverbiales de tipo I como frases que son conmutables por palabras o sintagmas como Armar las de San Quintín (Ruiz Gurillo, 1997: 69-70).
} 
Gacía-Page (2008: 23) también aboga por una concepción estrecha de la fraseología aunque, desde nuestro punto de vista, es más estructurada que la de sus predecesores:

Los refranes [...] han de ser estudiados por la Paremiología [...]; las colocaciones y los predicados con verbo soporte han de ser estudiados por la Gramática (Sintaxis); [...] Las solidaridades, entendidas a veces como clase de colocaciones, también quedarían fuera del ámbito de la Fraseología.

Así pues, para García-Page la locución o unidad fraseológica sería el núcleo y objeto de estudio de la Fraseología, que incluiría locuciones con función sintáctica de elemento oracional (nominal, verbal, adjetival, adverbial, preposicional, conjuntiva), como jugarse el tipo, en un periquete, y las fórmulas pragmáticas (locuciones interjectivas), como tanto gusto. ${ }^{11}$

La investigación más moderna, a juicio de García-Page:

Ha ido atribuyendo a la Fraseología unidades que no le pertenecen, y se ha ido convirtiendo en una especie de cajón de sastre al que han ido a parar estructuras sintagmáticas modernamente conocidas como colocaciones, solidaridades, predicados de verbo soporte y compuestos sintagmáticos (García-Page: 2008, 8).

En definitiva, las delimitaciones de los estudios fraseológicos siguiendo una concepción ancha o estrecha de la fraseología responden al mismo intento de precisar el alcance de la materia, bien extendiéndolo a diferentes tipos de unidades, bien acotándolo en beneficio de alguna de ellas. Se trata, obviamente de la necesaria cuestión de los límites en cualquier investigación.

\subsection{LA FRASEOLOGÍA EN LAS DIFERENTES TRADICIONES FILOLÓGICAS}

Los orígenes en el tratamiento científico de las expresiones fraseológicas suelen situarse en la Europa central, con la publicación en 1909 del Traité de

\footnotetext{
${ }^{11}$ Puesto que aparecen en inicio de frase, consignamos estas expresiones en mayúscula.
} 
stylistique française de Bally. Este impulso fue recogido y desarrollado más tarde por la filología soviética.

A continuación, ofrecemos una síntesis de los estudios fraseológicos por las diferentes tradiciones filológicas y mostramos su relevancia para la disciplina objeto del presente estudio. En un principio hacemos mención de la fraseología de la extinta Unión Soviética, como precursora de la concepción moderna de la fraseología, posteriormente aludimos a la tradición alemana y finalizaremos con la fraseología española. ${ }^{12}$

\subsubsection{LA FRASEOLOGÍA RUSA}

En la tradición rusa, al igual que en otras filologías, la fraseología puede ser entendida bien como un subsistema del léxico que contempla todo tipo de unidades fraseológicas ${ }^{13}$ de una lengua dada, o bien como la disciplina lingüística que se ocupa del análisis de dichas unidades fraseológicas. Ambas concepciones suelen coexistir, pues difícilmente puede separarse una de otra, todo ello dependiendo del enfoque que en cada momento se quiera aplicar.

El nacimiento de la Fraseología como disciplina científica suele situarse en la antigua URSS durante las décadas de los 40 y los 50 con los trabajos de Vinogradov. A pesar de la novedad que por esas mismas fechas planteaban aquí los trabajos de Julio Casares, la naciente disciplina no tuvo en nuestro país la continuidad y el desarrollo con que contó en la antigua Unión Soviética, muy prolífica desde los inicios.

\footnotetext{
${ }^{12}$ No se alude a la fraseología francesa (Mejri, 2007) o a la anglosajona (Norrick, 2007), por cuestiones obvias de espacio, y lo mismo sucede con otras de nuestro entorno. Las consignadas son las de mayor importancia para nuestro estudio.

${ }_{13}$ Unidad fraseológica (UF) es el término genérico más utilizado en español, aglutinador de diferentes unidades, todas ellas expresiones fijas (también será el que utilizaremos en el presente estudio). En inglés suele ser Phrasem el más usado, aunque también se usa Idiom en ese sentido. En alemán el término más utilizado es Phraseologismus.
} 


\subsubsection{FASES}

Tradicionalmente, se establece la siguiente cronología en los estudios fraseológicos soviéticos (Dobrovol'skij y Filipenko, 2007: 714):

- Primera fase, que tendría sus inicios en la década de los años 40 y que se prolongaría hasta la década de los 80 . Se trataría de la tradición fraseológica presidida por la figura de Vinogradov.

- Segunda fase, cuyo representante más importante serían Mel'čuk y sus seguidores, y que se inicia a partir de la década de los 60 .

- Tercera fase, a partir de la década de los 80 hasta la actualidad.

Las primeras obras importantes de Vinogradov, publicadas en la década de los cuarenta, marcarán un punto de partida en los estudios fraseológicos. Tanto él como sus seguidores abordan los problemas terminológicos y delimitan no solo la disciplina, sino también su objeto de estudio. La ocupación predominante por entonces era la distinción entre tipos de unidades y la clasificación taxonómica de estas, para lo cual se basaba en la motivación más que en criterios estructurales. Así, Vinogradov (1946) presentaba una clasificación en tres tipos básicos: expresiones fijas, expresiones motivadas y colocaciones restringidas. ${ }^{14}$

Los trabajos de Vinogradov gozaron de la mayor relevancia y dominaron durante muchos años la investigación fraseológica rusa. A pesar de ello, surgieron ya desde los primeros momentos algunas aproximaciones alternativas, como la propuesta por Aničkov (1964), quien consideraba la fraseología como una disciplina lingüística que se ocupa de combinaciones de palabras: ${ }^{15}$

\footnotetext{
${ }^{14}$ Más adelante, se hace una nueva referencia a Vinogradov en la que se explican estas denominaciones (cf. § 2.2.1.1).

${ }^{15}$ Sin embargo, sus propuestas no gozaron de popularidad, y no sería hasta mucho después, durante la década de los 90, cuando se retomarían sus ideas, interesantes para la fraseología más moderna, pues sus criterios de clasificación eran estructurales. Aničkov entendía que todas las combinaciones de palabras estaban unidas más o menos y distinguía entre tres tipos de combinaciones:

- una palabra 'autosemántica' + una 'sinsemántica', es decir, palabras con significado léxico en el primer caso, o simplemente relacional, en el segundo, p. ej. 'en casa',
} 
He considers phraseology as a linguistic discipline concerned with general mechanisms of lexical combinatorics, rather than one dealing with special types of lexical units (Dobrovol'skij y Filipenko, 2007: 715).

Šanskij es otro autor importante de esta primera etapa, a la que se suele caracterizar como el periodo clásico de la fraseología rusa. Šanskij (1963) añadió un cuarto tipo a los sugeridos por Vinogradov, al que denominó expresiones fraseológicas, que a su vez subdividía en dos clases: expresiones fraseológicas comunicativas, que tenían estructura de frase, y expresiones fraseológicas nominativas.

La segunda corriente, parcialmente coétanea con la anterior, se desarrolla a partir de la década de los 60 y su principal exponente será Mel'čuk. Tanto él como sus seguidores plantean una alternativa a las investigaciones de Vinogradov, y se centran en las unidades fraseológicas y en las propiedades combinatorias de estas. En este periodo desarrollan sus propias teorías numerosos autores, como Amosova (1963), Cernyševa (1970), Molotkov (1970) y Telija (1966), entre otros. Incluso algunos de ellos realizan estudios en contraste con otras lenguas diferentes al ruso, como las aportaciones de Kunin y Amosova en inglés, Cernyševa en alemán o Gak en francés, por mencionar solo algunos de los más conocidos. Merece la pena comentar el trabajo de Molotkov (1977) por la concreción de su propuesta: este autor considera que el objeto de la fraseología son los idioms (término equivalente a locuciones/ unidades fraseológicas) y excluye las colocaciones, pero también los refranes, etc. Los criterios que utiliza son la la estructura de frase y la idiomaticidad alta: así pues, aúna un criterio estructuralista con otro semántico. Considera que el núcleo de la fraseología ha de poseer idiomaticidad, pero no estructura de frase. Distingue tipos clásicos también en la tradición fraseológica hispánica como locuciones nominales, verbales, adjetivales, etc.

- dos palabras autosemánticas: 'hoja de papel',

- tres o más palabras autosemánticas que tienen estructura de frase, o incluso uniones de frases.

A pesar de esta clasificación de tipo estructural, también contemplaba la motivación, como mostraba su clasificación de unidades fraseológicas como colocaciones restringidas y expresiones fijas (Idiom). 
A partir de la década de los 80 hasta el momento presente, la fraseología rusa centra su interés especialmente en los aspectos cognitivos y etnoculturales de las expresiones fraseológicas como novedad, aunque también se investigan las otras vertientes. Una aportación interesante es la de Šmeley (2003), quien diferencia las unidades fraseológicas de las combinaciones libres de palabras en que, en las primeras, sus elementos están unidos de alguna manera. Distingue tres tipos de combinaciones de palabras dentro de la fraseología:

- Paradigmáticamente unidas (paradigmatically bound word combinations), p. ej. white mushrooms (boletus), que pertenecería al paradigma léxico de mushroom.

- Sintagmáticamente unidas (syntagmatically bound word combinations): son frasemas que incluyen un constituyente usado solo en ciertas combinaciones, p. ej. en ruso pisčaja bumaga (papel para escribir), donde pisčaja es constituyente único.

- Derivacionalmente unidas (bound word combinations), p. ej. en ruso glubokaja osen (en inglés deep autumn, late autumn, otoño profundo, tardío), donde glubokaja está utilizado en su segunda acepción metafórica, derivada de la primera.

Según Dobrovol'skij y Filipenko (2007: 718), dicho planteamiento:

Explains certain relations in the lexical system relevant to phraseology rather than suggesting a typology of phrasemes

Por supuesto que es importante delimitar unidades fraseológicas, pero lo importante de esta aportación es la puesta en evidencia del comportamiento de estas unidades.

Los campos de estudio de la fraseología rusa abarcan un elenco muy amplio, pues tratan entre otros:

- la clasificación de frasemas y el aparato conceptual de la fraseología 
- los aspectos connotativos y la estructura de la imagen que subyace en la semántica de los frasemas

- Ias propiedades combinatorias de las unidades léxicas

- el análisis contrastivo de las unidades fraseológicas

- las investigaciones lexicográficas

- los estudios de índole cognitiva

- las investigaciones etnoculturales

Al final del capítulo desarrollaremos este apartado, cuando abordemos las líneas de investigación. De alguna manera, la investigación fraseológica rusa ha tendido, con el tiempo, al igual que otras de nuestro entorno, a superar una etapa taxonómica inicial, de carácter predominantemente teórico, a ofrecer planteamientos más generales, tendentes a unir más que a separar unidades: es decir, se supera la necesidad de nombrar y delimitar expresiones por encima de todo, a considerarlas y observarlas como un conjunto, a estudiar su comportamiento, más que a definirlas. Como han señalado Dobrovol'skij y Filipenko:

Current approaches to classification of phrasemes do not concentrate on postulating new types and classes, but try to discover constitutive criteria for various phrasemes types. (Dobrovol'skij y Filipenko, 2007: 718).

\subsubsection{UNIDADES}

Uno de los principales objetivos de Vinogradov respecto a la fraseología rusa era desarrollar conceptos para describir frasemas y establecer criterios para clasificarlos, así como esbozar una clasificación de la fraseología rusa. Vinogradov (1946) clasificó las UF en tres tipos:

- Frozen idioms (frazeologičeskie sraščenija, expresiones fijas): expresiones completamente inmotivadas, cuyo significado no puede derivarse del significado de sus constituyentes, pues la imagen 
subyacente ha desaparecido: Armar las de San Quintín, A buenas horas, mangas verdes. ${ }^{16}$

- Motivated idioms (frazeologičeskie edinstva, expresiones motivadas): poseen una forma interna viva, de manera que la estructura de la imagen juega un importante papel para entender la expresión: Coger el toro por los cuernos.

- Restricted collocations (frazeologičeskie sočetanija, colocaciones restringidas): el significado puede derivarse del significado de sus constituyentes, pues uno de ellos tiene un significado fraseológico unido a la expresión, pelo ensortijado.

La crítica que se le hace a Vinogradov es que su clasificación está basada en el fenómeno de la motivación y no tiene en cuenta criterios estructurales, lo que conlleva que UF que pertenecen a una misma tipología con estructura de frase (proverbs, speech formulae, entre otros) puedan ser clasificados, atendiendo a su teoría, a veces como frozen idioms, otras como motivated idioms e incluso como restricted collocations (Dobrovol'skij y Filipenko, 2007: 715).

Otra de las clasificaciones de la fraseología rusa es la que nos porporciona Aničkov (1937), que a diferencia de Vinogradov, utiliza criterios estructurales. Así, este autor diferencia entre diversos tipos:

- Combinaciones de palabras que consisten en una palabra autosemántica (autosemantic) y otra sinsemántica (synsemantic), ${ }^{17}$

- Combinaciones de dos palabras autosemánticas,

- Combinaciones de palabras de más de tres autosemánticas.

La concepción como objeto de estudio de combinaciones de palabras, incluso de varias que no tienen estructura de frase, muestra que Aničkov considera la fraseología como una disciplina lingüística relacionada con mecanismos generales de la combinación léxica, más que relacionada con tipos especiales

\footnotetext{
${ }^{16}$ En este caso, los ejemplos en español son nuestros.

${ }^{17}$ Los conceptos hacen referencia a palabras con significado propio o relacional. En inglés, los phrasal verbs como go into, sería un ejemplo de primer tipo, mientras que a bad headache lo sería del segundo.
} 
de unidades léxicas. No obstante, también tiene en cuenta el fenómeno de la idiomaticidad y distingue entre restricted collocations y idioms.

Šanskij (1963) añade un cuarto tipo a las de Vinogradov, las expresiones fraseológicas, 'phraseological expresions' (frazeologičeskie vyraženija), que subdivide en dos tipos:

- Communicative phraseological expressions (expresiones fraseológicas comunicativas), con una estructura de oración. Por ejemplo, la expresión it's a choice between the devil and the deep blue see (lit. tener que elegir entre dos situaciones desagradables;

- Nominative phraseological expressions (expresiones fraseológicas nominativas). Por ejemplo: higher educational institution (lit. institución educativa superior.

Molotkov (1977) también realiza una clasificación estructural. Dicha clasificación es tildada de 'punto de vista estrecho' (narrow view), y recuerda la dicotomía entre perspectiva ancha o estrecha. Distingue entre frasemas nominales, verbales, adjetivales, adverbiales, verbo-proposicionales e interjeccionales.

Respecto a las unidades objeto de estudio que los enfoques más actuales de la fraseología rusa tienen en consideración, se mencionan tres tipos de frasemas ${ }^{18}$ más comunes, que equivaldrían en español a locuciones/unidades fraseológicas (UF) (echar leña al fuego), colocaciones (brazo de gitano) y proverbios ( $A$ quien buen árbol se arrima, buena sombra le cobija):

They widely adopt the more or less commonly accepted types of phrasemes, such as idioms, restricted collocations and proverbs (Dobrovol'skij y Filipenko, 2007: 718).

\footnotetext{
${ }^{18}$ Dobrovol'skij y Filipenko utilizan en inglés el término Phrasem/e como genérico, por lo que en momentos nos permitimos su uso, aunque no es el que consideramos más adecuado. Otras veces lo hemos sustituido por unidad fraseológica (UF), que es el término más empleado en el presente trabajo.
} 
Por su parte, la clasificación propuesta por Baranov y Dobrovol'skij (1998) en los años noventa presenta los siguientes cuatro tipos:

- Idioms (locuciones/UF), con las subclases binomia (binomios), p. ej. (mujer) de rompe y rasga, similes (símiles), p. ej. Como agua para chocolate, y speech formulae (fórmulas discursivas), p. ej. ¡Encantada!);

- Restricted collocations (colocaciones restringidas), p. ej. ojo de buey,

- Proverbs (cercanos a los Idioms) (proverbios), p.ej. El hábito no hace al monje,

- Grammatical Phrasemes, se trataría de unidades pluriverbales prefabricadas que no poseen ningún tipo de significado figurativo, serían locuciones gramaticales, como la expresión en ruso kak tol'ko (en inglés as soon as, tan pronto como).

Como en cualquier intento de clasificación, Baranov y Dobrovol'skij también subrayan aquí la dificultad de establecer límites nítidos:

There are borderline cases where it's difficult to decide whether a given text fragment has already been conventionalised and entered the lexicon or not (Dobrovol'skij y Filipenko, 2007: 718).

En cualquier caso, una gran mayoría de lingüistas conciben hoy los idioms como el núcleo central de la fraseología.

En cuanto a las características y criterios utilizados para definir y delimitar las diferentes unidades fraseológicas (UF), ${ }^{19}$ Baranov y Dobrovol'skij (1998), realizan aportaciones teóricas interesantes. Afirman, por ejemplo, que la

\footnotetext{
${ }^{19}$ Resulta a veces difícil en lingüística expresar todos lo matices sin caer en redundancias, repeticiones, cacofonías, etc. No en vano, sobre la dificultatd de la expresión científica cuando el instrumento y el objeto de estudio son el mismo, el lenguaje, afirmaba M. Yaguello (1983: 11):

La lingüística posee una característica que la distingue de las demás ciencias. Su objeto no puede ser aprehendido, descrito, analizado más que utilizando el lenguaje mismo. Existe una relación denominada metalingüística entre el lenguaje objeto de análisis y el lenguaje instrumento.
} 
característica principal que afecta a todas las expresiones fraseológicas es la irregularidad. Así pues, si de alguna manera se pueden establecer grados de esta en una serie de expresiones, el mayor grado de irregularidad supondría la constatación de la presencia de idioms; por el contrario, si el grado de irregularidad es bajo, estaremos ante restricted collocations.

En cuanto a los criterios que permiten definir un idiom, Dobrovol'skij y Filipenko (2007: 719) establecen dos como los más importantes, que denominan factores:

- Factor I: Tipo de modelo metafórico (The metaphorical model type)

- Factor II: Comparatum no standard (Non-standard comparatum)

El primer factor, alude a que muchos nombres utilizados en expresiones fraseológicas tienen cierto grado de idiomaticidad y pertenecen a campos temáticos específicos que resultan particularmente fructíferos (specific tematic field), como las partes del cuerpo o los nombres de animales. ${ }^{20}$ Se considerará idiom aquella expresión fraseológica en la que el valor semántico de sustantivo (key constituent) no responda al modelo metafórico típico o más usual. Lo ejemplifica con la palabra um (cerebro, mente, intelecto), bien interpretada como instrumento (tool), o como contenedor (container). De tal manera que hay dos opciones:

- um puede funcionar metafóricamente como un instrumento con el que la gente puede pensar, tomar decisiones, etc. Véase la siguiente expresión: žit 'svoim umom (lit. vivir con la propia mente, es decir hacer lo que uno quiera y no lo que se le dice que haga). Las expresiones en que aparece el sustantivo um con el valor metafórico de herramienta no pueden ser consideradas todas como idioms, ya que la metáfora de instrumento es natural y característica de la palabra um, en cuanto mente, cerebro, etc.

\footnotetext{
${ }^{20}$ Los estudios fraseológicos denominan estos frasemas con términos específicos, como somatismos, cuando el sustantivo principal alude a una parte del cuerpo humano; zoologismos, si aluden a nombres de animales, etc.
} 
- um puede también ser interpretada metafóricamente como un contenedor, como en la expresión: vižit 'iz uma (lit. vivir fuera de la mente). En este caso, la metáfora no es tan común para entender la naturaleza del significado de um. Además, el grado de irregularidad es mayor en este caso que en el primero. Así pues, este ejemplo, vižit 'iz uma (lit. vivir fuera de la mente) ha de considerarse como idiom.

El segundo factor o criterio definitorio que permite identificar un idiom se denomina comparatum no estandard (non-standard comparatum). Según Dobrovol'skij y Filipenko, la mayoría de símiles han sido tradicionalmente englobados dentro del grupo de los idioms, por ejemplo belyj kak sneg (lit. blanco como la nieve), pero no es correcto, a su juicio,, precisamente porque presentan la mayoría un alto grado de regularidad (Dobrovol'skij y Filipenko, 2007: 719). Para ellos, el subtipo de los símiles idiomáticos es más bien un grupo homogéneo en el que un factor especial de irregularidad es relevante, el 'comparatum' o la base de la comparación (factor of the basis of comparison), con lo que se pueden dar dos situaciones a tener en cuenta:

- si el comparatum es estándar, la expresión al completo parece regular y composicional, p. ej. lento como un caracol: un caracol es lento y es frecuente esta comparación; por tanto, no debe entenderse como idiom.

- si el comparatum es completamente arbitrario, y no es un ejemplo prototípico, la expresión al completo debe entenderse como idiom: glupyj kak probka (lit. estúpido como un corcho/tapón). En este caso se muestra, pues, un prototipo impredecible: no es usual identificar un corcho con la estupidez.

En el siguiente símil, aparece un constituyente único, zenica (la niña del ojo), que es utilizado en ruso moderno únicamente en esta expresión: bereč 'kak zenicu oka čto-libo/kogo-libo. En este caso se habla de opacidad de los constituyentes (constituent opacity), es decir, el significado no es claro, lo que también constituye un factor adicional de irregularidad. Así pues, es importante 
para la teoría de la fraseología distinguir entre los símiles que son idioms y los que no lo son y estos dos factores mencionados son determiantes a su juicio para establecer tal diferencia (Dobrovol'skij y Filipenko, 2007: 720).

Además de estos criterios enunciados para diferenciar y establecer qué es un idiom frente a otras estructuras que no lo son, como símiles o colocaciones, el tipo de modelo metafórico que presentan las expresiones y en el caso de los símiles, el comparatum no estándar, Dobrovol'skij y Filipenko (2007) también dan muestra de otro mecanismo utilizado en la filología rusa: las denominadas funciones léxicas (Lexical Functions) (LF). El apparatus de las Lexical Functions (LF) es usado para la descripción lingüística de la irregularidad de una colocación:

The fact that a huge number of collocations can be constructed with the help of a limited set of LF (Lexical Functions) shows that the degree of irregularity of a collocation is fairly low in comparison to the irregularity of idioms (Dobrovol'skij y Filipenko, 2007: 720).

Las colocaciones restringidas (restricted collocations) se configuran como un término genérico o aglutinante (umbrella term), pues, a juicio de estos autores, engloban una gran heterogeneidad de expresiones. Las colocaciones son combinaciones usuales, pero completamente transparentes y caracterizadas porque uno de sus elementos tiene un significado especializado que se manifiesta en combinación con otro. Véase, por ejemplo, el sintagma cabello ensortijado: la palabra ensortijado (colocativo) hace preveer la aparición de cabello (base). En estas colocaciones se asume que en la mayoría de casos hay una base seguida de un colocativo. Mientras que la base contendría el significado literal, el colocativo aportaría el sentido, hasta cierto punto, arbitrario. De todas ellas, un tipo estructuralmente homogéneo es el de las expresiones con verbos soporte (support verb constructions, Funktionsverbgefüge en alemán), como, por ejemplo, en prinimat' rešenie (to make/take a decisión, en español tomar una decisión), que en el inglés presenta una variación establecida. Incluso, a pesar de contener elementos únicos que las hacen irregulares, algunas expresiones no lo son 
suficientemente como para considerarlas idioms, sino que serán otro tipo de estructuras, principalmente colocaciones, como se ha visto.

Si se abordan otras unidades como los proverbios (proverbs), se pone en evidencia que los parámetros utilizados de estabilidad e idiomaticidad, que permiten distinguir los idioms de otros unidades, como collocations o grammatical phrasemes, no sirven ahora, ya que los proverbios son más o menos estables e idiomáticos, es decir, que compartirían estas características con los idioms, por tanto no serían útiles para la diferenciación. De manera que en este caso, la definición de proverbs, Dobrovol'skij y Filipenko recurren a criterios formales y estructurales para su delimitación:

\footnotetext{
Most idioms are phrases (constituent parts of a sentence) and can be classified as either verb phrases, noun phrases or prepositional phrases. [...] Patterns similar to sentences in their form and functions have traditionally been excluded from the class of idioms and refered to the domain of Paremiology (Dobrovol'skij y Filipenko, 2007: 721).
}

Estos autores convienen en que, si bien los idioms suelen ser partes de una frase, clasificándose e identificándose como formantes de ella, por el contrario las expresiones que tienen estructura de oración en su forma y funciones suelen excluirse tradicionalmente de la clase idioms y trasladadas al ámbito de la Paremiología.

La diferencia entre el tipo de frasemas con estuctura de frase (sentence idioms or speech formulae) y los proverbs no tiene lugar en el nivel sintáctico, sino que está basada especialmente en parámetros semióticos, semánticos y pragmáticos. Baranov y Dobrovol'skij (1998) establecen parámetros para distinguir entre los proverbs y otros frasemas con estructura de frase:

- La huella de la sabiduría popular (folk-wisdom): la poseen los proverbs, mientras que no la poseen los idioms

- La presencia de una fuerza ilocutiva de recomendación: presente en los proverbs, mientras que no la poseen los idioms 
- La dependencia del discurso: no aparece en los proverbs, mientras que sí lo hace en los idioms

Finalmente, Baranov y Dobrovol'skij (1998) concluyen con dos afirmaciones evidentes y generalizadas sobre la diferenciación de idioms, collocations y proverbs: en primer lugar, que las fronteras entre las expresiones no son siempre claras $y$, en segundo lugar, que se hace indispensable trazar criterios delimitadores en el marco de una investigación fraseológica:

There are no clear boundaries between idioms and other phrasemes (restricted collocations or proverbs). [...] It is practical and convenient for every investigation concerned with fixed expressions to have some operational criteria for discriminating between idioms, which are the central class of the phraseological system, and other types of phrasemes (Dobrovol'skij y Filipenko, 2007: 722).

\subsubsection{LÍNEAS DE INVESTIGACIÓN}

Dentro de la investigación fraseológica rusa de los años 70-80, los aspectos connotativos del significado de los frasemas y la imagen mental subyacente, esto es, la imagen interna (inner form) se consideraban centrales para la semántica y la pragmática de las unidades fraseológicas. Fedorov (1980) analizó frasemas en dialectos de Siberia y afirmó que los «idioms are created not to name the objects of the real world, but to ascribe evaluative and emotional characteristics to them ${ }^{21}$ (apud Dobrovol'skij y Filipenko, 2007: 722), es decir, las expresiones fraseológicas no fueron creadas para denominar objetos, sino para añadirles características evaluativas y emocionales, es decir, sobre todo tendrían una función expresiva. En las décadas de los 80 y los 90 del pasado siglo el papel de las connotaciones en fraseología fue investigado más a fondo por Telija. El centro de interés radicaba en los estereotipos sociales encerrados en las expresiones fraseológicas, trasladando algunas actitudes hacia ciertas maneras de comportamiento social.

\footnotetext{
${ }^{21}$ Esta observación nos parece muy interesante, ya que el valor específico de gran parte de la fraseología en comparación con las unidades libres radica en la carga expresiva. Véase a propósito la carga expresiva de la expresión coger el toro por los cuernos, frente a su explicación literal 'afrontar una situación'.
} 
En la línea del enfoque cognitivo para el análisis de los idioms, Baranov y Dobrovol'skij (1998) propusieron un nuevo tipo de metalenguaje para definir la semántica de los idioms. La idea principal de este enfoque es que el componente de la imagen (image component), es decir, el conjunto de rasgos lingüísticos relevantes de la imagen mental subyacente (linguistically relevant traces of the underlying mental imagery), pertenece al plano del contenido del idiom. Además, el componente de la imagen ha de reflejarse en la definición semántica, según los autores, de manera explícita o implícita. Es importante descubrir y entender la relación entre esa imagen subyacente y el significado actual, al que denominan vínculo motivante: «motivating link, i.e. the bridge between the image encoded in the lexical structure of the idiom and his actual meaning» (Dobrovol'skij y Filipenko, 2007: 723).

La mayoría de estudios de la fraseología rusa hasta las postrimerías de los años ochenta consideran los idioms como su objeto de estudio principal. estatus de las colocaciones (frazeologičeskie sočetanija, según Vinogradov), que por otro lado constituye una parte extensa del sistema fraseológico de la lengua, es incierto. A ellas dedicó su atención Mel'čuk, entre otros estudiosos. Mel'čuk y sus colegas describen las colocaciones con la ayuda de una nueva herramienta teórica que llaman Lexical Functions (LF), a mediados de la década de los sesenta. Dichas funciones léxicas fueron desarrolladas como herramientas para la descripción de las propiedades combinatorias de las unidades léxicas en la teoría del significado del texto (Meaning-text theory).

Mel'čuk (1974) clasifica las lexical functions (LF) en paradigmatic LF y sintagmatic $L F$. Las primeras están relacionadas con la selección de unidades léxicas, la segunda con la relación entre ellas, que es la relevante para la fraseología, a juicio de este autor. Esta teoría permite la descripción de expresiones lingüísticas que son muy diferentes en la superficie como variantes de la misma entidad semántica profunda $y$, por tanto, la descripción de mecanismos regulares de las combinaciones léxicas. La idea de las LF tiene algunos predecesores, como el autor del primer diccionario de sinónimos rusos: Abramov (1915). Sin embargo, las publicaciones de Mel'čuk y sus colegas fueron los primeros trabajos teóricos donde la idea de las funciones léxicas (LF) 
adquirió su fundamentación teórica. También fue desarrollada por Telija (1981). Uno de los más recientes estudios sobre colocaciones que utiliza las LF es el de Apresjan (2004). El método introducido por Apresjan pretende diferenciar las colocaciones semi-libres (frequent lexical co-occurrences) de las colocaciones restringidas (restricted collocactions), que son parte de la fraseología. Dobrovol'skij y Filipenko consideran este método importante para la teoría de la fraseología en conjunto, pues permite encontrar criterios operacionales para distinguir las colocaciones que constituyen un tipo de frasemas de las que son simplemente combinaciones léxicas (Dobrovol'skij y Filipenko, 2007: 725).

Otro de los ámbitos de investigación que han interesado a la fraseología rusa es precisamente el tema objeto del presente estudio: la fraseología contrastiva (contrastive idiom analysis). La primera publicación en este campo fue la de Rojzenzon y Avaliani (1967), que estableció algunos fundamentos para la comparación sistemática de los sistemas fraseológicos de diferentes lenguas. Los autores diferenciaban entre dos aspectos:

- análisis comparativo de unidades fraseológicas (UF), entendido como comparación de lenguas afines genéticamente

- análisis de la tipología estructural de la fraseología

- aspectos areales de la comparación idiomática

Además de Rojzenzon y Avalian, otros autores rusos han abordado la vertiente de la investigación contrastiva. Estos son los más representativos:

- Gak (1977) comparó idioms y colocaciones del francés y el ruso

- Rajxštejn (1980) contrastó unidades del alemán y del ruso, desde un punto de vista léxico sintáctico y semántico

- Morienko (1980) realizó un análisis etimológico de lenguas eslavas

- Dobrovol'skij (1988) analizó la tipología estructural de idioms del inglés, holandés y alemán

- Solodub (2003) comparó correspondencias semánticas y frasemas del ruso, inglés, francés, alemán y español 
El rasgo actual de la fraseología contrastiva es la focalización en las propiedades semánticas, sintácticas y pragmáticas relevantes de los idioms en contraste, mientras que en los años setenta y ochenta los intereses se centraron, fundamentalmente, en el debate sobre los tipos de equivalencia.

En lo que respecta a los proyectos lexicográficos importantes hay que destacar el proyecto iniciado en los ochenta para sentar las bases de lo que pretendía ser el Diccionario digital de fraseología rusa (Automatizirovannyj slovar' russkoj frazeologii), el cual no llegó a buen puerto, en parte por la creciente e incesante disponibilidad de corpora digitales en la red. En cualquier caso, sí que motivó investigaciones y sugirió aplicaciones posteriores (p. ej.: Materialy, 1988; Fraseografija, 1990 y Maket, 1991). También se percibe la incidencia en la base de datos Berlin-Brandenburg Academy of Sciences dentro del proyecto sobre idioms alemanes dirigido por Feldbaum, pues muestra similitud con el formato propuesto en Maket.

Por su parte, los enfoques de índole cognitivo no han propiciado un campo de investigación separado; de hecho los avances cognitivos han sido aplicados a todos los campos de la fraseología. Dobrovol'skij y Filipenko (2007: 726) definen el aspecto cognitivo: "The basic idea of cognitive linguistics is that there are linguistically-relevant knowledge structures standing behind the corresponding linguistic structures», es decir, la idea básica de la lingüística cognitiva es que hay estructuras de conocimiento relevantes lingüísticamente bajo las correspondientes estructuras lingüísticas.

Otra línea de investigación es el enfoque etnocultural, la interacción entre lengua y cultura, especialmente popular en los años ochenta y noventa. Dentro de los enfoques etnoculturales se pueden destacar diferentes líneas de investigación. Entre ellas, sobresale una centrada en la etimología y que produce explicaciones fundamentadas históricamente de lo que se denominan culture-specific idioms, es decir, aquellos que de alguna manera están especialmente relacionados con el acervo cultural de un lugar. Otra línea de investigación interesante es la abordada por Telija (1996, 1999), que presta especial atención al concepto de mujer en los idioms. Las investigaciones 
alrededor de la relación del lenguaje con los estudios de género también se han desarrollado en otras filologías.

Como conclusión, las líneas de investigación en la filología rusa van desde las discusiones generales sobre terminología hasta vertientes más prácticas que buscan criterios operacionales: «It goes from general terminology discussion to exploitable research and finding operational criteria» (Dobrovol'skij y Filipenko, 2007: 726).

La influencia de la filología rusa es innegable para la tradición filológica occidental, no solo por la precocidad en el interés por la materia, sino por lo prolífico de los autores. A pesar de que el acceso a estos trabajos en la lengua de origen no es fácil, la confluencia con la filología germánica es evidente, a partir de la conexión con ella de la antigua DDR. Por otro lado, su legado directo a la fraseología hispánica viene a través de las autoras cubanas, especialmente Carneado y Tristá.

\subsubsection{LA FRASEOLOGÍA GERMÁNICA}

En el ámbito de los estudios fraseológicos germánicos, al igual que ocurrió con otras lenguas, el interés por la fraseología está centrado en unos primeros momentos en las expresiones objeto de la paremiología, es decir, refranes y similares, siendo la finalidad principal de esta disciplina la elaboración de recapitulaciones y compendios más que el estudio científico-filológico de las expresiones (Zurdo, 2005: 41).

El cambio de foco de la fraseología germánica desde las aproximaciones iniciales a una visión más científica tiene su origen a los trabajos realizados en ámbito soviético: estos propiciaron un cambio de perspectiva, centrada en el estudio de unidades fraseológicas desde un punto de vista científico y no como meros objetos de léxicos y catalogaciones. Este cambio de rumbo, y lo que se denominó el 'despertar de la Fraseología' en el ámbito germánico, suele situarse cronológicamente a partir de finales de la década de los sesenta (Klappenbach, 1968). 
Precisamente, los investigadores de la antigua RDA deben situarse como el verdadero germen en la investigación fraseológica germánica, pues aportaron su actualización en este campo también a través de sus contactos con la filología rusa, pero también con la eslava (Zurdo: 2005, 41). De esa intensa relación entre germanistas y eslavistas ${ }^{22}$ dan testimonio dos obras clave en los inicios de la etapa de consolidación de la fraseología alemana:

- Phraseologie der deutschen Gegenwartssprache (Fleischer, 1982), resultado de la intensa tarea investigadora realizada en la universidad de Leipzig bajo su dirección; y

- Handbuch der Phraseologie (1982), editado por Burger/Buhofer/Sialm, proyecto también común de eslavistas y germanistas, de la universidad de Zurich.

\subsubsection{PRINCIPALES ETAPAS Y LÍNEAS DE INVESTIGACIÓN}

En términos generales, muchos especialistas coinciden en establecer alrededor de 1970 el punto de inflexión en el despegue de los estudios fraseológicos germánicos, ${ }^{23}$ estableciendo etapas que responden a cronologías similares. Al respecto, se ofrecen dos visiones: la de Zurdo (2005) y la de Kühn (2007), bastante coincidentes, aunque con matices. Mientras que Zurdo inicia su cronología a partir de la etapa de los años setenta y marca los años noventa como inicio de la etapa de consolidación, Kühn indica una fase previa y considera a partir de los ochenta hasta la actualidad como un continuum. A continuación, se ofrecen detalladamente las dos visiones por la importancia que tienen los dos autores para la disciplina.

Zurdo establece las siguientes etapas en los estudios fraseológicos germánicos (Zurdo: 2005, 44):

\footnotetext{
${ }^{22} \mathrm{Y}$ no solo en los albores, sino también posteriormente, pues autores como Ďurčo son de gran importancia para la germanística y, especialmente en el terreno que nos interesa, la fraseología constrastiva.

${ }^{23}$ En el apartado de la fraseología germánica no tratamos monográficamente las cuestiones acerca de taxonomía sobre disciplina y objeto de estudio, puesto que ya aludiremos a ello al tratar la filología hispánica.
} 
- Primera etapa (1970-1982): pervivencia de la tradición y avance de la reflexión teórica

- Segunda etapa (1983-1992): consolidación teórica y metodológica

- Tercera etapa (1992-2003): ${ }^{24}$ afianzamiento y progreso como disciplina científica

Por su parte, Kühn ofrece una perspectiva diacrónica similar, aunque con los matices expresados anteriormente, y establece las siguientes fases (Kühn, 2007: 620):

- Prefase (Vorphase): hasta los años 70

- Fase de inicio (Anfangsphase): a partir de 1970 hasta 1980

- Fase de consolidación (Konsolidierungsphase): a partir de 1980

Por establecer criterios unitarios, aunaremos las dos propuestas de sistematización, recopilando las aportaciones de uno y otro autor. Así, establecemos la siguiente división:

- Prefase: hasta 1970 (solo para Kühn)

- Fase de inicio: 1970-1980 (hasta 1982 para Zurdo)

- Fase de consolidación: 1980-90 (1983 para Zurdo)

- Fase de afianzamiento: a partir de 1990 (solo para Zurdo)

\subsection{PREFASE: HASTA 1970}

En la delimitación y caracterización de las etapas en los estudios fraseológicos germánicos propuesta por Kühn, una primera fase abarcaría cronológicamente desde los inicios hasta la década de los 70 . Esta primera etapa, que denomina Prefase (Vorphase), está especialmente caracterizada por la redacción de colecciones y léxicos de refranes. J. Agricola reúne ya en 1529 la primera colección de refranes. Los autores no solían ser especialistas en lenguas, sino

\footnotetext{
${ }^{24}$ Suponemos que cierra la etapa en 2003, por tratarse de una fecha anterior a la publicación de su manual (2005). De no ser así, suponemos que hubiera abarcado hasta la actualidad, pues de alguna manera se siguen las líneas de investigación marcadas hasta entonces.
} 
curas, maestros o personas de algún nivel cultural. Estos compendios eran utilizados a veces con fines religiosos. ${ }^{25}$

\subsubsection{FASE DE INICIO: 1970-1980 (1982)}

La primera etapa, que comprendería de 1970 a 1982 aproximadamente ${ }^{26}$ se caracteriza por un despertar en el interés por la materia. Etapa de fuerte influencia de la tradición eslava, en la que se recoge e intensifica lo investigado por esta escuela. Predomina, como en momentos anteriores, la tradición paremiológica. Se abordan cuestiones teóricas y metodológicas, de manera que se abre un debate fecundo sobre cuestiones terminológicas y taxonómicas por un lado, al tiempo que, por otro, se abordan las relaciones de la fraseología con otros ámbitos lingüísticos, en aras de conseguir una delimitación de la disciplina y de su objeto. ${ }^{27}$

El impulso en el ámbito germánico es aupado por la tradición investigadora rusa: con razón es en la antigua DDR, en Leipzig, donde surge una de las primeras aportaciones, la de Fix (1971). Otros autores también destacables en estos momentos son Rothkegel (1973), o Burger (1973). Esta primera fase de la investigación fraseológica tiene una clara orientación estructuralista y ofrece una viva discusión tanto sobre la concepción ancha o estrecha de la fraseología, como sobre las clasificaciones y definiciones del objeto de estudio:

\footnotetext{
Diese frühe Phase der phraseologischen Diskussion ist sprachstrukturell ausgerichtet und gekennzeichnet durch eine lebhafte Auseinandersetzung über einen eher engen oder weiten Objektbereich der Phraseologie sowie über unterschiedliche Klassifikationen-in Abhängigkeit verschiedenartiger Kriterien (Kühn, 2007: 621).
}

Esta etapa, denominada por Kühn 'fase de inicio' (Anfangsphase) supone, como hemos dicho, el comienzo de la investigación fraseológica. Anteriormente, la fraseología centraba su interés en aspectos histórico-

\footnotetext{
${ }^{25}$ Zurdo no contempla como fase estos momentos previos.

${ }^{26}$ Ponemos entre paréntesis los años de las fases delimitadas por Zurdo.

${ }^{27}$ Kühn llega a referirse a esta etapa como 'terminologische Chaos', de caos terminológico (2007: 622).
} 
etimológicos o culturales-etnográficos. No en vano, la situación fue criticada en 1970 por Ĉerniševa, que evidenciaba el vacío de la lingüística germánica y aportaba su visión a estas cuestiones relacionadas con terminología y líneas de investigación desde la tradición rusa (apud Kühn, 2007: 621).

Se desarrolla también el campo lexicográfico, con publicaciones de E. Agricola (1962), Röhrich (1973), Friedrich (1976), Schemann (1989). Por otro lado, se abren también nuevas perspectivas de investigación interlingüística (contrastiva) y psicológica. Algunos autores con aportaciones importantes de esta fase, según Zurdo (2005: 44), son: Cerniševa (1975); Burger y Jaksche (1973); Fleischer (1976, 1982); Burger (1977); Burger y Buhofer (1981); Burger, Buhofer y Sialm (1982); Dobrovol'skij (1981, 1982); Gréciano (1978, 1982); Hessky (1980); Jaksche (1982), Sialm y Burger (1982); Mieder (1975); Mieder (ed.) (1979); Pilz (1981); Röhrich (1973); Rothkegel (1973); Thun (1978); y Zuluaga $(1975,1980)$.

\subsection{FASE DE CONSOLIDACIÓN: 1980-1990 (1983-1992)}

Esta etapa (1983-1992) supone la madurez en los presupuestos teóricos, aunque todavía pueden apreciarse controversias entre los autores. En el ámbito terminológico, se afianza su carácter interdisciplinar, se desarrolla especialmente la vertiente pragmática y se intensifica la investigación contrastiva. Los aspectos didácticos (Phraseodidaktik) y lexicográficos (Phraseographie) también experimentan un claro avance. Finalmente, los estudios abordan la fraseología en los lenguajes específicos.

En esta etapa, que Kühn (2007) denomina fase de consolidación (Konsolidierungsphase), se establecen las prioridades de la investigación fraseológica. La superación de las múltiples controversias del momento previo tiene su inicio en dos obras clave, de las cuales Kühn afirma que llevan a la Fraseología a su etapa de consolidación: Phraseologie der deutschen Gegenwartsprache, de Fleischer, y Handbuch der Phraseologie de Burger, Buhofer y Sialm (eds.), las dos publicadas en 1982. Aunque continúa la controversia terminológica, se abandona el caos (Chaos) en pro de una 
concreción que se plasmará en los términos de Phraseologismus y Phrasem, usados como genéricos. En cuanto a los criterios definitorios, cohesiónestabilidad-fijación, e incluso la idiomaticidad, dejan de considerarse irrefutables, aunque este último en menor medida. ${ }^{28}$ Por una parte, se intenta aunar criterios definitorios y clasificatorios de las unidades objeto de estudio, y de esta manera, documentar la riqueza de aspectos que ofrecían las investigaciones; y por otro lado, se plantea la renuncia a definiciones estrechas. Según Kühn, la situación a partir de los años ochenta es la siguiente:

Zudem zeigt sich seit den 80er Jahren eine deutliche Entwicklung weg von rein sprachstrukturellen Abgrenzungen, Analysen und Typologisierungen, in denen Phraseologismen vor allem isoliert betrachten werden, in Richtung einer Phraseopragmatik: Phraseologismen werden in ihrer kommunikativen Verwendung analysiert (Kühn, 2007: 626).

En síntesis, Kühn afirma que las expresiones fraseológicas van abandonando los límites, análisis y tipologías puramente estructuralistas hacia una fraseología pragmática: las expresiones fraseológicas se analizan en su uso comunicativo. A partir de este planteamiento, surgen conclusiones y deducciones sobre las diferentes funciones de las expresiones fraseológicas en los textos y tipologías textuales; sobre la adquisición y adecuación en la enseñanza de lenguas, Phraseodidaktik; sobre la codificación y descripción en los diccionarios, Phraseographie; y finalmente, sobre sus particularidades en análisis contrastivos entre lenguas, kontrastive Phraseologie.

A juicio de Kühn, ha sido precisamente este contacto con las premisas pragmáticas lo que ha llevado a la ampliación de perspectivas de investigación de los planteamientos fraseológicos: «Es ist gerade die Auseinandersetzung mit pragmatische Fragestellungen, die $\mathrm{zu}$ einer Perspektiverweiterung phraseologischer Forschungsansätze geführt hat» (2007: 626). Partiendo de cierto anquilosamiento en posiciones teóricas y discusiones que parecían no tener fin, se ha dado un salto cualitativo y cuantitativo en la investigación fraseológica: se investiga mucho, y en muchos aspectos, y especialmente en lo

${ }^{28}$ Estos rasgos se explican monográficamente en § 3.2. 
que populariza la disciplina: los estudios aplicados. Por lo que respecta a la fraseología contrastiva, los estudios se centran, fundamentalmente, en las comparaciones del alemán con las lenguas eslavas, el húngaro o el finés. La vertiente histórica de la fraseología está menos desarrollada que la de la paremiología. Se potencia siempre la interdisciplinaridad, y se aborda desde nuevos ámbitos científicos cercanos o afines: Lingüística general, Sociolingüística, Pedagogía, etc. Prueba de la madurez que alcanza la fraseología es la proliferación de congresos monográficos. Algunos en el marco de la asociación EUROPHRAS (Zurich 1984, Oulu 1986, Estrasburgo 1988, Aske 1990, entre otros).

Algunos de los autores y años de publicaciones más destacados de este periodo: Cerniševa (1986); Dobrovol'skij (1987, 1988, 1992); Eismann (1989); Földes (1989, 1992); Gläser (1986); Häcki-Buhofer (1987, 1989); Hessky (1989,1992); Korhonen (1991); Korhonen (ed.) (1989, 1992); Mieder (1983, 1985, 1992); Palm (1992); Palm (ed.) (1991); Pilz (1983); Röhrich (1989); B. Wotjak (1989,1992); B. Wotjak y Richter (1988); G. Wotjak (1986, 1989).

\subsection{FASE DE AFIANZAMIENTO: 1992-2003}

A partir de la década de los noventa (1992-2003) ${ }^{29}$ se aprecia una expansión de los estudios fraseológicos en todas las áreas y un desarrollo de líneas anteriores, pero que llegan a una madurez no conseguida anteriormente (Zurdo: 2005, 47). Por un lado, supone la superación de las discusiones sobre la relación de la Fraseología con la Paremiología, y por otro, el acuerdo implícito sobre la necesaria concreción de las denominaciones de la disciplina y su objeto:

\footnotetext{
${ }^{29}$ A diferencia de Zurdo, Kühn no establece una nueva etapa a partir de los años noventa, que sin duda representa la eclosión de los estudios fraseológicos, sino que los considera como continuación, una vez se dieron por consolidados los estudios sobre la disciplina.
} 
- Cesa la oposición fraseología-paremiología, ${ }^{30}$ y se diferencia bajo el nombre genérico de fraseología, entre una concepción ancha, que incluiría la vertiente paremiológica, y una concepción estrecha, excluida la vertiente paremiológica.

- La disciplina se denomina unánimemente Phraseologie (fraseología) y su objeto Phraseologismus (fraseologismo), aunque también se utiliza Phrasem (frasema) o Phraseolexem (fraseolexema), e incluso idioma, propuesto por Burger para los casos de opacidad de significado (Zurdo 2005: 47).

En cualquier caso, la cuestión terminológica-taxonómica ya no tiene el seguimiento de etapas anteriores. De igual modo, también son más laxas las interpretaciones sobre los rasgos definitorios de las unidades.

Por el contrario, se intensifica la investigación en vertientes ya iniciadas en la etapa anterior, como el enfoque pragmático-comunicativo, los estudios contrastivos y los didácticos (Zurdo: 2007, 48). Por otro lado, se retoma una orientación poco desarrollada en la etapa previa: la historiográfica y la búsqueda de las fuentes.

Como tendencias de investigación emergentes, en el momento de redacción de su artículo, Zurdo (2005) destacaba las siguientes:

- Estudios cognitivos y perspectiva comunicativa

- Estudios sobre motivación y connotación, mecanismos de formación de fraseologismos y posibles mecanismos de trasferencias interculturales

- Estudios sobre lenguajes específicos

- Estudios contrastivos, ahora también aplicados a la confección de diccionarios

\footnotetext{
${ }^{30}$ Las concepciones 'ancha' y 'estrecha' de la fraseología se han presentado ya en $\S 2.1$. En síntesis, la concepción 'amplia' integra los refranes y las colocaciones, mientras que la 'estrecha' no los tiene en consideración y es, por tanto, mucho más restrictiva.
} 
Algunas de las referencias bibliográficas más destacadas en este prolífico periodo son los siguientes: Baur y C. Chlosta (eds.) (1995); Burger (1998, 1999, 2001); Chlosta, Grzybek y Piirainen (eds.) (1994); Corpas (2001); Dobrovol'skij (1995, 1999, 2001); Dobrovol'skij y Piirainen (eds.) (1996, 2002); Ďurčo (1994, 2001); Eismann (1994, 1995, 2001); Fernández (2001); Fleischer (1994, 1997); Földes (2001); Gréciano (1994, 1999); Graciano y Rothkegel (1997); Griesbach y Schultz (1994); Häcki-Buhofer, Burger y Gautier (eds.) (2001); Hartmann (2001); Hessky (1999, 2001).

Coincidimos con Burger (1998) cuando destaca el crecimiento espectacular que ha tenido en los últimos años el interés por la fraseología, y que se pone en evidencia en la enorme cantidad de publicaciones derivadas:

In den letzten Jahren ist das Interesse an Phraseologie noch einmal sprunghaft gewachsen, wie die Vielzahl an neuen Publikationen in den verschiedenen Teilbereichen des Gebietes zeigt (Burger, 1998: 9).

Aún así, por entonces quedaban pendientes, a juicio de Zurdo, las siguientes cuestiones en la investigación fraseológica (Zurdo, 2005: 50):

- Insuficiencia de los criterios semánticos para clasificar y denominar las expresiones fraseológicas,

- Necesidad de estudiar más a fondo las restricciones o expansiones funcionales (variación/ modificaciones),

- La revisión del concepto de colocación y la inserción sistemática en la teoría de la traducción,

- La realización de estudios empíricos basados en corpus y encuestas directas. ${ }^{31}$

${ }^{31}$ Precisamente frente a esta carencia, el presente trabajo pretende aportar su granito de arena. 


\subsubsection{LA FRASEOLOGÍA HISPÁNICA}

A pesar de ser coetáneas de Vinogradov algunas publicaciones españolas influyentes, como la de Julio Casares, Introducción a la Lexicografía moderna, que data de 1950 (Casares, 1950/1992), el desarrollo de los estudios fraseológicos en nuestro país se hizo esperar. Tanto que Corpas, una de las exponentes más representativas de la investigación fraseológica actual, afirmaba en 1996 que «poco se había avanzado desde entonces sobre el tema» (Corpas, 1996: 11). Durante muchos años, tan solo se encontraban estudios parciales, repertorios y meras catalogaciones, casi siempre con un exceso de terminología y poco rendimiento práctico. También Martínez Marín ofrecía en 1991 su visión pesimista sobre el tema con relación a los diccionarios:

Un tratamiento objetivo y sistemático de la fraseología sigue siendo prácticamente imposible hoy por hoy por no haberse realizado los estudios descriptivos previos (apud Corpas, 1996: 11).

En el momento de publicación del manual de Corpas el panorama no era muy diferente, a juicio de su autora. No solo observaba deficiencias en los diccionarios generales, sino también en los especializados, ya que seguían sin aplicarse criterios claros para la inclusión y clasificación de las UF.

A pesar de esta situación, en los años 90 se suscitó entre los estudiosos españoles un renovado interés por la materia, siendo prueba de ello la cantidad de publicaciones sobre el tema que surgieron en esa década. Entre ellas cabe destacar los trabajos de Fontanillo Merino (1993), Varela y Kubarth (1994), Doval (1995), Moreta Lara y Álvarez Curiel (1995) o el de Candón y Bonet (1994), entre otros. Y en este marco, el Manual de Fraseología española de Corpas (1996), intentó suplir esta carencia en el mundo hispánico, presentando un estudio teórico muy pormenorizado. Otras aportaciones a la disciplina muy importantes son las de Martínez Marín (1996) y Ruiz Gurillo (1997), o las de hispanistas no peninsulares como Zuluaga (1980) y las cubanas Carneado 
(1985) y Tristá (1985), sin dejar de lado hispanistas de origen no hispanohablante como G. Wotjak.

Sin duda, se puede afirmar que a partir de la década de los noventa, la actividad alrededor de la fraseología experimenta un crecimiento espectacular, no solo por las aportaciones anteriormente mencionadas, sino también por la presencia de los estudios fraseológicos en la convocatoria de congresos sobre lexicografía, la creación de la revista Paremia (1993) por parte de Julia Sevilla, e incluso la impartición de esta disciplina en estudios universitarios de ámbitos lingüísticos y humanísticos, desde el nivel de grado hasta los cursos de doctorado. También cabe mencionar las aportaciones de otras lenguas peninsulares durante estos últimos años. No podemos obviar algunas de ellas, ya que no solo han contribuido al desarrollo de la terminología, sino que muchas veces han superado en algunos aspectos a los estudios en español. De imprescindible mención es, por ejemplo, el laureado trabajo de Conca, Paremiologia (1987/1990), y las aportaciones a la fraseología de Salvador, especialmente en su obra El Discurs Prefabricat (2000).

Según Zurdo, en este momento de impulso de los estudios de fraseología española de los años noventa las contribuciones versan mayoritariamente sobre características específicas del sistema fraseológico español (Zurdo, 2007: 704). Posteriormente, las investigaciones se basan en perspectivas científicas, bien monolingües, bien orientadas contrastivamente, hacia vertientes morfológicas, sintácticas, léxico-semánticas, pragmáticas, textuales o culturales, entre otras. Cabe destacar ya en una época reciente, la aparición del exhaustivo estudio sobre fraseología de García-Page, Introducción a la fraseología española. Estudio de las locuciones (2008), que supera en amplitud y profundidad a cuantos le han precedido y que a buen seguro se ha convertido ya en el nuevo manual de referencia.

La situación actual puede considerarse bastante más esperanzadora. No solo ha crecido de manera espectacular el interés por la disciplina, sino que se van trazando progresivamente las líneas que llevan de una visión de la fraseología exclusivamente teórico-descriptiva a otra perspectiva más aplicada, escasa 
todavía en nuestro idioma si la comparamos con otras lenguas, como el ruso o el alemán.

No obstante, se pueden ver muchas similitudes e influencias de las filologías ya reseñadas, en los estudios fraseológicos hispánicos. Respecto a la delimitación del objeto de estudio de la fraseología, se suele adoptar la concepción de la fraseología en sentido amplio en la mayoría de las investigaciones sobre el español, como también ocurre en otras filologías. Del mismo modo, se deja entrever también en la fraseología española la influencia de las diferentes corrientes y avances del desarrollo general de la lingüística, desde el estructuralismo y los principios de la lingüística cognitiva, hasta el giro hacia nuevo ámbitos de investigación, que le han aportado nuevos enfoques a la fraseología, como son el análisis del discurso y la lingüística de corpus, la traductología y la lingüística aplicada a la enseñanza de lenguas. ${ }^{32}$ Todo ello, junto al impulso de la aplicación de las nuevas tecnologías, hace que el momento actual sea más prolífico y optimista que en épocas anteriores en cuanto a la consolidación de la disciplina también en el ámbito hispánico por el crecimiento continuo observado.

Cabe mencionar que la discusión paremiología-fraseología ha continuado presente, como en otras filologías, pero sin ser una cuestión prioritaria, sino como una dualidad no resuelta con la que se convive ahora cómodamente. En definitiva, la mayoría de trabajos se asientan ya sobre sólidos principios teóricos y metodológicos (Zurdo 2007: 704).

\subsubsection{UNIDADES}

La delimitación de la nomenclatura es indispensable para cualquier disciplina científica y su objeto de estudio, y de la misma manera que era una cuestión crucial en otras tradiciones filológicas, también lo es para la fraseología española. Sin embargo, esto debe afirmarse con matices, pues la cuestión

\footnotetext{
${ }^{32}$ La didáctica de la fraseología ha estado presente en la fraseología germánica desde hace tiempo (B. Wotjak, 1996; Baur y Chlosta 1996a, 1996b; Elorduy y Fandrich 1996; Kühn, 1996). También en español encontramos bibliografía al respecto (Domínguez y otros, 1995; Ortega y Rochel, 1995).
} 
terminológica nunca ha sido un tema demasiado controvertido en el ámbito hispánico: «l'obstacle terminologique n'est pas prope à l'espagnol», según Pellen (2001, apud Zurdo, 2007: 705), a diferencia de lo que ocurre, por ejemplo, en alemán. En español, las expresiones utilizadas, provenientes de la fase pre-científica de la fraseología, sirven más bien para caracterizar a las subclases y rara vez para los conceptos genéricos. Otra diferencia respecto al alemán es que los términos españoles son mayoritariamente monoléxicos: adagio, expresión, refrán, dicho, giro, locución, etc., con excepciones como frase hecha, expresión fija, etc. En definitiva, a juicio de Zurdo, las palabras que se han convertido en términos genéricos (Fachtermini ${ }^{33}$ ) son locución, modismo, ${ }^{34}$ proverbio y refrán.

Destaca también la autora una cuestión importante sobre el término locución, respecto a su carácter no inequívoco, pudiendo llegar a tener significados diferentes atendiendo al enfoque en sentido estrecho o amplio de la fraseología: en la concepción estrecha se utiliza como hiperónimo (Oberbegriff), mientras que en la fraseología en sentido amplio se utiliza como hipónimo (Unterklassenbegriff). En un lugar intermedio se encuentran diferentes definiciones, puramente fraseológicas, algunas de las cuales, más frecuentes, son las siguients: expresión fija, expresión pluriverbal, expresión idiomática, fraseologismo, fraseolexema y unidad fraseológica. Otras, menos frecuentes son frasema y texto repetido.

Normalmente, son meras acuñaciones que dependen de la orientación científica. Así, tomando por ejemplo el término unidad fraseológica, Zurdo (2007: 706) ofrece las diferentes interpretaciones que realizan de esta categoría diferentes hispanistas: para las linguistas cubanas Carneado y Moré, es sinónimo de fraseologismo, para Zuluaga es sinónimo de expresión fija o fraseologismo, y finalmente, García-Page y Wotjak la emplean como sinónimo de locución. En conclusión, las denominaciones más extendidas en el ámbito

\footnotetext{
${ }^{33}$ Mantenemos la terminología en alemán, pues es la lengua en que está redactado el artículo.

${ }^{34}$ Casares (1950/1992: 208) rechazaba este término por su imprecisión.
} 
de la fraseología española son unidad fraseológica, ${ }^{35}$ locución y enunciado fraseológico. El concepto de unidad fraseológica (UF) se utiliza como hiperónimo para el conjunto, ${ }^{36}$ compartiendo protagonismo con el de expresión fraseológica. El de locución tiene la primacía en cuanto Idiome (en alemán) con valor de miembro de frase, según Zurdo (2007: 706). Además, como sinónimos de esta se utilizan otras acepciones, algunas de ellas ya mencionadas, como expresión fija, expresión idiomática, fraseologismo, fraseolexema, frasema, modismo, unidad poliléxica, etc. Finalmente, el concepto de enunciado fraseológico se utiliza como hiperónimo para expresiones equivalentes a la oración o proposicionales y clases especiales, en sentido de Burger (1998: 38 ss).

\subsubsection{PRINCIPALES APORTACIONES}

A pesar de que más adelante se presenta un apartado monográfico sobre el objeto de estudio y la terminología utilizada en el estudio, se esbozarán aquí unos pocos apuntes sobre la cuestión, tal y como se ha hecho al presentar los estudios sobre cada una de las tradiciones filológicas.

Por lo que respecta a la filología hispánica cabe decir que la terminología fraseológica utilizada no dista mucho de la de otras filologías, y las desviaciones se deben más, según Zurdo (2007: 706), a orientaciones lingüístico-teóricas o a objetivos prácticos que a opiniones diferenciadas con los propios criterios de clasificación. Así, rasgos ${ }^{37}$ como la polilexicalidad, idiomaticidad, fijación, frecuencia, estructura formal, función morfosintáctica, motivación semántica, reproducibilidad y función pragmática se seleccionan en función de la corriente investigadora.

Para Casares eran importantes, por ejemplo, la polilexicalidad, la fijación, la idiomaticidad y el carácter de valor de frase para distinguir las locuciones de

\footnotetext{
${ }^{35}$ Esta es la referencia que más se leerá a lo largo de la presente tesis, como hemos comentado, especialmente en la parte de investigación propia, pues se la considera muy apropiada como concepto genérico para las unidades estudiadas en este trabajo. En muchas ocasiones, para abreviar, se utilizará las siglas UF.

${ }^{36}$ Como genérico lo adopta Corpas (Corpas, 1996: 18).

${ }^{37}$ Explicados en $\S 3.2$.
} 
otras expresiones como refranes, frases proverbiales, fórmulas pluriverbales y modismos (Casares, 1950/1992: 167 ss.). Además proponía la función de denominación y la función en la frase, para distinguir entre tipos de locuciones. Zuluaga (1980: 16), por su parte, defiende la fijación como factor fundamental y distingue dos tipos: la fijación fraseológica y la fijación pragmática. Ambos utilizan criterios sintácticos y semánticos para hacer sus clasificaciones, criticándo por ello Zurdo (2007: 706) que proporcionen nombres diferentes a una misma expresión: mientras que a tontas y a locas es para Casares una locución + significativa + adverbial, para Zuluaga es una expresión fija + (idiomática + frase nominal) + (unidad léxica + locución + adverbial).

Corpas propone combinar el criterio de enunciado con el de fijación, a partir de los cuales proporciona una clasificación de las unidades fraseológicas en tres esferas: colocaciones, fijadas en la norma, locuciones, fijadas en el sistema, y enunciados fraseológicos, fijados en el habla (1996: 50-51). Los dos primeros casos constituirían enunciados incompletos, mientras que el tercer caso sería un enunciado completo. Además, cada esfera es susceptible de ser dividida en otras.

Ruiz Gurillo (1997) presenta una propuesta en cierto modo diferente de las anteriores, tomando la fijación y la idomaticidad como rasgos graduales:

Por lo que a la fraseología se refiere, parece estar estructurada como un continuum difícil de segmentar (1997: 71).

La unidad fraseológica prototípica poseería el mayor grado de fijación e idiomaticidad en varios niveles del sistema lingüístico. Basándose en las teorías de centro y periferia de la Escuela de Praga, establece un continuum en la fraseología cuyo punto de partida lo ocuparía el prototipo y el final lo ocuparían las uniones de palabras sintácticamente libres. Según Ruiz Gurillo: 
Una concepción estrecha [de la fraseología] que tenga en cuenta, fundamentalmente, las locuciones, las frases proverbiales del tipo I y las unidades sintagmáticas (Ruiz Gurillo, 1997: 72). ${ }^{38}$

Por su parte, Zurdo destaca la importancia de la clasificación de las unidades de la fraseología que presenta Corpas:

Bildet die Grundlage für eine nähere Bestimmung der spanische PE (phaseologische Einheiten) anhand dreier Hauptkriterien-nämlich die der strukturellen Festigkeit, der Idiomatizität und der syntaktischen Funktion (Zurdo, 2007: 707).

Con ello, Zurdo sienta las bases para una clasificación atendiendo a los tres criterios básicos: la fijación estructural, la idiomaticidad y la función sintáctica. Corpas sugiere tres tipos de unidades fraseológicas principales: colocaciones, locuciones y enunciados fraseológicos. El uso del término colocación en la filología española es relativamente reciente, y hay que situar su origen en la escuela británica, especialmente Firth (1957) y Halliday (1966).

Corpas define las colocaciones como unidades fraseológicas que desde el punto de vista del sistema de la lengua son unidades completamente libres, pero que presentan cierto grado de restricción combinatoria determinada por el uso (fijación interna) (1996: 53). En relación con la idiomaticidad pueden ser no-idiomáticas, como poner la mesa, débilmente idiomáticas, como ganar limpiamente. La función sintáctica no se puede analizar a partir de sus componentes, pues el compuesto ha de ser analizado en bloque. Las estructuras más frecuentes que presentan las colocaciones según Corpas son las siguientes (1996: 66-76):

- N. (Sujeto) + V.: recaer la culpa

- V. + N. (Objeto): poner la mesa

- N. + Adj./ Adj.+ N.: densa humareda

- N. + C Prep.: bandada de pájaros

- V. + Adv.: ganar limpiamente

\footnotetext{
${ }^{38}$ Ruiz Gurillo define las frases proverbiales de tipo I como frases no conmutables por una palabra: armar la de San Quintín (1997: 69-70).
} 
- Adv. + Adj.: rotundamente falso

- V./ N. + C Prep.: poner a buen recaudo

Algunas de las colocaciones poseen simplemente función relacional, entre las cuales las preposiciones tienen un papel importante, por ser un grupo especialmente prolífico en español a diferencia del alemán (Zurdo 2007: 707708). La estructura más productiva consta de un adverbio, con valor temporal o local principalmente y de la preposición de: alrededor de, cerca de, en casa de, etc.

Las locuciones son expresiones fraseológicas, caracterizadas según Ruiz Gurillo por el alto grado de fijación e idiomaticidad (apud Zurdo, 2007: 708), y además presentan anomalías formativas morfosintácticas. Estas unidades muestran fijación en la disposición de palabras, componentes léxicos y estructura morfosintáctica, aunque hay expresiones que no exhiben ningún signo especial: meterse en harina, a toda costa.

En las locuciones puede aparecer la variación léxica, por razones de sinonimia, o bien por razones diatópicas o estilísticas: ser de/tener manga ancha, apearse/ caerse/ bajarse del burro. A nivel estructural, también existen esquemas de casillas vacías del tipo $\left\{N_{\text {. }}\right\}$ a $\left\{N_{\text {. }}\right\}$, que seguirían expresiones como paso a paso, golpe a golpe, que no obstante muestran estabilidad estructural. En relación con la idiomaticidad, las locuciones pueden presentar divergencia total entre el significado literal y el fraseológico, o bien una diferencia parcial: dar alas, hacer de la necesidad virtud.

Finalmente, apunta Zurdo a que estas unidades fraseológicas (phraseologische Einheiten, en adelante $P E)$, se pueden dividir en dos clases desde el punto de vista del significado referencial:

- Satzgliedwertige PE, locuciones o UF equivalentes a una parte de la oración

- Satzwertige PE, locuciones o UF con valor de oración 
Dentro del primer tipo, las locuciones equivalentes a una parte de la oración (satzgliedwertige PE), Zurdo establece varios subtipos, como locución nominal (ave de mal agüero), locución adjetiva atributiva/predicativa (duro de mollera), locución verbal (dar calabazas) y locución adverbial (de cabeza). Destaca la autora la diferencia especialmente llamativa entre el alemán y el español con respecto a las locuciones con valor adjetivo, pues mientras en alemán se trata de una función poco documentada, es muy frecuente encontrarse con esta función en español:

Besonders auffallend ist der Unterschied zwischen dem Deutschen und dem Spanischen in Hinblick auf die adjektivischen PE. Während es sich im Deutschen um eine eher schwach belegte Funktion handelt, wird sie dagegen für das Spanische äußerst häufig belegt (Zurdo, 2007: 908).

Ejemplos del segundo subtipo de expresiones, las locuciones con valor de frase (satzwertige PE), serían frases como las paredes oyen, caérsele a alguien el alma a los pies o írsele la mano a alguien. ${ }^{39}$

Por último, los enunciados fraseológicos serían construccciones léxicas fijas, cuyo rasgo principal consiste en que funcionan como enunciados comunicativos completos. Dentro de este grupo, se diferenciarían dos subtipos que presentan diferencias respecto a la forma lingüística y el tipo de acto lingüístico en que son formulados: las paremias y las fórmulas rutinarias.

Bajo el concepto de paremia se engloban diversas expresiones, que a partir de la interrelación de aspectos socioculturales e históricos propios y ajenos, han impreso su propio sello, a juicio de Zurdo:

Unter diesem Begriff werden verschiedene sprachliche Erscheinungen zusammengefasst, die als Folge der Mitwirkung von eigenen und fremden geschichtlichen und sozio-kulturellen Aspekten eine eigene Prägung erhalten haben (Zurdo, 2007: 909).

\footnotetext{
${ }^{39}$ Este tipo de expresiones son las que conforman el corpus del presente estudio.
} 
Dentro del grupo de las paremias, Zurdo distingue tres tipos de unidades fraseológicas (UF): frases proverbiales, proverbios y refranes, de los que este último constituye el grupo más numeroso en español. Mucho menos frecuentes son los denominados adagio, apotegma, máxima, etc.

Los refranes (Sprichwörter en alemán, sentences en francés, proverbs en inglés) se caracterizan por presentar:

- Fijación interna y externa con relación a su existencia lexicográfica

- Significado generalizador y/o universal

- Diferente grado de idiomaticidad

En español se aprecian tres tipos de esquemas sintácticos para las expresiones denominadas refranes:

- Estructura sin núcleo verbal, mayoritariamente bimembre y asindética: Año de nieves, año de bienes,

- Expresión de una frase con núcleo verbal: $A$ caballo regalado no le mires el dentado,

- Estructura de más de una frase, normalmente dos y asindética/sindética: El hombre propone y dios dispone.

Las fórmulas rutinarias constituyen la unidad comunicativa mínima vinculada al discurso. Se diferencian mucho de unas lenguas a otras, e incluso de un estrato social a otro. No muestran idiomaticidad y su estabilidad está condicionada por factores sociales, expresivos, discursivos en cada situación comunicativa específica. Son denominadas por otros autores también fórmulas pragmáticas, por su función fuertemente vinculada al discurso. Ejemplos de estas expresiones tomados de Zurdo (2007: 909) serían: Me parece, ¿Qué tal?, ¡Buen viaje!, pertenecientes todas ellas al lenguaje estándar. 


\subsection{LA FRASEOLOGÍA ACTUAL}

Los estudios fraseológicos en el entorno románico, no solo hispánicos sino también franceses e italianos, no fueron a la par de los estudios germánicos 0 rusos, sino que se desarrollaron más tardíamente, pudiendo situarse el punto de inflexión en la década de los 90 . En cualquier caso, podemos afirmar sin reparo que, aunque sus inicios han sido posteriores a los ruso-eslavos y germánicos, la situación actual presenta tal evolución que no le quedan a la zaga respecto a calidad y profundidad de los temas abordados, compartiendo muchos puntos en común.

\subsubsection{PRINCIPALES LÍNEAS DE INVESTIGACIÓN}

Superados en cierta manera los debates en torno a las cuestiones terminológicas y taxonómicas, el interés de la fraseología está centrado ahora en el estudio de las UF como entidades reales con finalidades aplicadas que abordan diferentes perspectivas; entre ellas, y de forma destacada, la vertiente contrastiva. Tampoco suelen predominar las cuestiones sobre los orígenes de las UF, aunque sí en el ámbito de la búsqueda de posibles bases conceptuales comunes en estudios interlingüísticos.

Así pues, las líneas actuales de investigación predominantes serían:

- Estudio de las UF no solo en el sistema, sino también en el planteamiento de enfoques cognitivos y perspectivas comunicativas,

- Investigaciones sobre motivación y connotación, de especial novedad, sobre mecanismos de formación de fraseologismos y sobre posibles mecanismos de trasferencias interculturales,

- Investigación fraseológica de ámbitos específicos puesto que, como ocurre en la investigación de lenguas en general, el interés por los lenguajes específicos se acrecienta en esta época, 
- Estudios contrastivos, de forma muy especial, no solo desde enfoques interlingüísticos, aunque sí mayoritariamente.

En este sentido, tenemos que señalar que hay un especial interés en la aplicación de los estudios a finalidades no solo docentes, sino también hermenéuticas, por lo cual las investigaciones se plantean no solo desde puntos de vista teóricos, sino también aplicados, con especial interés por ejemplo en el desarrollo de corpora y diccionarios válidos.

\subsubsection{DIVULGACIÓN CIENTÍFICA Y ACADÉMICA}

\subsubsection{CONGRESOS}

Un reflejo de la salud de que goza la disciplina fraseológica es su presencia en congresos monográficos, aparte de los encuentros de temática múltiple vinculados a aspectos más generales de la lingüística. Desde su afianzamiento como disciplina, especialmente a partir de las décadas de los años 80 y 90 , se ha vivido un crecimiento espectacular en la actividad científica y divulgativa alrededor de la fraseología. Los primeros congresos internacionales específicos sobre la materia en la Europa occidental que tuvieron especial relevancia fueron:

- 1981, Mannheim (Alemania), Primer Encuentro Internacional de Fraseología, impulsado por las escuelas eslava y germánica

- 1984, Zurich (Suiza)

- 1986, Oulu (Finlandia)

- 1988, Estrasburgo (Francia)

- 1990, Aske (Noruega)

- 1992, Saarbrücken (Alemania)

- 1995, Graz (Austria)

- 1997, Liptovsky Ján (Eslovaquia) 
En 1999 se crea EUROPHRAS (European Society of Phraseology) en Bielefeld (Alemania), con sede en Zurich, y de especial importancia para el desarrollo de las investigaciones fraseológicas, no solo por la institucionalización de sus congresos periódicamente, sino por el apoyo que realiza a la tarea investigadora en general. A partir del momento de creación de la sociedad, se han realizado numerosas ediciones:

- 2000, primer congreso de EUROPHRAS en Uppsala (Suecia)

- 2002, Loccum (Alemania)

- 2004, Basilea (Suiza)

- 2006, Veszpém (Hungría)

- 2008, Helsinki (Finlandia)

- 2010, Granada (España)

- 2012, Maribor (Eslovenia)

- 2014, París (Francia)

La fraseología hispánica está muy presente en las últimas ediciones de los congresos de EUROPHRAS, pero ha sido la fraseología alemana una de las más conspicuas asistentes. Tanto los fraseológos alemane ${ }^{40}$ como los eslavos constituyen el 'centro neurálgico de la disciplina', según Corpas, y ello se percibe en la cantidad de participantes con ponencias sobre estas lenguas (Corpas, 2003: 40). De estas colaboraciones germanoeslavas merece la pena destacar la publicación de Basaj-Rytel (1994): Z problemów frazeologii polskiej $i$ słowiańskiej.

Importante también para la divulgación científica de la disciplina es el grupo de Westfalia, que organiza congresos desde 1991, y que está en estrecha relación con la asociación EUROPHRAS, de manera que alguno de sus miembros también forma parte de esta, como Burger (Corpas, 2003: 41).

En Francia cabe destacar la actividad de l'École Normale Supérieure de Fontenay/Saint Cloud, especialmente de los departamentos siguientes: el

40 Habría que matizar y decir que, en realidad, deberíamos hablar de los fraseólogos germanistas, entre los que se encuentran muchos de origen hispánico. 
CRÉDIF (Centre de Recherche et d'Étude pour la difussion du Français), el ÉLI (Équipe d'accueil Linguistique et Informatique) y el UMR (Unité Mixte de Recherche), que han participado en la organización de congresos.

En la lengua inglesa, nos tenemos que remitir a la sociedad EURALEX (European Association for Lexicography), creada en 1983. Esta asociación da cuenta de las relaciones entre lexicografía y fraseología, pues a partir de 1994 la fraseología dispone de una sección propia. Otros Simposios internacionales de Fraseología realizados en el momento de auge de la disciplina serían los de 1994, Leeds; 1996, Moscú; 1998, Sttutgart. Corpas afirma al respecto de los estudios anglosajones, que salvo excepciones como Gläser, se trata de una escuela tradicionalmente aislada, centrada en la idiomaticidad y desconocedora de otras escuelas europeas.

En el ámbito hispánico peninsular, a partir de la década de los noventa, presenciamos un crecimiento notable de los congresos sobre fraseología. Entre los celebrados, podemos mencionar algunos:

- En 1996 tiene lugar el I Congreso Internacional de Paremiología, que no solo se ocupó de las paremias (actas a cargo de Julia Sevilla, 1997). También las Jornadas de literatura popular de Durango, recogidas en la revista Euskera, 3 (1996).

- En 1997 se celebra el Coloquio Galego de Fraseoloxía (actas a cargo de Ferro Ruibal, 1998).

- En 1998 tiene lugar el II Congreso Internacional de Paremiología (actas a cargo de Julia Sevilla, 1999). También se celebran el mismo año las I Jornadas de Fraseología comparada (actas Salvador y Piquer, 2000).

- En 2000 se convocan las Jornadas de Literatura Popular/Fraseología.

- En 2001 se celebra el XXIV Curso de Lingüística textual de la Universidad de Murcia, centrado en la fraseología y el texto, desde una perspectiva monolingüe, multilingüe y traductológica. 
En la vertiente interlingüística, hay que destacar la tarea investigadora de FRASESPAL, un grupo de investigación dirigido por la Dra. Mellado Blanco (Universidad de Santiado de Compostela), formado por ocho investigadores de distintas universidades españolas y una universidad portuguesa. Su creación surgió a raíz de un proyecto de investigación concedido por parte del Ministerio de Ciencia e Innovación en 2007: La estructura idiomática del alemán y el español. Un estudio cognitivo a partir de un corpus onomasiológico (código HUM2007-62198/FILO; 2007-2010). Promueven congresos, como el celebrado en 2011, y desarrollan investigaciones muy diversas. Precisamente, Mellado y Schemann, integrantes de este grupo, son algunos de los artífices de una gran obra fraseográfica, Idiomatik Deutsch-Spanisch (2012), que hemos utilizado para la verificación de las UF integrantes del corpus del presente trabajo.

\subsubsection{INVESTIGACIÓN: TESIS/PROYECTOS/REVISTAS}

De alguna manera se considera a Zuluaga como precursor de la fraseología hispánica moderna, el cual defendió su tesis en 1978 en Tübingen, publicada después con el título Introducción al estudio de las expresiones fijas (1980). A partir de ese momento, es posible apreciar un notable incremento en la cantidad de tesis sobre temas fraseológicos.

En cuanto a revistas, es imprescindible mencionar la creación de la revista Paremia, por Julia Sevilla, sobre paremiología y fraseología. Asimismo, se llevan a cabo también numerosas colaboraciones con CINDOC (CSIC), para realizar directorios de paremiólogos. Se presentan también proyectos de Paremiología contrastiva (español, francés, italiano, portugués y provenzal), Estudio lingüístico y contrastivo con aplicación a la enseñanza de lenguas, en el que participaron Maria Conca y Ramón Almela. En esta línea investigadora y de colaboraciones, cabe destacar el grupo de trabajo PROHEMIO (Programme de Recherches sur l'Oralité, Histoire et Écriture dans le Monde Ibérique, Université d'Orléans, France), en el que participan activamente fraseológos hispánicos. Además de múltiples encuentros científicos, el grupo PROHEMIO 
en Francia desarrolla un proyecto de traducción de fraseología francés/ español.

También es frecuente encontrar en el ámbito de la investigación lingüística algunas tesis relevantes sobre fraseología: Ruiz Gurillo (1995); Blasco (2000), Iñesta (2000), Asensio (2001) o Koiké (2001), entre otras. También podemos destacar, en sentido amplio, las contribuciones a la paremiología de Sevilla (1987, tesis francés-español).

Como contribuciones a la vertiente contrastiva podemos mencionar las de Corpas (1994, español-inglés), Ugarte (1998, español-inglés-francés), Forment (2000), que trabaja desde un punto de vista contrastivo intralingüístico (Productividad fraseológica de los somatismos en sincronía, cuestionarios entre estudiantes de Madrid y Barcelona), Mena (2002, inglés-español). Por su parte, Martín Martínez realizó su tesis (2001) sobre el tratamiento de las unidades fraseológicas en los diccionarios bilingües. Entre las tesis contrastivas de español con otras lenguas también cabe destacar la de Sagban (2010), que hace un estudio contrastivo español-árabe para su aplicación a la docencia de español. Para las combinaciones lingüísticas del alemán con otras lenguas, quisiéramos destacar la tesis de Mellado (1996), que plantea un enfoque cognitivo de la fraseología germano-rusa, sobre unidades fraseológicas del alemán.

En la vertiente contrastiva alemán-español, mencionaremos las tesis de Írsula (1993), o Larreta (1998/2001). Este último presenta somatismos verbales en un corpus organizado ideográficamente y extraído de diccionarios y de datos proporcionados por informantes nativos. Mencionaremos también a López Roig (2001), quien hace un estudio de aspectos traductológicos, centrándose en el establecimiento de tipos de equivalencia fraseológica a partir de una dimensión cuantitativa y otra cualitativa. De muy reciente aparición podemos mencionar también la tesis de Velázquez (2015) en la que aborda el par español-alemán desde un punto de vista cognitivo. 
En cuanto a proyectos de investigación a nivel peninsular, podemos destacar entre otros, Fraseología, régimen y sintaxis de las unidades verbales: estudio comparado español-catalán, Universitat Rovira i Virgili (PB98-1517, DGICYT). $O$ tesis surgidas en el marco de un proyecto (Alhamano, 2002): El contrato de viaje combinado en alemán y en español: las condiciones generales. Un estudio basado en Corpus. Esta tesis surge de un proyecto, como hemos avanzado, del cual es directora Gloria Corpas [proyecto, PB98-1399 DGICYT, Diseño de tipologizador textual para la traducción automática de textos jurídicos (español-inglés-alemán-italiano-árabe)].

Además, cabe mencionar el IULA (Institut Universitari de Lingüística Aplicada, Universitat Pompeu Fabra), dirigido por Teresa Cabré hasta fechas muy recientes. EI IULA disfrutó de tres proyectos sobre terminología y lenguajes de especialidad, en los que de alguna manera se aborda la fraseología. Otro centro para la investigación en fraseología terminológica es el Instituto de Terminología bilingüe y traducción especializada (ITBYTE) de la Universidad de Valladolid. Bravo ha dirigido un proyecto coordinado entre esta universidad y la de Ottawa (Canadá) sobre fraseología, lingüística de corpus y lexicografía bilingüe, español-inglés (DGES, PR1999-0185). Posteriormente, coordinó otro junto a la Universidad de León (BFF2001-0112, 2001-2004).

La universidad de Eötvös Loránd (ELTE; Budapest, Hungría) también ha sido testigo de algunas tesis en contraste con el español: entre otras, la de Lux (1984) sobre locuciones verbales, o Flachner (1992): Coincidencia de las expresiones idiomáticas entre las lenguas española y húngara; Bodnár (1998): Unidades fraseológicas en español-catalán; Kiss (1998): Análisis comparativo fraseológico español-húngaro-Dineros son calidad; Gyôri (1999): Alusiones eróticas en los refranes de Hungría y España.

Corpas (2003) concluye en el momento de publicar su libro, que la fraseología española se encuentra al mismo nivel que el resto de países de Europa, que se trabaja en las mismas líneas, que aunque conserva todavía, en algunos trabajos, una cierta metodología de corte más tradicional, se ha hecho un gran esfuerzo por integrar nuevas perspectivas, como la lingüística del corpus, la 
semántica cognitiva y la semiótica. No obstante, según Corpas, nuestro país adolece de proyectos de investigación de primer nivel y se echa en falta una mayor coordinación entre los existentes (Corpas, 2003: 32). A día de hoy, el panorama ha cambiado bastante, quizá también por la característica de la investigación fraseológica hispánica actual: el carácter predominantemente interlingüístico y contrastivo que está adoptando mayoritariamente, sin duda es uno de los motores de avance de la disciplina en estos momentos.

\subsubsection{OTRAS CONTRIBUCIONES}

Partiendo de Zuluaga como precursor de alguna manera de la nueva fraseología hispánica, tal y como se comentó al inicio, podemos mencionar también contribuciones importantísimas a nivel científico, además de las ya mencionadas como tesis, como serían los trabajos paremiológicos de Conca (1987) y Calero (1991). En 1994 se publica la tesis de Corpas, que junto al trabajo de Martínez Marín (1996), son el pistoletazo de salida de los estudios fraseológicos en España a juicio de Corpas (2003: 42).

Las publicaciones en la península sobre lenguas diferentes al español también son numerosas, pues sus aportaciones se pueden trasladar al conocimiento general de la fraseología. En 1995 se publican dos obras sobre la enseñanza de la fraseología gallega, de López Taboada y Soto Arias, respectivamente. Ese mismo año, Salvador publica en la revista Caplletra una reflexión sobre la fraseología catalana. Mencionamos también otras aportaciones, como la de Castillo-Carballo (tesis doctoral sobre colocaciones y locuciones en el corpus Vox-Bibliograf), o Ruiz Gurillo (1997) quien publica, en primer lugar, la parte teórica de su tesis, recogiendo corrientes europeas también, y posteriormente la segunda parte sobre aspectos sintácticos y pragmáticos (locuciones adverbiales en español oral), en 1998. Muy interesante también resulta la contribución de hispanistas alemanes, como G. Wotjak (1998), quien publica entre otras investigaciones, una monografía sobre fraseología y fraseografía; también Luque (1998), o Corpas (2000), sobre aspectos de fraseología, fraseografía y traducción en diversas lenguas. 
La lista sería interminable, pues apenas hemos recogido el inicio de la eclosión de las publicaciones en nuestro ámbito inmediato. No obstante, consideramos que es suficientemente representativa para dar cuenta de que la fraseología hispánica ha recuperado terreno frente a otras. Ciertamente, tal y como afirmaba Corpas, no hay duda de que en España se está creando escuela (Corpas, 2003: 28).

\subsection{LA FRASEOLOGÍA CONTRASTIVA}

\subsubsection{INTRODUCCIÓN}

La metodología comparativista siempre ha estado presente en el ámbito de la investigación lingüística, no en vano la teoría del indoeuropeo apareció formulada por primera vez en el primer tercio del siglo XIX por los filólogos Rask y Bopp. Tales conclusiones se obtuvieron a raíz de la observación de las coincidencias detectadas en el vocabulario y en la construcción gramatical entre lenguas tan distantes como el antiguo indio y las lenguas europeas:

\footnotetext{
Auf Grund von Übereinstimmungen im Wortschatz und im grammatischen Bau, endeckte man Ende des 18. Jahrhunderts den Zusammenhang des Altindischen mit den europäischen Sprachen (Sir William Jones, Rasmus Rask, Franz Bopp). Durch intensiveren Sprachvergleich stellte man die verschiedenen Grade der Verwandtschaft unter den einzelnen Sprachen fest und glaubte sogar, eine indogermanische Grundsprache rekonstruiren zu können (König, 1998: 37).
}

De esta manera, a partir de un método contrastivo se llegó a la hipótesis de que debía de haber existido una lengua común a todas ellas, denominada indogermánico en el ámbito de la lingüística germánica e indoeuropeo en la anglosajona y europea en general.

Ha pasado mucho tiempo desde estas investigaciones lingüísticas, y la metodología comparativista no ha gozado siempre del beneplácito de los lingüistas, quienes han llegado incluso a considerarla arcaizante y anacrónica. 
A partir de los años noventa y de mano de los estudios fraseológicos, la metodología comparativista ha recobrado nueva vida: precisamente la vertiente contrastiva de la disciplina fraseológica, la conocida como fraseología contrastiva, atrae la atención de numerosos lingüistas y se erige como eminentemente útil para los avances en investigación lingüística.

En este ámbito contrastivo de la fraseología llama poderosamente la atención que los esfuerzos no solo se invierten en el enfoque teórico necesario para cualquier investigación, sino que la orientación mayoritaria se centra en el enfoque aplicado, con el foco de atención puesto especialmente en la docencia de idiomas y en la traducción, y en un aspecto indispensable para ambas: el desarrollo lexicográfico, la fraseografía.

Ese interés didáctico por el aspecto fraseológico contrastivo se puede observar ya desde hace tiempo en nuestro entorno cercano, pues en algunos planes de estudio de carreras del ámbito de la lingüística, como los de la Universidad de Valencia, ofrecía en sus últimos cursos de filología germánica asignaturas sobre la fraseología, especialmente en su vertiente contrastiva, de mano del profesor Holzinger, al igual que la Universidad de Alicante, a instancias de la profesora Ruiz Gurillo. También en otras universidades aparecía como materia, tanto en los estudios conducentes a las licenciaturas/grados, como en los estudios de doctorado.

\subsection{2. ÁMBITO DE ESTUDIO}

Entendida la fraseología como disciplina que estudia las unidades fraseológicas, en sentido estrecho, y casi toda formulación lingüística que suponga una expresión fija, en sentido amplio, la vertiente contrastiva de la fraseología intenta encontrar y explicar las correspondencias fraseológicas que pueden existir entre UF de distintas lenguas.

Aunque la finalidad aplicada de la fraseología contrastiva es evidente, ha desarrollado también una base teórica que sustenta sus presupuestos, 
especialmente en el difícil apartado de las equivalencias. Pues si las unidades fraseológicas ya escapaban per se del interés de los estudiosos, tal vez por la dificultad de catalogar, sistematizar y explicar su naturaleza, no es de extrañar el desafío que supone adentrarse en la vertiente contrastiva, cuando además se ponen en comparación sistemas lingüísticos pertenecientes a patrones culturales diferentes.

\subsubsection{ESTADO DE LA CUESTIÓN}

\subsubsection{INTRODUCCIÓN}

El desarrollo de la fraseología ya como disciplina autónoma ha sido incesante en las últimas décadas, como ya se ha visto en capítulos anteriores. En este contexto, una de las líneas de investigación en las que más se está trabajando es, sin duda, en la fraseología contrastiva, centrada mayoritariamente en estudios tanto interlingüísticos, como intralingüísticos. Incluso va más allá de una mera comparación y, de la misma manera que la lingüística comparada pretendió establecer un punto en común en las lenguas que observaba, también aquí se menciona la posibilidad de la existencia de universales fraseológicos: puesto que hay mucha coincidencia entre UF de países distintos, cabe la posibilidad de que haya una base metafórica, de conocimiento 0 experiencias humanas comunes que permitan afirmar y comprobar dicha existencia.

A partir de la derivación de los estudios contrastivos, interlingüísticos o intralingüísticos, hacia una perspectiva globalizadora se hace referencia desde hace tiempo a cuestiones como los universales fraseológicos. Esto queda evidenciado, por ejemplo, en las denominaciones acuñadas recientemente como título del congreso 2008 de EUROPHRAS, Phraseologie global-arealregional (fraseología global-areal-regional). La referencia a los universales fraseológicos está presente, al menos, dentro del marco de las lenguas indoeuropeas, especialmente desarrollado por la fraseología histórica, que pretende no sin dificultades dilucidar las fuentes de muchas coincidencias observadas. 
En esta línea encontramos diferentes aportaciones de renombrados filólogos, en las que comparan más de dos lenguas, como Piirainen (2010) que estudia los rasgos comunes de la fraseología en las lenguas europeas, y la de Bock (2010), que alude incluso a la posibilidad de reconstruir fraseologismos indogermánicos (indoeuropeos). La influencia de una determinada cultura en otras también se estudia, desde una perspectiva multilingüe, como muestran los estudios de la influencia rusa sobre la fraseología europea, de Eismann (2010), o la francesa e italiana sobre la alemana, de Burger y Zürrer (2010); y al contrario, de la lengua alemana sobre las lenguas colindantes al este, de Földes (2010) o sobre las nórdicas, de Keinästö (2010).

De alguna manera conviven, por un lado, esa tendencia globalizadorauniversalizante, y por otro, el factor fraseológico como definidor de nacionalidades, como presenta Diacechko (2010) en su artículo. Ciertamente, se trata de la difícil simbiosis entre lo general y lo particular. También esa perspectiva multilingüe se aplica a la fraseografía, herramienta necesaria para la docencia de las lenguas y la traducción. Como contribuciones al respecto, podemos mencionar la de Luque Durán y Luque Nadal (2010), Fundamentos teóricos del diccionario intercultural e interlingüístico, basada en las metáforas, - Berthemet (2010), Phraseological Equivalence in digital multilingual dictionaries, o también la de Pamies y otros (2010), en la que plantea la implementación léxica de los símbolos. Otro trabajo que aborda la fraseología desde un punto de vista multilingüe es el de Migla (2010), en el que contrasta alemán-ruso-letón, y que forma parte de las comunicaciones publicadas en internet por la universidad de Helsinki, como complemento a la edición del libro de actas de la convocatoria EUROPHRAS 2008 (Korhonen y otros (eds.), 2010b). ${ }^{41}$ También está presente la paremiología desde este punto de vista multilingüe, tal y como acredita el trabajo de Sardelli (2010) respecto a la combinación español-italiano-inglés.

\footnotetext{
${ }^{41}$ Disponible en: http://homepage.univie.ac.at/beata.trawinski/publications/europhras_08.pdf
} 
La perspectiva contrastiva se va afianzando en la fraseología, como demuestra la presencia de la misma en congresos, especialmente el de EUROPHRAS, de referencia ineludible para el presente trabajo por la preponderancia que tienen en su seno las dos lenguas objeto de este estudio. El congreso que tuvo lugar en 2010 en Granada evidenciaba con el título la tendencia de la fraseología actual: Interkulturelle und sprachvergleichende Perspektiven auf Phraseologie und Parömiologie (lit. Perspectivas contrastivas e interculturales de la fraseología y la paremiología). Desde un punto de vista multilingüe se abordaron cuestiones también sobre la fraseografía en sendos trabajos presentados por Berthemet (2011) y Arsenteva (2011). También se planteó la búsqueda de equivalentes funcionales entre alemán-polaco-inglés, presentado por Szczepaniak y Urban (2011).

Desde esa perspectiva multilingüe, en relación al español también se presentaron ponencias en EUROPHRAS 2010, como por ejemplo la de Martí (2012), que presentaba equivalentes y variaciones en español-inglés-francés.

\subsubsection{ESTUDIOS INTERLINGÜÍSTICOS}

En general, las investigaciones de fraseología contrastiva pueden adoptar dos perspectivas básicas, la perspectiva contrastiva interlingüística y la perspectiva contrastiva intralingüística. La primera, la perspectiva contrastiva interlingüística, tiene como objeto de estudio lenguas diferentes, tratadas desde un punto de vista sincrónico. La segunda, perspectiva contrastiva intralingüística, toma como referencia la fraseología de una sola lengua, y trabajo como puntos de contraste aspectos diatópicos, diastráticos, etc. en su ámbito de extensión, por lo que puede adoptar tanto perspectivas sincrónicas como diacrónicas.

Dentro de esa vertiente contrastiva, los trabajos en la fraseología hispánica adoptan mayoritariamente una perspectiva interlingüística, de manera que son principalmente estudios comparativos del español con otras lenguas, extranjeras mayoritariamente, aunque también peninsulares. En la 
investigación germánica, por su parte, la fraseología contrastiva se contempla también bajo los dos puntos de vista: por una lado, puede concebirse como una comparación interlingüística, es decir las constataciones y descripciones de coincidencias, puntos de encuentro fraseológicos, similitudes o diferencias entre dos o más idiomas, o por el contrario, estos estudios pueden adoptar una perspectiva intralingüística. Esta última visión distingue a su vez una perspectiva diacrónica, que atiende a derivaciones etimológicas y de historia cultural así como a la descripción de fraseologismos; y una perspectiva sincrónica, que estudia coincidencias o puntos de encuentro morfosintácticos, semánticos y estilístico-funcionales, similitudes o diferencias en diferentes estadios lingüísticos, para después poder aplicar una perspectiva diacrónica, especialmente en comparación con el alemán contemporáneo.

De ellas, la perspectiva interlingüística hace más evidente la importancia de los planteamientos culturales, pues a través de las unidades fraseológicas se muestran los valores de una cultura específica, los clichés, prejuicios y estereotipos existentes entre culturas diferentes.

\subsection{ESTUDIOS DEL ESPAÑOL CON OTRAS LENGUAS}

Entre los estudios comparativos que tienen como una de las lenguas el español podemos destacar como pioneras las aportaciones de Sevilla (1988, 1998, 2000, 2001, 2004) en el análisis español-francés; y los de Pamies (1998) y Corpas (2003), para la correspondiente comparación con el inglés.

También encontramos trabajos contrastivos desde la perspectiva de la semántica cognitiva, como el de Pamies y Potápova (2005), que compara las lenguas español-ruso. En esta misma publicación, otras contribuciones contrastivas destacables del español con lenguas diferentes al alemán, en este caso francés, serían la de González (2005), que compara los hápax de las UF del español y el francés, y Sierra (2005), que presenta una tipología de medios y técnicas de traducción. 
En la edición de EUROPHRAS 2010 también se presentaron ponencias que trataban contrastivamente el español con otras lenguas distintas al alemán. Así, como ejemplo del par español-italiano, se presentaron la de Alessandro y Zamora (2011), y la de Valli y otros (2012); con el par español-francés, la de Marcos (2012); con el par español-portugués, presentada por Baptista y Català (2012); con el español-serbio, de Pejovic (2011); con el español-checo Calero (2011); con el español-ruso, presentada por Zholobova (2011); o el españolgriego, de Crida (2011). También se presentó una ponencia que contrastaba el español-islandés, de Riutort (2011), y el español-ruso, de Zaynuldinov (2010).

\subsection{ESTUDIOS DEL ALEMÁN CON OTRAS LENGUAS}

Con el alemán como lengua de partida o llegada se han publicado numerosos trabajos, en relación con lenguas como el árabe, búlgaro, checo, chino, coreano, danés, eslovaco, finlandés, francés, griego, holandés inglés, islandés, italiano, japonés, polaco, portugués, serbocroata o húngaro.

En muchos trabajos de fraseología contrastiva también se tratan aspectos lexicográficos (Hessky, 1992; Dobrovol'skij, 1998) o traductológicos (Gläser, 2010). Incluso se abordan los interfraseologismos (Inter-phraseologismen ${ }^{42}$ como forma especial de los internacionalismos (Internationalismen). Las comparaciones lingüístico-contrastivas potencian también la observación de perspectivas interculturales en la fraseología, por ejemplo, las UF específicas de una cultura o sobre los 'rasgos populares interculturales' (interkulturelle Landeskunde), ${ }^{43}$ o la comunicación intercultural con fraseologismos, también bajo la perspectiva de diferentes influencias: lenguajes especializados, comparaciones fraseológicas basadas en lo específicamente cultural (Kulturspezifik phraseologischer Vergleiche) o pares (Zwillingsformeln).

Por mencionar algunas de las contribuciones a las últimas convocatorias de EUROPHRAS, la sociedad europea de fraseología, mencionaremos el estudio de Mohr-Elfadl (2010) sobre la expresión de la temporalidad en las UF alemán-

\footnotetext{
${ }^{42}$ Como hemos comentado anteriormente, ofrecemos la palabra en alemán del original.

${ }^{43}$ Este término tiene una traducción compleja, pues aúna cultura y civilización.
} 
francés; sobre la influencia del inglés sobre el alemán presentado por Fiedler (2010), o la de Gläser (2010), sobre la herencia rural en la fraseología inglesa y alemana. Otras aportaciones serían la de Aktaş (2010), que compara las UF que contienen la palabra Geld ('dinero') en el par alemán-turco; o el análisis contrastivo entre alemán y croata de Pavič (2010). El par catalán-alemán estuvo también presente, con una ponencia de de Van Lawick (2010) con un estudio sobre traducciones de unidades fraseológicas.

Estudios del alemán en comparación con lenguas eslavas, podemos mencionar los de Umborg (2010) sobre ruso-estonio-alemán y de Dobrovol'skij y otros (2010) sobre el ruso-alemán. También en relación con el eslovaco encontramos una contribución interesante de Ďurčo (2010).

Especialmente prolífico fue el par alemán-polaco en la convocatoria de EUROPHRAS 2008, pues diversos autores presentaron ponencias al respecto: Gondek (2010), Gulawska-Gawkowska (2010), Misiek (2010), Szczęk (2010), que fueron publicadas en internet por la universidad de Helsinki, como complemento de la publicación en libro (Korhonen y otros (eds.), 2010b).

También en la edición de EUROPHRAS 2010 aparecen trabajos contrastivos del alemán con lenguas eslavas, como el que aborda el par alemán-checo desde un punto de vista de la fraseografía, presentado por Žáská (2011); con el búlgaro, de Kyryakova-Dinieva (2011); con el italiano, Meloni (2011); o también con el inglés Stavtseva (2011).

\subsection{ESTUDIOS INTERLINGÜÍSTICOS ESPAÑOL-ALEMÁN}

El estudio contrastivo de fraseología español-alemán ha sido especialmente prolífico en los últimos tiempos, no solo por la publicación de numerosos artículos y libros, sino también por la intensa tarea investigadora plasmada en otros formatos como tesis doctorales, proyectos de investigación, etc. Mencionaremos a este respecto las tesis de Geck (lectura en 2000), López Roig (lectura en 2001) o Tabares (lectura en 2008), entre otros. 
Las contribuciones de los germanistas españoles son numerosas. Entre los estudios comparativos español-alemán destacamos los de Holzinger (1993, 1994, 1998a, 1998b), López Roig (2002), Zurdo (1993, 1999, 2001, 2002, 2003), Mellado (2000), Mansilla (2003, 2008), Piñel (2003, 2008). Dignas de mención también las contribuciones de G. Wotjak (1983), B. Wotjak (1987), Cox (1991), Larreta (1998/2001), Balzer y Raders (2004), Balzer y otros (2005).

Otras contribuciones al análisis contrastivo de fraseología del par españolalemán son por ejemplo, la Tabares y Batista (2005), sobre un corpus de fraseología jurídica, con una vertiente aplicada o el de Bustos (2005), que analiza contrastivamente estructuras verbales.

En el ámbito de la divulgación hay que destacar la importancia creciente de la vertiente contrastiva también en los congresos lingüísticos. Sirva como ejemplo las Jornadas Internacionales de Lingüística Contrastiva realizadas en Leipzig en 2003 (posteriores al VI Congreso de Lingúística Hispánica), que no solo comparaba las lenguas románicas entre sí, sino también con el alemán (Schmitt y B. Wotjak (eds.), 2004).

Dada la formidable salud de que goza la perspectiva contrastiva españolalemán la lista sería de nuevo interminable. Mencionaremos solo algunas contribuciones más, como son las ponencias a congresos, que consideramos muy importantes, pues suponen un indicio de hacia dónde pueden ir las cosas y un intercambio enriquecedor. Sin duda, hay que hacer referencia a las sesiones que realiza EUROPHRAS, donde el español está presente incluso como lengua vehicular y muy bien representado en número de comunicaciones. Así, por mencionar algunas, destacaremos el estudio de Mellado (2010) sobre la equivalencia fraseológica en el sistema y en el texto; o Tabares (2010), que plantea los problemas en la traducción de estructuras jurídicas. Otra contribución en el mismo congreso, pero publicada en internet, aborda el par español-alemán desde el punto de vista de la fraseografía, la confección de diccionarios, presentado por Torrent-Lenzen (2010). 
En la edición de 2010 de EUROPHRAS se presentaron numerosos trabajos sobre el par español-alemán. Podemos mencionar las ponencias de Amigot (2011), o la de Balzer (2012), Schilling (2012), Piñel (2011), Mellado (2011), o la de Geck (2011).

Mientras los estudios de fraseología contrastiva intralingüística pueden considerarse escasos, los estudios de fraseología contrastiva interlingüística representan un ámbito de investigación ya consolidado. De hecho, muchas iniciativas sobre el campo de la fraseologia interlingüística español-alemán proceden de representantes de la germanística extranjera. Y los resultados de estas investigaciones tienen también influencia sobre la propia fraseología germánica al uso. Por ejemplo, B. Wotjak publicó en 1992 un esbozo sobre la problemática de la fraseología contrastiva.

\subsubsection{ESTUDIOS INTRALINGÜÍSTICOS}

\subsection{ESTUDIOS DEL ESPAÑOL}

Como ya se ha avanzado, los estudios de fraseología contrastiva intralingüística son sensiblemente menos numerosos que los interlingüísticos, especialmente en el ámbito hispánico. Sin embargo, hay que señalar que en el ámbito germánico la fraseología contrastiva intralingüística cuenta con más referencias bibliográficas que la hispánica.

No obstante, mencionaremos alguna contribución a la fraseología hispánica contrastiva desde una perspectiva intralingüística, como el artículo de Sarmiento y Alfaro sobre el español de Canarias (2011), o los estudios anteriores de Carneado y Tristá (1985), sobre la fraseología del español de Cuba. De hecho, cada estudio diatópico de la fraseología del español lleva implícito una comparación indirecta con el estándar. Esto se observa por ejemplo, en la creación de diccionarios, como el Diccionario de expresiones y refranes del español de Canarias, de Ortega y González (2000). 


\subsection{ESTUDIOS DEL ALEMÁN}

Los estudios germánicos sobre la fraseología de los dialectos y sociolectos son escasos, aunque en este panorama destacan los de Piirainen $(2000,2002)$ y Korhonen $(1982,1986,2002)$. Por el contrario, son numerosos los trabajos dialectales sobre fraseología de los países de habla alemana distintos a Alemania, como, por ejemplo, sobre Helvetismen (lit. helvecismos) o sobre Austriazismen (lit. austriacismos). También se ha estudiado en situaciones de lengua minoritaria, como el húngaro-alemán o el caso luxemburgués. Para este tipo de análisis contrastivos se han utilizado especialmente corpus extraídos de diccionarios, como fuente y material de análisis.

En la última edición publicada de EUROPHRAS se presentó algún trabajo sobre fraseología alemana desde una perspectiva intralingüística, el de JuskaBacher y Meier (2012), que llevaba por título die areale Verbreitung sog. Phraseologischer 'Helvetismen' (lit. sobre la extensión areal de los denominados 'helvecismos').

Desde una perspectiva contrastiva, pero aunando a un tiempo la interlingualidad y la intralingualidad (estudios inter-intralingüísticos), podemos mencionar como ejemplo la contribución de Schmale (2010: 185-193), Französische Einflüsse auf phraseologische Ausdrücke des Rheinfränkischen (lit. Influencias francesas sobre las expresiones fraseológicas del dialecto 'Rheinfränkisch'). 


\section{EL OBJETO DE ESTUDIO}

La variedad terminológica utilizada en la filología hispánica para delimitar el objeto de estudio de la fraseología es muy amplia, pues se barajan términos tan diversos como los de unidades fraseológicas, locuciones, refranes, proverbios y otras paremias, aforismos, máximas, apotegmas, sentencias, dichos, frases proverbiales, modismos, entre los más frecuentes. Y lo mismo sucede en la lingüística alemana, donde encontramos denominaciones muy diferentes, como Phraseologismus (fraseologismo, unidad fraseológica), Redewendung (giro, frase hecha), Sprichwort (proverbio, refrán), Redensart (locución, modismo, frase hecha), por mencionar solo algunas de las más habituales.

Es evidente que no todos los términos se utilizan del mismo modo, que algunos han caído prácticamente en desuso, e incluso que otros se han convertido en verdaderos hiperónimos que engloban en su seno términos de alcance más limitado. Ha sido el devenir científico de la disciplina y el contacto entre lingüistas de diferentes tradiciones filológicas lo que, con el tiempo, ha propiciado una mayor delimitación y precisión terminológicas. En este apartado ofrecemos una propuesta de caracterización de tales unidades a partir de sus rasgos más destacados.

\subsection{DEFINICIÓN}

El término genérico más acertado para definir el objeto de la fraseología es, a nuestro juicio, el de unidad fraseológica. Zuluaga (1985: 23) lo delimita de la siguiente manera:

Toda UF tiene el estatus de una palabra: es un elemento virtual anterior a la actividad lingüística que la realiza, reproduciéndola y/o modificándola y/o combinándola con otros elementos. 
Esta sería para nosotros una pieza clave para distinguir lo que es realmente una unidad fraseológica (UF) y lo que no lo es: una unidad fraseológica es básicamente una estructura conocida antes del momento de su formulación, que funciona en sentido unitario aunque implica la combinación de palabras. De ahí se deriva que esté formada por dos o más palabras, y que se diferencie como unidad de las del discurso libre, ya que su estructura está fijada y tiene una posibilidad relativa o escasa de variación. En definitiva, a las UF no se les pueden aplicar las técnicas del discurso libre que imprimen creatividad y espontaneidad.

La definición y delimitación de las UF han sido cuestiones cruciales en la investigación fraseológica desde el primer momento. Desde siempre, se han esgrimido los criterios de definición y delimitación de las unidades fraseológicas (UF), como la pluriverbalidad o polilexicalidad, la fijación y la idiomaticidad.

La pluriverbalidad (Mehrwortcharakter) hace referencia al hecho de tratarse de unidades formadas por más de una palabra (lágrimas de cocodrilo). La fijación (Stabilität) hace referencia a la indisolubilidad de esas estructuras o unidades, a la aparición conjunta y reiterada de términos (lágrimas de cocodrilo, pero no lágrimas de cocodrilo/*elefante). Finalmente, la idiomaticidad (Idiomatizität) alude a la asunción de un significado propio de esas unidades, diferente del significado resultante de la suma de las palabras que lo integran (lágrimas de cocodrilo: el significado no es deducible de sus integrantes, pues significa 'llorar fingidamente').

La delimitación de estos rasgos fue importante que algunos autores se sirvieron de ellos para la conocida distinción entre una concepción estrecha y una concepción ancha de la disciplina: la fraseología en sentido estrecho y la fraseología en sentido amplio (Phraseologie im engen Sinne/ im weiteren Sinne). Así, las UF caracterizadas por la pluriverbalidad y la fijación conformarían la fraseología del primer grupo; si además se les añadimos el criterio de la idiomaticidad, nos encontramos ya ante las unidades del segundo. Por supuesto, hay que tener en cuenta que la frontera lingüística entre las dos perspectivas no puede ser rígida. 
No obstante las perspectivas mencionadas respecto a la delimitación del objeto de estudio, en la investigación fraseológica se acepta mayoritariamente un límite mínimo, la estructura formada por al menos dos palabras básicas, y un límite máximo, la oración. Sirvan como ejemplos para el primer caso la expresión luna de miel, y para el segundo A quien madruga, Dios le ayuda.

Como hemos mencionado anteriormente, las denominaciones utilizadas para el objeto superan en número a las de la propia disciplina. Así, en español se han propuesto entre otros los siguientes conceptos:

- Expresión pluriverbal, locución (Casares, 1950/1992)

- Unidad pluriverbal lexicalizada y habitualizada (Haensch y otros, 1982; Corpas, 1995)

- Unidad léxica pluriverbal (Hernández, 1989)

- Expresión fija (Zuluaga, 1980; García-Page, 1990)

- Unidad fraseológica o fraseologismo (Zuluaga, 1980; Haensch y otros, 1982; Carneado, 1985; Tristá, 1988; Martínez López, 1996)

- Locuciones (García-Page, 2008)

A juicio de Corpas (1996: 18), la variedad terminológica muestra la inestabilidad que hay en esta parcela. Por nuestra parte, creemos que responde también al propio enfoque de las investigaciones fraseológicas: si durante mucho tiempo estas se centraron preferentemente en cuestiones teóricas y terminológicas, es lógico que ello se tradujera en la dispersión que observamos aquí.

Puesto que para poder llegar a una definición de las UF es inevitable basarse en las características o criterios que estas deben cumplir, a continuación detallamos dichos criterios y posteriormente ofreceremos las definiciones para nuestro objeto de estudio.

\subsection{RASGOS DELIMITADORES}

Como apunta García-Page (2008: 23): 
Los rasgos, características o criterios esgrimidos para la delimitación y clasificación de locuciones no suponen automáticamente la concreción, sino que estarían compartidos con otro tipo de unidades lingüísticas.

En definitiva, si tomamos estos rasgos individualmente, observamos que no son privativos de las UF, ni están presentes todos a la vez, ni se dan en todas las UF.

Según García-Page (2008: 23), estos son los principales criterios delimitadores que encontramos en las principales tradiciones filológicas para definir las unidades fraseológicas:

- Estructura compuesta por al menos dos palabras, rasgo habitualmente acuñado como pluriverbalidad o polilexicalidad

- Fijación/estabilidad y variación potencial

- Idiomaticidad

- Institucionalización

- Estructura oracional

- Frecuencia

- Nominación

El primero es uno de los criterios más objetivos. En efecto, la pluriverbalidad tiene que ver con la estructura externa y, por ello, es fácilmente reconocible. El segundo, la fijación, también denominada estabilidad, hace referencia a la indisolubilidad de la forma en que aparece. La idiomaticidad es más difícil de delimitar, pues ya se adentra en el terreno del significado y, a veces, de lo subjetivo. Con la institucionalización, se define de alguna manera la aceptación de una forma por la comunidad lingüística que la utiliza. Por su parte, el rasgo de la estructura oracional hace referencia a la constitución sintáctica completa o no de las UF. La frecuencia alude tanto a la repetición de este tipo de estructuras en la comunicación (frecuencia de uso), como a la reiterada aparición conjunta de los términos en una UF (frecuencia de coaparición). Finalmente, con nominación se refiere al proceso de nueva designación que implica la desviación del significado primario. Ahora bien, además de los 
reseñados arriba, la bibliografía especializada hace también alusión a otros rasgos de las UF, como la presencia de anomalías y figuras de repetición, o la función eminentemente pragmática de estas unidades. A continuación, definiremos y ejemplificaremos con detalle cada uno estos rasgos.

\subsubsection{PLURIVERBALIDAD}

La pluriverbalidad es un rasgo de las UF en el que los lingüistas coinciden unánimemente, aunque también evidencian que no es un rasgo privativo de ellas. Se utiliza a veces como sinónimo el término polilexicalidad, muy extendido en el ámbito germánico (Polylexikalität) y en otras filologías, pero que García-Page (2008: 24) critica por no ser del todo exacto. A este respecto, pone como ejemplo el de unidades compuestas de una sola lexía (palabra con sentido pleno) más otros elementos que, a pesar de ser combinaciones de varios términos, no constituyen UF, como a horcajadas, o a lo mejor. Tambien, el de lexías gramaticalizadas que no conservan su significado original, como en a fin de que, y a pesar de que (los términos fin, pesar no tienen sentido pleno en estas estructuras).

Por el contrario, la noción de pluriverbalidad se cumple siempre, pues alude a la concurrencia de, al menos, dos términos gráficamente separados: matar dos pájaros de un tiro. Además, permite descartar como materia de la fraseología términos escritos juntos como compuestos gráficos parasol, duermevela, palabras simples con acepciones figuradas o idiomáticas como abrirse o fórmulas aglutinadas como arreglárselas (García-Page 2008: 24). Aunque en los ejemplos anteriores la pluriverbalidad o polilexicalidad constituyen criterios parcialmente válidos, pues hacen que se incluya el primer ejemplo y se descarten los siguientes, no dejarían de provocar confusión en otras expresiones, que no serían consideradas como UF en una concepción estrecha. Este es, por ejemplo, el caso de las siguientes:

- compuestos sintagmáticos o sinápticos: guardia civil, coche cama

- compuestos gráficos, con o sin guión: bocamanga, físico-químico,

- colocaciones: secreto sumarial 
- predicados con verbo soporte: dar permiso

- paremias, citas, etc.: Agua que no has de beber, déjala correr

- estereotipos nominativos, como nombres propios, terminología específica o fraseotérminos: Canal de Suez, Gran Bretaña, Organización de las Naciones Unidas

Entendida literalmente como la presencia de más de un término, la pluriverbalidad o polilexicalidad sería un criterio suficiente para identificar a estas últimas estructuras, compuestos o colocaciones, y se cumpliría más regularmente en estas expresiones que en el conjunto de las locuciones, al poder quedar excluidas algunas de estas, en particular todas aquellas que estén constituidas por un solo término.

En resumen, la pluriverbalidad es una condición necesaria pero no privativa de las UF, aunque suficientemente restrictiva, a juicio de García-Page, para dejar fuera del campo de estudio de la fraseología muchas estructuras.

\subsubsection{FIJACIÓN}

La fijación o estabilidad es uno de los rasgos más importantes de las UF, el principal rasgo definitorio, según García-Page (2008: 24). Se entiende como el resultado de un proceso diacrónico que da lugar a la conversión paulatina de una construcción libre y variable en una fija, estable e invariable, gracias a la continua repetición. Una forma analítica libre llega a adquirir a través de la historia un significado traslaticio o específico hasta concebirse como un todo distinto y con entidad propia, diferente de la suma de los significados de los elementos integrantes. En este sentido, una locución o UF es ante todo una combinación de palabras, fija o estable, que se reproduce al hablar.

Corpas (1996: 23) define esta característica como estabilidad, y como derivados de ella, alude a la fijación, entendida como fijación de la forma, y a la especialización semántica, que es el proceso de fijación del significado. Por su parte, López Roig (2002: 42) utiliza el concepto de fraseologización, refiriéndose al proceso de conversión de una unidad sintáctica en UF, aunque 
con el término representa un fenómeno más amplio si incluye ambas posibilidades de fijación: la fijación de la forma y la fijación semántica. ${ }^{44} \mathrm{~A}$ este respecto, Burguer (1998: 15) distingue entre fraseologización o conversión de sintagma libre en UF (fijación de la forma) e idiomatización o conversión de sintagma libre en idiom (fijación del sentido).

La fijación (Festigkeit) no es tampoco un rasgo privativo de las UF, pues otras unidades que no son fraseológicas la poseen en cierto grado. Por otro lado, hay unidades fraseológicas en las que el criterio se incumple en mayor o menor medida, como revela la existencia de variantes y variaciones a las que nos referimos a continuación.

\subsubsection{VARIANTES}

Por variantes se entiende la coexistencia de diversas formas intercambiables de una UF, es decir, cuando alguno de sus términos presenta un doblete/triplete con idéntico significado, ya aceptado y codificado por la comunidad lingüística. Estas variantes pueden responder a diferentes motivos, y pueden funcionar como marcas diatópicas o diastráticas, marcas de expresividad o economía lingüística, entre otras. Algunos ejemplos de variantes en español, codificadas y difundidas ampliamente en la comunidad, serían buscar los tres/cinco pies al gato, ponérsele a alguien la piel/carne de gallina. Cabe decir que estas variantes suelen estar recogidas en las obras fraseográficas.

La característica de la fijación no es tampoco estanca pues, como ocurre con otras, presenta cierta gradación, hecho que aprovechan algunos autores para cuestionar su fiabilidad. García-Page, por el contrario, considera que esa percepción se debe a la inclusión en la fraseología de expresiones que deben ser objeto de estudio de otras ramas: la sintaxis debería encargarse de las colocaciones y las estructuras con verbo soporte; la morfología se ocuparía de

\footnotetext{
${ }^{44}$ Fijación o estabilidad de la forma de una UF frente a fijación del significado (normalmente adquisición de un nuevo significado que no se deduce de la sumade los significados de los términos).
} 
los compuestos, gráficos y no gráficos. Estos ejemplos (colocaciones, construcciones con verbo soporte, etc.) tendrían que estar fuera de la fraseología, pues sus cambios nada tienen que ver con las que se denominan propiamente variantes fraseológicas codificadas, ya fijadas por la tradición, como las siguientes:

- variantes gráficas: a tente bonete/ a tentebonete

- variantes fónicas: a volapié/ a vuelapié

- variantes morfológicas: a horcajadas/ a horcajadillas

- variantes gramaticales: a favor de/ en favor de

- variantes léxicas: salir por la puerta de perros/ de carros

\subsubsection{VARIACIONES}

Se hace referencia a variaciones o modificaciones cuando, esas opciones alternativas surgen mediante signos de la técnica libre del discurso. Es el caso, según García-Page (2008: 25), de los siguientes ejemplos del español:

1. incrementos léxicos con valor intensificador: tener muy mala uva, no tener ni pajolera idea. Aún así, y a pesar de simular las técnicas de la variación libre, estas modificaciones están de alguna manera fijadas, pues no se acepta cualquier palabra en el eje paradigmático;

2. variaciones internas propias de las combinaciones libres:

- acortamientos: de golpe (y porrazo)

- cambios flexivos o derivativos: sano y salvo/ sana y salva; echar una cana/ canita al aire

- transformaciones sintácticas diversas: tener mucha vistal Mucha vista es lo que tiene.

Coincidimos con García-Page (2008: 26) al precisar que la posibilidad de variación en las UF, es decir, la existencia de variantes y variaciones, lejos de plantear una contradicción a la fijación, se erige como rasgo característico de las UF. Sin embargo, al igual que como ocurre en los anteriores rasgos 
esgrimidos, este no es privativo de las UF, puesto que es compartido por otras unidades de la fraseología en su concepción amplia, como son las colocaciones o las paremias, donde también es posible encontrar variantes codificadas. El hecho de que se encuentren parcelas de no aplicación, no indica que sea un rasgo vacilante.

\subsubsection{IDIOMATICIDAD}

Se menciona la idiomaticidad (Idiomatizität) como otra de las características definitorias de las UF. Destaca también su carácter variable, dada la gran cantidad de locuciones o UF que no tienen significado traslaticio o lo tienen solo parcialmente. De todas las características definitorias de las UF, seguramente es la que más controversia plantea, no solo por la delimitación del propio concepto, sino por el cumplimiento de este en las unidades.

Corpas (1996: 27) identifica idiomaticidad con opacidad semántica, por ejemplo. Otras veces, se encuentra definida en términos de no composicionalidad, como por ejemplo en Casares (1950/1992: 170), quien destaca la existencia de idiomaticidad cuando se está ante la siguiente situación:

Combinación estable de dos o más términos, que funciona como elemento oracional y cuyo sentido unitario consabido no se justifica, sin más, como una suma del significado normal de los componentes.

En otras ocasiones, el término idiomático se emplea como sinónimo de figurado - metafórico, con lo que se podría interpretar como fraseológica cualquier expresión que hubiera sufrido una transposición semántica, como $X$ es un sol, fumarse el tiempo o una colocación con un colocativo metafórico como calurosa acogida. 
La idiomaticidad se identifica también con la fraseologicidad, la esencia de las expresiones idiomáticas o idioms..$^{45}$ La misma delimitación de idiom frente a otras unidades provoca, a veces, una cierta confusió por la amplitud de uso del término, ${ }^{46}$ con lo que remitir el concepto fraseologicidad al objeto idiom resulta peliagudo, a juicio de García-Page (2008: 27).

Al igual que la fijación, la idiomaticidad se muestra a veces de modo diverso y también con cierta gradación. Cuantificar la idiomaticidad o la motivación de una locución o UF es tarea compleja. Será sencillo distinguir el significado literal o cuasi literal y significado idiomático en expresiones como en público o blanco como la nieve, pero no está tan claro cuando se contrastan expresiones semánticamente opacas como tomar el olivo (que significan huir, escapar), en el que los referentes literales no son evidentes.

A veces, la percepción de mayor o menor índice de literalidad es una cuestión profundamente subjetiva y debida a causas no estrictamente lingüísticas (García-Page, 2008: 27-28). ${ }^{47}$ De ahí se deriva que, tal y como se ha mencionado antes, debido al carácter predominantemente subjetivo, el establecimiento de la idiomaticidad y sus grados mediante criterios empíricos es aún una asignatura pendiente. Precisamente, muchas veces se toman como ejemplo de transparencia aquellas unidades que se establecen al margen de la fraseología, como colocaciones y estructuras con verbo soporte.

Además, como ocurre con otras características, la idiomaticidad no es privativa de las UF, pues por un lado no las define todas, ya que algunas son completamente transparentes (negro como el azabache, locuciones con significado literal), y por otro lado, está presente en algunas expresiones que no son fraseológicas pero disponen también de significado traslaticio, como en las colocaciones diente de león; en compuestos, como cantamañanas,

\footnotetext{
${ }^{45}$ García-Page no traduce la expresión idiom al español, tal y como sí hacen otros, sino que la utiliza en su misma acepción inglesa, con lo cual diferencia esa unidad fraseológica de las collocations o proverbs.

${ }^{46}$ Se utiliza como definición tanto para expresiones con verbo soporte, como para locuciones propiamente dichas y para colocaciones.

${ }^{47}$ En este sentido, García-Page alude a la posibilidad de realizar encuestas para dilucidar esta cuestión.
} 
pelagatos, meapilas; en paremias, como Agua pasada no mueve molino $;^{48} \mathrm{y}$ también la encontramos en el colocativo de algunas colocaciones con sentido idiomático esgrimir un argumento, depositar la confianza, etc.

\subsubsection{INSTITUCIONALIZACIÓN}

Corpas afirma que la institucionalización caracteriza las producciones lingüísticas de los hablantes, pues no hacen sus propias combinaciones de palabras, sino que "utilizan combinaciones ya creadas y reproducidas constantemente en el discurso, que han sido sancionadas por el uso" (Corpas, 1996: 22).

Esas UF repetidas, institucionalizadas a través del uso frecuente, funcionan como unidades del lexicón mental, a juicio de Corpas, y valora el hecho del registro de estas UF en los diccionarios pues avala también el carácter de reproducibilidad de las mismas.

Por su parte, García-Page (2008: 29) considera la institucionalización como otro de los rasgos fundamentales atribuibles a la fraseología, una característica pareja a la fijación y la fraseologización, hasta el punto que algunos lingüistas como Zuluaga (1998) o López Roig (2002), entre otros identifican la institucionalización con estas últimas. En palabras de García-Page (2008: 29), se entiende por institucionalización:

El proceso por el cual una comunidad lingüística adopta una expresión fija, la sanciona como algo propio [...] como cualquier signo convencional y pasa a formar parte del vocabulario.

En la institucionalización de una estructura se precisa la acción fijadora del uso repetido, de ahí que la fijación se identifique a veces con la reproducibilidad. De hecho, García-Page afirma que la repetición lleva a la institucionalización y que esta, a su vez, favorece la repetición.

\footnotetext{
${ }^{48}$ Hay que recordar que García-Page también excluye de la fraseología las paremias.
} 
Otros autores identifican la institucionalización con la lexicalización, pero para García-Page el concepto va más allá, pues trata de la fijación definitiva de un significado especial o particular que adquirió una combinación libre al ir fraguando en combinación fija, o el de la conformación de la estructura sintáctica en estructura léxica.

De nuevo, tampoco se considera esta característica de las UF como intrínseca y privativa de las locuciones, de las UF que se consideran objeto de estudio de la fraseología, sino que también la poseen refranes, colocaciones, etc.

\subsubsection{ESTRUCTURA ORACIONAL}

La concepción más tradicional sostiene que la locución no puede tener estructura de oración completa. Algunos lo equiparan como rasgo a la fijación o a la idiomaticidad a nivel de importancia, como Larreta $(1998,1998 / 2001)$ o Fleischer (1982). Incluso se utiliza como argumento suficiente para distinguir la locución del refrán o del enunciado fraseológico, pero no sirve evidentemente para diferenciar una locución de otras creaciones fraseológicas como las colocaciones. Esta estructura oracional sería, pues, lo que permitiría distinguir, por una parte, entre colocaciones de diferentes tipos (ojo de buey), estructuras de verbo soporte (esgrimir un argumento), locuciones (llevar cada cual su cruz) combinaciones todas de estructura no-oracional, y por otra, los enunciados fraseológicos en general, refranes ( $A$ nadie le amarga un dulce), fórmulas de rutina (Estimados/as Sres./as.) y enunciados pragmáticos ( $A$ mi parecer), que de alguna manera están provistos de cierta estructura oracional. ${ }^{49}$

Frente a esta opinión, muchos autores, incluida la RAE (1992), entienden que la locución sí puede tener estructura de oración completa. García-Page considera esta posibilidad al hablar de locuciones oracionales, teniendo en cuenta expresiones como haber moros en la costa, no estar el horno para bollos (2008: 30), las cuales, a pesar de tener estructura oracional, no se dejan

\footnotetext{
${ }^{49}$ Es evidente que no se utiliza el concepto de estructura oracional a nivel superficial (unidad compuesta de sujeto y predicado), sino de estructura profunda (enunciado o unidad comunicativa autónoma, García-Page, 2008: 31).
} 
encasillar en otros tipos como refranes, etc. A pesar de ello, ${ }^{50}$ así las han descrito otros autores como Casares (1950/1992), que se refirió a ellas como frases proverbiales; Corpas (1998), que las llamó enunciados de valor específico, o Mendivil (1999), para quien serían proverbios.

Además de estas, García-Page incluye en este grupo de locuciones oracionales otras expresiones como El tiempo lo dirá, A nadie le amarga un dulce, En todas partes cuecen habas, las cuales han sido tradicionalmente ubicadas entre los diferentes tipos de paremias. El autor defiende que así se perciben por los hablantes y critica la clasificación que hacen de ellas otros autores como simples locuciones, que atienden - a su juicio- más a criterios pragmáticos que formales, y por tanto no exentos de cierta dosis de arbitrariedad. Según el criterio de locución oracional que utiliza García-Page, se pueden adscribir a ellas las denominadas locuciones exclamativas 0 interjectivas ( Válgame Dios!).

La escasa fiabilidad de este criterio de rango oracional también parecen advertirla Baranov y Dobrovol'skij (1998), quienes hacen notar que algunas locuciones verbales han desarrollado versiones con estatuto sintáctico de oración o a la inversa, como echar a suertes y La suerte está echada. También lo considera de este modo Zuluaga (2001), quien considera que locución y enunciado fraseológico son tipos no discretos, al emplearse a veces las locuciones como enunciados y los enunciados como locuciones.

\subsubsection{FRECUENCIA}

Algunos lingüistas españoles, como Corpas (1996: 20), Ruiz Gurillo (1997: 80) - García-Page (2008: 32) esgrimen también el criterio de la frecuencia de uso como rasgo general de las UF. Corpas afirma que es una característica importante, pues la frecuencia de aparición de las UF en la comunicación cotidiana se sitúa en un $20 \%$ y el uso de estas expresiones con su sentido idiomático o fraseológico supera muchas veces al literal $u$ originario, un

50 De este tipo son las expresiones utilizadas en el presente estudio y se considera la clasificación de García-Page como muy acertada al respecto. 
argumento que queda corroborado también por otros investigadores como Tristá (1988: 46), López Roig (2002: 33) y Burguer y otros (1982: 27).

También se utiliza el criterio de frecuencia en el sentido de frecuencia de coaparición de los componentes en las UF, con más propiedad según GarcíaPage (2008: 32) en las colocaciones (cabello ensortijado): ${ }^{51}$

En ellas la frecuencia de coaparición (hecho sintagmático), si bien derivada de su vínculo semántico (hecho paradigmático) contribuye a su estabilidad completa y definitiva.

Este concepto trambién es mencionado por Corpas (1996).

\subsubsection{NOMINACIÓN}

García-Page (2008: 32) también señala la nominación o función nominativa como una característica de las UF: es la capacidad que poseen estas unidades en tanto que formas compuestas de las unidades simples primarias de designar un nuevo concepto. Aduce que, al igual que otras características ya comentadas, su presencia es desigual en las diferentes expresiones y tampoco goza de exclusividad, pues a los compuestos también se les puede atribuir la propiedad de la nominación secundaria, la capacidad de añadir un significado nuevo a partir de uno primario (cabello de ángel es un dulce; tomar el olivo significa 'huir'). También, según el autor (2008: 33), los refranes asimilables a las locuciones oracionales pueden desempeñar una función nominativa similar.

\subsubsection{ANOMALÍAS}

La presencia de anomalías léxico-semánticas o sintácticas en los diversos niveles del análisis se señala también como índice fraseológico, es decir, las UF presentan formas que de alguna manera incumplen la norma gramatical. Así lo indican autores como Burguer (1973, 1998), Fleischer (1982), Pilz

\footnotetext{
${ }^{51}$ Los términos suelen aparecer juntos, de manera que la aparición de uno hace que otro sea 'esperado'.
} 
(1981), Tristá (1988), Gréciano (1978, 1982), Ruiz Gurillo (1997), Corpas (1996) o García-Page (2008), aunque este último, solo parcialmente.

Hasta tal punto se consideran importantes que autores como Tristá (1988: 2938) las describen como indicadores fraseológicos y aportan algunos ejemplos: a) anomalías semánticas: consultar con la almohada (complemento no personificado); b) anomalías gramaticales: a ojos vistas (en lugar de vistos). De este modo, la presencia o ausencia de tales anomalías permite a la autora diferenciar entre dos tipos diferentes de UF: las UF con indicador de anomalía y las UF sin indicador, ambiguas estas últimas a juicio de Tristá al no disponer de esta marca que evidencie la presencia de una unidad fraseológica. Como ejemplos de UF sin indicador proporciona abrir la puerta o morder el anzuelo.

En otras tradiciones lingüísticas, también se ha llamado la atención acerca de la relevancia de este factor. Así, Černyševa (1975: 200) destacaba ya la importancia de lo anómalo en el ámbito fraseológico. Asimismo, los generativistas han hablado de las limitaciones de la gramática para explicar los hechos fraseológicos. García-Page (2008), por su parte, considera también que la presencia de anomalías de diferentes tipos es síntoma inequívoco de la presencia de una locución, pese a lo cual advierte que ni afecta a todas las locuciones ni son rasgos exclusivos de ellas. Entre estas anomalías en las UF destaca la presencia de arcaísmos (no parar mientes) o la ausencia del artículo (no levantar cabeza).

Otros ejemplos en los que se aprecian anomalías semánticas serían algunas de las siguientes expresiones, proporcionadas por Tristá (1988), en las que la presencia de figuras como la metáfora, la hipérbole o la metonimia enmascara un significado fácilmente aprehensible a primera vista: comerse el mundo, ahogarse en un vaso de agua, no caber el corazón en el pecho o salirse de madre.

Algunos ejemplos de anomalías gramaticales en diferentes categorías serían los siguientes (García-Page, 2008: 34): 
- en locuciones: a ojos vistas, a pie juntillas, a campo traviesa

- en refranes: Quien ve su comida aparejar, harto está sin la probar

- en compuestos: guardiaciviles, Latinoamérica

- colocaciones: garrafal (error), bizantina (discusión)

Con todo, las anomalías no son exclusivas de las locuciones, sino que afectan también a otras expresiones.

\subsubsection{FIGURAS DE REPETICIÓN}

Se suele ver en la artificiosidad formal otro síntoma de la naturaleza fraseológica, pues hay muchas locuciones que presentan algún fenómeno de los que se podrían denominar fonéticos, y que son mencionados por autores como Zuluaga (1980: 115-120) o Ruiz Gurillo (1997: 75). Entre otros, cabe mencionar recursos como paronomasias (ir $y$ venir), aliteraciones (santo $y$ seña), o ritmos métricos (rima consonante: contante y sonante), todos ellos recursos que contribuyen sin duda a la fijación. Estos rasgos están especialmente presentes en paremias, sobre todo refranes, y en las unidades de la fraseología en sentido amplio.

\subsubsection{RASGOS PRAGMÁTICO-DISCURSIVOS}

La perspectiva que ofrece Martínez Marín (1996: 101) respecto a los rasgos de las unidades fraseológicas nos resulta también interesante. Además de destacar como rasgos más importantes de las UF algunos de los ya mencionados, como el aspecto formal (la fijación), y la significación (la idiomaticidad), Martínez Marín destaca como rasgo de especial relevancia el valor comunicativo, esto es, la carga expresiva habitual en estas expresiones. Esta consideración ha llevado a algunos investigadores a analizar las UF desde una perspectiva pragmática en la que prima el interés por el contenido comunicativo antes que por el meramente semántico. Martínez Marín ofrece las siguientes comparaciones como ejemplo de la fuerza expresiva de estas expresiones frente a verbos simples, cuyo significado semántico podría coincidir en el sistema lingüístico: confiarse vs. dormirse en los laureles; 
sorprenderse vs. quedarse de piedra; tener cautela vs. andarse con pies de plomo. Esta especial carga expresiva de las UF recibe en el ámbito germánico el nombre de Bildhaftigkeit (lit. iconicidad).

Algunos estudiosos han incluido el aspecto pragmático incluso en las propias denominaciones empleadas para las UF. Así Burger (1973), en su Idiomatik des Deutschen, denomina a las UF pragmatische Idiome (lit. idioms pragmáticos). O también lo hizo Zuluaga (1980), quien utilizó el término de fijación pragmática para referirse al hecho de que las UF están especializadas en situaciones concretas de interacción pragmática.

Los valores comunicativos o pragmáticos son fundamentales en las UF, pues explican la restricción de uso de estas expresiones en determinados contextos. Estos aspectos son especialmente importantes para las llamadas fórmulas de rutina. Así, para Martínez Marín (1996: 104) estas pueden estar determinadas por:

1. situaciones de comunicación:

a. tipo de acontecimiento o situación (encuentro, despedida, pésame: ;buenos días!)

b. datos sociológicos de los interlocutores: edad, sexo, posición y relación social, etc. (mismo nivel o diferente nivel determina diferentes saludos, despedidas: ¡buenas tardes!, frente a ¡hasta luego!)

c. canal de comunicación (orales, escritos, audiovisuales, verboicónicos: ¡hola!, frente a estimados lectores)

2. expresión de las particulares relaciones entre los interlocutores:

a. actitud del hablante respecto a otra persona, que puede ser el oyente o no (anuencia, desaprobación, etc.: meterse en camisa de once varas, que muestra actitud de censura hacia la actuación de alguien)

b. valoración del hablante: 
i. de cualidades de las personas (ser la niña de mis/sus ojos, por analogía con la parte más importante del ojo, la pupila)

ii. de hechos o circunstancias (sacar la cabeza caliente)

c. comportamientos estereotipados (obstinación: cerrarse en banda; terquedad: mantenerse en sus trece)

A pesar de que las UF se emplean en todo tipo de textos, precisamente por sus valores comunicativos están muy presentes en el registro coloquial, pero también en algunos textos escritos, como los periodísticos, en los que se utilizan abundantemente las UF por su fuerza expresiva.

Varios factores interrelacionados propician y justifican el estudio de la vertiente pragmática de las UF: el reconocimiento de la fraseología como portadora de sentido, la revalorización de la perspectiva del valor oral de las lenguas, las aportaciones de la lingüística estructural europea, con representantes como Martinet y Coseriu, la necesidad de atender a los textos, y la consecuente elaboración del enfoque conocido como análisis del discurso. A partir de la obra de Coseriu, por ejemplo, se difunde una distinción fundamental en la lingüística europea, aplicada posteriormente a las UF, entre los conceptos de técnica libre del discurso y discurso repetido. Ambos conceptos dan cuenta de la existencia de unidades diferenciadas que responden a cada una de estas técnicas. De las primeras se dice que se producen al hablar; de las segundas, que se reproducen. Y así, las UF serían unidades del discurso repetido, según Martínez Marín (1996: 101).

En el ámbito de la estilística del discurso, Martínez Marín (1996) describe la función de las UF como elementos de la estructura general de los textos, que abarcan desde los estilos funcionales (coloquial, culto o periodístico, entre otros) hasta la consideración del contenido ideológico y cultural en general. Asimismo, destacan también las funciones de apertura y cierre que tienen algunas expresiones, por ejemplo en el lenguaje administrativo (Estimada Señora; Atentamente). 
Corpas (1996) también apunta hacia una revalorización de la dimensión pragmática. Además de destacar la importancia de circunscribir las UF al marco teórico adecuado (gramática oracional y gramática textual), reclama la necesidad de traspasar el nivel de la oración y llegar al del texto, que es donde muchas UF encuentran su explicación más satisfactoria. Y es que, en definitiva, el enfoque discursivo arroja luz sobre los aspectos más destacados de las expresiones fijas: el significado, la función comunicativa (informar, argumentar, comentar, etc.); la manera de integrarse en el texto y su posición discursiva (apertura, cierre, diálogo, narración, etc.), pragmáticamente fijadas; e incluso la estructura formal.

Según Corpas, todavía quedan muchos aspectos por estudiar, entre ellos los fenómenos que provocan la aparición de enunciados fraseológicos en ciertos textos, consecuencia de la propia dinámica de estos. Concluye que el avance en los estudios de las UF desde la perspectiva de la lingüística textual pronostica grandes logros, no solo en la vertiente descriptiva, sino también en la aplicada: téngase en cuenta, por ejemplo, la escasez de fraseología en los métodos de enseñanza de lenguas extranjeras, consecuencia sin duda de la ausencia de estudios descriptivos previos.

\subsection{TIPOS DE UNIDADES}

Si bien hay un amplio consenso en la aceptación de término fraseología para denominar la disciplina, no ocurre lo mismo con los términos que designan su objeto de estudio. De hecho, encontramos en este terreno una notable variedad terminológica, especialmente en los estudios hispánicos. Así, se utilizan vocablos como locución para las unidades menores de la oración, y refrán y frase hecha para las de mayor extensión, aunque para estas últimas se utilizan también otras denominaciones como sentencia, modismo, adagio, o giro idiomático, aunque bien es cierto que estas últimas denominaciones son poco utilizadas en la actualidad por los lingüistas por su imprecisión. Por otro lado, el término unidad fraseológica, usado con frecuencia, se emplea a veces como 
hiperónimo, otras como hipónimo, y en este último caso como sinónimo de locución.

En alemán la profusión terminológica también es destacable, aunque para las unidades menores se prefiere casi ya unánimemente el término Phraseologismus (fraseologismo) como genérico, que convive con otros como phraseologische Einheit (unidad fraseológica), o Phraseolexeme en combinaciones como Verbalephraseolexeme (fraseolexema verbal). Para las de mayor extensión se utilizan las denominaciones Redewendung, Redensart (giro idiomático, frase hecha), Sprichwort (refrán).

No obstante, como se ha indicado anteriormente, la impresión de caos terminológico de otras épocas parece haber cesado en intensidad: de alguna manera se ha superado esa etapa y la tipología ya no es el centro de los debates científicos. En general, se tiende a utilizar menos términos y a asimilar la terminología propia de una lengua a la utilizada en las filologías cercanas. ${ }^{52}$ Este talante unificador y homogeneizador es fruto sin duda de los numerosos encuentros e intercambios científicos, especialmente en el continente europeo, impulsados sobre todo por las filologías eslavas y germánica. Otras, como la escuela hispánica, tampoco van a la zaga en estos momentos en cuanto a la investigación fraseológica se refiere. La tendencia en las dos tradiciones filológicas que son objeto del presente estudio, la española y la alemana, es utilizar mayoritariamente para el objeto de estudio los términos relacionados semánticamente con la denominación de la disciplina, en español unidad fraseológica (UF) y fraseología, y en alemán Phraseologismus o phraseologische Einheit y Phraseologie.

Dos de las autoras más representativas de la investigación fraseológica hispánica, Corpas y Carneado, ofrecen sus clasificaciones desde una visión amplia de la fraseología. En esta perspectiva, el término unidad fraseológica se

\footnotetext{
52 Una excepción a los intentos de unificar las denominaciones bajo este paraguas terminológico la encontramos en los estudios del inglés, en los que ni el concepto de unidad fraseológica, ni el de frasema han llegado a calar, prefiriendo en su lugar hiperónimos como set-phrase o idiom.
} 
consideraría como un hiperónimo: todas las expresiones que estudia la fraseología serían, pues, unidades fraseológicas (UF).

Corpas (1996: 50-52) propone combinar el criterio del enunciado o estructura oracional con el de fijación para hacer su clasificación, y así distingue entre colocaciones, locuciones y enunciados fraseológicos. Se entiende por enunciado una unidad de comunicación mínima, producto de un acto de habla, que puede ser una oración simple o compuesta, sintagma o palabra, lo que permite distinguir entre dos grupos de unidades fraseológicas: aquellas que no constituyen enunciados completos y aquellas que sí lo son (colocaciones y locuciones no lo serían, los enunciados fraseológicos sí). Por otro lado, la combinación de este criterio con el tipo de fijación que presenta cada grupo, permite seguir perfilando la taxonomía. Y así, dentro del grupo de UF que no constituyen enunciados completos, Corpas establece otra diferencia atendiendo a su nivel de fijación:

- fijadas en la norma: colocaciones (cabello + rubio)

- fijadas en el sistema: locuciones (dar gato por liebre)

Por otro lado, tendríamos las UF que constituyen enunciados completos y su nivel de fijación se encontraría en el habla: son las UF denominadas enunciados fraseológicos (Agua que no has de beber, déjala correr).

Otra clasificación interesante es la que establece Carneado (1985: 9), quien atiende al grado de motivación y a la estructura gramatical de las UF, distinguiendo a este respecto entre diferentes tipos de locuciones, siguiendo a Vinogradov (1946):

- adherencias fraseológicas, son UF inmotivadas, es decir, no se ve claramente la realidad de la cual ha surgido la expresión. Se consideran, por tanto, de significado unitario traslaticio, p. ej.: perder la chaveta;

- unidades fraseológicas, UF motivadas, p. ej.: buscar la boca; 
- combinaciones fraseológicas, UF en las que un elemento actualiza un significado especial, p. ej.: reinar el silencio;

- expresiones fraseológicas: que engloban refranes, proverbios, etc., denominadas también con el hiperónimo paremias, p. ej.: Muerto el perro, se acabó la rabia.

Carneado (1985: 79) resume así los tipos que toma en consideración:

Como partidarios del criterio amplio, unidades fraseológicas podrían ser para nosotros las denominadas por Casares locuciones, las frases proverbiales, los refranes y demás fórmulas estables de la lengua.

La lista de clasificaciones ofrecida por diferentes autores sería interminable. No obstante, mencionaremos la que ofrece García-Page (2008), por el interés que tiene para el estudio de las expresiones que utilizamos en el presente estudio. El sentido particular de la concepción estrecha de la fraseología de GarcíaPage radica en la utilización de un concepto nuevo de locución, distinto del de Casares (1950/1992): la locución oracional, que para García-Page englobaría expresiones como volver las aguas a su cauce. Además, dentro de estas estarían las locuciones semi-oracionales, un subconjunto de las oracionales que, a diferencia de ellas, no actualizan el sujeto: morder el polvo (GarcíaPage, 2008: 9).

Este tipo de UF denominadas locuciones oracionales y semi-oracionales para dar cuenta de expresiones como hacérsele a alguien la boca agua constituyen, pues, el objeto de nuestro estudio. Como hemos visto, así las denomina García-Page, mientras que Corpas prefiere hablar de locuciones clausales y Carneado de locuciones proposicionales, para aludir, en todo caso, a una misma realidad fraseológica.

Después de la esta pequeña introducción, en la que hemos presentado las clasificaciones propuestas por autores españoles representativos, pasamos a continuación a valorar algunas denominaciones utilizadas en una visión amplia de la fraseología. 


\subsubsection{UNIDAD FRASEOLÓGICA}

La denominación genérica unidad fraseológica (UF) (phraseologische Einheit) es una de las expresiones más utilizadas en la filología hispánica, tal vez debido a que es la de mayor aceptación en la Europa continental y la antigua URSS, precisamente las escuelas lingüísticas precursoras de los estudios fraseológicos. Se utiliza generalmente como hiperónimo (Oberbegriff) para designar el objeto de la fraseología. Un concepto equivalente, aunque no idéntico, sería el utilizado por la filología germánica como concepto neutro Phraseologismus, en plural Phraseologismen. También encontramos en la fraseología germánica el término Phrasem (frasema) como correlato a morfema y lexema, muy utilizado en los primeros momentos de auge de los estudios, pero postergado después por las limitaciones expresivas que presentaba. En la filología hispánica apenas se ha utilizado la denominación de frasema.

Sin duda, la acepción de unidad fraseológica ha calado en la fraseología española, su uso es frecuente, por lo que también será el más utilizado en la presente tesis. Hay que diferenciar el doble significado que se le atribuye, unas veces como hiperónimo y equivalente a expresión fraseológica, y otras simplemente como objeto de la fraseología en sentido estrecho, y equivalente a locución.

\subsubsection{LOCUCIÓN}

Locución es otro de los términos más empleados en la filología hispánica para denominar las expresiones idiomáticas, utilizado también no solo como hipónimo para denominar un tipo en confrontación con otros, sino también como hiperónimo, como término aglutinante de tipos diferentes de unidades.

Se entiende por locución una unidad compleja fija, que es definida por Casares como: 
Combinación estable de dos o más términos, que funciona como elemento oracional y cuyo sentido unitario consabido no se justifica, sin más, como una suma del significado normal de los componentes (1950/1992: 170).

Dentro de lo que considera locuciones, Casares (1950/1992: 182-183) propone la siguiente clasificación en locuciones significantes y locuciones conexivas. Dentro de las locuciones significantes engloba diversos tipos: locuciones nominales como tocino de cielo; locuciones adjetivales como de brocha gorda; locuciones verbales como tomar el olivo; locuciones adverbiales como en un santiamén; locuciones pronominales como cada quisque y locuciones exclamativas como ;Ancha es Castilla! Por otro lado, dentro de las locuciones conexivas destaca dos tipos: locuciones conjuntivas como con tal que y locuciones propositivas como en pos de.

García-Page (2008) deja muy clara su elección de terminología ya en el título de su exhaustivo estudio sobre la disciplina Introducción a la fraseología española. Estudio de las locuciones y asimila el término de unidad fraseológica y locución. El autor utiliza el término locución para denominar las unidades fraseológicas que son, a su entender, objeto de estudio exclusivo de la fraseología, siguiendo una concepción estrecha de la misma:

En síntesis, nuestro concepto de unidad fraseológica o locución [...] incluye las tradicionales locuciones con función sintáctica de elemento oracional (nominal, verbal, adjetival, preposicional, conjuntiva), como jugarse el tipo, en un periquete, y las fórmulas pragmáticas [...], como ;Válgame Dios! (García-Page, 2008: 21-22).

No obstante, García-Page engloba en el concepto de locución también las estructuras que denomina como locuciones oracionales (ir la procesión por dentro), con lo cual amplía el el alcance del concepto de Casares y otros autores, que trataban a las expresiones con estructura oracional como tipos de paremias. 


\subsubsection{EXPRESIÓN PLURIVERBAL}

La denominación expresión pluriverbal alude a la característica denominada pluriverbalidad a la que hacíamos referencia anteriormente: caracteriza a las unidades compuestas por más de una palabra. Esta expresión no goza de mucha difusión, aunque otras similares tienen más adeptos, como unidad pluriverbal lexicalizada, que además de contener indicación explícita sobre la naturaleza pluriverbal añade otras características sobresalientes como la fijación y la lexicalización. Como ya hemos mencionado anteriormente, se entiende por fijación la aparición conjunta de los miembros que componen una unidad, como establecida con anterioridad (también denominada como coaparición). Por su parte, la lexicalización alude a la adquisición paulatina de un significado unitario de estas unidades. Sirva como ejemplo de expresión pluriverbal dicho y hecho, formada por tres palabras.

\subsubsection{EXPRESIÓN FIJA}

La denominación expresión fija hace referencia únicamente a la característica de la fijación. Su uso es muy extendido en fraseología a pesar de la restricción que supone esta denominación respecto a otras, pues solo alude a uno de los rasgos posibles. Por ello, es utilizada generalmente como hiperónimo. También la encontramos en otras lenguas, como en alemán, que equivale exactamente a feste Wendungen.

\subsubsection{PAREMIA, REFRÁN, FRASE PROVERBIAL}

Estas tres denominaciones se utilizan a veces como sinónimos, otras veces permiten distinguir unidades específicas. El término paremia se suele utilizar generalmente como hiperónimo, para definir el objeto que define aquellas unidades fraseológicas que constituyen enunciados completos. Según la clasificación de Corpas (1996: 50-52), son UF que constituyen enunciados completos y su nivel de fijación se encuentra en el habla. Son las denominadas por ella enunciados fraseológicos (Agua que no has de beber, déjala correr). Utilizada, pues, la denominación de paremia como genérico para cualquiera de 
estos enunciados, se corresponde etimológicamente con la disciplina, la Paremiología, considerada subdisciplina de la fraseología en una concepción amplia de esta.

El refrán es, según Casares:

\begin{abstract}
Una frase completa e independiente que en sentido directo o alegórico, y por lo general en forma sentenciosa o elíptica, expresa un pensamiento - hecho de experiencia, enseñanza, admonición, etc.- a manera de juicio, en el que se relacionan al menos dos ideas (Casares, 1950/1992: 192).
\end{abstract}

Ejemplos de refranes serían $A$ buen entendedor, sobran palabras, o De tal palo, tal astilla.

La frase proverbial coincide con el refrán en que establece un paralelismo entre hechos que transcurren en diferentes épocas, pasado y presente, y Casares lo define como:

Algo que se dijo o se escribió, y su uso en la lengua tiene el carácter de una cita, de una recordación, de algo que se trae a cuento ante una situación que en modo alguno se asemeja a la que dio origen al dicho (Casares, 1950/1992: 190).

Ejemplos de estas expresiones serían llevar cada cual su cruz o buscar una aguja en un pajar. En alemán se utilizan los términos idiomatische Redewendung, Redensart como equivalentes a frase proverbial y además Sprichwort, sprichwortliche Redensart como refrán.

\title{
3.3.6. COLOCACIÓN
}

Según García-Page (2008: 37), los rasgos presentes en las locuciones también lo están de alguna manera en las colocaciones, por ejemplo, la institucionalización. Este rasgo explicaría la selección idiosincrásica que, pongamos por caso, impediría una modificación en la expresión cambiar radicalmente. En lugar del adverbio que aparece, no sería posible otro como 
intensamente. De ahí, pues, que la libertad creativa quede limitada a veces también en las colocaciones.

Por el contrario, hay muchos elementos que diferenciarían las colocaciones de otras expresiones fraseológicas, como la existencia de esquemas sintácticos específicos que siguen muchas de las primeras, como los siguientes:

- N. + A.: lucha intestina

- V. + N. CD/ N. Suj.: saldar una deuda

- A.+ ADV. o a la inversa: clínicamente muerto

- V. + ADV.: prohibir terminantemente

- N.+ de + N.: mazorca de maíz

Se suele afirmar que, a diferencia de otras unidades fraseológicas, las colocaciones son transparentes en relación con el rasgo de la idiomaticidad. Con todo, esto no ocurre siempre, pues existen las que García-Page (2008) denomina colocaciones parcialmente transparentes o idiomáticas (banco de peces). Aún así, el elemento de la idiomaticidad no es decisivo para delimitarlas: lo importante en ellas es el carácter de estructura composicional, aunque el colocativo ${ }^{53}$ intervenga en la formación con significado traslaticio.

En este capítulo se han apuntado definiciones de las UF y también los rasgos que deben cumplir para ser consideradas como tales. De entre los numerosos rasgos mencionados, nosotros destacaríamos dos como principales: la fijación y la idiomaticidad. Consideramos la fijación como rasgo destacado, porque sirve para caracterizar estas unidades en cierta manera 'prefabricadas' frente a otras del discurso libre, y porque además es la causa de otros rasgos también importantes, como serían la posibilidad de aparición de variantes y variaciones. Asimismo, muy relacionada también con la fijación se encuentra otro rasgo no menos relevante: las anomalías, cuya presencia es habitual en estas expresiones. El segundo rasgo, la idiomaticidad, es de gran importancia también, pues precisamente el uso no denotativo de estas UF es lo que les confiere su particular idiosincrasia, ya que el significado no resulta de la suma

\footnotetext{
${ }^{53}$ Se entiende que una colocación (interés vivo) está formada por una base (interés) y un colocativo (vivo).
} 
de sus componentes, sino que adquiere una dimensión semántica peculiar, a veces muy alejada del significado primario. Finalmente, cabe destacar que la presencia de cualquier rasgo en las UF es gradual, no se da del mismo modo en todas las UF e incluso en una misma UF puede variar en diversos momentos de la historia de una lengua.

En lo que atañe a las denominaciones más apropiadas para el objeto de estudio, ya hemos avanzado anteriormente que la de unidad fraseológica nos parecía un concepto idóneo, no solo por la aceptación que ya tiene en diversas tradiciones filológicas, sino por la coherencia etimológica con el nombre de la disciplina, y sobre todo por la precisión conceptual del término (unidad + fraseológica), con el que se significa por un lado que estamos ante un todo estable, reproducible, y por otro, que posee un significado peculiar, no deducible fácilmente de los elementos integrantes.

Finalmente, y concretando ya el tipo de UF que comprende nuestro corpus, ${ }^{54}$ diremos que se trata de expresiones fraseológicas en las que falta algún actante, un elemento por actualizar en el contexto en que se utilizan. En definitiva, no constituyen a priori textos, ya que se completan en el mismo momento de la comunicación. Así, por ejemplo, en ser la oveja negra de la familia, el sujeto, que está ausente en la formulación genérica virtual, se actualiza en los hechos concretos de habla (p. ej.: 'Juan/mi tío/... es la oveja negra de la familia').

\footnotetext{
${ }^{54}$ Tanto en español, como en alemán, la investigación fraseológica alude a corpus de mínimos, especialmente de refranes. Entre los diferentes autores, Tarnowska (2004) para el español, o Baur y Chlosta (1996a, 1996b) y Mieder (1993) para el alemán.
} 


\section{LA EQUIVALENCIA FRASEOLÓGICA}

\subsection{DEFINICIÓN}

$\mathrm{Si}$ abordar en lenguas diferentes la equivalencia de significados de las unidades simples, las palabras, se convierte a veces en una tarea compleja por la dificultad que comporta encontrar sinónimos perfectos, mucho más complicado resulta todavía la tarea de encontrar expresiones fijas (UF) equivalentes. La sinonimia, la polisemia y otros fenómenos semánticos relacionados con el significado de las palabras revelan la escasez de relaciones biunívocas en el vocabulario, un hecho que se agrava en el caso de las UF, donde los potenciales sinónimos de una unidad fraseológica ofrecen muchas veces matices añadidos a los puramente semánticos, relacionados con aspectos culturales, comunicativos, etc. De ahí que cualquier elección a favor de un u otro equivalente ponga en evidencia, en última instancia y entre otras cosas, la posición del emisor del mensaje.

Pese a lo anterior, los investigadores no han cejado en su empeño por encontrar verdaderas equivalencias entre las UF de diferentes lenguas. ${ }^{55} \mathrm{De}$ hecho, en los últimos tiempos, la fraseología, desarrollada especialmente en su vertiente contrastiva, se ha esforzado por delimitar y reelaborar sus bases teóricas precisamente a partir de la noción de equivalencia, con desarrollos no solo en el terreno conceptual, sino también en las aplicaciones didácticas y traductológicas de las UF.

Sobre la noción de equivalencia, presentamos a continuación dos interpretaciones que consideramos de interés: por un lado, la visión tradicional del concepto de equivalencia, ${ }^{56}$ ampliamente extendida y aceptada en los

\footnotetext{
${ }^{55}$ No tratamos en este caso la equivalencia a nivel traductológico, sino semántico-lingüístico. No obstante, en un ámbito y otro la presencia del concepto de equivalencia es recurrente e indispensable.

${ }^{56}$ Respecto a la superación de las concepciones tradicionales en la búsqueda de equivalentes, Agost (2007) incide en la necesidad de «desterrar [...] los prejuicios y concepciones populares sobre la equivalencia entendida como identidad» (Agost, 2007b: 98).
} 
estudios fraseológicos, que establece entre tres y cuatro tipos diferentes de equivalencia, según los autores; y, por otro lado, el concepto de equivalencia fraseológica introducido por Dobrovol'skij (2011: 7-24).

\subsection{INTERPRETACIONES TRADICIONALES DE LA EQUIVALENCIA}

En su artículo «Cross-linguistic equivalence of idioms: does it really exist?», 57 Dobrovol'skij (2011) plantea una cuestión crucial para la fraseología, que ha ocupado a decenas de investigadores de diferentes tradiciones filológicas (entre otros autores, Eckert (1979), Gréciano (1988), Abraham (1989), Günther (1990), Ďurčo (1994), Eismann (1995), Földes (1996), Rothkegel (1997), Holzinger (1998), Dobrovol'skij (2002), Korhonen (2007), entre otros muchos) y sobre la que, obviamente, tenemos que hacernos eco en un estudio de fraseología contrastiva como el presente.

Korhonen (2007: 575) apunta la existencia de dos formas básicas de abordar la cuestión de la equivalencia bajo enfoques contrastivos: a) ir de la forma al significado, o b) del significado a la forma:

Grundsätzlich kann bei der Kontrastierung phraseologischer Einheiten von zwei oder mehr Sprachen entweder die Bedeutung oder die Form zum Ausgangspunkt genommen werden. ${ }^{58}$

Con todo, el proceso seguido mayoritariamente es el primero, de la forma al significado, y será el que utilicemos a continuación para las siguientes clasificaciones. En este apartado se aborda la equivalencia según el grado que presenta (cf $\S 4.2 .1$ ), con dos clasificaciones usuales en la bibliografía, una tripartita y otra cuatripartita.

\subsubsection{CLASIFICACIÓN TRIPARTITA}

\footnotetext{
${ }^{57}$ Hemos respetado las comillas en los casos en que aparecían en el original.

${ }^{58}$ Literalmente en español: [...] Básicamente, en el contraste de unidades fraseológicas de dos o más idiomas se puede tomar como punto de partida el significado o la forma.
} 
Entendiendo el concepto de equivalencia como una categoría gradual, en la comparación fraseológica se acepta ampliamente bien una división en tres tipos de equivalencia (equivalencia total, equivalencia parcial, equivalencia nula), bien en cuatro tipos (equivalencia total, equivalencia parcial, paralelismos fraseológicos, no-equivalencia). Un representante de la división en tres tipos de equivalencia sería Holzinger (1998), y de los cuatro tipos autores como Rajxštein (1980), Soloduxo (1982), Arsent'eva (1993), Korhonen (2007), Koller (2007) o Mellado (2007).

\subsubsection{EQUIVALENCIA TOTAL}

El contexto de aparición de la equivalencia total, denominada en alemán Volläquivalenz, supone la coincidencia formal y de contenido entre dos UF, según Holzinger (1998: 340): "[Volläquivalenz] liegt davon vor, wenn zwischen zwei PHR eine volle formalle und inhaltliche Übereinstimmung besteht». Ejemplo de esta equivalencia total entre las lenguas española y alemana lo constituiría la UF que hemos utilizado en el título de nuestra tesis doctoral como ilustración de nuestro objeto de estudio: den Stier bei den Hörnern packen $\approx$ coger el toro por los cuernos. ${ }^{59}$

Otros muchos ejemplos pueden presentar equivalencia total, aunque con matices, como los presentados a continuación, elegidos también por Holzinger. Uno de ellos sería das Wort ergreifen/*nehmen=tomar/coger la palabra, en el que la peculiaridad radica en que, aunque las dos lenguas ofrecen variantes en las formas verbales, estas no se actualizan de la misma manera, pues mientras que en español son habituales las dos y su uso es indistinto, en el caso del alemán una de las variantes es poco frecuente (la señalada con el símbolo *). Mostramos a continuación otro ejemplo que, a pesar de una aparente similitud con el anterior, presenta dos matices que hacen dudar finalmente de su equivalencia plena: jemandem beim Wort nehmen/*ergreifen= tomar/coger la palabra a alguien, donde de nuevo podemos observar variantes que no se actualizan de la misma manera en ambas lenguas ( ${ }^{*}$ ergreifen no se usa en la

\footnotetext{
${ }^{59}$ En el presente trabajo utilizamos el símbolo $\approx$ para indicar la similitud, la equivalencia de las UF. Asimismo, respetamos el símbolo =, que utiliza Holzinger en su trabajo.
} 
UF alemana), añadiendo en este caso además otra salvedad, que en alemán aparece con preposición y en español no.

\subsubsection{EQUIVALENCIA PARCIAL}

La equivalencia parcial, en alemán Teiläquivalenz, es definida por Holzinger (1998: 341) como sigue: "[Teiläquivalenz] ist $\mathrm{zu}$ verstehen als volle semantische Äquivalenz bei formalen Unterschieden, die veschiedener Art sein können", es decir, la equivalencia parcial se entiende como la equivalencia semántica con diferencias formales, que pueden ser de diverso tipo.

Las siguientes expresiones serían ejemplos de este tipo de equivalencia, según Holzinger: jemandem sind die Hände gebunden= tener las manos atadas. Estas dos expresiones muestran sutiles diferencias: la UF alemana tiene una estructura sintáctica en la que en sustantivo (Hände) hace de sujeto, mientras que en la española (manos) tiene la función de complemento directo del verbo tener. Algo parecido ocurre con el siguiente ejemplo: seine Hände in Unschuld waschen= lavarse las manos, a lo que además se añaden otros matices: en primer lugar, el verbo alemán no es reflexivo, pero sí el español; en segundo lugar, en alemán aparece un posesivo (seine), ausente en la UF española; en tercer lugar, la expresión alemana está desarrollada con un complemento (in Unschuld, lit. en la inocencia, ausencia de culpabilidad).

Según Dobrovol'skij (1988: 118), en las lenguas fuertemente analíticas, como es el caso del español frente al alemán, las palabras muestran tendencia a la polisemia y a la ampliación de significado (Bedeutungsweite), lo que se refleja también en su sistema fraseológico, que resulta, por lo general, más regular (y por ello también, más fácil de aprender y dominar). Como ejemplo, la productividad del verbo hacer en las UF españolas, que a veces encuentran su equivalente exacto en alemán, y otras no. Sirvan de ejemplo las expresiones hacer un examen= eine Prüfung machen, que muestran equivalencia plena, (Volläquivalenz); y, sin embargo, las UF hacer una pregunta=eine Frage stellen presentan una equivalencia parcial. 


\subsubsection{EQUIVALENCIA NULA}

Nos encontramos ante una equivalencia nula cuando a una UF en una lengua no le corresponde ninguna en otra lengua: «wenn für einen PHR in einer Sprache in der anderen kein semantisch entsprechender zur Verfügung steht» (Holzinger, 1998: 342). En ese caso, la traducción a la otra lengua se deberá hacer mediante una paráfrasis o incluso una simple palabra. Por ejemplo, la UF alemana seinen Herzen Luft machen no dispone de un equivalente en español, pero se puede traducir por 'desahogarse'.

\subsubsection{CLASIFICACIÓN CUATRIPARTITA}

Los criterios establecidos para esta división en cuatro y la anterior en tres tipos de equivalencia son muy similares. Las posibilidades que se mostrarán a continuación son: 1. equivalentes exactos; 2 . equivalentes parciales; 3. paralelismos fraseológicos; 4. no-equivalentes.

\subsubsection{EQUIVALENTES EXACTOS}

Con la denominación equivalentes exactos (full equivalents, absolute equivalents) $^{60}$ se hace referencia a UF de diferentes lenguas que resultan idénticas en cuanto a significado, sintaxis, estructura léxica e imagen de base (imagery basis) o base metafórica. Además de ser muy completa, la definición de Dobrovol'skij es interesante porque plantea referencias a la base metafórica subyacente en esas UF de diferentes lenguas (Dobrovol'skij, 2011: 7). Es decir, no solo coinciden el léxico empleado, la sintaxis, el significado fraseológico, sino que además van más allá y comparten una misma base metafórica. Ejemplos de este tipo de equivalentes serían las siguentes UF:

alemán: seine Hand ins Feuer legen für etwas

(lit. poner su mano en el fuego por algo)

inglés: to put one's hand into the fire for sth.

\footnotetext{
${ }^{60}$ Correspondería a la equivalencia total de Holzinger (1998), mencionada más arriba.
} 
(lit. poner la mano de uno en el fuego por algo) español: poner la mano en el fuego por alguien (algo $)^{61}$

Ahora bien, puede llamar la atención que se considere en el grupo de equivalentes exactos expresiones como las siguientes, a pesar de que presentan un cambio morfológico (número gramatical), así como un orden oracional diferente:

alemán: von Kopf bis Fuß (lit. de cabeza a pie) (sg./sg.)

ruso: $s$ golory do nog (lit. de cabeza a pies) (sg./pl.)

español: de pies a cabeza (pl./sg., cambio de orden)

O bien estos otros, en los que hay variación de número:

alemán: ganz Ohr sein (lit. ser todo oído) (sg.)

inglés: to be all ear's (lit. ser todo oído de uno) (pl.)

español: ser todo oídos (pl.)

Sobre la presencia de pequeñas diferencias entre las UF, Dobrovol'skij (2011: 7) opina: «some 'full equivalents' allow for morfological or certain lexical alternations». El autor sugiere que estas UF se deben considerar en el tipo 1, equivalentes totales (full equivalents), y no en el tipo 2, equivalentes parciales (partial equivalents), aunque otros lingüistas disienten, pues cuando las UF presentan alguna diferencia de una lengua a otra ya no son consideradas equivalentes totales, sino parciales.

\subsubsection{EQUIVALENTES PARCIALES}

Con la denominación equivalentes parciales (partial equivalents) se hace referencia a UF que tienen idénticos o casi-idénticos significados, pero no presentan correspondencia de estructura léxica y/o sintáctica, ni de base metafórica (imagery basis).

\footnotetext{
${ }^{61}$ Hemos añadido los ejemplos del español, que no aparecen en el artículo de Dobrovol'skij, teniendo en cuenta la oportunidad de los mismos.
} 
Ejemplos de UF que presentan este tipo de equivalencia y muestran una leve variación léxica (alemán mosquito/ruso mosca):

alemán: aus einer Mücke einen Elefanten machen (lit. hacer de un mosquito un elefante)

ruso: delat'iz muxi slona (lit. hacer de una mosca un elefante)

O bien este otro par, que también alude a léxico diferente (poner/depositarł abrir/mostrar), e incluso diferencias sintácticas, como el desarrollo del complemento en alemán (auf dem Tisch, lit. sobre la mesa), ausente en ruso:

alemán: seine Karten auf dem Tisch legen (lit. poner sus cartas sobre la mesa)

ruso: raskryt' (svol) karty (to open one's cards, lit. mostrar sus cartas)

Como se puede comprobar, las diferencias son mínimas en cuanto al significado fraseológico, otra cosa es la estructura que presentan las UF en cada una de las lenguas, en la que se aprecian diferencias tanto a nivel léxico, como en ocasiones sintáctico.

\subsubsection{PARALELISMOS FRASEOLÓGICOS}

Según Dobrovol'skij (2011: 7), los paralelismos fraseológicos (phraseological parallels) son UF que presentan correspondencia en el significado básico (core meaning), pero no en relación a la imagen de la cual han surgido (image component).

Ejemplos de pares de UF que suponen paralelismos fraseológicos serían las siguientes UF:

alemán: heißes Eisen (lit. hierro caliente)

inglés: hot potato (lit. patata caliente) 
O bien estas UF, a las que hemos añadido la versión española, que difiere de la alemana y la inglesa en que no refleja el proceso de la acción (comprar), sino el resultado (haber), aún así remiten a una misma realidad conceptual:

alemán: die Katze im Sack kaufen (lit. comprar el gato en el saco) inglés: to buy a pig in a poke (lit. comprar el cerdo en el saco) español: haber gato encerrado

A pesar de las evidentes divergencias en el plano de la expresión, en este punto es posible hablar todavía de cierta equivalencia, como defiende Dobrovol'skij (2011: 8): “'phraseological parallels' are semantically similar, but their plane of expression mostly do not have much in common». En cualquier caso, teniendo en cuenta que el punto de coincidencia más importante entre las UF es el significado fraseológico, todavía en este nivel se considera que las UF aludidas suponen una buena opción de equivalencia fraseológica.

No obstante, a nuestro parecer cabe objetar que la diferenciación entre equivalentes parciales y paralelismos fraseológicos a partir de los ejemplos proporcionados por el autor no está suficientemente justificada.

\subsection{NO-EQUIVALENTES}

La no-equivalencia (non-equivalents), o equivalencia nula en la acepción de Holzinger (1998) explicada más arriba (cf. § 4.2.1.1.3), se da cuando la UF de una lengua 1 (L1) no tiene correspondientes fraseológicos en la lengua 2 (L2). Un ejemplo del alemán que no posee correspondencia en ruso sería etwas nicht übers Herz bringen können (lit. no ser capaz de llevar algo sobre el corazón, es decir, no tener coraje para algo), por lo que en este caso en ruso se establece una combinación libre de palabras como correspondencia: ne moč' sebja zastavit (sdelat' čto-l.) (lit. no ser capaz de obligarse a uno mismo a hacer algo).

Retomando la pregunta inicial de Dobrovol'skij (2011), de si existe realmente la equivalencia de unidades fraseológicas desde un punto de vista interlingüístico, 
podríamos concluir que sí: pueden ser buenos modelos de equivalencia aquellos que cumplen los requisitos de la equivalencia ideal, que Dobrovol'skij denomina equivalencia total, pero también aceptables la equivalencia parcial (tipo 2) y los paralelismos fraseológicos (tipo 3), según la tipología establecida por el autor:

\footnotetext{
So, at least in category (1) we seemingly are dealing with real cross-equivalents, almost members of category (2) and even some members of the category (3) can be considered good candidates for equivalence (Dobrovol'skij, 2011: 8).
}

A tenor de lo expuesto, podemos constatar que Dobrovol'skij considera que es posible establecer la equivalencia interlingüística de las UF y que, en el nivel de equivalencia descrito, el que va de la forma al contenido, se puede establecer una gradación hasta la situación de no existencia de equivalencia fraseológica. No obstante, advertimos que la división entre los tipos 2 y 3 de Dobrovol'skij es, en ocasiones, muy tenue debido a la dificultad de marcar límites precisos. Por el contrario, Holzinger (1998) plantea un solo tipo intermedio, la equivalencia parcial, grupo que por otra parte aglutinaría el mayor número de UF. ${ }^{62}$

\subsection{ALGUNAS INTERPRETACIONES SOBRE LA NO-EQUIVALENCIA}

Además de tratar la equivalencia de una manera tardicional, resulta interesante considerar la interpretación que han hecho algunos autores acerca del concepto aparentemente contrario, la no-equivalencia. ${ }^{63}$ Tres conceptos resultan pertinentes en este apartado:

- Falsos amigos idiomáticos (idiomatic false friends)

- Cuasi sinónimos interlingüísticos (cross-linguistic near synonymous)

- Polisemia asimétrica (asymetrical polysemy) ${ }^{64}$

\footnotetext{
${ }^{62}$ No conocemos la existencia de estudios descriptivos interlingüísticos sobre el tipo de equivalencia que abarque un número de UF suficientemente significativo.

${ }^{63}$ Se trata de casos de no equivalencia plena, en los que si hay cierta equivalencia o equivalencia conflictiva, como en los false friends.

${ }^{64}$ Entre otros, Holzinger (1998) y Dobrovol'skij (2011).
} 


\subsubsection{FALSOS AMIGOS IDIOMÁTICOS}

Al margen de los esquemas de equivalencia gradual a los que nos referíamos anteriormente (cf. $\S 4.2 .1$ ), Holzinger (1998) señala un tipo específico que denomina equivalencia falsa. Se trata de un problema especial de equivalencia que provocan los denominados falsos amigos (falsche Freunde, del inglés false-friends) por su parecido con lo que ocurre en el léxico en general: se trata de UF que tienen forma idéntica o similar en ambas lenguas, pero significado diferente. Los matices de significado pueden ser importantes o mostrar solo alguna connotación diferente en las lenguas contrastadas. Es el caso, por ejemplo, de las UF das Geld zum Fenster hinauswerfen vs. tirar la casa por la ventana: ${ }^{65}$ en el caso alemán (lit. tirar el dinero por la ventana) tiene connotaciones negativas (malgastar el dinero, derrochar), mientras que la UF española no tiene por qué ser así siempre (hacer un gran dispendio para una gran ocasión).

En algún caso, este tipo de UF puede funcionar, a juicio de Holzinger (1998: 342), como equivalentes virtuales (virtuelle Äquivalente): en determinados contextos traductológicos pueden resultar apropiados en la traducción de una lengua a otra, a pesar de no ser sinónimos (a veces como antónimos, remarca el autor, aunque esto último es mucho menos frecuente). Un ejemplo de este tipo lo constituiría el par Haare auf den Zähnen haben vs. no tener pelos en la lengua (lit. tener pelos en los dientes). La peculiaridad de este par de expresiones es que parecen estructuras similares a simple vista, presentada la UF en forma afirmativa en alemán y negativa en español. Sin embargo, hay algo más que una simple diferencia de modalidad sintáctica, ya que la forma alemana significa tener coraje, en lugar de hablar sin tapujos. Y así, a pesar de que se pudiesen utilizar en determinados contextos como equivalentes virtuales, hay que tener claro que la equivalente funcional de la UF española no

\footnotetext{
${ }^{65}$ Estas UF forman parte de nuestro corpus, consideradas por Holzinger como falsos amigos idiomáticos (idiomatische false Freunde), pero presentes en obras fraseográficas en definitiva como equivalentes (sin matizar si equivalentes parciales o incluso equivalentes totales).
} 
sería la anterior, sino esta otra: kein Blatt vor den Mund nehmen ${ }^{66}$ (lit. no llevar una tabla delante de la boca). Holzinger (1998: 348) advierte sobre la importancia de identificar bien estas UF, especialmente en la docencia de lenguas, para prevenir errores.

\subsubsection{CASI-SINÓNIMOS INTERLINGÜÍSTICOS}

El siguiente tipo de no equivalencia es el denominado por Dobrovol'skij (2011) casi sinónimos interlingüísticos (cross-linguistic near-synonymous), y es definido como sigue:

Cross-linguistic near-synonyms, i.e. semantics quasi-equivalents are idioms of two or more different languages that show almost the same image component and very similar, but non identical lexicalized meanings (Dobrovol'skij, 2011: 18).

Los significados lexicalizados pueden coincidir en el núcleo (core), pero muestran diferentes matices, por lo que pueden funcionar como equivalentes en algunos contextos, pero no en todos.

Como ejemplo de este tipo, menciona el autor la UF rusa 'sdat'v arxiv čto-I./ kogo-l. (lit. poner algo/alguien para archivar) y la alemana zu den Akten legen (lit. archivar), pues mientras que en ruso tiene un significado similar a poner algo de lado por considerarlo obsoleto, en alemán significaría consignar algo para el olvido. Por supuesto, las dificultades y matices que entraña la comparación de UF son numerosos, por lo que los investigadores apuntan a la necesidad de recurrir a medios tecnológicos avanzados y a grandes bases de datos que permitan un tratamiento electrónico de tales unidades.

\subsubsection{POLISEMIA ASIMÉTRICA}

Otro tipo de equivalencia peculiar es la denominada por diversos autores polisemia asimétrica (asymetrical polysemy), que Dobrovol'skij (2011: 20)

\footnotetext{
${ }^{66}$ Este par de UF forman parte de nuestro corpus (no tener pelos en la lengua vs. kein Blatt vor den Mund nehmen), a juicio de Holzinger serían equivalentes parciales, según Dobrovol'skij paralelismos fraseológicos.
} 
define como sigue: «we deal with this semantic property in all cases in which a given L1-idiom has more than one meaning, or viceversa». Puede ejemplificarse con la siguiente expresión del inglés around the corner (a la vuelta de la esquina): esta tiene dos significados, uno espacial y otro temporal, como ocurre en español, mientras que la UF equivalente alemana, um die Ecke (lit. en la esquina), solo posee la primera acepción, la espacial, de manera que para la acepción temporal habría que utilizar otra expresión, vor die Tür (lit. ante la puerta). Por el contrario, el par inglés-español comparte los dos matices, tiene el de estar a la vuelta de la esquina tanto local como temporalmente.

A modo de conclusión, citamos de nuevo a Dobrovol'skij, cuando responde a la pregunta de si existen equivalentes fraseológicos interlingüísticos (crosslinguistic equivalents):

If cross-linguistic equivalents are understood only as idioms of L1 and L2 which look rather similar (something like the traditional 'full equivalents') and besides can be used in the same situations, then the answer has to be NO. Equivalents of this kind are so rare that it would be better to consider them accidental exceptions. [...] But if we define cross-linguistic equivalence in a less rigid way we arrive at two possibilities to find idioms of various languages which may be considered to be the equivalent: [...] to look for a translation, $[\ldots]$ to compare phraseological systems. In both approaches crosslinguistics equivalents can be found [...]. They have rather to be labeled nearequivalents (Dobrovol'skij, 2011: 21).

En definitiva, si lo que pretendemos es encontrar una equivalencia total de las UF de lenguas diferentes, la respuesta inicial sería negativa, pues siempre existirán pequeños matices que impedirán la sustitución automática en todos los contextos. Si por el contrario, nuestra pretensión es más laxa y nos asombramos de que, a pesar de la lejanía lingüística, cultural, geográfica, etc., en la práctica nos encontramos con notables similitudes semánticas en el seno de estas expresiones, el sentido de esa respuesta cambia radicalmente y se convierte en un rotundo sí. $\mathrm{Y}$ con este concepto nos adentramos ya en la presentación de nuestro corpus, equivalente, sí, pero no ideal, porque lo ideal, confundido a menudo con la idea de identidad, igualdad o exactitud, no existe. 


\section{METODOLOGÍA}

\subsection{HIPÓTESIS DE TRABAJO}

A partir del estudio de los conceptos de unidad fraseológica y de equivalencia, hemos llevado a cabo una selección de UF en español y en alemán con el objeto de centrarnos en el análisis de los niveles de competencia lingüística que poseen los jóvenes de estas estructuras en sus lenguas maternas respectivas: los españoles en español, los alemanes en alemán. Para ello nos planteamos dos premisas de trabajo, que desarrollamos en diferentes hipótesis, a las que intentaremos dar respuesta empírica en las secciones siguientes del trabajo. Estas dos premisas de las que partimos son:

- la competencia fraseológica global de los jóvenes de las comunidades lingüísticas española y alemana es distinta,

- en ambas comunidades, la competencia fraseológica se halla condicionada por factores sociales diversos como el sexo, el bilingüismo, el nivel de convivencia con los abuelos o la edad.

Estas premisas iniciales se plantearon ya como hipótesis en una investigación previa (Andúgar: 2010), realizada también en ambas comunidades lingüísticas, y en la que se observaron ya algunas diferencias cualitativas y cuantitativas relevantes respecto a la competencia fraseológica en la lengua materna de los jóvenes españoles y alemanes. Asimismo, se comprobó que existían diversos factores sociales que incidían significativamente en dicho nivel de conocimiento fraseológico. Nuestra intención ahora es verificar el alcance de estas conclusiones parciales a partir de una encuesta más amplia que la utilizada entonces.

A continuación, enunciaremos las hipótesis planteadas para la presente investigación, organizadas en dos fases: en un primer nivel se realiza el estudio 
meramente lingüístico y en una segunda fase se realiza el estudio sociolingüístico (Cuadro 1).

FASE I: NIVEL LINGÜÍSTICO

Hipótesis 1 La competencia fraseológica global de los jóvenes de las comunidades lingüísticas española y alemana presenta diferencias significativas

Hipótesis 2 Determinadas UF son más conocidas en una lengua que en otra

Hipótesis 3 Hay diferencias en el grado de competencia activa y pasiva

Hipótesis 4 El tipo de ejercicio condiciona la competencia que muestran los jóvenes

Hipótesis 5 La adscripción temática de las UF determina diferencias en la competencia

5.1. Las UF del par no adscrito al mismo grupo temático en ambas lenguas presentan un nivel de competencia diferente en las dos lenguas.

5.2. Los zoologismos presentan un nivel de competencia diferente en las dos lenguas

5.3. El grupo de UF denominadas somatismos presentan un nivel de competencia diferente en las dos lenguas

5.4. Las UF referidas a la experiencia humana presentan un nivel de competencia diferente en las dos lenguas

5.5. Las UF que se refieren a la herencia cultural presentan un nivel de competencia diferente en las dos lenguas

FASE II: NIVEL SOCIOLINGÜÍSTICO

Hipótesis 6 La competencia fraseológica está condicionada por diversos factores sociales

6.1. Las diferencias de edad se reflejan en la competencia fraseológica de los jóvenes

6.2. Chicos y chicas muestran diferencias significativas en el conocimiento de las UF

6.3. La competencia fraseológica está condicionada por la adscripción lingüística y el grado de bilingüismo de los hablantes

6.4. El entorno familiar de los jóvenes influye en el nivel de competencia fraseológica

Hipótesis 7 La interacción entre algunas variables son significativas para explicar la competencia fraseológica

7.1. La interacción entre las variables edad y sexo es significativa para explicar la competencia fraseológica

7.2. La interacción entre las variables edad y bilinguismo es significativa para explicar la competencia fraseológica

7.3. La interacción entre las variables edad y entorno familiar es significativa para explicar la competencia fraseológica 
7.4. La interacción entre las variables sexo y bilingüismo es significativa para explicar la competencia fraseológica

7.5. La interacción entre las variables sexo y entorno familiar es significativa para explicarla competencia fraseológica

7.6. La interacción entre las variables bilingüismo y entorno familiar es significativa para explicar la competencia fraseológica

Cuadro 1. Hipótesis de la investigación

Para evaluar todas estas hipótesis hemos seleccionado un corpus y seguido una metodología específica. A partir de un corpus compuesto por 50 UF equivalentes en español y alemán, hemos elaboramos una encuesta ${ }^{67}$ en cada una de las lenguas en la que se distinguen dos partes: la encuesta lingüística propiamente dicha, que recoge los datos de competencia fraseológica de estos jóvenes, y la encuesta sociológica sociológica, en la que se recogen los datos personales de los sujetos entrevistados (cf. Anexo II). A continuación presentamos tanto el corpus de UF la explicación de los modelos de encuesta en ambas lenguas.

\subsection{EL CORPUS}

Seleccionar bien las unidades fraseológicas ha sido una tarea decisiva en la planificación del presente estudio. Para ello hemos seguido dos criterios:

- que las UF fueran conocidas o muy conocidas en las respectivas comunidades lingüísticas;

- que fueran equivalentes en las dos lenguas objeto de nuestro estudio de acuerdo con los parámetros que hemos visto más arriba (cf. § 4).

Para cumplir con la primera condición, no solo nos hemos basado en nuestra conciencia lingüística, sino que además hemos realizado encuestas previas a sujetos de ambas lenguas y de diferentes edades, que nos confirmaron su

${ }^{67}$ Antes de la realización de las encuestas definitivas en una y otra lengua, se procedió a pasar encuestas previas a muestras de sujetos de ambas poblaciones, en las que se verificó el uso frecuente de estas UF. 
popularidad. Para la segunda condición, el estatus de equivalencia hemos procedido también a su verificación lexicográfica, que se presenta más adelante (cf. Anexo I). ${ }^{68}$

No obstante, y como hemos tenido ocasión de comprobar anteriormente, en la cuestión de la equivalencia es difícil llegar a la identidad absoluta. De hecho, siempre caben matices que convierten las UF en parcialmente diferentes, lo que explica que en los últimos tiempos los lingüistas comiencen a interesarse también por las divergencias y no necesariamente solo por la idea de equivalencia como identidad absoluta. Por tanto, en este trabajo partiremos de esa base: más que de equivalentes ideales o totales, hablaremos de equivalentes óptimos, pues acercan una y otra lengua, el español y el alemán, y nos permiten establecer un paralelismo estructural para realizar nuestro estudio. Las UF que componen nuestro corpus se analizarán una por una, y se resaltarán especialmente las similitudes para justificar la equivalencia, amplia en algunos casos, en otros casos más limitada a su significado fraseológico (cf. Anexo I).

En cuanto a la tipología de expresiones elegidas, las unidades fraseológicas objeto del presente estudio son aquellas denominadas locuciones oracionales o semi-oracionales por García-Page (2008), o locuciones por Corpas (1996), es decir, aquellas unidades lingüísticas que, teniendo estructura superior al sintagma, no poseen una estructura oracional completa (a diferencia de los refranes), pues les falta actualizar un actante, generalmente el sujeto: ${ }^{69}$ coger el toro por los cuernos, estar en el séptimo cielo, etc. En el presente trabajo utilizaremos la denominación de unidad fraseológica (UF) para estas expresiones, tal como se ha expuesto anteriormente (cf. § 3.3.1).

\footnotetext{
${ }^{68}$ En ambas lenguas se verificó la inclusión de estas expresiones en obras especializadas, tanto monolingües, como bilingües español-alemán, su existencia como entidades lingüísticas reconocidas, en definitiva, su institucionalización. Se realizaron además búsquedas en internet, lo que también avaló las UF como conocidas.

69 Entre ellas hay dos UF que presentan estructura oracional: a) bien en las dos lenguas comparadas: la UF10 jemandem das Wasser im Mund zusammenlaufen $\approx$ hacerse la boca agua a alguien, en la que en ambas lenguas se actualiza el $\mathrm{Cl}$; b) o bien en una de las lenguas (alemán): UF18 tener (algo) en la punta de la lengua etwas auf der Zunge liegen, que también actualiza opcionalmente en contexto es el CIndirecto de persona (alemán jemandem, lit. a alguien).
} 
Las unidades seleccionadas para el presente estudio forman un corpus de cincuenta UF equivalentes en español-alemán, numeradas sucesivamente para facilitar la consulta. Las UF aparecen en todos los casos bajo su forma no conjugada, en infinitivo. ${ }^{70}$ En el siguiente cuadro ofrecemos el listado completo de todas las UF para su visualización conjunta.

UF1 poner los cuernos $\approx$ Hörner aufsetzen

UF2 poner la mano en el fuego die Hand ins Feuer legen

UF3 como el perro y el gato wie Hund und Katze

UF4 no tener pelos en la lenguaz kein Blatt vor den Mund haben

UF5 ponerse los pelos de punta jemandem stehen die Haare zu Berge

UF6 descubrir la pólvora das Pulver erfunden haben

UF7 tirar la casa por la ventana das Geld zum Fenster hinauswerfen

UF8 sonar a chino Spanisch vorkommen

UF9 ser todo oídos ganz Ohr sein

UF10 hacerse la boca agua das Wasser im Mund zusammenlaufen

UF11 llamar a las cosas por su nombre die Dinge bei ihrem Namen nennen

UF12 echar leña al fuego Öl ins Feuer giessen

UF13 pagar con la misma monedaz mit gleicher Münze heimzahlen

UF14 no tener pies ni cabeza weder Hand noch Fuss haben

UF15 matar dos pájaros de un tiro z zwei Fliegen mit einer Klappe schlagen

UF16 faltar un tornillo nicht alle Tassen im Schrank haben

UF17 amor a primera vista Liebe auf den ersten Blick

UF18 tener algo en la punta de la lengua etwas auf der Zunge liegen

UF19 nadar en la abundancia im Geld schwimmen

UF20 perder hasta la camisa bis aufs Hemd ausziehen

UF21 meter la cuchara seinen Senf dazu geben

UF22 estar en el séptimo cielo im siebten Himmel sein

\footnotetext{
${ }^{70}$ La distribución y ordenamiento de las UF en el cuestionario se realizó aleatoriamente, en cinco ejercicios diferentes, en bloques de diez unidades cada uno (cf. § 5.3.1).
} 
UF23 ser la oveja negra de la familia das schwarze Schaf der Familie sein

UF24 ser un lobo con la piel de cordero $\approx$ ein Wolf im Schafspelz sein

UF25 tener sangre azul blaues Blut haben

UF26 no ser carne ni pescado weder Fisch noch Fleisch

UF27 nadar a contracorriente $\approx$ gegen den Strom schwimmen

UF28 saber dónde le aprieta el zapato a alguien₹ wissen, wo einen der Schuh drückt

UF29 tender un puente de plata eine goldene Brücke bauen

UF30 perder el hilo $\approx$ den Faden verlieren

UF31 jugar con las cartas boca arriba mit offenen Karten spielen

UF32 llevar los pantalones $\approx$ die Hosen anhaben

UF33 hacer la corte a alguien $\approx$ jemandem den Hof machen

UF34 llevar una venda en los ojos ein Brett vor dem Kopf haben

UF35 ser el cuento de la lechera eine Milchmädchenrechnung sein

UF36 estar en boca de todos $\approx$ in aller Munde sein

UF37 estar hasta las narices $\approx$ die Nase voll haben

UF38 construir sobre arena auf Sand bauen

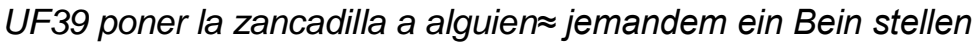

UF40 ponerle los nervios de punta a alguien $\approx$ jemandem auf die Nerven gehen

UF41 hacer una montaña de un grano de arena aus einer Mücke einen Elefanten machen

UF42 tener gato encerrado $\approx$ die Katze im Sack kaufen

UF43 levantarse con el pie izquierdo $\approx$ mit dem linken Fuß zuerst aufstehen

UF44 sacar las castañas del fuego a alguien jemandem die Kastanien aus dem Feuer holen

UF45 coger el toro por los cuernos $\approx$ den Stier bei den Hörnern packen

UF46 ser pobre como una rata $\approx$ arm wie ein Kirchenmaus sein

UF47 echar tierra en los ojos a alguien jemandem Sand in die Augen streuen

UF48 encontrar un pelo en la sopa ein Haar in der Suppe finden

UF49 meter las narices en todo die Nase in alles stecken

UF50 enseñarle los dientes a alguien jemandem die Zähnen zeigen

Cuadro 2. Corpus de UF español-alemán 
A partir de cada uno de los pares contrastados hemos emprendido dos tareas diferentes: en primer lugar, el análisis acerca del grado de equivalencia de las UF, y en segundo lugar, la verificación de la forma utilizada (fijada, institucionalizada) tras su localización en diversos medios fraseográficos y lexicográficos. ${ }^{71}$

El análisis de la equivalencia de las UF se estructura en tres niveles considerados importantes para el presente estudio y que avalan conjuntamente la elección de nuestro corpus: el nivel estructural, el nivel léxico y el nivel fraseológico. Cada uno de ellos quedaría definido como sigue:

- Nivel estructural: da cuenta de la similitud morfosintáctica y gramatical de las UF contrastadas; ${ }^{72}$

- Nivel léxico: muestra si el vocabulario integrante de cada una de las UF del par contrastado es también equivalente, es decir, si se refieren a los mismos campos semánticos (p. ej.: somatismos);

- Nivel fraseológico: es el más importante para nosotros, ya que determina si esas UF pueden funcionar como equivalentes fraseológicos en ambas lenguas. ${ }^{73}$

Este análisis de los pares de UF no pretende ser exhaustivo, sino simplemente trata de ofrecer un análisis contrastivo inicial, a fin de explicar los puntos de encuentro de esas UF, las diferencias y convergencias interlingüísticas y justificar a su vez nuestra elección. Como apunta Larreta (1998/2001):

A menudo las diferencias que imposibilitan una equivalencia total propotípica son gramaticales antes que léxicas. Ejemplos son aquellos casos cuya estructura sintáctica es isomórfica, pero plantean diferencias gramaticales de superficie (Larreta, 1998/2001: 100).

\footnotetext{
${ }^{71}$ Conca y Guia (2014) se refieren a la forma establecida como 'forma canònica'.

${ }^{72}$ Se trata de UF, tal y como se han definido anteriormente, excepto en el caso de la UF10 hacerse la boca agua jemandem das Wasser im Mund zusammenlaufen, en que sí estamos ante una estructura oracional, en la que en ambas lenguas se dispone de sujeto, boca y Wasser, respectivamente.

${ }^{73}$ Lo que nos interesa en este trabajo es la equivalencia de estas unidades bajo una óptica muy amplia; abordar otros aspectos como las equivalencias pragmáticas o traductológicas supondrían el inicio de otras posibles investigaciones que tenemos el propósito de llevar a cabo en trabajos posteriores.
} 
Acto seguido, Larreta pasa a mencionar casos como algunos de los que plantean las UF elegidas por nosotros, como la diferencia en el uso de determinantes en las UF de una y otra lengua, las diferencias en los tiempos verbales, o la posibilidad de que la estructura de las UF contrastadas sea anisomórfica debido a componentes externos a la UF, como complementos preposicionales, indirectos, etc. Coincidimos con Larreta (1998/2001: 117) en su afirmación sobre la cuestión de los límites de una UF: «Resultaría una discusión compleja decidir hasta qué punto estos componentes forman parte del fraseologismo». ${ }^{74}$

Respecto al proceso de verificación de la forma de las UF en recursos fraseográficos y generales, destacamos la abundancia de bibliografía especializada. Para el alemán, encontramos investigaciones consideradas como auténticos referentes, como Friedrich (1976), Moderne deutsche Idiomatik, o Griesbach y Schulz (1961/2000), 1000 deutsche Redensarten. Posteriormente, se han publicado otras obras no menos representativas, como el manual de Drosdowski y Scholze-Stubenrecht (1992) de la serie Duden, Redewendungen und sprichwörtliche Redensarten, o la publicación bilingüe de Beinhauer (1978), Stilistisch-phraseologisches Wörterbuch Spanisch-Deutsch, con el par español-alemán en el punto de mira. De reciente aparición, podemos mencionar la ingente obra compiladora Idiomatik Deutsch- Spanisch (2013), de Schemann, Mellado, Buján, Iglesias, Larreta y Mansilla (Schemann y otros, 2013).

En español también existen en la actualidad numerosas obras de consulta monográficas. Una de las primeras es la obra, predecesora en tantos aspectos, de Iribaren (1955/2005), El porqué de los dichos, cuya primera edición data de los años sesenta. Cabe destacar tiempo después el Diccionario del español moderno de Varela y Kubarth (1995), conciso pero muy práctico para lo que aquí nos interesa. Con posterioridad a esta, se han editado otras de mayor extensión y exhaustividad, como la de Seco, Andres y Ramos (Seco y otros, 2005), Diccionario fraseológico documentado del español actual, Junceda

\footnotetext{
${ }^{74}$ Otra denominación para UF, poco extendida en la escuela española.
} 
(2006), Diccionario de refranes, dichos y proverbios, o Buitrago (2008), Diccionario de dichos y frases hechas.

Esta proliferación de publicaciones sobre UF es indicativa de la pujanza que ha adquirido la materia fraseológica en los últimos tiempos tanto en el ámbito hispánico como en el alemán, y tiene un efecto positivo inmediato sobre los usuarios de las lenguas, pues les aporta estabilidad y seguridad sobre el uso de estas expresiones, tanto a los que se enfrentan a ellas en su lengua materna, como a aquellos que se encuentran en proceso de aprendizaje del español o alemán como lenguas extranjeras.

Los detalles acerca de la verificación de las UF en las obras lexicográficas se presentarán divididos en varias fases. En primer lugar, presentaremos la documentación hallada en obras especializadas en cada lengua (español y alemán $^{75}$ de manera independiente para cada UF, y después se ofrecerá la información obtenida desde el punto de vista bilingüe. Además, hemos creído también conveniente completar esta información con la que nos proporciona en la actualidad el inmenso banco de datos que es internet. Así pues, mediante la ayuda de diversos buscadores de contrastada fiabilidad, hemos comprobado la vigencia y actualidad de estas unidades a través de la red informática.

La selección de obras utilizadas en la consulta de entre tanta oferta no se ha hecho al azar, ya que en ambas lenguas se han tenido en cuenta dos criterios: 1) actualidad, de manera que fueran lo más cercanas al momento actual, y 2) exhaustividad, esto es, que contuvieran la mayor cantidad de UF posible. Para

75 Resulta necesario mencionar la dificultad de la localización de estas expresiones en catalogaciones impresas, por dos motivos que se condicionan mutuamente: la indexación que presentan y el tipo de soporte. La indexación, porque se siguen criterios a veces diferentes en una misma obra, de manera que no queda claro en ocasiones cómo localizar las entradas. El tipo de soporte, porque es más lento buscar las entradas en papel, especialmente si además no queda claro cómo se ha catalogado una UF (por este motivo resulta indispensable la aplicación de la tecnología en esta materia). Todo ello hace de la búsqueda una tarea en ocasiones muy difícil. Sirva de muestra el ejemplo: la UF42 tener gato encerrado, cuya indexación usual sería onomasiológica, por el sustantivo utilizado gato, o en su defecto por el primer término tener, no aparece como tal ni de una forma ni de otra, sino Aquí hay gato encerrado en la obra de Buitrago (2008: 53). Por el contrario, la UF45 coger el toro por los cuernos, aparece indexada en su forma en infinitivo (2008: 101). No obstante, consideramos esta obra como accesible, comparada con otras. Simplemente evidenciamos un hecho que se habrá podido comprobar si se ha consultado UF en algún tipo de obra editada: no nos extenderemos, pues tal vez sería un aspecto que podría abordarse en otra investigación. 
el español, la consulta primaria ha sido el Diccionario fraseológico documentado del español actual, de Seco y otros (2005), ${ }^{76}$ que cuenta con 16.000 locuciones. Cuando algunas expresiones no aparecían catalogadas en este diccionario, se ha recurrido a otras obras alternativas. Estas, relacionadas a continuación por orden de utilidad y consulta, son las siguientes: Diccionario de dichos y frases hechas de Buitrago (2008); Diccionario de refranes, dichos y proverbios de Junceda (2009); Diccionario fraseológico del español moderno (1994), de Varela y Kubarth (1994), y El español idiomático, de Domínguez y otros (1994). Aún así, en estos diccionarios monolingües no están registradas la UF47 echar tierra en los ojos y la UF48 encontrar un pelo en la sopa. ${ }^{77}$

En lo que atañe a las obras fraseográficas alemanas destacamos la ingente obra de compilación fraseológica Idiomatik Deutsch-Spanisch de Schemann y otros (2013) (en adelante Schemann, 2013). Debido a su actualidad, amplitud (35.000 UF) y el tratamiento de los contenidos ha proporcionado suficiente información para nuestras UF, por lo que en el caso de alemán no se ha tenido la necesidad de recurrir a otras. ${ }^{78}$

Respecto a la documentación fraseográfica bilingüe español-alemán destacaremos el Diccionario de fraseología del español y alemán (2009), de Nedwed y Romeu (en adelante Nedwed, 2009), en su versión electrónica. En no pocas ocasiones, se dan como equivalentes los pares de UF seleccionados en el presente estudio, y en otras se deduce fácilmente la equivalencia tras algunas búsquedas adicionales. ${ }^{79}$ Con todo, es llamativo que en esta obra no aparezca una expresión de amplio uso como es la UF17 ser amor a primera vista $\approx$ Liebe auf den ersten Blick, presente tanto en Seco (2005) como en Schemann (2013).

\footnotetext{
${ }^{76}$ En el Anexo I, la presentación de la bibliografía de los autores aparecerá simplificada en el caso de que sea más de uno. Así aparece Seco (2005), Varela (1994), Domínguez (1994), Schemann (2013) y Nedwed (2009).

${ }_{77}$ Estos casos sí aparecen en páginas de Internet y en fuentes bilingües (cf. Anexo I).

${ }^{78}$ Se trata de una obra bilingüe, aunque desde la perspectiva del alemán. Por otro lado, cabe subrayar que la indexación es mayoritariamente onomasiológica, es decir, atiende sobre todo al sustantivo que aparece en primer lugar, aunque esto no se cumple siempre.

${ }^{79}$ Hay que mencionar que, aunque sea bilingüe, no siempre aparecen las UF buscadas en las dos lenguas, e incluso, en ocasiones, se presentan como equivalentes después de una búsqueda a través de otras UF sinónimas, como encadenamientos de UF.
} 
Para terminar, y como advertíamos ya anteriormente, en la localización de estas unidades hemos acudido también a internet. La búsqueda de las UF españolas ha proporcionado resultados satisfactorios: unas veces ofrecen traducciones, otras son simples aclaraciones de significado, parciales en muchos casos, pero que en definitiva constituyen siempre un buen recurso de consulta y demuestranque las UF disfrutan de plena actualidad. Estas páginas sirven a los hablantes, sean nativos o no, para realizar una consulta rápida e incluso para una búsqueda de información más detallada.

En cuanto a la información sobre las UF del alemán disponible en los buscadores de internet, hay que destacar la amplia oferta de páginas, de la que se ha seleccionado las opciones que aparecen entre las primeras entradas, alternando entre aquellas más frecuentes. En relación con estas fuentes informáticas, hay que destacar la notable cantidad de información, así como la eficaz estructuración de la mayoría de ellas, pues no solo se explican las UF y se presentan variaciones posibles y traducciones, sino que además se rastrean las fuentes e incluso en algunos casos se presentan contextos muy cuidados e ilustraciones que facilitan su uso. ${ }^{80}$

Toda la información relativa a cada uno de los pares español-alemán de UF del corpus utilizado, la del análisis de la equivalencia y la de la verificación fraseográfica, ha sido dispuesta en forma de fichas bibliográficas (cf. Anexo I). La información de cada ficha se presenta de la siguiente manera:

1. Presentación de la UF en ambas lenguas

2. Análisis contrastivo de cada par de UF en relación a los diferentes niveles de equivalencia considerados

3. Bibliografía fraseográfica monolingüe empleada, en español y alemán, y a continuación la bilingüe

4. Referencia a las páginas de internet en las que se localiza

\footnotetext{
${ }^{80}$ Así ocurre, por ejemplo, con la UF35 ser el cuento de la lechera, sobre la que algunas páginas de internet ofrecen información exhaustiva ( http://www.materialesdelengua.org/LITERATURA/TEXTOS_LITERARIOS/CUENTOS/contar/lec hera.htm).
} 
5. Forma ampliada de las UF, si es pertinente, por aparecer las UF usualmente en su forma breve

6. Comentarios adicionales, si es pertinente

\subsection{PROCESO DE RECOGIDA DE DATOS}

\subsubsection{LA ENCUESTA}

La encuesta, preparada ad $h o c^{81}$ para la presente investigación, consta de dos partes diferenciadas: una primera parte, de contenido lingüístico, y una segunda en la que se reúnen los datos sociológicos de los sujetos encuestados (cf. Anexo II). En este apartado presentaremos únicamente la encuesta fraseológica, es decir, lingüística. Más adelante se comentará la parte sociológica (cf. § 5.3.4).

El cuestionario lingüístico consta de cinco ejercicios diferentes y en cada uno de ellos se busca información sobre diez unidades fraseológicas, hasta completar la cifra de cincuenta UF que conforman el corpus del presente estudio. En el momento de realizar la encuesta, los entrevistadores alertaron de que la investigación versaba sobre un tema lingüístico, aunque sin especificar que se trataba de unidades fraseológicas. Como se ha avanzado anteriormente, la distribución de las expresiones en los diferentes ejercicios se hizo de manera aleatoria.

Los ejercicios pretenden medir la competencia o disponibilidad fraseológica de los informantes por medio de mecanismos diferentes. Inicialmente,

\footnotetext{
${ }^{81}$ Respecto a las dos posibles técnicas de recogida de datos (técnicas de observación o técnicas de encuesta) que menciona Moreno Fernández (1990: 94), nos decantamos para nuestra investigación por las de encuesta. Dentro de estas, se clasifican en directas e indirectas. Las directas serían la entrevista y el cuestionario. $Y$ este último es la técnica que hemos elegido para la presente investigación. Moreno Fernández (1990: 94) define de tal manera la técnica de encuesta definida como 'cuestionario': se trata de «una serie de preguntas establecidas previamente y que deben ser presentadas de idéntica forma a todos los individuos. No requiere interacción directa entre la persona del informante y la del investigador». Además, este puede ser de alternativas fijas o de final abierto, y cabe destacar que en nuestra investigación no se ha excluido ninguna, sino que se presentan ambas, en función de los ejercicios.
} 
establecemos una clasificación en dos grandes bloques, que responden al tipo de competencia ${ }^{82} \mathrm{o}$ aptitud lingüística que se mide:

- un primer bloque formado por los ejercicios 1 y 2 , en los que se evalúa la competencia activa de los informantes, ya que en ellos las UF objeto de investigación no vienen dadas de manera directa;

- un segundo bloque, compuesto por los ejercicios 3, 4 y 5, en el que se mide la competencia pasiva, pues en ellos aparecen ya las UF explícitas.

Además de esta diferencia esencial, los ejercicios dentro de cada uno de los bloques presentan también algunos matices particulares. Así, los ejercicios del primer bloque (ejercicios 1 y 2 ) muestran el mismo tipo de ejercicio pero con una gradación en la dificultad que entrañan.

El primer ejercicio es el más difícil, puesto que no solo aparece en primer lugar, sino que las referencias a las UF que busca son muy débiles. Así pues, cabe decir que es el ejercicio que más aludiría a la sensibilidad idiomática (Schemann y otros, 2013: XXV). A continuación mostramos este primer ejercicio en la versión española y a continuación en la alemana.

ENCUESTA ESPAÑOL

COMPETENCIA ACTIVA. EJERCICIO 1

Completa las siguientes frases con las expresiones que consideres oportunas.

Ejemplo:

Las presiones que sufre el director son tanto por parte de los clientes, como de los proveedores. Difícil solución, se diría que

Solución: está entre dos fuegos

82 En la didáctica de lenguas, se entiende por competencia activa la capacidad de los sujetos de utilizar los conocimientos lingüísticos adquiridos de una manera activa, es decir, la capacidad de producción oral o escrita. Por competencia pasiva se entiende la capacidad de comprensión, tanto visual como auditiva. Lógicamente, simpre es menor la competencia activa que la pasiva, pues no se utiliza todo aquello que se sabe o se comprende, sino solo una parte. En nuestro caso, los dos primeros ejercicios (ejercicio 1, 2) miden la competencia activa porque las UF no están dadas, sino que han de surgir del sujeto. Por el contrario, los ejercicios 3, 4 y 5 miden la competencia pasiva, pues las UF vienen dadas y se comprueba su comprensión y conocimiento. 
1. Ana se ve con otro, y no es sólo una buena amistad. Lo siento por su novio, pero creo que le

2. No estoy del todo seguro de la honestidad de Esteban, y más en estos tiempos de corrupción. Yo por él hoy no

3. Juan y Pedro no paran de discutir todo el día, están siempre

4. Pedro dice siempre lo que piensa, aunque pueda ofender a alguien. Desde luego, de él se puede decir claramente que no

5. La historia que contó era para a cualquiera: si me pasa a mí, me muero de miedo.

6. Ahora dicen que conducir suavemente reduce el consumo... ¡Vaya novedad!, se creerán que han

7. La comunión de la niña les está suponiendo muchos gastos: se empeñaron en que fuera diferente a todas y están

8. El profesor hablaba y hablaba, pero no entendíamos nada, todo aquello nos

9. Por fin acabé el trabajo y puedo sentarme contigo. Cuéntame con detalle eso que me decías, soy

10. No sigas hablando de los deliciosos platos que degustaste en la cena-maridaje, no puedo más, se me

Cuadro 3. Encuesta español: Ejercicio 1

En la encuesta alemana, el ejercicio 1 tenía la siguiente formulación:

ENCUESTA ALEMÁN

COMPETENCIA ACTIVA. EJERCICIO 1

Ergänzen Sie die Sätze mit den Ausdrücken, die Sie für korrekt halten .

Beispiel:

Karl war angeblich sehr traurig, aber es ist nicht wahr: er hat

Lösung: Krokodilstränen geweint

1. Björn betrügt seine Frau. Ich finde das nicht richtig, dass er

2. Ich traue ihm, er ist ein ehrlicher Kerl. Ich würde für ihn meine Hand

3. Sie streiten immer noch. Sie sind wie

4. Ute sagt immer, was sie meint, auch wenn sie jemanden beleidigen könnte. Sie

5. Seine Erzählung war so spannend, dass mir

6. Die Idee des Direktors ist nicht ganz neu, aber er tut so, als hätte er das 
7. Jens kauft sich jeden Tag Dinge, die er gar nicht braucht. Er

8. Der Chemielehrer sprach ununterbrochen mehr als zwei Stunden, ich verstand überhaupt nichts. Der Vortrag

9. Erzähle mir von deinem Problem. Ich

10. Hör bitte auf! Ich bin hungrig und du sprichst nur übers Essen. Mir

Cuadro 4. Encuesta alemán: Ejercicio 1

Como se puede observar, en el ejemplo del ejercicio 1 simplemente aparece el pronombre le como elemento de la UF, con lo cual la información acerca de la UF esperada es mínima.

Las expresiones esperadas en el ejercicio 1 según orden aparición en los contextos son las siguientes (de la UF1 a la UF10):

UF1 poner los cuernos $\approx$ Hörner aufsetzen

UF2 poner la mano en el fuego $\approx$ die Hand ins Feuer legen

UF3 como el perro y el gato $\approx$ wie Hund und Katze

UF4 no tener pelos en la lengua $\approx$ kein Blatt vor den Mund haben

UF5 ponerse los pelos de punta (a alguien) (jemandem) stehen die Haare zu Berge

UF6 descubrir la pólvora das Pulver erfunden haben

UF7 tirar la casa por la ventana das Geld zum Fenster hinauswerfen

UF8 sonar a chino $\approx$ Spanisch vorkommen

UF9 ser todo oídos $\approx$ ganz Ohr sein

UF10 hacerse la boca agua das Wasser im Mund zusammenlaufen

Así pues, con este ejercicio se apunta de la manera más directa posible a la disponibilidad fraseológica de los informantes: dado que la información cotextual es mínima, se pretende comprobar si estas unidades fraseológicas se activan de una manera espontánea en su conciencia lingüística.

A continuación vemos las versiones del ejercicio 2 en español y en alemán, muy parecido al ejercicio 1, aunque con menos dificultad, pues se observa más 
información respecto a la UF esperada, por lo que se puede inducir la UF de manera más evidente.

ENCUESTA ESPAÑOL

COMPETENCIA ACTIVA. EJERCICIO 2

Ahora haz lo mismo con estas otras frases:

1. A María no le gusta utilizar eufemismos como 'pompis' o 'trasero'. Si tiene que decir 'culo', esa es la palabra que utiliza. Defiende que hay que llamar

2. Déjalo ya estar, no lo empeores más. La situación ya es bastante crítica, no hace falta que eches

3. Nunca hace nada por nadie. Si algún día necesita algo, que no se extrañe si le pagan

4. Juan nos ha contado una historia que no tiene ningún sentido. Vamos, que no tiene

5. Al periodista le pidieron que redactase un cuento en conmemoración del aniversario de la revista. En él dejó entrever el ambiente laboral que se respiraba en ese momento. Inmejorable ocasión, pensó, para matar

6. Lo conozco bien, y no es que esté ahora trastornado por su situación actual, es de siempre. A veces parece que le falte

7. En cuanto la conoció, supo que era su chica. Desde luego aquello fue amor

8. ¿Cómo era el título de la película? Estoy todo el día dándole vueltas, y el caso es que lo tengo en

9. No te preocupes, Juan puede aportar la cantidad exigida como fianza sin problemas, pues dicen que en estos momentos él nada

10. Esther no hace más que invertir en negocios sin calcular demasiado los resultados. A este paso, me temo que perderá

Cuadro 5. Encuesta español: Ejercicio 2

A continuación ofrecemos la versión alemana de este ejercicio 2:

ENCUESTA ALEMÁN

COMPETENCIA ACTIVA. EJERCICIO 2

Ergänzen Sie weiter diese Sätze mit den Ausdrücken, die Sie für korrekt halten.

1. Petra redet nicht um den heißen Brei herum. Sie die Dinge

2. Sie haben schon einen großen Streit. Sag ihnen nichts, kein ! 
3. Sie hat ihn schlecht behandelt. Sie darf sich nicht wundern, wenn er ihr es heimzahlt.

4. Die Geschichte von Johannes ergibt keinen Sinn. Sie hat weder

5. Du bist bei deiner Chefin zur Party eingeladen: wenn du gehst, wirst du Spaß haben und die Beziehung mit ihr verbessern. So schlägst du

6. Seine Mutter benimmt sich ständig komisch. Die Leute sagen, sie hat nicht alle

7. Als sie inn kennenlernte, wusste sie sofort, dass er ihr Typ war. Es war

8. Ich komme gerade nicht darauf. Es liegt

9. Sie hat im Lotto gewonnen. Jetzt schwimmt

10. Beim Poker hat er alles verloren. Seine Mitspieler haben ihn bis aufs

Cuadro 6. Encuesta alemán: Ejercicio 2

Como se ha podido observar, en el ejercicio 2 se presentan también unos contextos que han de ser completados, pero con menor dificultad que en el ejercicio 1, pues en este caso se aporta más información co-textual: en la frase que debe completarse está ya presente algún elemento esperable de las UF, en general el verbo. De esta manera, el uso de las UF se encuentran ya más inducido, por lo que el esfuerzo cognitivo por parte del hablante es considerablemente menor.

Las diez UF que se esperan para completar el ejercicio 2 por orden de aparición en el mismo son las siguientes (de la UF11 a la UF20):

UF11 llamar a las cosas por su nombre die Dinge bei ihrem Namen nennen

UF12 echar leña al fuego $\approx$ Öl ins Feuer giessen

UF13 pagar con la misma moneda mit gleicher Münze heimzahlen

UF14 no tener pies ni cabeza w weder Hand noch Fuss haben

UF15 matar dos pájaros de un tiro z zwei Fliegen mit einer Klappe schlagen

UF16 faltar un tornillo nicht alle Tassen im Schrank haben

UF17 amor a primera vista Liebe auf den ersten Blick

UF18 tener algo en la punta de la lengua etwas auf der Zunge liegen

UF19 nadar en la abundancia im Geld schwimmen 
A partir de este momento, nuestro foco de interés cambia desde la competencia fraseológica activa a la competencia pasiva y cuya medición se realiza igualmente a través de diferentes pruebas, son los ejercicios 3,4 y 5 . Puesto que apelan a la disponibilidad o competencia pasiva las UF vienen ya dadas en cada uno de ellos, que presentan matices particulares.

Así, en el ejercicio 3 se proporcionan diez UF y los estudiantes han de elegir la respuesta que, a su juicio, resulta más apropiada para cada contexto. Al tratarse de un ejercicio cerrado, la dificultad es menor que en los anteriores. A continuación, mostramos los ejercicios en cada lengua, en primer lugar en español.

ENCUESTA ESPAÑOL

COMPETENCIA PASIVA. EJERCICIO 3

Relaciona estas expresiones con las frases que aparecen a continuación:

Meter la cuchara

Estar en el séptimo cielo

Ser la oveja negra de la familia

Ser un lobo con piel de cordero

Tener sangre azul

No ser ni carne ni pescado

Nadar a contracorriente

Saber dónde le aprieta el zapato a alguien

Tender un puente de plata

Perder el hilo

1. Cuando se lleva la falda larga, Ester utiliza minifalda. Cuando se lleva la minifalda, ella se pone falda larga. Le gusta

2. Pedro parece muy amable y dulce, pero procura no tener problemas con él; como dice Ana, es

3. En casa de María ya no saben qué hacer con él: ni estudia, ni trabaja, y siempre con problemas. Desde luego ya dice la propia María que su hermano

4. En mitad de su conferencia, en el momento en que estaba haciendo un análisis de la situación internacional, se calló de repente, adelante. de lo que estaba diciendo, y ya no pudo seguir

5. ¡Cómo se estaba en Punta Cana! Todo el día de la playa a la piscina del hotel, y por la noche fiesta siempre. Vamos, que esos días

6. Al principio, no decía nada, pero conforme fue avanzando la reunión aprovechó cualquier ocasión para 
7. A mí la música de ese grupo no me acaba de gustar: no es exactamente ni rock, ni pop, ni música indi. Vamos, que

8. Ya nos causó bastantes problemas en el pasado. Si ahora se quiere marchar de la empresa, adelante, Como se suele decir:

9. No te preocupes, déjamelo a mí, que lo conozco bien: hemos pasado muchas juntas, buenas y malas, como si lo hubiera criado yo:

10. Según dicen, su familia es de ascendencia noble. ¿Quién nos iba a decir que nuestra amiga ?

Cuadro 7. Encuesta español: Ejercicio 3

\section{A continuación ofrecemos la versión alemana:}

\section{ENCUESTA ALEMÁN}

COMPETENCIA PASIVA. EJERCICIO 3

Jede Redewendung passt zu einem Satz. Ergänzen Sie bitte:

gegen den Strom schwimmen

seinen Senf dazu geben

im siebten Himmel sein

den Faden verlieren

weder Fisch noch Fleisch

das schwarze Schaf der Familie sein

ein Wolf im Schafspelz sein

blaues Blut haben

wissen, wo einen der Schuh drückt

eine goldene Brücke bauen

1. Sie glaubt, über jedes beliebige Thema Bescheid zu wissen. Immer muss sie

2. Ich bin total verliebt. Ich bin

3. Seine Eltern wissen nicht, was sie mit ihm machen sollen: Er arbeitet nicht und bereitet innen immer Sorgen. Er ist

4. Stephan sieht sehr nett und höflich aus, aber er ist ganz anders. Er ist

5. Der Volksmund sagt, dass Adelige

6. Entweder man ist dafür oder dagegen. Dieses Verfahren ist

7. Wenn lange Röcke in Mode kommen, zieht Simone sich einen kurzen Rock an. Wenn kurze Röcke Mode sind, zieht sie sich einen langen Rock an. Ihr gefällt es, gegen

8. Er spricht nie über seine Probleme, aber ich weiß, wo

9. Die Professorin ist sehr beliebt. Wenn die Studenten nicht auf die Lösung kommen,

10. Ich wusste genau, was ich sagen wollte. Aber durch die Unterbrechung

Cuadro 8. Encuesta alemán: Ejercicio 3 
Como se observa, la dificultad es menor que en los dos anteriores (ejercicio 1 y ejercicio 2) puesto que se ofrecen las UF y los estudiantes simplemente deben asociarlas a un contexto dado.

Las UF utilizadas para completar del ejercicio 3 son las siguientes (de la UF21 a la UF 30):

UF21 meter la cuchara seinen Senf dazu geben

UF22 estar en el séptimo cielo im siebten Himmel sein

UF23 ser la oveja negra de la familia das schwarze Schaf der Familie sein

UF24 ser un lobo con la piel de cordero $\approx$ ein Wolf im Schafspelz sein

UF25 tener sangre azul $\approx$ blaues Blut haben

UF26 no ser carne ni pescado $\approx$ weder Fisch noch Fleisch

UF27 nadar a contracorriente $\approx$ gegen den Strom schwimmen

UF28 saber dónde le aprieta el zapato a alguien w wissen, wo einen der Schuh drückt

UF29 tender un puente de plata eine goldene Brücke bauen

UF30 perder el hilo den Faden verlieren

Continuamos con los ejercicios que miden la competencia pasiva. En el caso del ejercicio 4, se ofrecen tres opciones para cada UF de las que el informante tiene que elegir aquella que considera correcta: una es la UF esperada; otra, una modificación de la UF; y una tercera, una versión no fraseológica. Como es lógico, el orden de estas tres opciones es diferente en cada caso para no ofrecer pistas acerca de las respuestas potenciales. Mostramos a continuación el modelo de la encuesta de español. 


\section{ENCUESTA ESPAÑOL}

\section{COMPETENCIA PASIVA. EJERCICIO 4}

Elige la expresión que consideres más adecuada para finalizar las siguientes frases:

A. Desde el principio, Ana nos ha dicho bien claro por qué se queda con nosotros. Ella siempre...

1. juega con las cartas boca arriba.

2. juega con cartas marcadas.

3. es muy clara.

B. Pedro hace en su casa lo que quiere. Está bien claro quien...

1. Ileva la corbata.

2. manda.

3. Ileva los pantalones.

C. Carlos está colado por Diana. Por su manera de actuar, se ve bien claro que...

1. quiere conquistarla.

2. le está haciendo la ronda.

3. le está haciendo la corte.

D. Javier no sabe dónde se mete, parace que ....

1. esté ciego.

2. lleve una venda en los ojos.

3. lleve una venda en la cabeza.

E. Alberto está siempre haciendo planes de cómo va a invertir esto, y luego esto en aquello, pero las cosas no le salen bien, es lo mismo de siempre:

1. hace mal las cuentas.

2. el cuento de la lechera.

3. el cuento de nunca acabar.

F. Todos han sabido ya del escándalo. El acontecimiento está ...

1. muy extendido.

2. en boca de cualquiera.

3. en boca de todos.

G. No puedo soportar más su intolerable comportamiento. En verdad, estoy ...

1. bastante cansado de él.

2. hasta las narices de él.

3. hasta los codos de él.

$\mathrm{H}$. Sus planes no tienen fundamento, no le va a salir bien la venta: de nuevo ...

1. construye sobre arena.

2. construye sobre hierba.

3. hace mal los cálculos.

I. No le importunes más en su trabajo, deja de ....

1. ponerle la zancadilla.

2. molestarle.

3. ponerle la pierna.

J. Ella no soporta más a Pedro, siempre consigue ...

1. ponerle los pelos de punta

2. ponerla de mal humor.

3. ponerle los nervios de punta.

\section{Cuadro 9. Encuesta español: Ejercicio 4}




\section{A continuación ofrecemos el ejercicio 4 de la encuesta de alemán:}

\section{ENCUESTA ALEMÁN}

COMPETENCIA PASIVA. EJERCICIO 4

Jeder Satz passt zu einem Ausdruck. Ergänzen Sie bitte.
A. Anja hat uns ganz deutlich gesagt, warum sie bei uns bleibt, sie...
1. spielt mit offenen Karten.
2. spielt mit gezinkten Karten.
3. hat die besseren Karten.
B. Klaus macht zu Hause immer, was er will. Er...
1. zieht den Hut tief ins Gesicht.
2. hat eine weiße Weste.
3. hat die Hosen an.
C. Dieter ist in Diana verliebt, er...
1. fegt für sie den Hof.
2. singt unter ihrem Fenster im Hof.
3. macht ihr den Hof.
D. Karl weiß nicht mehr, was er tut.
1. Er ist ein kluger Kopf.
2. Er hat ein Brett vor dem Kopf.
3. Er hat den Kopf verloren.
E. Ihre Rechnung geht nicht auf.
1. Sie hat die Rechnung ohne den Wirt gemacht.
2. Das ist eine Milchmädchenrechnung.
3. Das ist eine Blumenmädchenrechnung.
F. Alle haben bereits von dem Skandal gehört. Das Ereignis ist...
1. auf allen Plätzen.
2. in allen Straßen.
3. in aller Munde.
G. Ich kann sein unanständiges Benehmen nicht mehr ertragen. Ich ...
1. habe das Auge voll.
2. habe die Nase voll.
3. habe den Kopf voll.
H. Seine Pläne sind sehr riskant. Er...
1. baut auf Sand.
2. baut auf sicherem Grund.
3. baut vor.
I. Lass inn seine Arbeit beenden und behindere inn nicht dabei.
1. Stell inm kein Bein.
2. Leg inm keine Steine vor die Füße.
3. Leg inm keine Steine in den Weg.
J. Sie kann Paul nicht mehr aushalten. Er...
1. geht mit ihr laufen.
2. geht nicht weg.
3. geht ihr auf die Nerven.

Cuadro 10. Encuesta alemán: Ejercicio 4 
Como se puede ver, el ejercicio 4 presenta también una selección de expresiones dadas, pero en este caso, y a diferencia del ejercicio 3, la prueba no es completamente cerrada, ya que para cada uno de los contextos se da a elegir entre tres opciones. De ellas, una es la UF propiamente esperada; la segunda opción es una variante creativa aproximada de la UF, por lo que cabe pensar en posibles confusiones en las respuestas de los informantes; finalmente, una tercera opción no corresponde a una UF, por lo que su elección denotaria una preferencia por un uso no fraseológico.

Las UF utilizadas en el ejercicio 4 son las siguientes (de la UF31 a la UF40):

UF31 jugar con las cartas boca arriba mit offenen Karten spielen UF32 llevar los pantalones $\approx$ die Hosen anhaben UF33 hacer la corte a alguien jemandem den Hof machen UF34 llevar una venda en los ojos $\approx$ ein Brett vor dem Kopf haben UF35 ser el cuento de la lechera $\approx$ eine Milchmädchenrechnung sein UF36 estar en boca de todos $\approx$ in aller Munde sein UF37 estar hasta las narices $\approx$ die Nase voll haben UF38 construir sobre arena auf Sand bauen UF39 poner la zancadilla a alguien $\approx$ jemandem ein Bein stellen UF40 ponerle los nervios de punta a alguien $\approx$ jemandem auf die Nerven gehen

Por último, en el ejercicio 5 se pide que se aporte la definición o proponga un ejemplo contextualizado para cada una de las diez UF acerca de las que se pregunta. Ofrecemos a continuación el ejercicio 4 en español:

\footnotetext{
ENCUESTA ESPAÑOL

COMPETENCIA PASIVA. EJERCICIO 5
}

Utiliza las siguientes expresiones en un contexto determinado o con una explicación.

Expresión: Quien hambre tiene, sopas sueña

CONTEXTO: Juan no suele ligar. Para colmo, cada vez que alguna mujer le mira, cree que está interesada en él. Ya se sabe: quien hambre tiene, sopas sueña. 
1. Hacer una montaña de un grano de arena $\rightarrow$

2. Tener gato encerrado $\rightarrow$

3. Levantarse con el pie izquierdo $\rightarrow$

4. Sacar las castañas del fuego a alguien $\rightarrow$

5. Coger el toro por los cuernos $\rightarrow$

6. Ser pobre como una rata $\rightarrow$

7. Echar tierra a los ojos $\rightarrow$

8. Encontrar un pelo en la sopa $\rightarrow$

9. Meter las narices en todo $\rightarrow$

10. Enseñar los dientes a alguien $\rightarrow$

Cuadro 11. Encuesta español: Ejercicio 5

\section{A continuación ofrecemos la versión alemana del ejercicio 5:}

ENCUESTA ALEMÁN

COMPETENCIA PASIVA. EJERCICIO 5

Erklären Sie, was diese Ausdrücke bedeuten. Sie können auch Synonyme benutzen.

Ausdruck: um den heißen Brei herumgehen

KONTEXT: Anja fühlt sich sehr unwohl, aber sie will nicht darüber sprechen. Sie geht um das Problem herum, wie die Katze um den heißen Brei.

ERKLÄRUNG: etwas Unangenehmes vermeiden

1. aus einer Mücke einen Elefanten machen $\rightarrow$

2. die Katze im Sack kaufen $\rightarrow$

3. mit dem linken Fuß zuerst aufstehen $\rightarrow$

4. jemandem die Kastanien aus dem Feuer holen $\rightarrow$

5. den Stier bei den Hörnern packen $\rightarrow$

6. arm wie eine Kirchenmaus sein $\rightarrow$

7. jemandem Sand in die Augen streuen $\rightarrow$

8. ein Haar in der Suppe finden $\rightarrow$

9. die Nase in alles stecken $\rightarrow$

10. jemandem die Zähne zeigen $\rightarrow$ 
A diferencia de los anteriores, se trata de un ejercicio abierto, donde el informante tiene más libertad de respuesta.

Las UF utilizadas en el ejercicio 5 son las siguientes (de la UF41 a la UF50):

UF41 hacer una montaña de un grano de arena aus einer Mücke einen Elefanten machen

UF42 tener gato encerrado die Katze im Sack kaufen

UF43 levantarse con el pie izquierdo mit dem linken Fuß zuerst aufstehen

UF44 sacar las castañas del fuego die Kastanien aus dem Feuer holen

UF45 coger el toro por los cuernos $\approx$ den Stier bei den Hörnern packen

UF46 ser pobre como una rata $\approx$ arm wie ein Kirchenmaus sein

UF47 echar tierra en los ojos a alguien $\approx$ jemandem Sand in die Augen streuen

UF48 encontrar un pelo en la sopa $\approx$ ein Haar in der Suppe finden

UF49 meter las narices en todo die Nase in alles stecken

UF50 enseñarle los dientes a alguien $\approx$ jemandem die Zähnen zeigen

Esta es, pues, la tipología de ejercicios presentados y la distribución de las UF en ellos. Como hemos comentado al principio del apartado, en el Anexo II ofrece las versiones completas de los dos cuestionarios referidos a la parte lingüística.

\subsubsection{FACTORES SOCIALES}


En la sección correspondiente a la recogida de datos sociológicos ${ }^{83}$ de los sujetos de la investigación se han planteado preguntas relativas tanto a los propios informantes como a los de su familia, así como a determinados aspectos de la convivencia en el seno de esta última. Los datos solicitados son los relacionados con la edad, el sexo, la lengua materna y la existencia de una segunda lengua habitual (bilingüismo). Asimismo se ha solicitado información acerca del grado de convivencia de los jóvenes con sus abuelos, que hemos denominado entorno familiar, por suponer que una mayor competencia fraseológica entre los miembros de esta generación puede condicionar la de otros miembros más jóvenes de la familia. Esta última hipótesis mostró datos interesantes en un estudio anterior (Andúgar, 2010), por lo que ahora queremos profundizar. Para medir objetivamente este factor, hemos realizado un cálculo sobre el tiempo medio semanal que los jóvenes dicen compartir con sus abuelos.

El perfil de los informantes es el de jóvenes españoles y alemanes, con edades comprendidas entre 14 y 17 años. Ambas muestras constan de 45 sujetos, $^{84}$ todos ellos estudiantes de enseñanza secundaria. Los alumnos de 14-15 años pertenecen a la fase obligatoria de la enseñanza secundaria, mientas que los de 16-17 forman parte de la fase post-obligatoria. En el momento de pasar las encuestas, los alumnos españoles pertenecían al IES la Plana de Castellón y los alemanes al Albrecht-Thaer-Gymnasium de Hamburgo.

La variable sexo fue tratada en sus dos opciones tradicionales de género: hombre-mujer. Por lo que a la variable lengua se refiere, se comprobó que los

${ }^{83}$ Otra cuestión controvertida en la investigación sociolingüística es qué cantidad de datos es necesaria para una óptima representatividad. A este respecto, Labov (apud Moreno Fernández, 1990: 69), afirma que «10 o 20 datos lingüísticos son suficientes para representar una matriz completa de variación estilística». Por su parte, Moreno Fernández (1990: 70) confirma que ello es cierto únicamente si partimos del principio de la homogeneidad de la conducta lingüística: según el, «el comportamiento lingüístico es lo suficiente homogéneo y constante como para ser representado por un número reducido de datos". En este sentido, pensamos que nuestra muestra, aunque moderada en extensión (90 informantes), reúne estos requisitos de representatividad.

${ }^{84}$ Puesto que es imposible tener datos de toda la población, los estudios sociolingüísticos seleccionan muestras de individuos que se convierten en informantes (Moreno Fernández, 1990: 82). En este caso se realizó un muestreo de no-probabilidad e intencionado, que exige menos recursos que los de probabilidad y los resultados no son muy diferentes, a juicio de Moreno Fernández. El muestreo intencionado se basa en el juicio del investigador para seleccionar los individuos que deben aparecer en la muestra. 
informantes utilizaban como idioma de comunicación habitual y/o lengua materna la lengua objeto de estudio, es decir, para los informantes castellonenses el español, para los estudiantes de Hamburgo el alemán. Asimismo, nos ha interesado recoger datos acerca de posibles situaciones de contacto de lenguas, ${ }^{85}$ puesto que muchos de ellos hablan una segunda lengua no aprendida en el ámbito escolar, es decir, viven en entornos de bilingüismo. ${ }^{86}$

\subsubsection{DESCRIPCIÓN DE LAS MUESTRAS}

La selección de los informantes no se ha hecho de forma manipulada respecto a ninguno de los factores sociales, aunque para llevar a cabo esta investigación ha sido necesario establecer premisas que determinaran un punto de partida básico, como es la edad. Para este fin, hemos elegido niveles educativos similares en ambas comunidades lingüísticas de manera que el rango similar de edades estuviera asegurado. En ambos casos son niveles de la enseñanza pre-universitaria. En ambos países son alumnos de instituto. En España, los alumnos son estudiantes de la ESO (3. ESO y 4. ESO) y de $1 . .9$ de Bachillerato; en Alemania, son alumnos del Gymnasium (lit. instituto), pertenecientes a cursos denominados Klasse (lit. clase), de la 8..$^{\underline{a}}$ y $9 .^{\underline{a}}$ los más jóvenes, y de la 10. ${ }^{\text {a }}$ los mayores. Así, las edades que se barajan oscilan entre los 14 y los 17 años.

Procedemos seguidamente a presentar los datos más relevantes acerca de la distribución de los informantes en función de las variables sociales consideradas en el estudio: edad, sexo, bilingüismo y entorno familiar.

\subsubsection{EDAD}

\footnotetext{
${ }^{85}$ La situación de contacto de lenguas en general y en concreto en Castellón ha sido ampliamente estudiada por Blas Arroyo $(1997,2005)$.

${ }^{86}$ A priori, la situación de Castellón y la de Hamburgo a este respecto puede ser diferente, pues Castellón es una ciudad en la que hay lenguas en contacto (español-catalán), mientras que en el caso de Hamburgo se trataría de una situación distinta, debida a movimientos migratorios.
} 
La distribución por edades de los estudiantes encuestados se muestra a continuación (Tabla 1). Pertenecerían al nivel de enseñanza obligatoria los estudiantes de 14 y 15 años, y al nivel post-obligatorio los de 16 y 17 años.

Tabla 1. Edad de los informantes

\begin{tabular}{lccccc}
\hline EDAD & 14 años & 15 años & 16 años & 17 años & TOTAL INF \\
\hline ESPAÑOL & 14 & 15 & 15 & 1 & 45 \\
\hline ALEMÁN & 16 & 16 & 5 & 8 & 45 \\
\hline
\end{tabular}

$\mathrm{Si}$ atendemos a las agrupaciones enseñanza obligatoria/enseñanza postobligatoria, se observa una distribución bastante homogénea de sujetos por edades en ambas muestras: así, los que cursan la enseñanza obligatoria suman 31 informantes en la muestra alemana, frente a 29 informantes españoles. También es similar la cantidad de alumnos en la post-obligatoria en ambas comunidades, donde hay 13 alemanes y 16 españoles. En este caso, con la salvedad de que la distribución por edades es parcialmente diferente: en la muestra alemana hay más sujetos de 17 años (8), mientras que en la española hay más de 16 años (15).

\subsubsection{SEXO}

La distribución de los sujetos entrevistados por sexos en cada una de las muestras aparece reflejada en la siguiente tabla (Tabla 2). De los estudiantes entrevistados, encontramos 21 informantes que son mujeres en la muestra española, frente a 25 en la muestra alemana. En cuanto a los hombres, aparecen 24 informantes en la muestra española y 20 en la alemana. Por tanto, en la muestra española es ligeramente superior el número de hombres, mientras que en la alemana ocurre lo contrario.

Tabla 2. Sexo de los informantes

\begin{tabular}{llll}
\hline SEXO & MUJERES & HOMBRES & TOTAL INF \\
\hline
\end{tabular}




\begin{tabular}{llll}
\hline ESPAÑOL & 21 & 24 & 45 \\
\hline ALEMÁN & 25 & 20 & 45 \\
\hline
\end{tabular}

\subsubsection{BILINGÜISMO}

El factor que atiende al bilingüismo de los informantes tiene connotaciones diferentes en una y otra muestra, puesto que, mientras que en la muestra alemana supone necesariamente inmigración o cambio de ámbito cultural para los informantes, puesto que se trata de un país monolingüe, en la muestra española no se da necesariamente la misma situación, pues encontramos tanto alumnos procedentes de inmigración, como de situación de contacto de lenguas (español-catalán), propia del enclave donde se realizó el estudio (comunidad autónoma bilingüe).

A continuación, presentamos la distribución de los informantes atendiendo a esta variable en cada una de las muestras:

Tabla 3. Bilingüismo de los informantes

\begin{tabular}{lcc}
\hline BILINGÜISMO & BILINGÜES & NO BILINGÜES \\
\hline ESPAÑOL & 19 & 26 \\
ALEMÁN & 10 & 35 \\
\hline TOTAL INFORMANTES & 45 & 45 \\
\hline
\end{tabular}

Como se puede observar, en la muestra se aprecia una distribución diferente de los alumnos alemanes y españoles, pues el corpus español supera al alemán en 9 INF bilingües (casi un $20 \%$ ). Esta diferencia se justifica por la especificidad cualitativa del factor que acabamos de reseñar, pues el centro educativo español pertenece a una comunidad reconocida oficialmente como bilingüe, por lo que el bilingüismo social e individual son una constante.

\subsubsection{ENTORNO FAMILIAR}


La distribución obtenida en cada una de las muestras respecto a la variable entorno familiar es la siguiente:

Tabla 4. Entorno familiar de los informantes

\begin{tabular}{lcc}
\hline ENTORNO FAMILIAR & ESPAÑOL & ALEMÁN \\
\hline 0 horas/ semana & 17 & 20 \\
1-5 horas/ semana & 5 & 15 \\
$6-10$ horas/ semana & 10 & 4 \\
$11-15$ horas/ semana & 4 & 3 \\
$16-20$ horas/ semana & 6 & 3 \\
$>20$ horas/ semana & 3 & 0 \\
\hline TOTAL INFORMANTES & 45 & 45 \\
\hline
\end{tabular}

En los datos de ambas muestras se observa una notable similitud: los alumnos que dicen tener un contacto nulo o prácticamente nulo con la generación de sus abuelos ( 0 horas) es similar en ambas muestras y suponen alrededor del $40 \%$ en ambos casos, ligeramente inferior en la muestra española. Esto significa que, en ambas comunidades, un número muy elevado de jóvenes no tiene apenas relación con sus abuelos.

Sin embargo, en los dos grupos siguientes, en los que ya hay mayor contacto familiar, se observa una distribución inversa en las muestras: el grupo de 1-5 horas es significativamente menor en la muestra española (5 INF) y mayor en la alemana (15 INF), mientras que el de 6-10 horas presenta más sujetos en la muestra española (10 INF) y menos en la alemana (4 INF).

De nuevo, en las subvariables de 11-15 horas y de 16-20 horas ambas muestras vuelven a aproximarse, aunque la muestra española sea algo mayor. Así, en el nivel de entorno familiar de 11-15 horas la muestra española presenta 4 INF, casi idéntica a la alemana, que tiene 3 INF. Sin embargo, en el nivel siguiente, de 16-20 horas, la muestra española tiene 6 INF, el doble que la alemana, que presenta 3 INF. 
Por último, en el nivel de entorno familiar más elevado (>20 horas), que implica probablemente la vida en domicilio compartido, encontramos 4 INF en la muestra española, frente a ninguno en la muestra alemana. ${ }^{87}$

\subsubsection{LOS ENCUESTADORES}

Las personas que llevaron a cabo las encuestas son profesores de lengua en sus respectivos países. En el caso de la encuesta alemana, el encuestador fue el profesor Jens Kappelhoff, docente de alemán en el Albrecht-ThaerGymnasium de Hamburgo. El mismo procedimiento se llevó a cabo en el caso de la encuesta española, realizada por el profesor Pedro Tejada, que imparte clases de lengua española en el IES la Plana de Castellón. Ambos se habían reunido con anterioridad con la investigadora a fin de concretar los detalles del cuestionario.

En el momento de realizar la encuesta, los profesores no alertaron a los informantes, que eran sus alumnos/as en ese momento, acerca del tema de esta, la competencia fraseológica; tan solo se informó de que se trataba de cuestiones relativas a la asignatura de lengua, sin entrar en más detalles.

Para su realización, los encuestadores dejaron un tiempo suficiente no superior a los treinta minutos, tasado a partir de la experiencia adquirida en una encuesta piloto previa que se llevó a cabo en un instituto de la provincia de Valencia. $^{88}$

A continuación se ofrece una tabla resumen de los datos de los informantes (Tabla 5):

Tabla 5. Resumen de datos sociológicos de los informantes

\footnotetext{
${ }^{87}$ La diferencia de modos de vida, en definitiva, de relaciones familiares en la sociedad mediterránea y centroeuropea pueden motivar esta diferencia, que no es grande en lo que se refiere a los informantes.

${ }^{88}$ Como se ha comentado, y siguiendo las recomendaciones metodológicas de Moreno Fernández (1990: 54) para la investigación sociolingüística, antes de pasar los cuestionarios definitivos se realizó un estudio exploratorio con una encuesta piloto, de cuya observación surgieron intuiciones que ahora se plasman como hipótesis.
} 


\begin{tabular}{llcc}
\hline FACTORES SOCIALES & ESPAÑOLES & ALEMANES \\
\hline Edad & 14 & 14 & 16 \\
& 15 & 15 & 16 \\
& 16 & 15 & 5 \\
\multirow{5}{*}{ Sexo } & 17 & 1 & 8 \\
& Mujer & 21 & 25 \\
Bilingüismo & Hombre & 24 & 20 \\
& Bilingüe & 19 & 10 \\
Entorno familiar & No bilingüe & 26 & 35 \\
& 0 horas/ semana & 17 & 20 \\
& $1-5$ horas & 5 & 15 \\
& $6-10$ horas & 10 & 4 \\
& $11-15$ horas & 4 & 3 \\
& $16-20$ horas & 6 & 3 \\
\hline
\end{tabular}

\subsubsection{HERRAMIENTAS ESTADÍSTICAS}

La finalidad de la investigación era realizar una descripción de la situación a partir de datos, por ello se hacía necesario contar con la ayuda de herramientas estadísticas que facilitasen la interpretación de los resultados obtenidos, tanto cuantitativa como cualitativamente. Entre otras posibilidades, el programa SPSS (Statistical Package for Social Sciences), versión 22, se erigía como una buena elección, pues se trata de un programa estadístico muy utilizado en investigaciones relacionadas con las ciencias sociales, como la psicología o la medicina, en las que se analizan las estadísticas en relación a datos sociológicos. Este tipo de datos también aparecen en nuestro estudio, pues las variables que se manejan son del mismo estilo que en investigaciones psicológicas o médicas, como el sexo, la edad, etc.

Una de las primeras tareas fue definir las variables que se iban a utilizar. Estas pueden ser de dos tipos básicos: variables independientes y variables dependientes. Las variables independientes son aquellas que vienen dadas en los sujetos y, a su vez, pueden condicionar la variable dependiente. Como su nombre indica, la variable dependiente es aquella cuyo valor cambia en 
relación con otras. Las variables independientes utilizadas en la investigación son:

- idioma: español, alemán

- edad: $14,15,16,17$

- sexo: mujer, hombre

- bilingüismo: bilingüe, no-bilingüe

- entorno familiar: 0 horas; 1-5 h.; 6-10 h.; 11-15 h.; 16-20 h.; >20 h.

Por su parte, la variable dependiente, es decir, aquella sobre la cual queremos ver la incidencia de las otras, es la competencia fraseológica. Así pues, una vez recogida toda información por medio de las encuestas, se procedió a la introducción de los datos y posteriormente a su análisis.

Las operaciones principales aplicadas para el análisis de los datos fueron de varios tipos. Por un lado, se utilizaron medidas de tendencia central, es decir, medidas que agrupan los datos obtenidos, y por lo tanto son valores que resultan representativos de todos los valores que toma la variable. Entre estas podemos destacar la media, que supone la media aritmética de todos los valores. Por otro lado, puesto que la investigación barajaba distintos tipos de variables, nos interesaba especialmente comprobar qué tipo de relación se podía establecer entre ellas. En estadística, el concepto de relación o correlación entre dos variables se refiere al grado de parecido o variación conjunta existente entre las mismas. Una relación positiva entre dos variables $X$ e $Y$ significa que los valores de las dos variables varían de forma parecida: si aumenta el valor de $\mathrm{X}$, aumenta el valor de $\mathrm{Y}$, y si disminuye $\mathrm{X}$ disminuye $\mathrm{Y}$. Una relación negativa significa que los valores de ambas variables evolucionan justamente al revés: si $X$ crece, disminuye $Y$, y si $X$ disminuye, aumenta $Y$. Esto también nos permite afirmar si existe o no dependencia entre variables.

Para poder observar además si los valores que ofrecen los análisis son significativos se utilizan también diferentes métodos, de los cuales hemos empleado, entre otros, los estadísticos conocidos como T-Student y Coeficiente 
de correlación de Pearson, así como otros que se detallarán más adelante en función de intereses específicos de cada hipótesis.

Una vez tratados y analizados los datos, se ha procedido a mostrarlos en tablas. Además, se ha completado la información con figuras para facilitar la interpretación visual rápida. 


\section{ANÁLISIS DE LOS DATOS}

Una vez presentada la base teórica sobre la que se sustenta nuestro estudio, en el capítulo que ahora nos ocupa procederemos al análisis de los resultados obtenidos en la investigación empírica que hemos llevado a cabo. Se procederá en primer lugar al examen de los datos de competencia fraseológica desde una perspectiva exclusivamente lingüística y posteriormente teniendo en cuenta la interacción con diversas variables sociales. El análisis de los resultados se presenta siguiendo el desarrollo de las hipótesis planteadas en un capítulo anterior (cf. § 5), y que recordaremos de nuevo más adelante.

Los datos de competencia fraseológica en ambas muestras se abordan de forma contrastiva. El análisis se presenta en diferentes apartados, que desarrollan las hipótesis planteadas en la Metodología (cf. § 5.1). A efectos expositivos, estos apartados se agrupan en dos niveles básicos: un primer nivel de análisis (fase lingüística), en el que se ofrecen los resultados de las hipótesis sobre competencia lingüística (cf. § 6.1), y un segundo, de naturaleza sociolingüística (fase sociolingüística), en el que se desarrolla las hipótesis sobre la competencia lingüística en correlación con diversas variables sociales (cf. § 6.2).

\subsection{FASE I: NIVEL LINGÜÍSTICO}

Los datos de la fase lingüística del análisis se dividen en apartados que desarrollan a su vez las diversas hipótesis planteadas al respecto. Se trata de las hipótesis 1 a 5 .

6.1.1. HIPÓTESIS 1: La competencia fraseológica global de los jóvenes de las comunidades lingüísticas española y alemana presenta diferencias significativas. 
La primera parte de la fase lingüística supone la comprobación de la hipótesis principal de la presente investigación, que plantea que la competencia fraseológica de los jóvenes de ambas comunidades es distinta.

A continuación (Tabla 6) se observan las medias de competencia obtenidas en ambas muestras:

Tabla 6. Nivel de competencia global de las muestras española y alemana

\begin{tabular}{|c|c|c|c|c|c|}
\hline \multicolumn{6}{|c|}{ Estadísticos de grupo } \\
\hline & IDIOMA & $\mathrm{N}$ & Media & $\begin{array}{c}\text { Desviación } \\
\text { típ. }\end{array}$ & $\begin{array}{l}\text { Error típ. de } \\
\text { la media }\end{array}$ \\
\hline COMPETENCIA & ESPAÑOL & 45 & 30,11 & 7,493 & 1,117 \\
\hline FRASEOLÓGICA GLOBAL & ALEMÁN & 45 & 28,02 & 6,538 & ,975 \\
\hline
\end{tabular}

De las 50 UF analizadas en el cuestionario, los estudiantes españoles muestran una media de competencia de 30,11 UF, mientras que los alemanes tienen una competencia del 28,02 UF. Aunque se observa diferencia de competencia, a priori se desconoce si esta puede ser significativa. Para comprobarlo, se ha realizado una prueba T-de Student (Tabla 7). Se trata de una prueba de contraste estadístico que considera las diferencias de medias entre dos muestras que son independientes entre sí como en este caso.

Tabla 7. Nivel de competencia global: Prueba T (1)

\begin{tabular}{|c|c|c|c|c|}
\hline \multicolumn{5}{|c|}{ Prueba de muestras independientes } \\
\hline & & \multicolumn{2}{|c|}{$\begin{array}{l}\text { Prueba de Levene para } \\
\text { la igualdad de varianzas }\end{array}$} & $\begin{array}{c}\text { Prueba T para la } \\
\text { igualdad de medias }\end{array}$ \\
\hline & & $\mathrm{F}$ & Sig. & $\mathrm{t}$ \\
\hline \multirow{4}{*}{$\begin{array}{l}\text { TOTAL COMPETENCIA } \\
\text { FRASEOLÓGICA }\end{array}$} & Se han asumido & ,377 &, 541 & $-1,409$ \\
\hline & varianzas iguales & & & \\
\hline & No se han asumido & & & $-1,409$ \\
\hline & varianzas iguales & & & \\
\hline
\end{tabular}

Y a continuación se observa si es significativa (Tabla 8): 
Prueba de muestras independientes

Prueba T para la igualdad de medias

gl Sig. (bilateral) Diferencia de medias

\begin{tabular}{|c|c|c|c|c|}
\hline \multirow{3}{*}{$\begin{array}{l}\text { TOTAL COMPETENCIA } \\
\text { FRASEOLÓGICA }\end{array}$} & Se han asumido varianzas & 88 & ,162 & $-2,089$ \\
\hline & iguales & & & \\
\hline & $\begin{array}{l}\text { No se han asumido } \\
\text { varianzas iguales }\end{array}$ & 86,414 & ,162 & $-2,089$ \\
\hline
\end{tabular}

Los análisis indican que, al menos con la muestra disponible en nuestro estudio, no hay diferencias entre los resultados de ambas poblaciones: $T=-1,41$ (Tabla 7), sig.=,162 (Tabla 8), ya que el valor de significación es mayor de ,05. Por tanto, aunque las medias son distintas, esa diferencia de medias no resulta significativa.

Puesto que ambas comunidades son distintas, tanto lingüística como culturalmente, cabía esperar diferencias significativas entre la competencia mostrada por los alumnos españoles y alemanes. Sin embargo, esta hipótesis no se ha visto confirmada por los datos.

6.1.2. HIPÓTESIS 2: Determinadas UF son más conocidas en una lengua que en otra.

Siguiendo con el análisis lingüístico, pasamos a presentar ahora los datos de competencia de cada UF en una y otra lengua. Esta hipótesis pretende verificar si determinadas UF son más conocidas en una lengua que en otra y si estas diferencias resultan significativas. A continuación se presentan los datos de competencia de cada una de los pares de 50 UF en español y alemán (Tabla 9). 
Tabla 9. Nivel de competencia por UF en español-alemán: Medias

\begin{tabular}{|c|c|c|c|c|c|}
\hline \multicolumn{6}{|c|}{ Estadísticos de grupo } \\
\hline & IDIOMA & $\mathrm{N}$ & Media & $\begin{array}{c}\text { Desviación } \\
\text { típ. }\end{array}$ & $\begin{array}{l}\text { Error típ. de } \\
\text { la media }\end{array}$ \\
\hline COMPETENCIA ACTIVA 1 & ALEMÁN & 45 &, 02 &, 149 &, 022 \\
\hline UF1 & ESPAÑOL & 45 & ,62 & ,490 & ,073 \\
\hline COMPETENCIA ACTIVA 1 & ALEMÁN & 45 & ,93 & ,252 & ,038 \\
\hline UF2 & ESPAÑOL & 45 & ,27 &, 447 & ,067 \\
\hline COMPETENCIA ACTIVA 1 & ALEMÁN & 45 &, 00 &, 000 &, 000 \\
\hline UF3 & ESPAÑOL & 45 &, 53 &, 505 &, 075 \\
\hline COMPETENCIA ACTIVA 1 & ALEMÁN & 45 & ,22 & ,420 &, 063 \\
\hline UF4 & ESPAÑOL & 45 & ,31 & ,468 &, 070 \\
\hline COMPETENCIA ACTIVA 1 & ALEMÁN & 45 &, 11 & ,318 &, 047 \\
\hline UF5 & ESPAÑOL & 45 &, 04 & ,208 &, 031 \\
\hline COMPETENCIA ACTIVA 1 & ALEMÁN & 45 &, 00 &, 000 &, 000 \\
\hline UF6 & ESPAÑOL & 45 & ,18 & ,387 & ,058 \\
\hline COMPETENCIA ACTIVA 1 & ALEMÁN & 45 & ,36 & ,484 & ,072 \\
\hline UF7 & ESPAÑOL & 45 & ,27 & ,447 & ,067 \\
\hline COMPETENCIA ACTIVA 1 & ALEMÁN & 45 &, 02 &, 149 &, 022 \\
\hline UF8 & ESPAÑOL & 45 & ,27 &, 447 &, 067 \\
\hline COMPETENCIA ACTIVA 1 & ALEMÁN & 45 &, 07 & ,252 & ,038 \\
\hline UF9 & ESPAÑOL & 45 & ,62 &, 490 & ,073 \\
\hline COMPETENCIA ACTIVA 1 & ALEMÁN & 45 & ,27 &, 447 & ,067 \\
\hline UF10 & ESPAÑOL & 45 &, 71 & ,458 &, 068 \\
\hline COMPETENCIA ACTIVA 2 & ALEMÁN & 45 &, 02 &, 149 &, 022 \\
\hline UF11 & ESPAÑOL & 45 & ,44 &, 503 &, 075 \\
\hline COMPETENCIA ACTIVA 2 & ALEMÁN & 45 &, 04 & ,208 &, 031 \\
\hline UF12 & ESPAÑOL & 45 &, 58 & ,499 &, 074 \\
\hline COMPETENCIA ACTIVA 2 & ALEMÁN & 45 &, 07 & ,252 & ,038 \\
\hline UF13 & ESPAÑOL & 45 &, 58 & ,499 & ,074 \\
\hline COMPETENCIA ACTIVA 2 & ALEMÁN & 45 & ,22 & ,420 &, 063 \\
\hline UF14 & ESPAÑOL & 45 & ,64 & ,484 &, 072 \\
\hline COMPETENCIA ACTIVA 2 & ALEMÁN & 45 & ,33 & ,477 &, 071 \\
\hline UF15 & ESPAÑOL & 45 & ,42 & ,499 &, 074 \\
\hline COMPETENCIA ACTIVA 2 & ALEMÁN & 45 & ,91 & ,288 &, 043 \\
\hline UF16 & ESPAÑOL & 45 &, 60 & ,495 &, 074 \\
\hline COMPETENCIA ACTIVA 2 & ALEMÁN & 45 & ,78 & ,420 &, 063 \\
\hline UF17 & ESPAÑOL & 45 &, 96 & ,208 &, 031 \\
\hline COMPETENCIA ACTIVA 2 & ALEMÁN & 45 &, 91 & ,288 &, 043 \\
\hline UF18 & ESPAÑOL & 45 & ,91 & ,288 &, 043 \\
\hline COMPETENCIA ACTIVA 2 & ALEMÁN & 45 & ,84 & ,367 &, 055 \\
\hline UF19 & ESPAÑOL & 45 &, 02 &, 149 &, 022 \\
\hline
\end{tabular}




\begin{tabular}{|c|c|c|c|c|c|}
\hline COMPETENCIA ACTIVA 2 & ALEMÁN & 45 & ,42 & ,499 & ,074 \\
\hline UF20 & ESPAÑOL & 45 & ,07 & ,252 & ,038 \\
\hline COMPETENCIA PASIVA 1 & ALEMÁN & 45 & 1,00 &, 000 &, 000 \\
\hline UF21 & ESPAÑOL & 45 & ,82 & ,387 & ,058 \\
\hline COMPETENCIA PASIVA 1 & ALEMÁN & 45 & ,96 & ,208 & ,031 \\
\hline UF22 & ESPAÑOL & 45 & ,89 & ,318 &, 047 \\
\hline COMPETENCIA PASIVA 1 & ALEMÁN & 45 & ,96 & ,208 & ,031 \\
\hline UF23 & ESPAÑOL & 45 & ,91 & ,288 &, 043 \\
\hline COMPETENCIA PASIVA 1 & ALEMÁN & 45 & ,93 & ,252 & ,038 \\
\hline UF24 & ESPAÑOL & 45 & ,89 & ,318 & ,047 \\
\hline COMPETENCIA PASIVA 1 & ALEMÁN & 45 & ,98 &, 149 & 022 \\
\hline UF25 & ESPAÑOL & 45 & ,91 & ,288 & 043 \\
\hline COMPETENCIA PASIVA 1 & ALEMÁN & 45 & ,82 & ,387 & ,058 \\
\hline UF26 & ESPAÑOL & 45 & ,84 & ,367 & ,055 \\
\hline COMPETENCIA PASIVA 1 & ALEMÁN & 45 & ,93 & ,252 & ,038 \\
\hline UF27 & ESPAÑOL & 45 & ,82 & ,387 & ,058 \\
\hline COMPETENCIA PASIVA 1 & ALEMÁN & 45 & ,89 & ,318 & ,047 \\
\hline UF28 & ESPAÑOL & 45 & ,87 & ,344 &, 051 \\
\hline COMPETENCIA PASIVA 1 & ALEMÁN & 45 &, 87 & ,344 &, 051 \\
\hline UF29 & ESPAÑOL & 45 & ,78 & ,420 & ,063 \\
\hline COMPETENCIA PASIVA 1 & ALEMÁN & 45 & ,91 & ,288 &, 043 \\
\hline UF30 & ESPAÑOL & 45 & ,87 & ,344 &, 051 \\
\hline COMPETENCIA PASIVA 2 & ALEMÁN & 45 & ,82 & ,387 & ,058 \\
\hline UF31 & ESPAÑOL & 45 &, 40 &, 495 & ,074 \\
\hline COMPETENCIA PASIVA 2 & ALEMÁN & 45 & ,80 & ,405 &, 060 \\
\hline UF32 & ESPAÑOL & 45 & ,64 & ,484 &, 072 \\
\hline COMPETENCIA PASIVA 2 & ALEMÁN & 45 & ,78 & ,420 & ,063 \\
\hline UF33 & ESPAÑOL & 45 &, 13 & ,344 & 051 \\
\hline COMPETENCIA PASIVA 2 & ALEMÁN & 45 & ,73 & ,447 &, 067 \\
\hline UF34 & ESPAÑOL & 45 & ,62 & ,490 & 073 \\
\hline COMPETENCIA PASIVA 2 & ALEMÁN & 45 & ,22 & ,420 &, 063 \\
\hline UF35 & ESPAÑOL & 45 &, 56 &, 503 & ,075 \\
\hline COMPETENCIA PASIVA 2 & ALEMÁN & 45 & ,82 & ,387 & ,058 \\
\hline UF36 & ESPAÑOL & 45 & ,91 & ,288 & 043 \\
\hline COMPETENCIA PASIVA 2 & ALEMÁN & 45 & ,91 & ,288 &, 043 \\
\hline UF37 & ESPAÑOL & 45 & ,96 & ,208 & 031 \\
\hline COMPETENCIA PASIVA 2 & ALEMÁN & 45 & ,87 & ,344 & ,051 \\
\hline UF38 & ESPAÑOL & 45 &, 69 & ,468 &, 070 \\
\hline COMPETENCIA PASIVA 2 & ALEMÁN & 45 &, 11 & ,318 &, 047 \\
\hline UF39 & ESPAÑOL & 45 &, 51 &, 506 &, 075 \\
\hline COMPETENCIA PASIVA 2 & ALEMÁN & 45 & ,89 & ,318 &, 047 \\
\hline UF40 & ESPAÑOL & 45 &, 36 & ,484 &, 072 \\
\hline COMPETENCIA PASIVA 3 & ALEMÁN & 45 &, 80 & ,405 & ,060 \\
\hline
\end{tabular}




\begin{tabular}{llllll}
\hline UF41 & ESPAÑOL & 45 &, 80 &, 405 &, 060 \\
COMPETENCIA PASIVA 3 & ALEMÁN & 45 &, 40 &, 495 &, 074 \\
UF42 & ESPAÑOL & 45 &, 69 &, 468 &, 070 \\
COMPETENCIA PASIVA 3 & ALEMÁN & 45 &, 76 &, 435 &, 065 \\
UF43 & ESPAÑOL & 45 &, 98 &, 149 &, 022 \\
COMPETENCIA PASIVA 3 & ALEMÁN & 45 &, 36 &, 484 &, 072 \\
UF44 & ESPAÑOL & 45 &, 56 &, 503 &, 075 \\
COMPETENCIA PASIVA 3 & ALEMÁN & 45 &, 49 &, 506 &, 075 \\
UF45 & ESPAÑOL & 45 &, 69 &, 468 &, 070 \\
COMPETENCIA PASIVA 3 & ALEMÁN & 45 &, 51 &, 506 &, 075 \\
UF46 & ESPAÑOL & 45 &, 80 &, 405 &, 060 \\
COMPETENCIA PASIVA 3 & ALEMÁN & 45 &, 29 &, 458 &, 068 \\
UF47 & ESPAÑOL & 45 &, 36 &, 484 &, 072 \\
COMPETENCIA PASIVA 3 & ALEMÁN & 45 &, 47 &, 505 &, 075 \\
UF48 & ESPAÑOL & 45 &, 33 &, 477 &, 071 \\
COMPETENCIA PASIVA 3 & ALEMÁN & 45 &, 78 &, 420 &, 063 \\
UF49 & ESPAÑOL & 45 &, 93 &, 252 &, 038 \\
COMPETENCIA PASIVA 3 & ALEMÁN & 45 &, 42 &, 499 &, 074 \\
UF50 & ESPAÑOL & 45 &, 56 &, 503 &, 075 \\
\hline
\end{tabular}

Como puede observarse, las UF muestran distintas medias de competencia en una y otra lengua en la mayoría de casos (48 UF) y una competencia idéntica en una pequeña minoría ( $2 \mathrm{UF})$. A continuación, destacaremos qué UF prevalecen en cada lengua.

En español los alumnos muestran más competencia en las siguientes 25 UF (Cuadro 13):

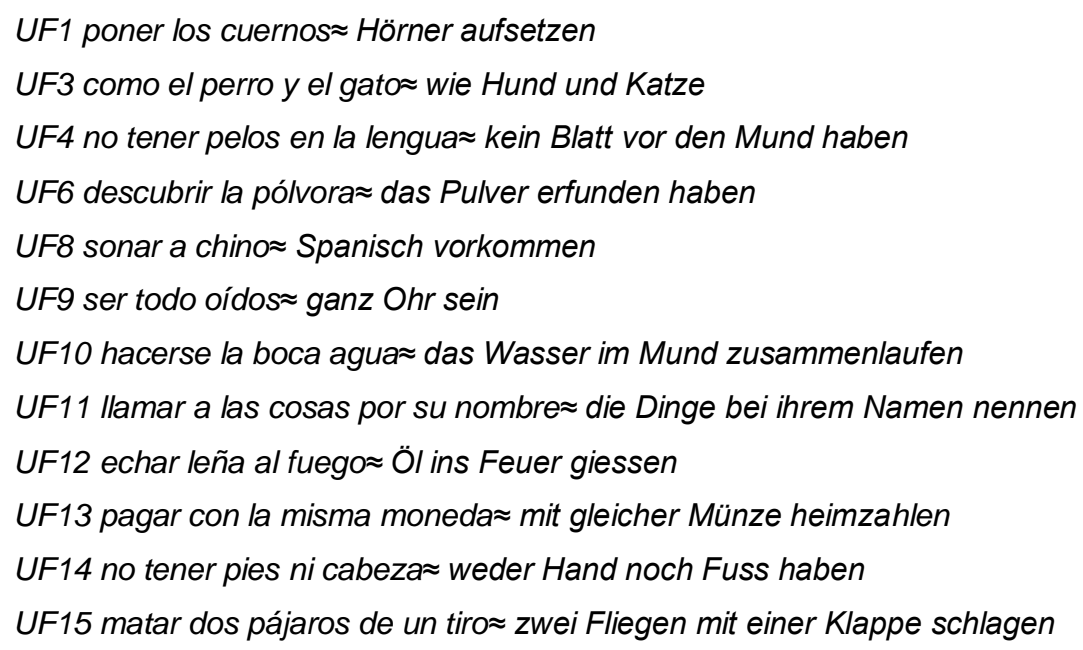




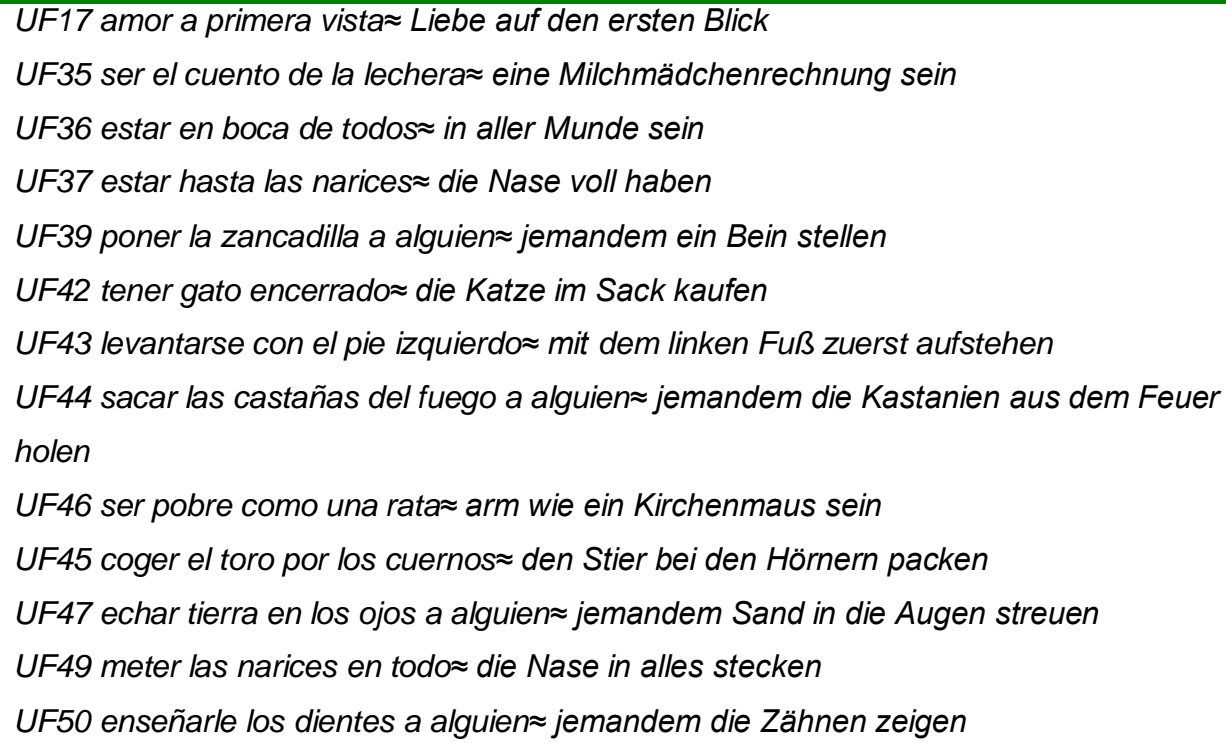

Cuadro 13. UF en las que se muestra mayor competencia en español

\section{Si observamos ahora lo que ocurre en la muestra alemana, vemos que los alumnos muestran más competencia en estas 15 UF (Cuadro 14):}

UF2 poner la mano en el fuego $\approx$ die Hand ins Feuer legen

UF5 ponerse los pelos de punta jemandem stehen die Haare zu Berge

UF7 tirar la casa por la ventana d das Geld zum Fenster hinauswerfen

UF16 faltar un tornillo $\approx$ nicht alle Tassen im Schrank haben

UF19 nadar en la abundancia im Geld schwimmen

UF20 perder hasta la camisa $\approx$ bis aufs Hemd ausziehen

UF21 meter la cuchara seinen Senf dazu geben

UF22 estar en el séptimo cielo im siebten Himmel sein

UF23 ser la oveja negra de la familia das schwarze Schaf der Familie sein

UF24 ser un lobo con la piel de cordero ein Wolf im Schafspelz sein

UF25 tener sangre azu $\approx$ blaues Blut haben

UF26 no ser carne ni pescado $\approx$ weder Fisch noch Fleisch

UF27 nadar a contracorriente $\approx$ gegen den Strom schwimmen

UF28 saber dónde le aprieta el zapato a alguien $\approx$ wissen, wo einen der Schuh drückt

UF29 tender un puente de plata eine goldene Brücke bauen

UF30 perder el hilo den Faden verlieren

UF31 jugar con las cartas boca arriba $\approx$ mit offenen Karten spielen

UF32 llevar los pantalones $\approx$ die Hosen anhaben

UF33 hacer la corte a alguien jemandem den Hof machen

UF34 llevar una venda en los ojos ein Brett vor dem Kopf haben

UF38 construir sobre arena auf Sand bauen

UF40 ponerle los nervios de punta a alguien $\approx$ jemandem auf die Nerven gehen 
Cuadro 14. UF en las que se aprecia mayor competencia en alemán

Finalmente, como habíamos observado con anterioridad, existe una competencia idéntica en dos UF (Cuadro 15):

UF18 tener algo en la punta de la lengua etwas auf der Zunge liegen

UF41 hacer una montaña de un grano de arena a aus einer Mücke einen Elefanten machen

Cuadro 15. UF con idéntica competencia en español y alemán

En el paso previo se ha observado que algunas UF parecen ser más conocidas en una lengua que otra. No obstante, para comprobar si esas diferencias son significativas se realiza de nuevo la prueba T-Student, que recogemos en la Tabla 10. El valor que indica si las diferencias de medias son significativas es el valor en la significación bilateral que debe ser inferior a 0,05.

Tabla 10. Nivel de competencia por UF en español-alemán: Prueba T-Student

\begin{tabular}{lcc}
\hline Competencia & T-Student & Sig \\
\hline UF1 & 7,85 &, 000 \\
UF2 & 8,71 &, 000 \\
UF3 & 7,09 &, 000 \\
UF4 &, 948 &, 346 \\
UF5 & 1,177 &, 242 \\
UF6 & 3,084 &, 004 \\
UF7 &, 905 &, 368 \\
UF8 & 3,479 &, 001 \\
UF9 & 6,759 &, 000 \\
UF10 & 4,656 &, 000 \\
UF11 & 5,404 &, 000 \\
UF12 & 6,610 &, 000 \\
UF13 & 6,127 &, 000 \\
\hline
\end{tabular}




\begin{tabular}{|c|c|c|}
\hline UF14 & 4,417 & ,000 \\
\hline UF15 & ,864 & 390 \\
\hline UF16 & 3,642 & ,001 \\
\hline UF17 & 2,541 & ,013 \\
\hline UF18 & ,000 & 1,000 \\
\hline UF19 & 13,940 & ,000 \\
\hline UF20 & 4,262 & ,000 \\
\hline UF21 & 3,084 & ,003 \\
\hline UF22 & 1,177 & 242 \\
\hline UF23 & ,839 & ,404 \\
\hline UF24 & ,735 & ,464 \\
\hline UF25 & 1,380 & ,171 \\
\hline UF26 & 280 & ,780 \\
\hline UF27 & 1,615 & ,110 \\
\hline UF28 & ,318 & ,751 \\
\hline UF29 & 1,098 & 275 \\
\hline UF30 & ,665 & ,508 \\
\hline UF31 & 4,507 & ,000 \\
\hline UF32 & 1,654 & ,102 \\
\hline UF33 & 7,960 & ,000 \\
\hline UF34 & 1,123 & 264 \\
\hline UF35 & 3,413 & ,001 \\
\hline UF36 & 1,237 & 219 \\
\hline UF37 & 839 & ,404 \\
\hline UF38 & 3,053 & ,043 \\
\hline UF39 & 4,494 & ,000 \\
\hline UF40 & 6,178 & ,000 \\
\hline UF41 &, 000 & 1,000 \\
\hline UF42 & 2,843 & ,006 \\
\hline UF43 & 3,244 & ,002 \\
\hline UF44 & 1,923 & ,058 \\
\hline UF45 & 1,947 & ,055 \\
\hline UF46 & 2,993 & ,004 \\
\hline UF47 & ,671 &, 504 \\
\hline
\end{tabular}




\begin{tabular}{lll}
\hline UF48 & 1,289 &, 201 \\
UF49 & 2,128 &, 036 \\
UF50 & 1,262 &, 210 \\
\hline
\end{tabular}

De los datos anteriores podemos observar que hay casos en que la diferencia de competencia entre las muestras es, efectivamente, significativa desde el punto de vista estadístico, y otros en que no lo es. Encontramos lo primero en las siguientes UF:

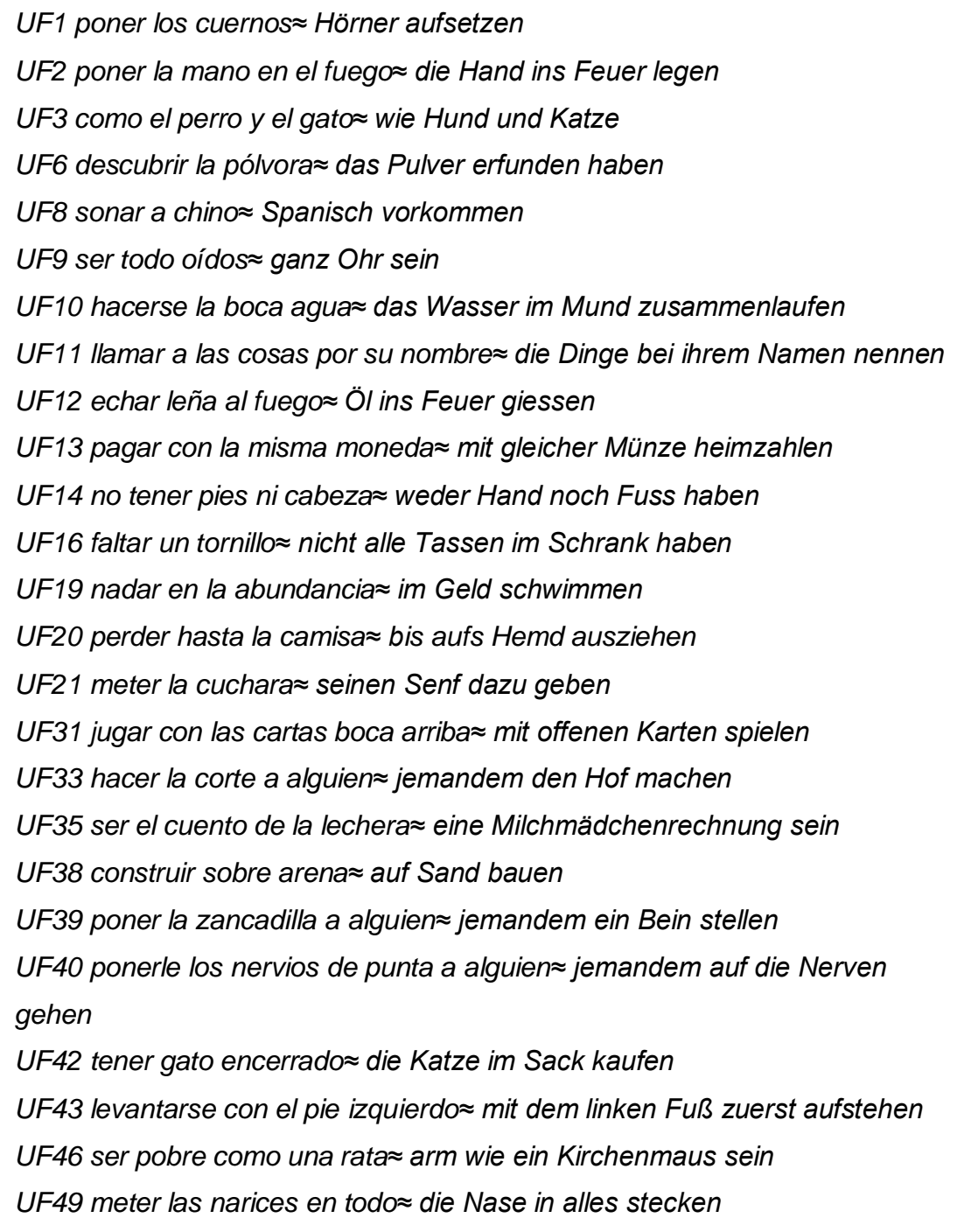

Cuadro 16. UF con diferencias significativas en español y alemán

A continuación mostramos las figuras de las UF que ofrecen diferencias significativas de competencia entre las dos muestras. Para su correcta 
interpretación aclararemos que en cada barra se indica el número de alumnos que han respondido de los 45 entrevistados y que el porcentaje en cada lengua suma en estas figuras un máximo de 50 . Antes de cada figura, recordamos la UF a la que hace referencia:

- UF1 poner los cuernos $\approx$ Hörner aufsetzen (Figura 1):

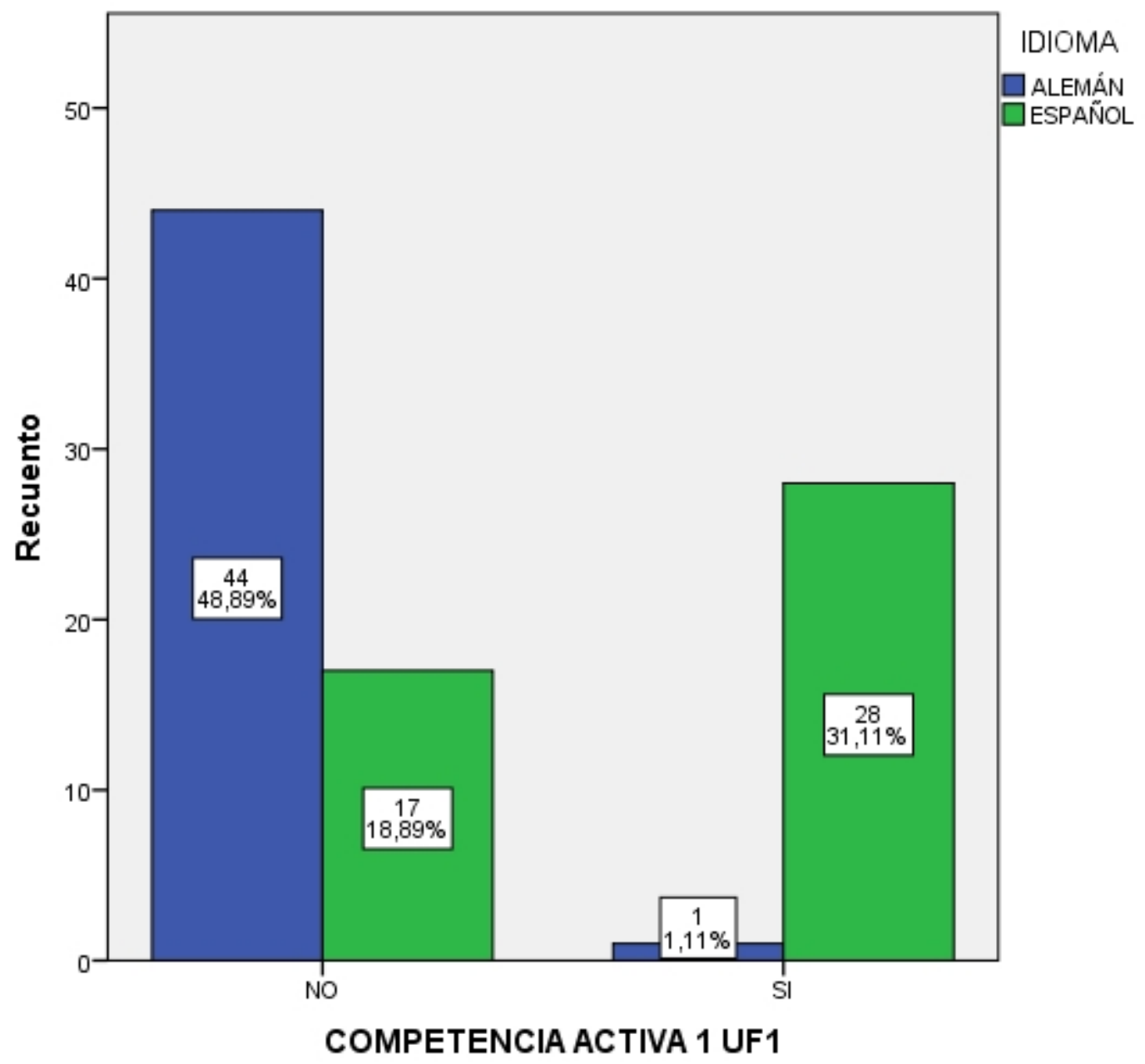

Figura 1. Competencia de la UF1 en español y alemán 
- UF2 poner la mano en el fuego $\approx$ die Hand ins Feuer legen (Figura 2):

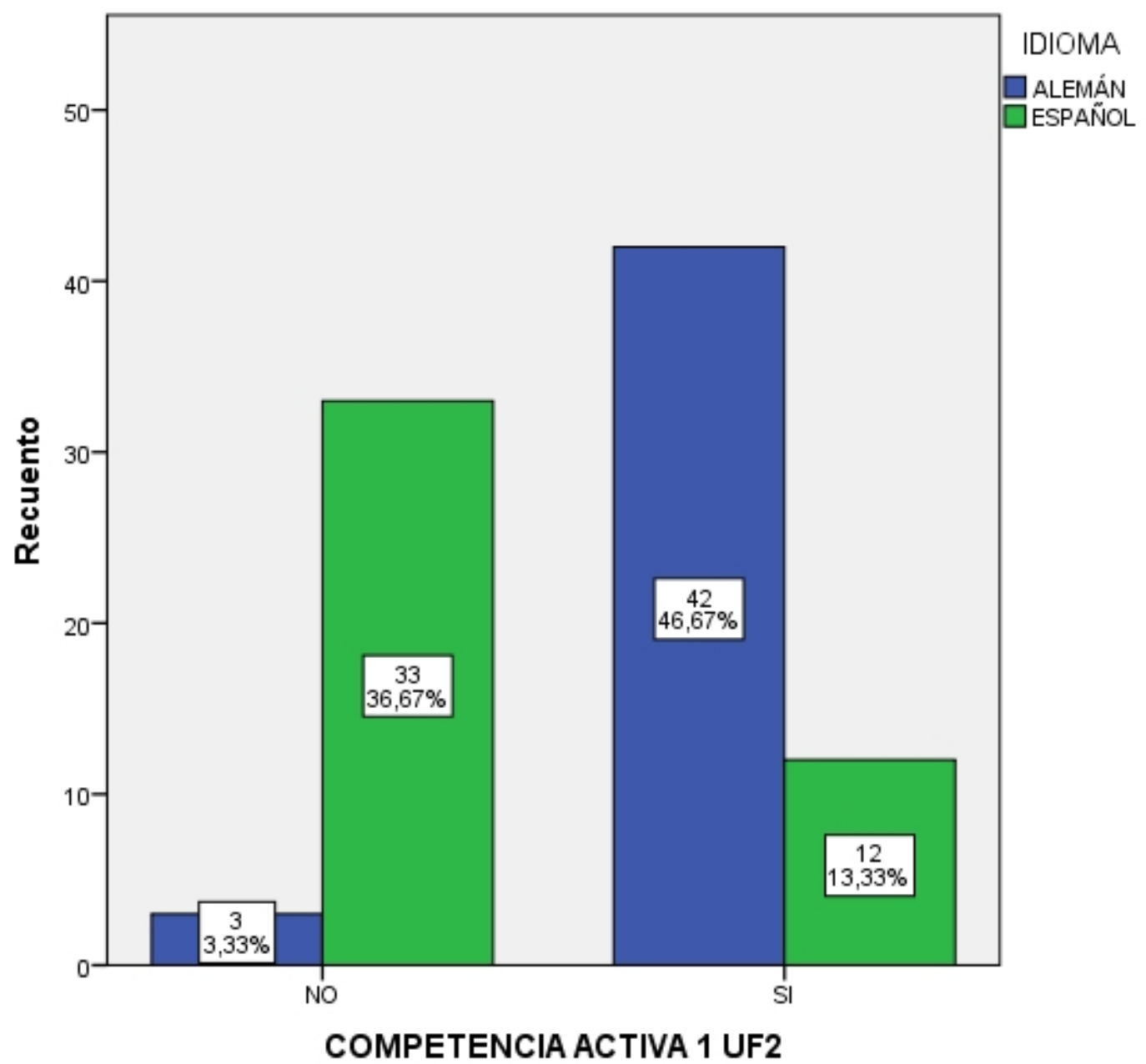

Figura 2. Competencia de la UF2 en español y alemán 
- UF3 como el perro y el gato $\approx$ wie Hund und Katze (Figura 3):

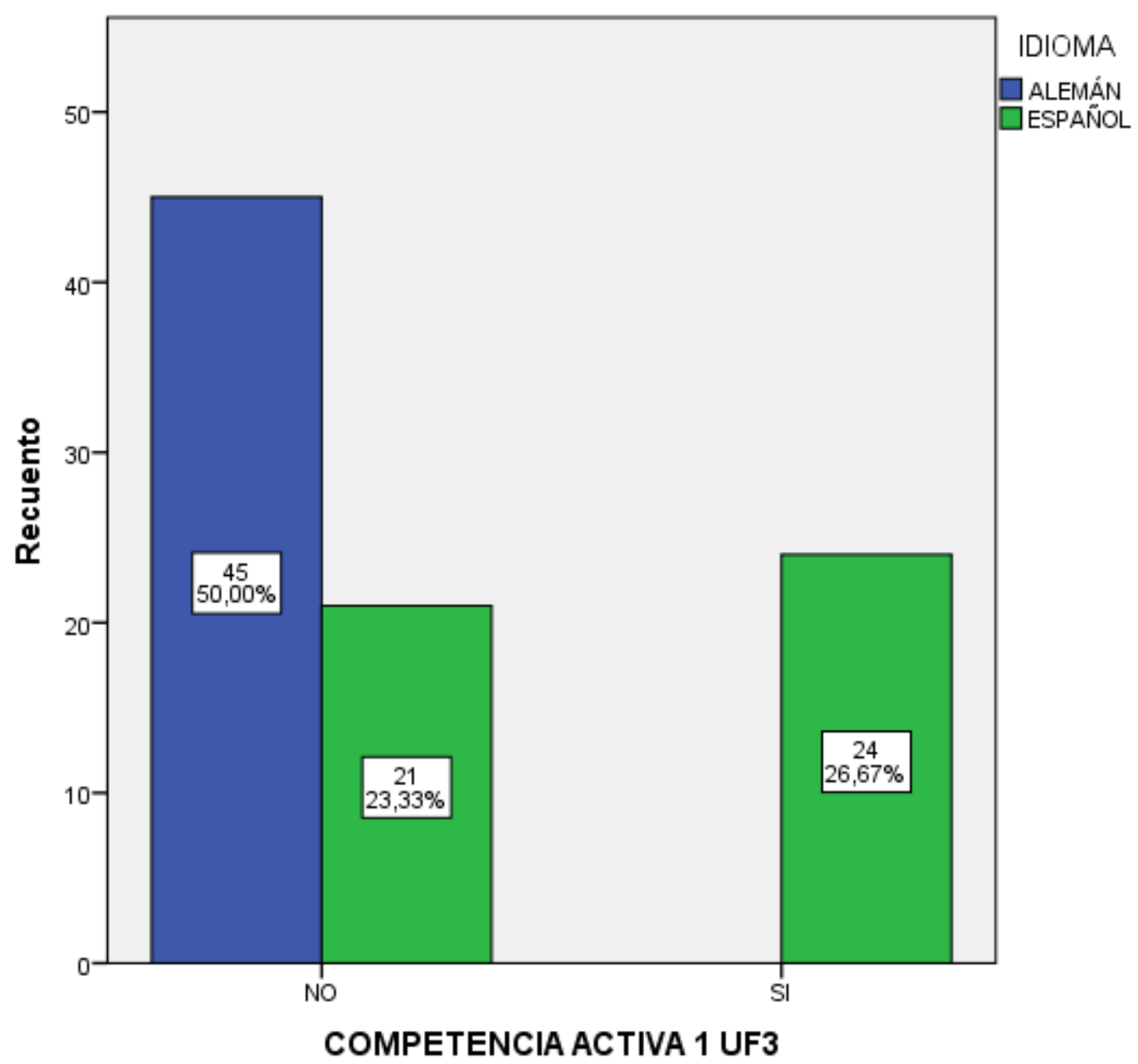

Figura 3. Competencia de la UF3 en español y alemán 
- UF6 descubrir la pólvora das Pulver erfunden haben (Figura 4):

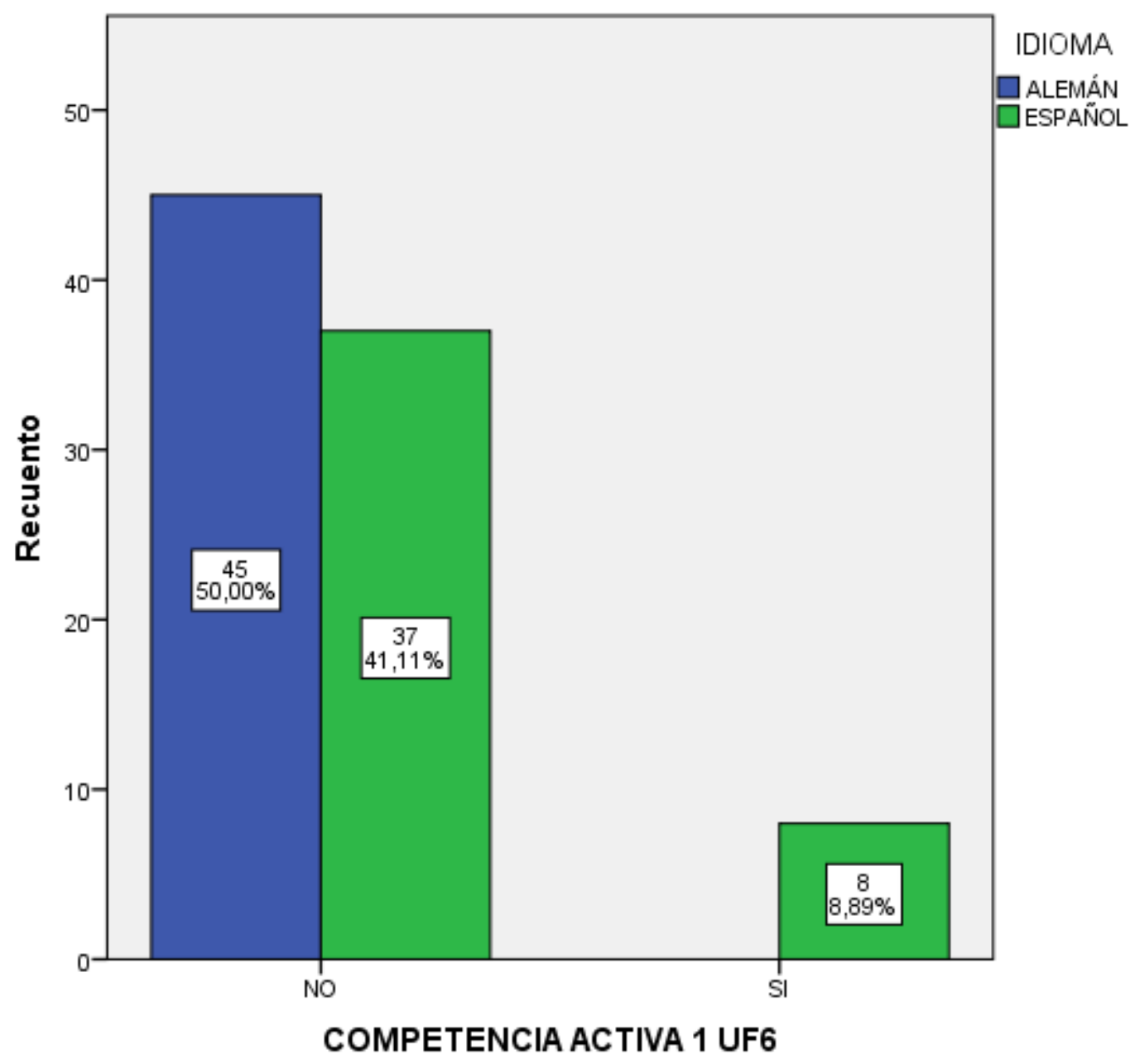

Figura 4. Competencia de la UF6 en español y alemán 
- UF8 sonar a chino Spanisch vorkommen (Figura 5):

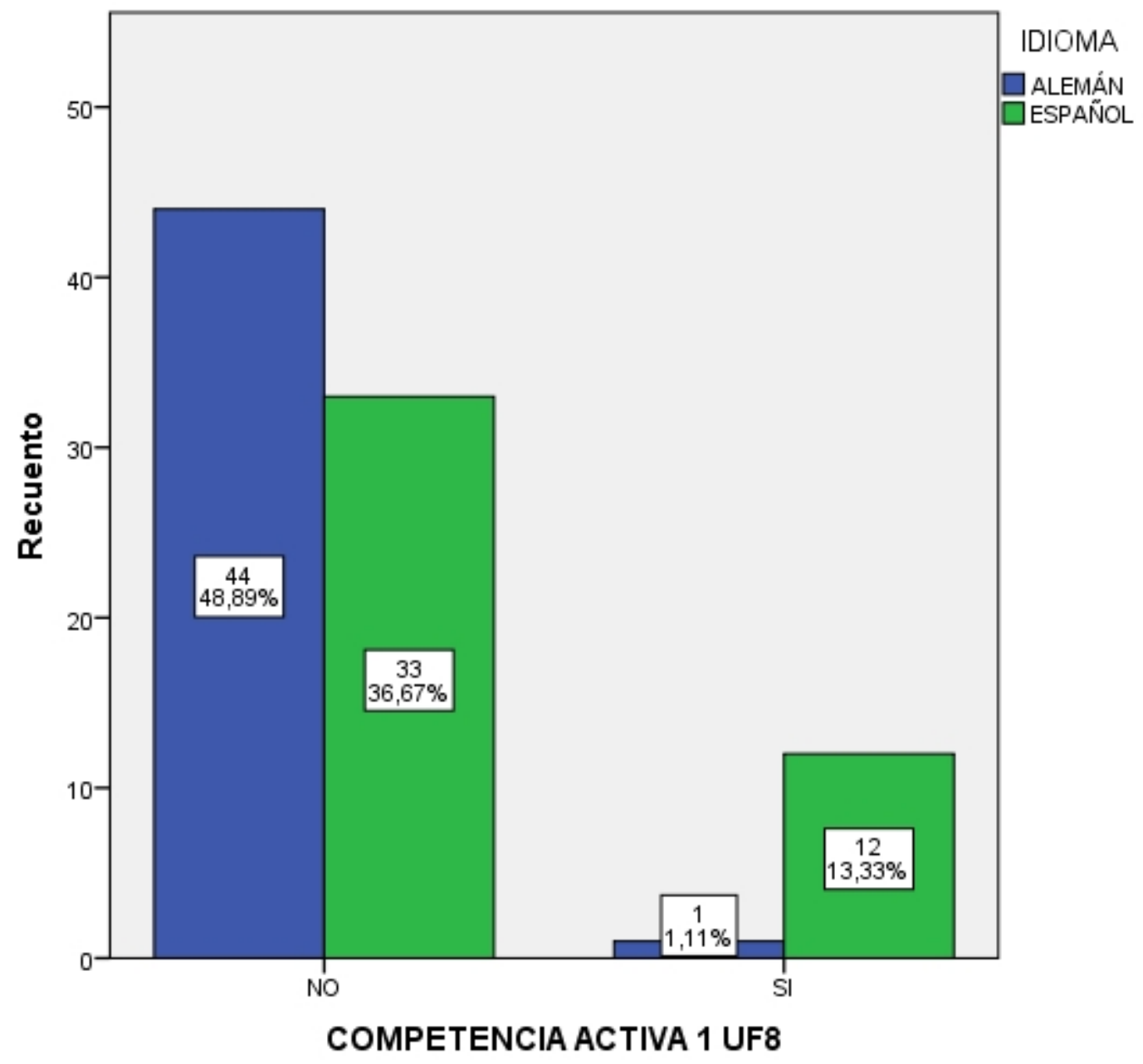

Figura 5. Competencia de la UF8 en español y alemán 
- UF9 ser todo oídos ₹ ganz Ohr sein (Figura 6):

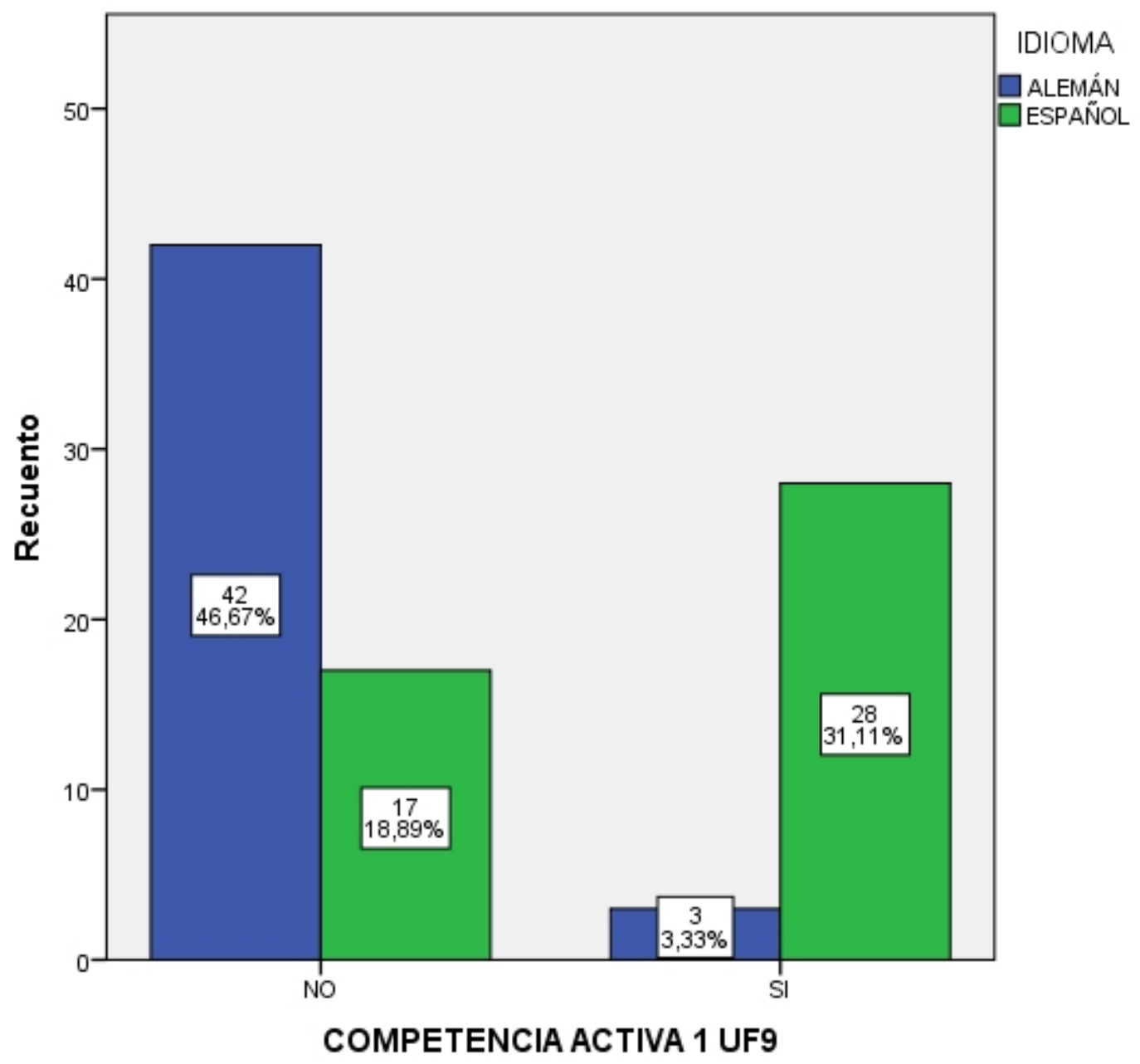

Figura 6. Competencia de la UF9 en español y alemán 
- UF10 hacerse la boca agua das Wasser im Mund zusammenlaufen (Figura 7):

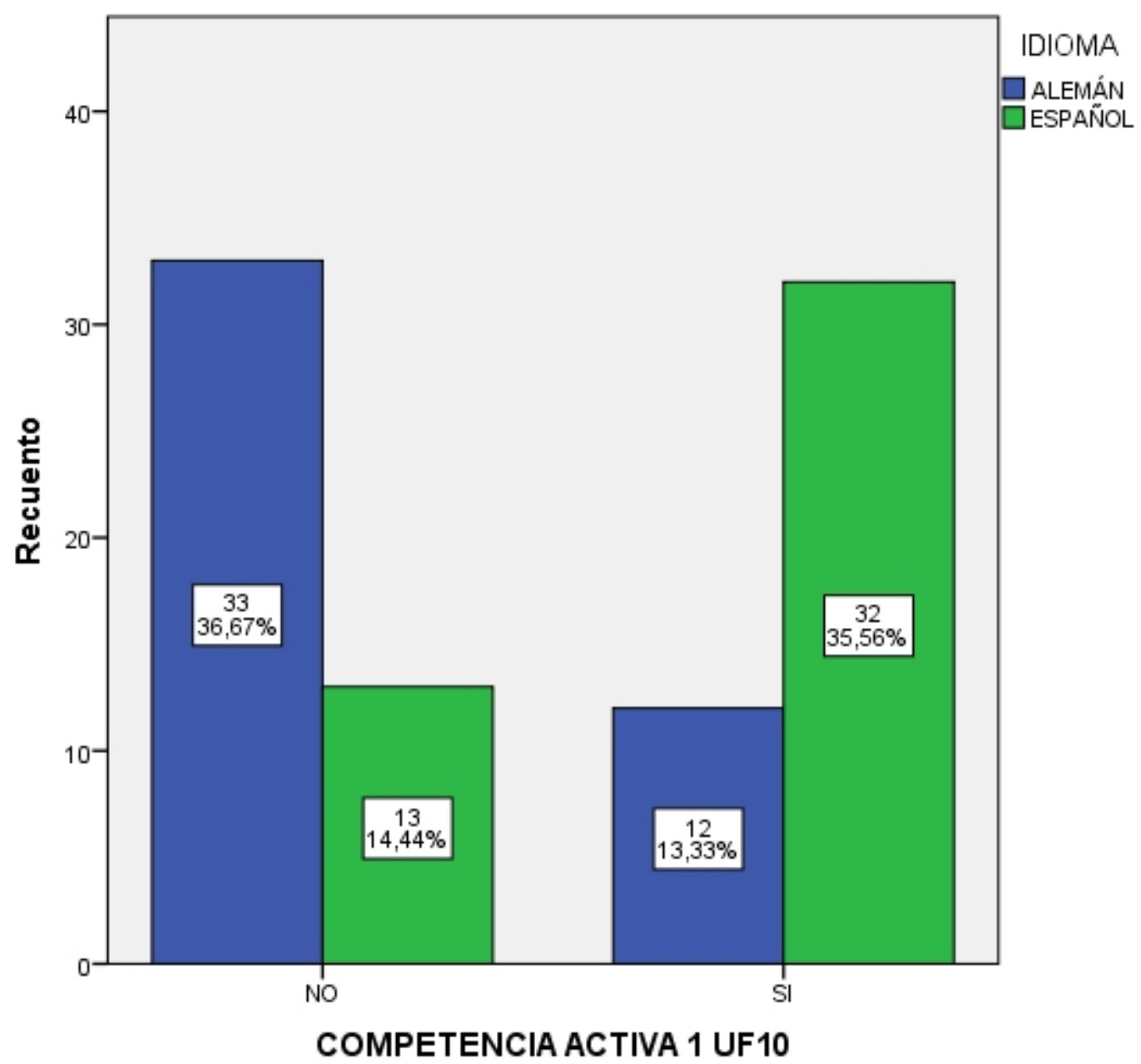

Figura 7. Competencia de la UF10 en español y alemán 
- UF11 llamar a las cosas por su nombre a die Dinge bei ihrem Namen nennen (Figura 8):

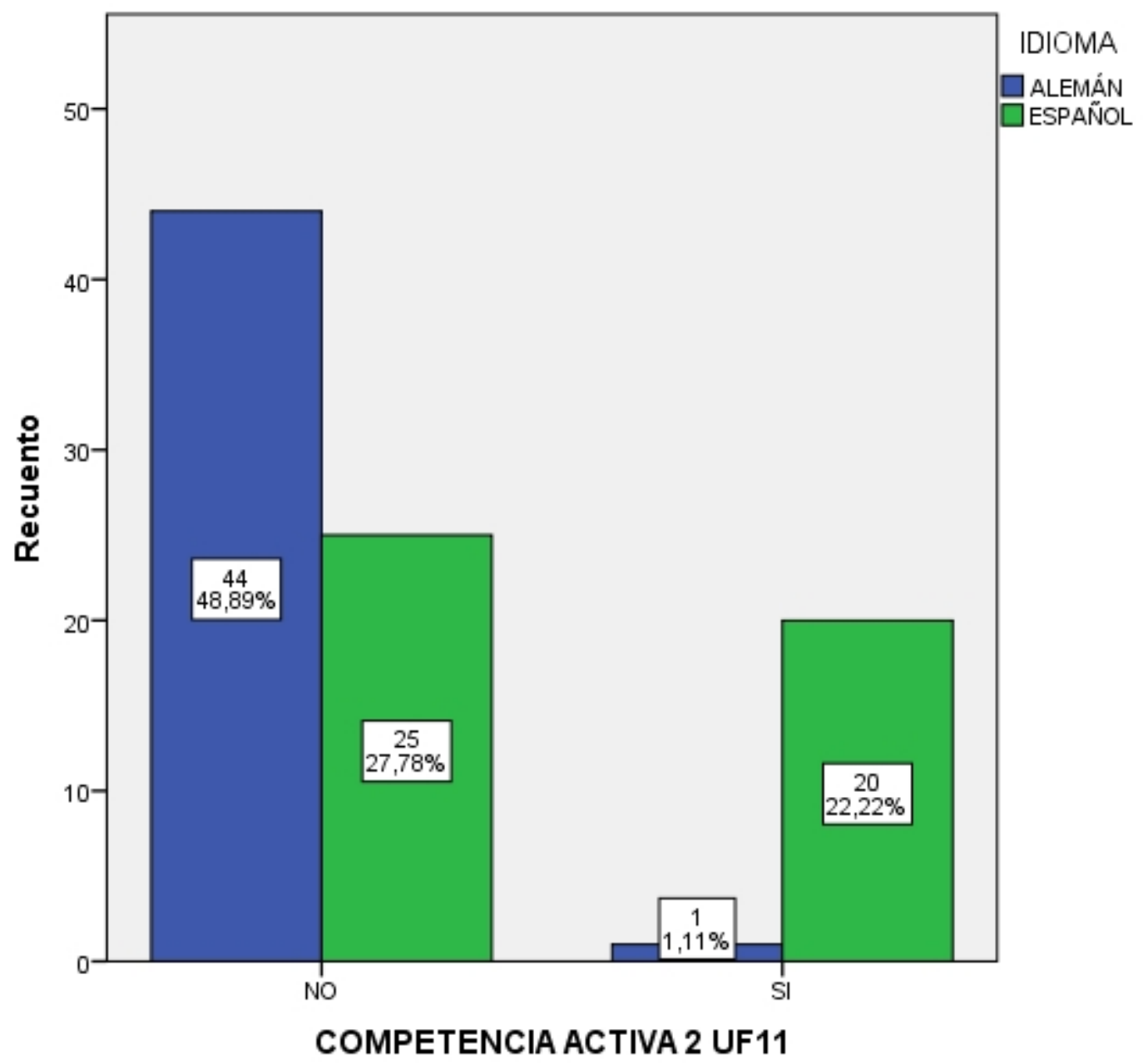

Figura 8. Competencia de la UF11 en español y alemán 
- UF12 echar leña al fuego $\approx$ Öl ins Feuer giessen (Figura 9):

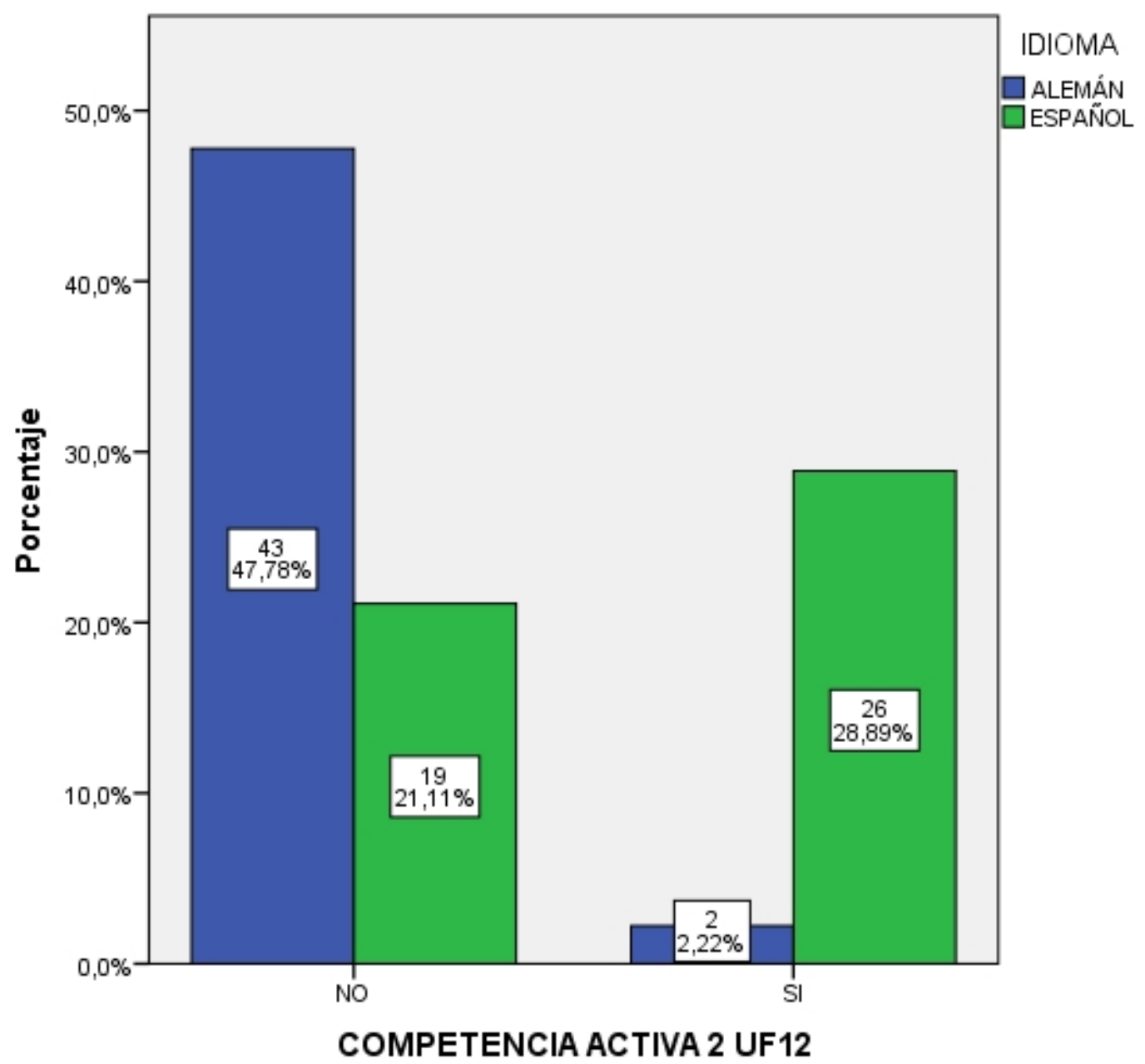

Figura 9. Competencia de la UF12 en español y alemán 
- UF13 pagar con la misma moneda mit gleicher Münze heimzahlen (Figura 10):

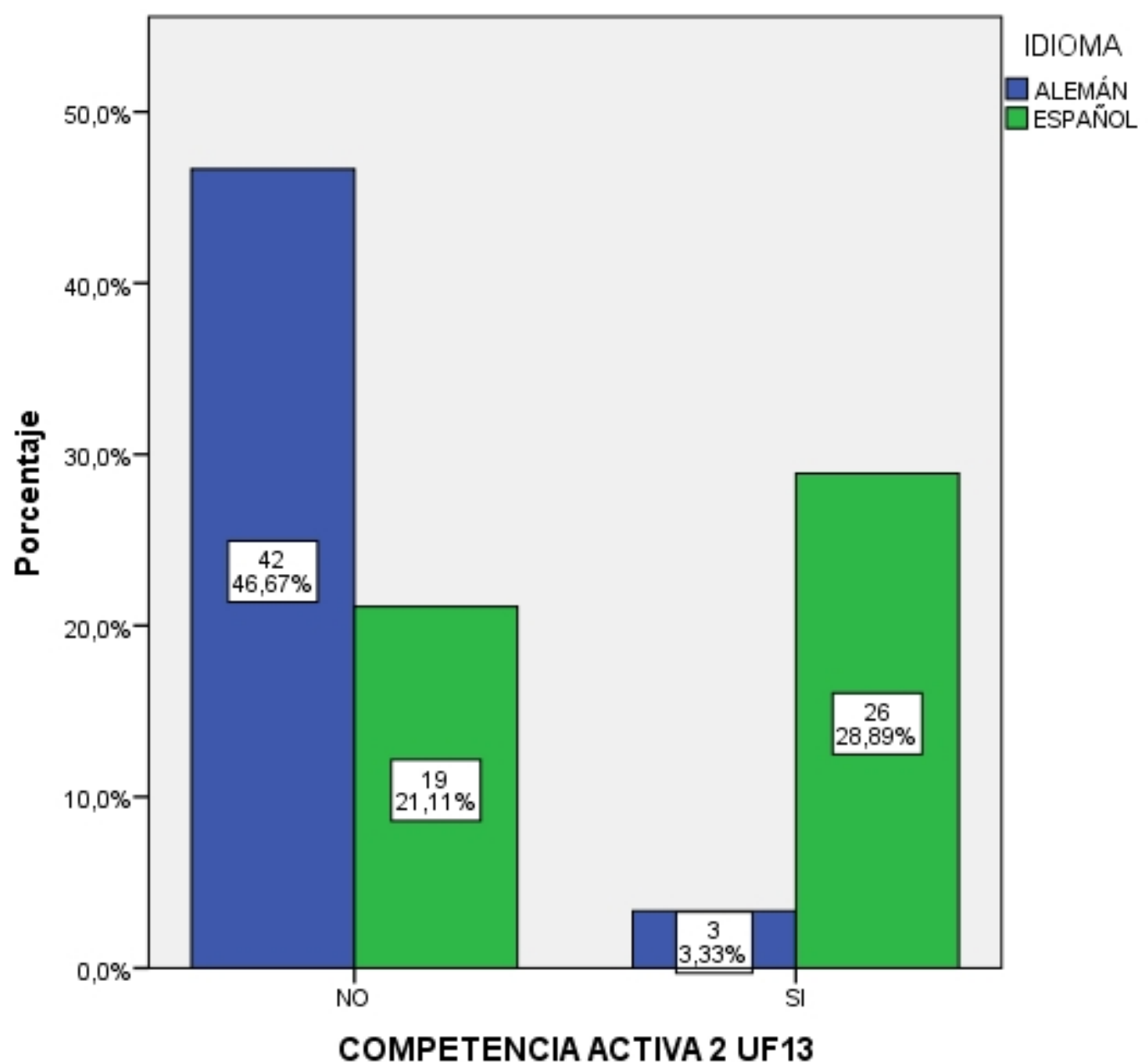

Figura 10. Competencia de la UF13 en español y alemán 
- UF14 no tener pies ni cabeza w weder Hand noch Fuss haben (Figura 11):

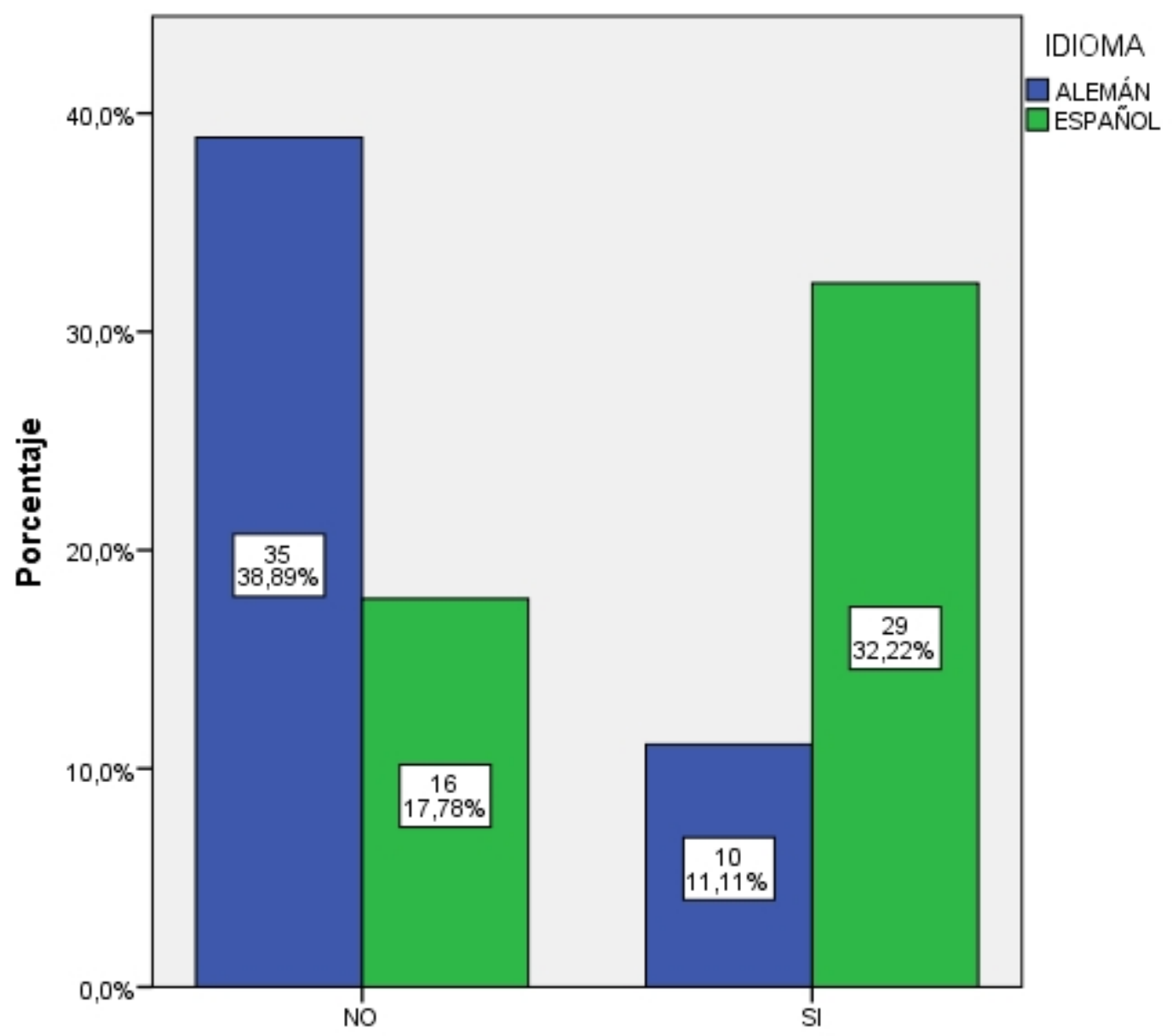

COMPETENCIA ACTIVA 2 UF14

Figura 11. Competencia de la UF14 en español y alemán 
- UF16 faltar un tornillo $\approx$ nicht alle Tassen im Schrank haben (Figura 12):

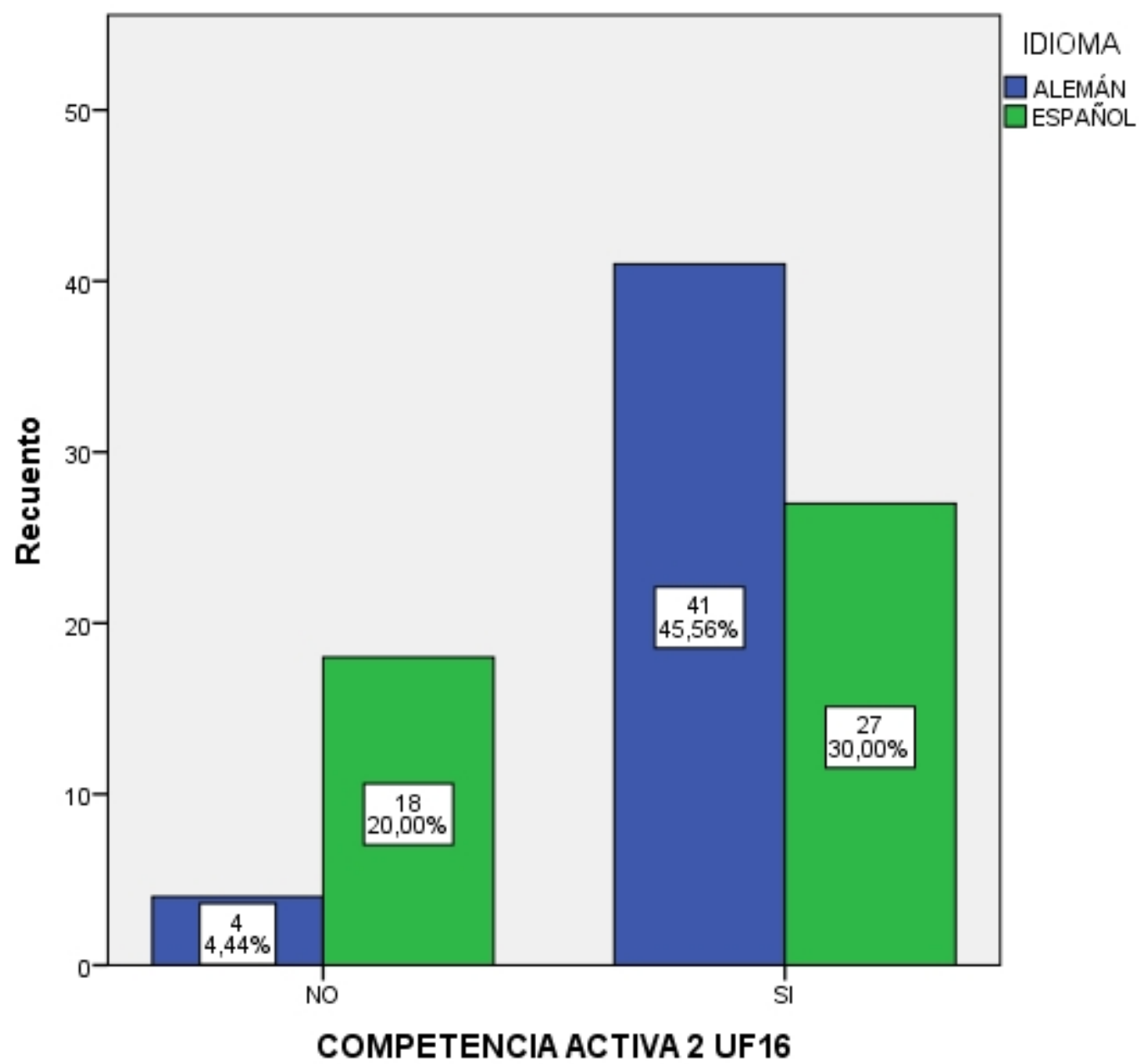

Figura 12. Competencia de la UF16 en español y alemán 
- UF19 nadar en la abundancia $\approx$ im Geld schwimmen (Figura 13):

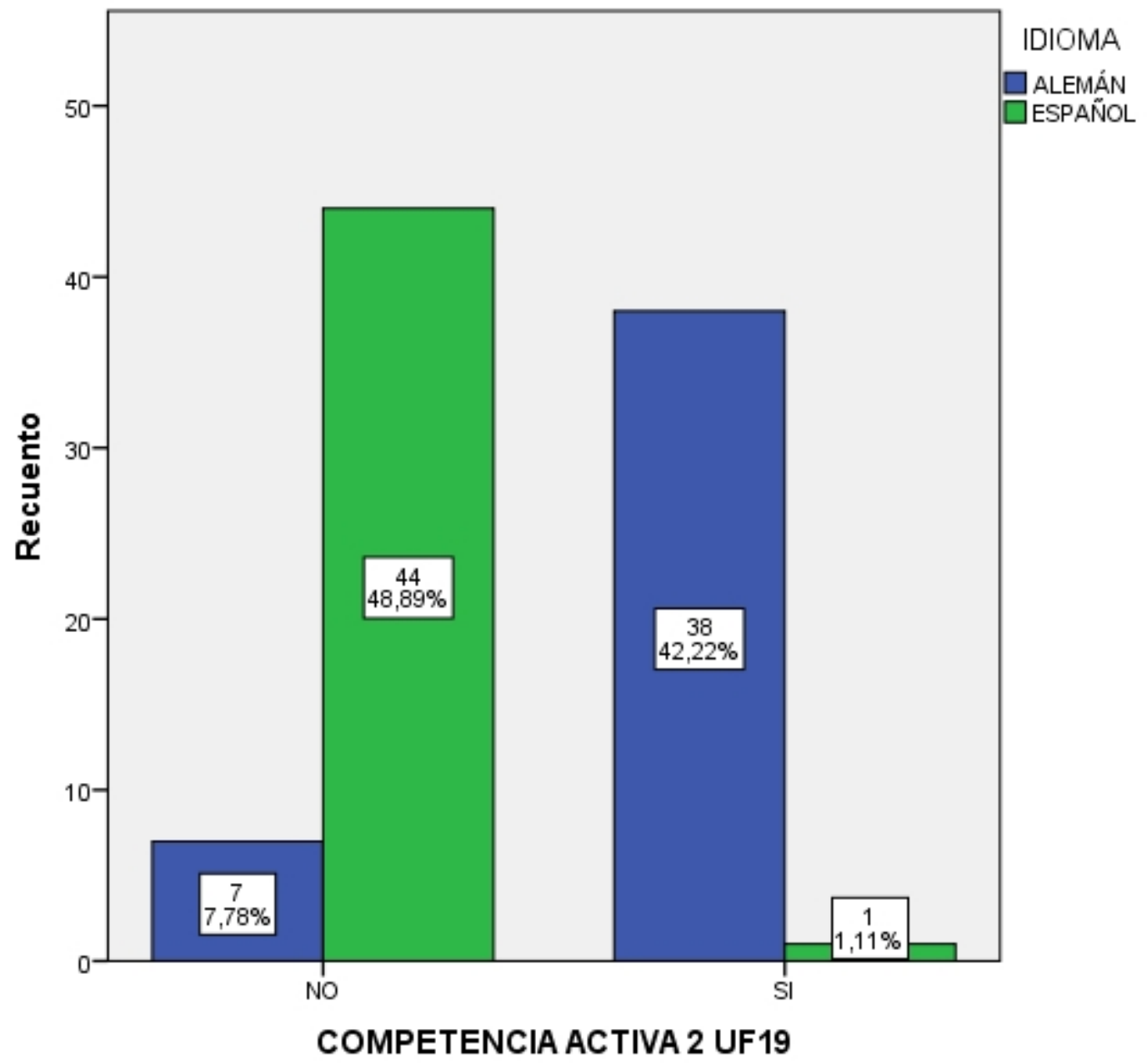

Figura 13. Competencia de la UF19 en español y alemán 
- UF20 perder hasta la camisa $\approx$ bis aufs Hemd ausziehen (Figura 14):

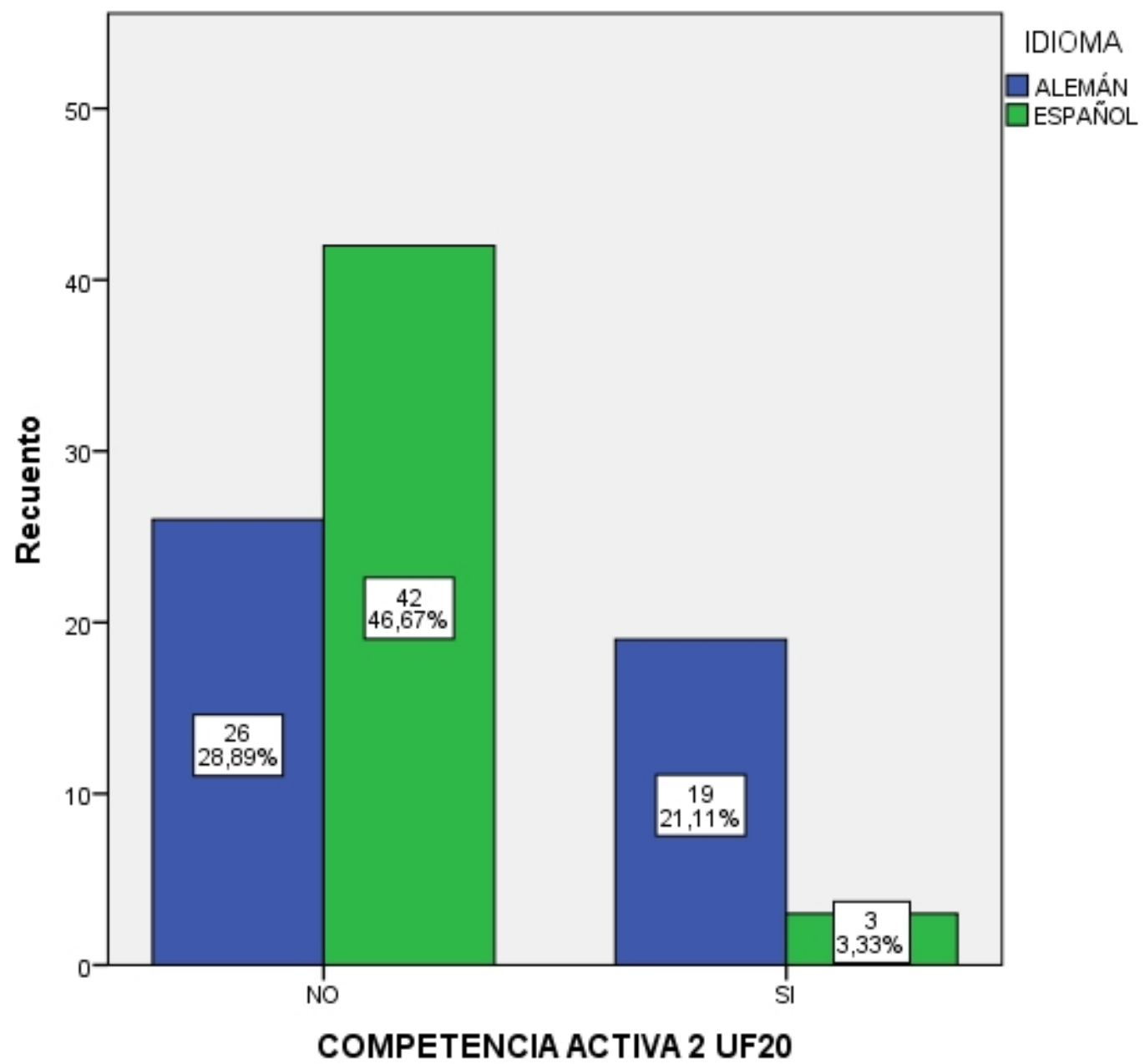

Figura 14. Competencia de la UF20 en español y alemán 
- UF21 meter la cuchara seinen Senf dazu geben (Figura 15):

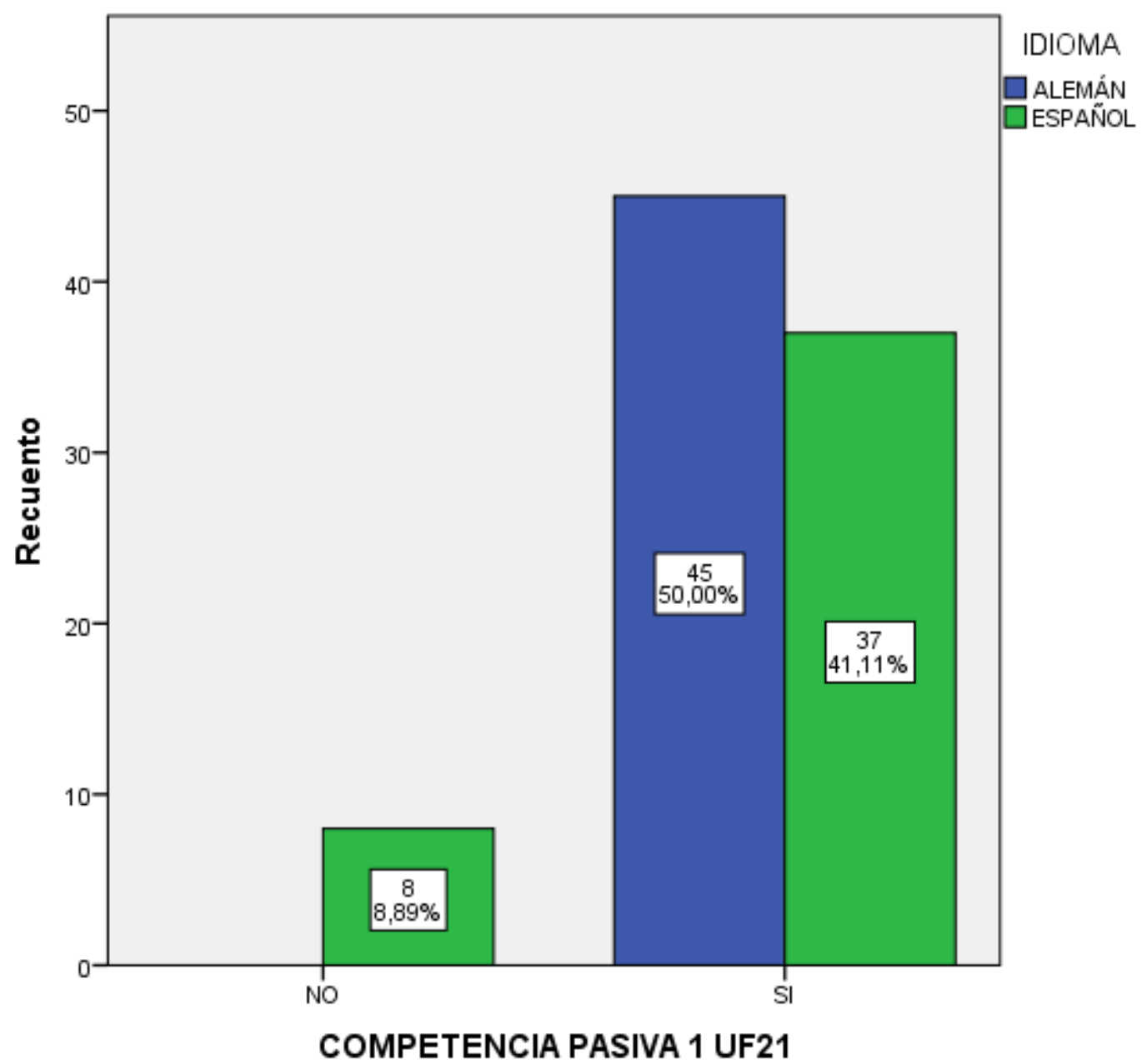

Figura 15. Competencia de la UF21 en español y alemán 
- UF31 jugar con las cartas boca arriba $\approx$ mit offenen Karten spielen (Figura 16):

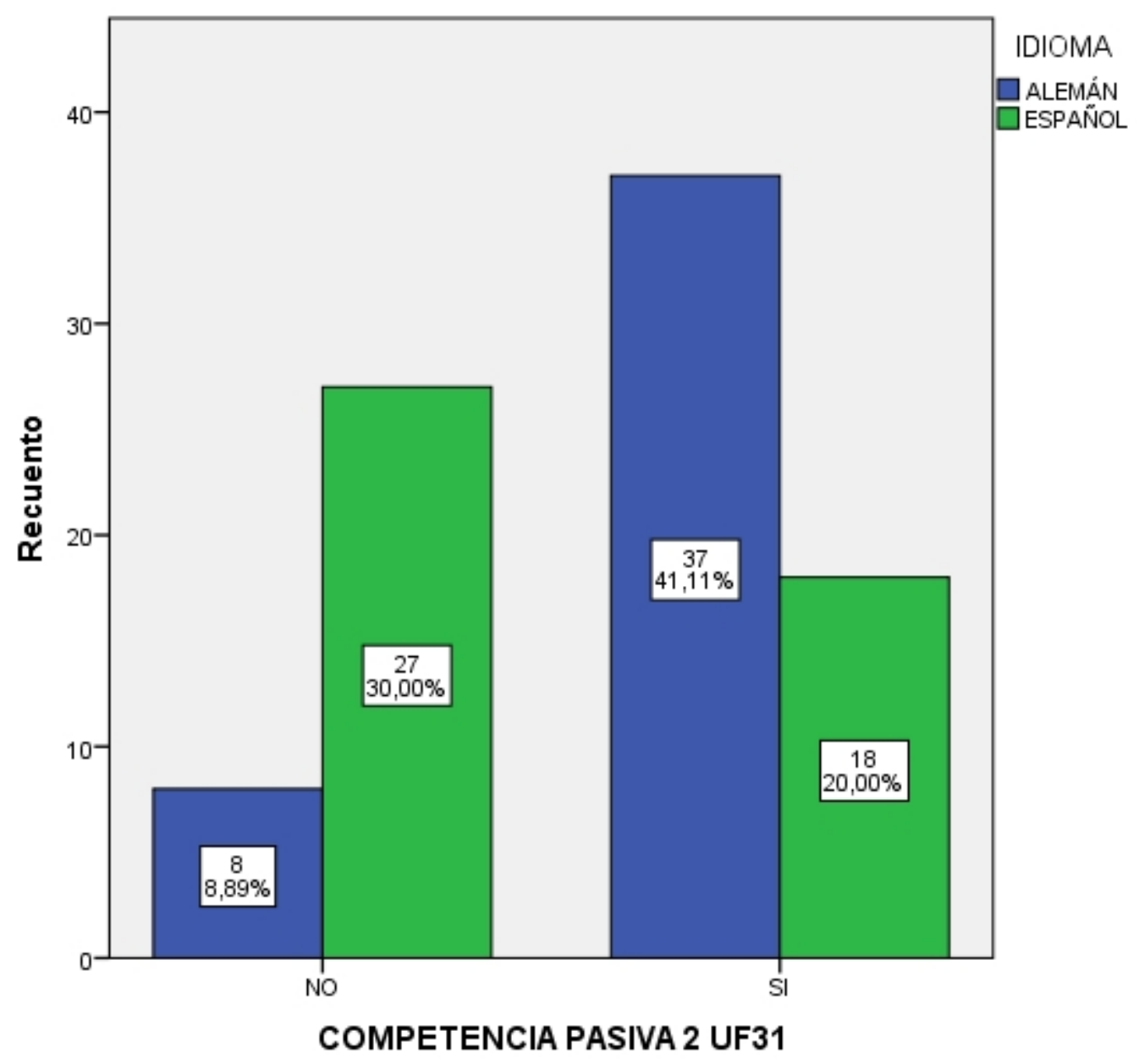

Figura 16. Competencia de la UF31 en español y alemán 
- UF33 hacer la corte a alguien jemandem den Hof machen (Figura 17):

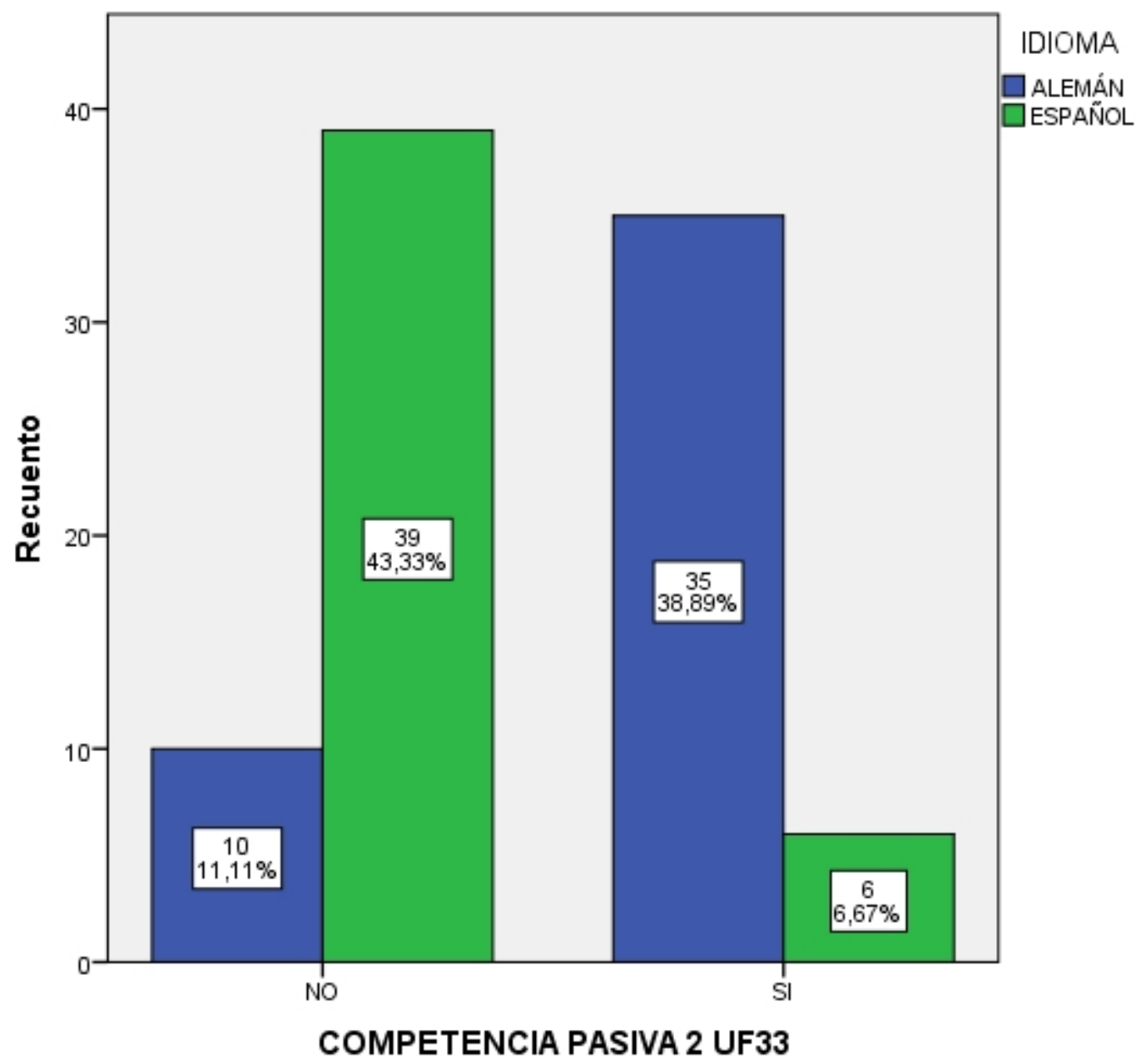

Figura 17. Competencia de la UF33 en español y alemán 
- UF35 ser el cuento de la lechera eine Milchmädchenrechnung sein (Figura 18):

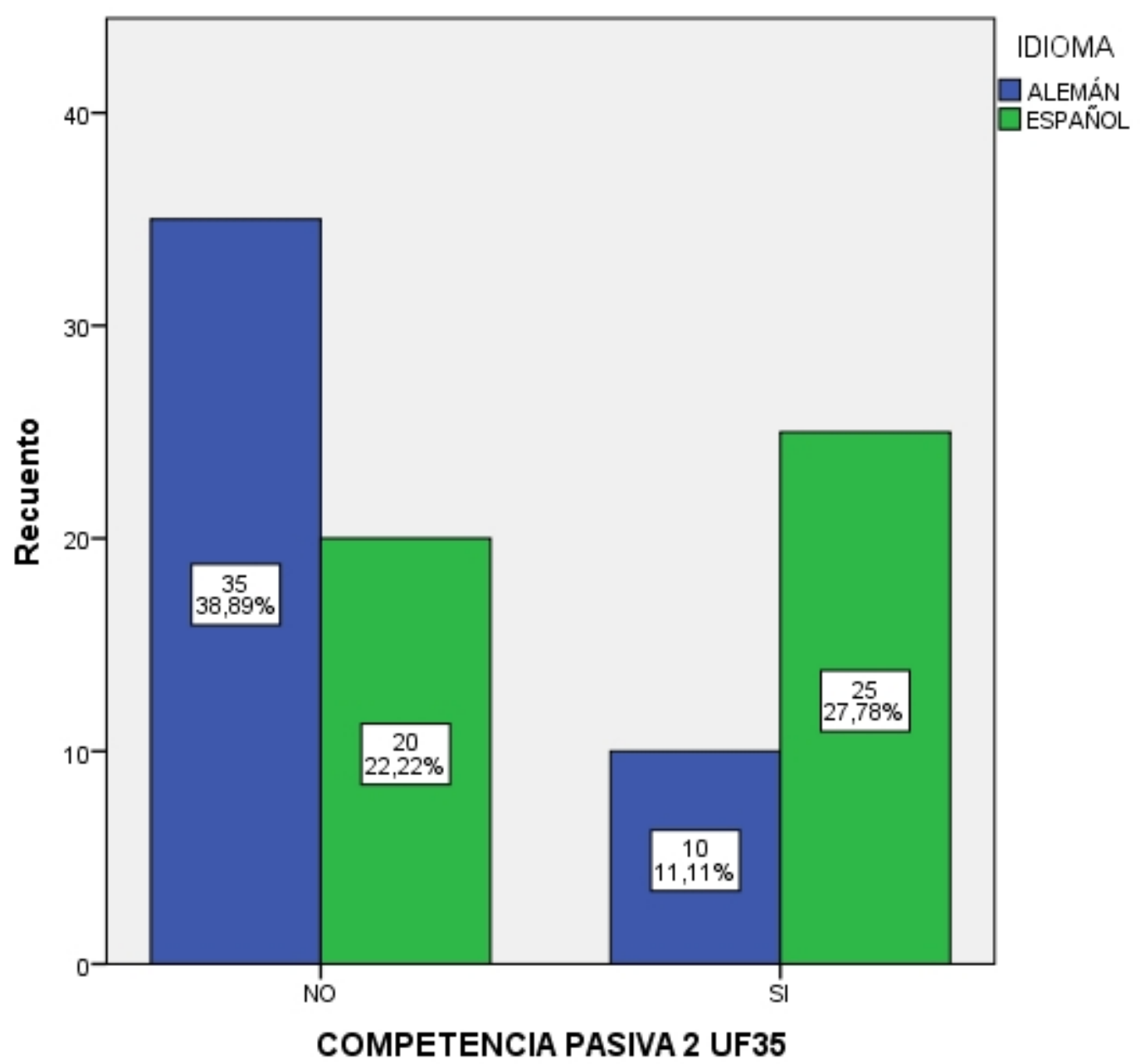

Figura 18. Competencia de la UF35 en español y alemán 
- UF38 construir sobre arena $\approx$ auf Sand bauen (Figura 19):

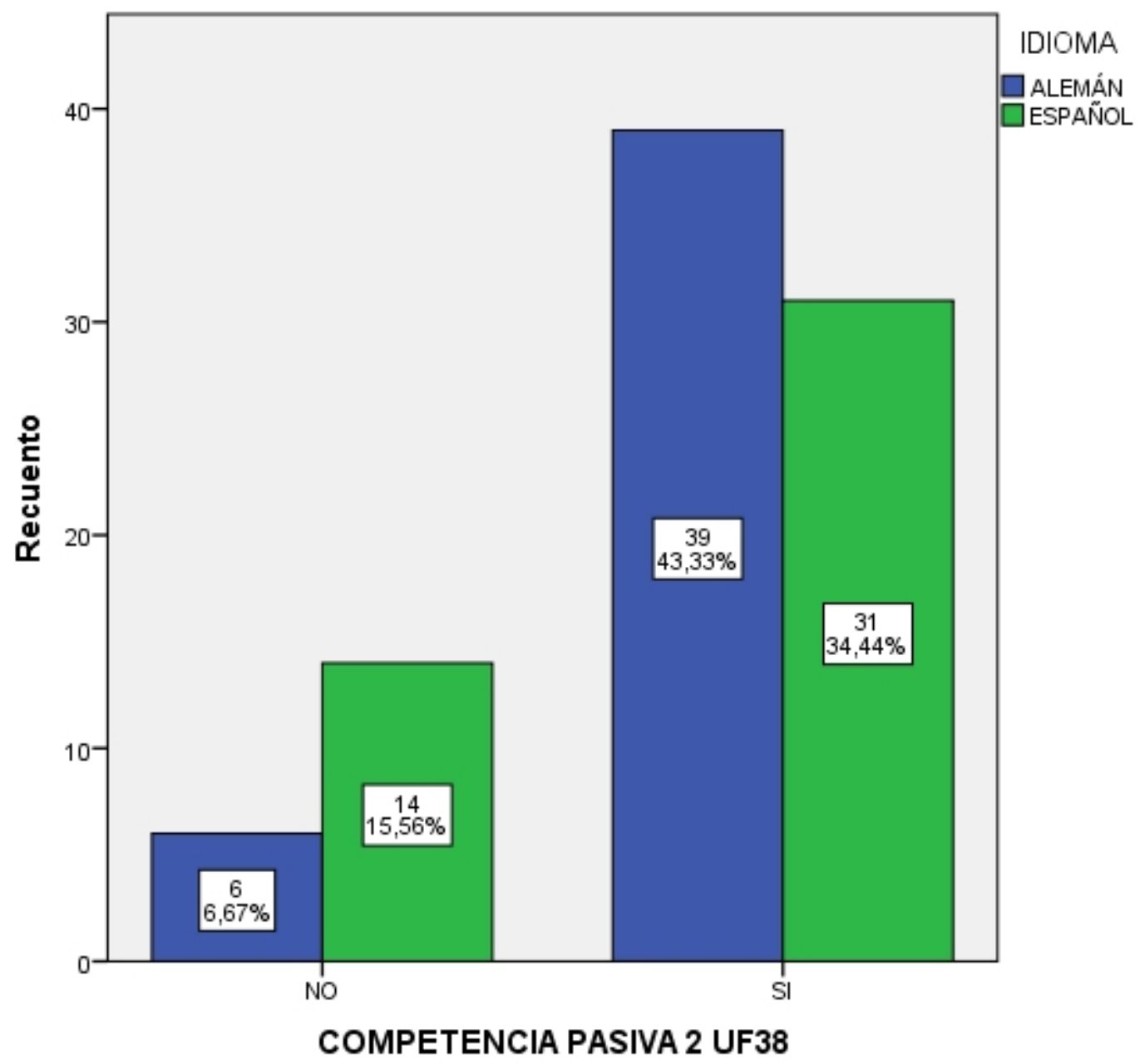

Figura 19. Competencia de la UF38 en español y alemán 
- UF39 poner la zancadilla a alguien jemandem ein Bein stellen (Figura 20):

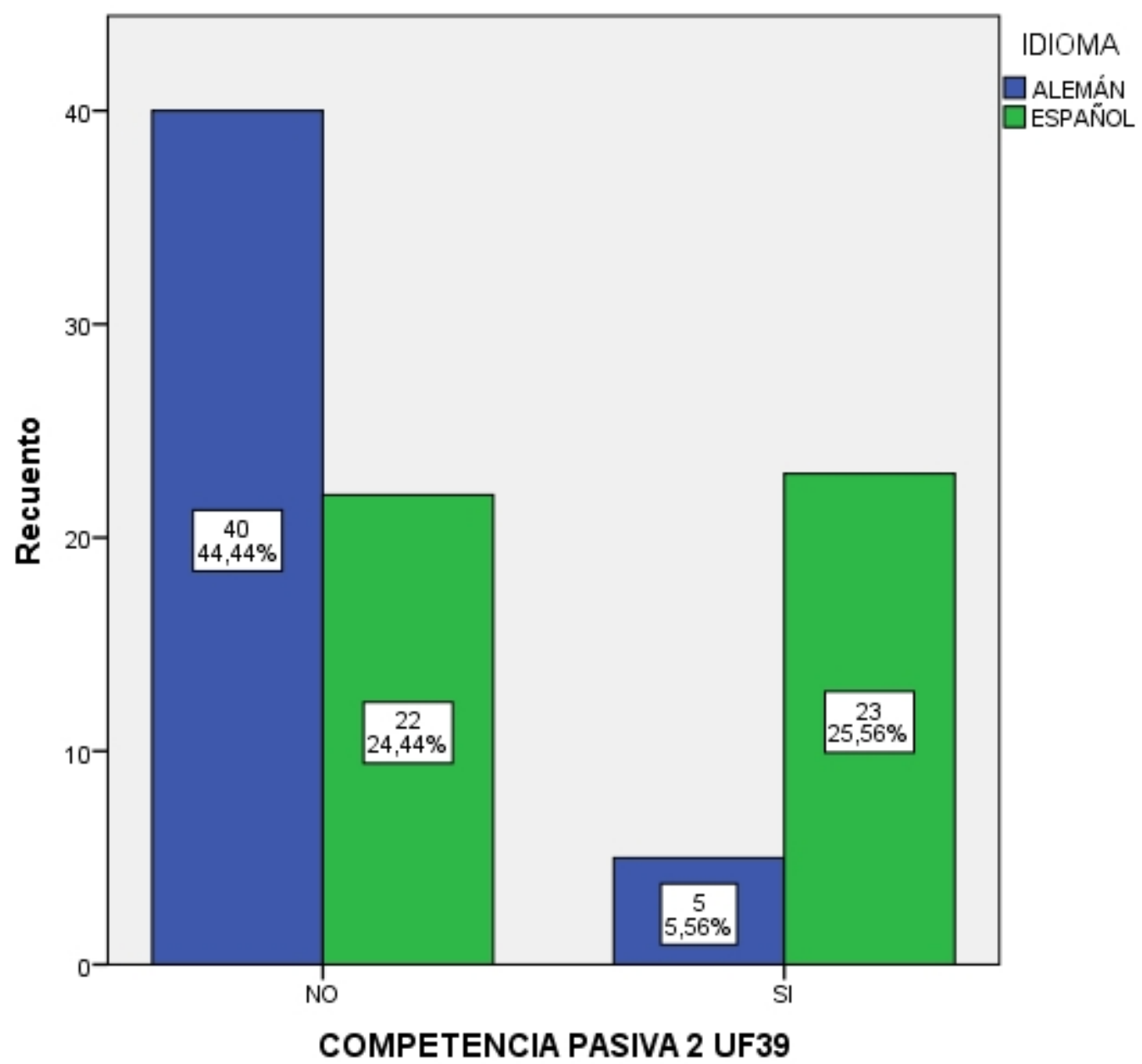

Figura 20. Competencia de la UF39 en español y alemán 
- UF40 ponerle los nervios de punta a alguien $\approx$ jemandem auf die Nerven gehen (Figura 21):

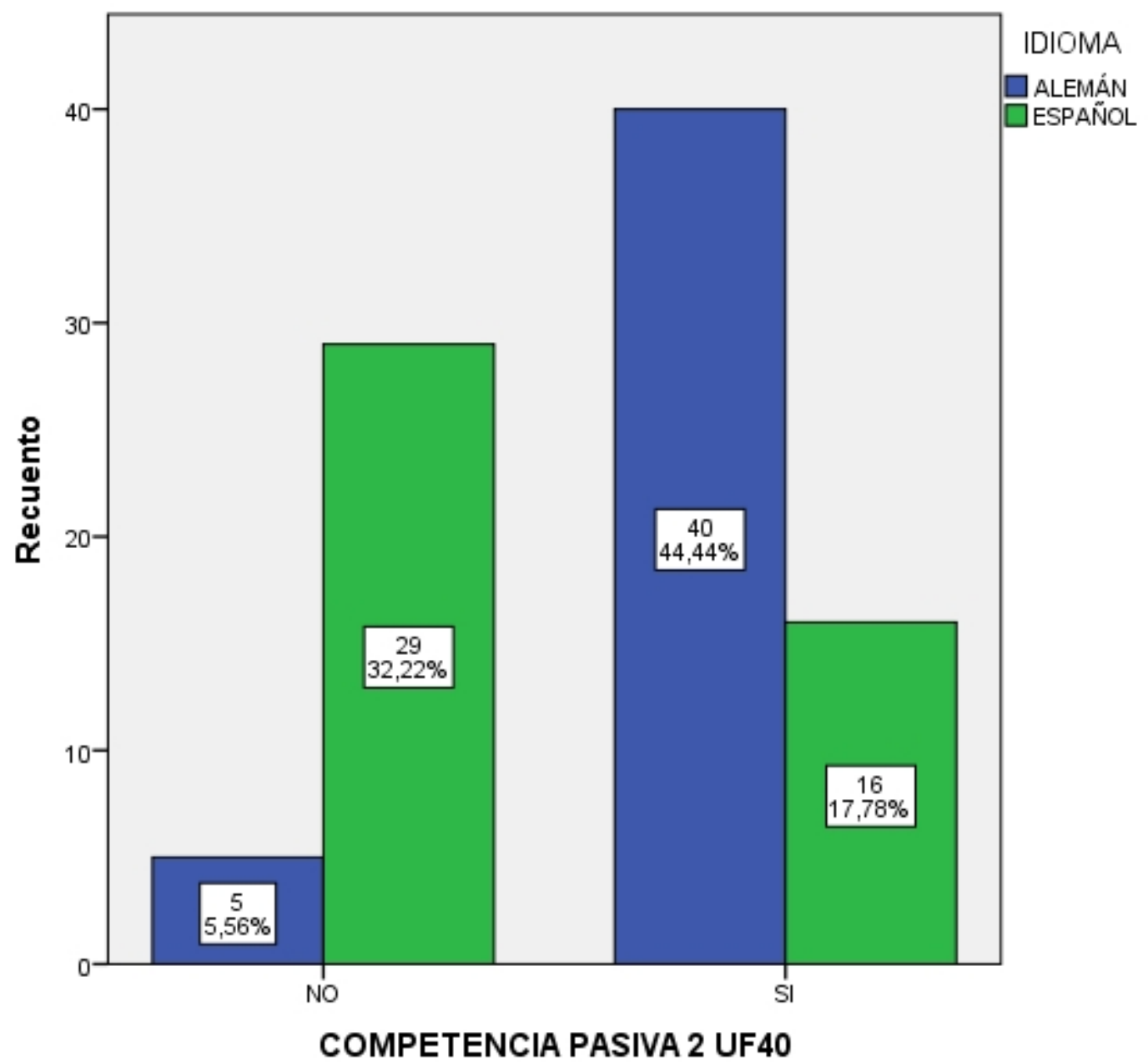

Figura 21. Competencia de la UF40 en español y alemán 
- UF42 tener gato encerrado die Katze im Sack kaufen (Figura 22):

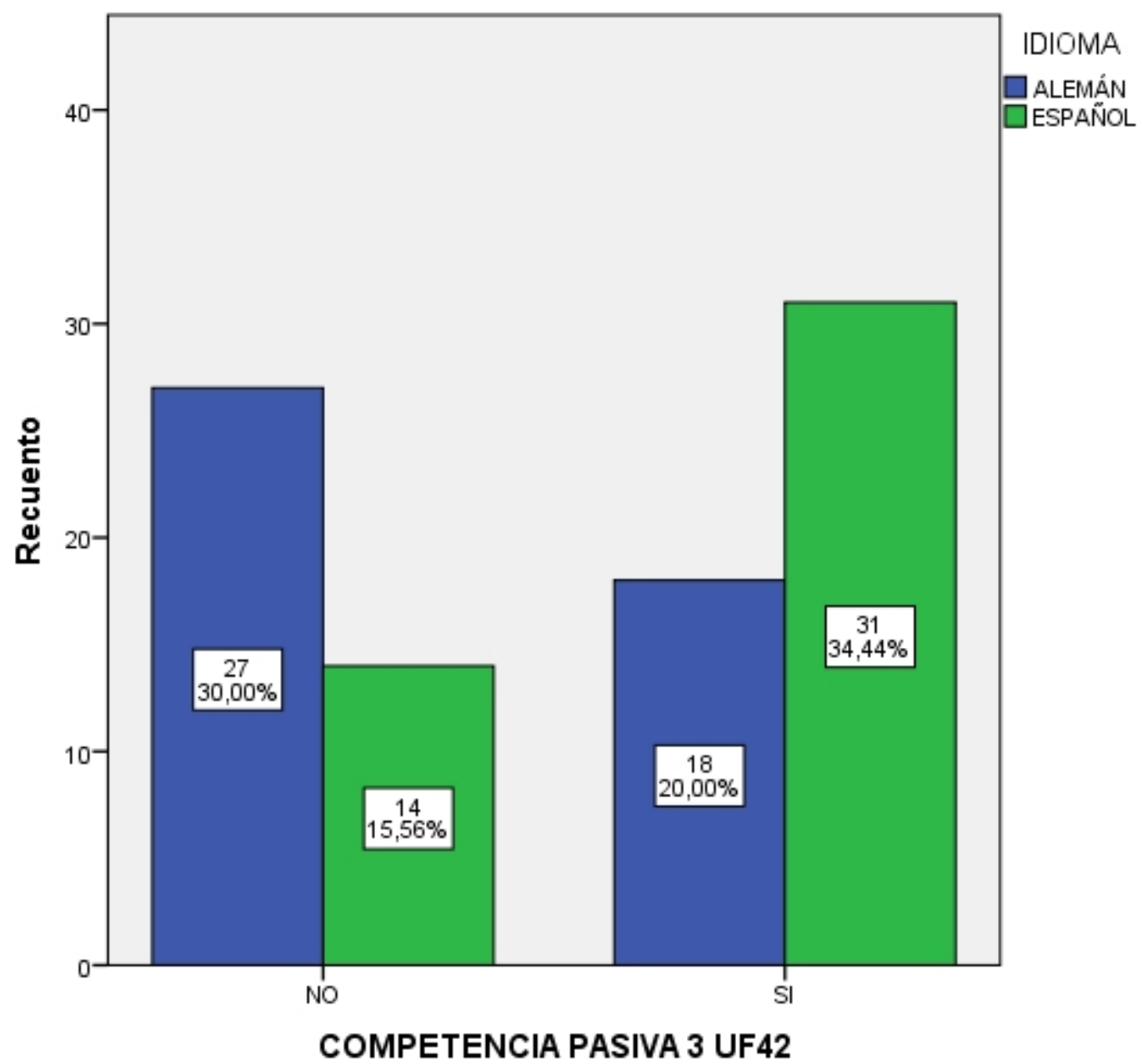

Figura 22. Competencia de la UF42 en español y alemán 
- UF43 levantarse con el pie izquierdo $\approx$ mit dem linken Fuß zuerst aufstehen (Figura 23):

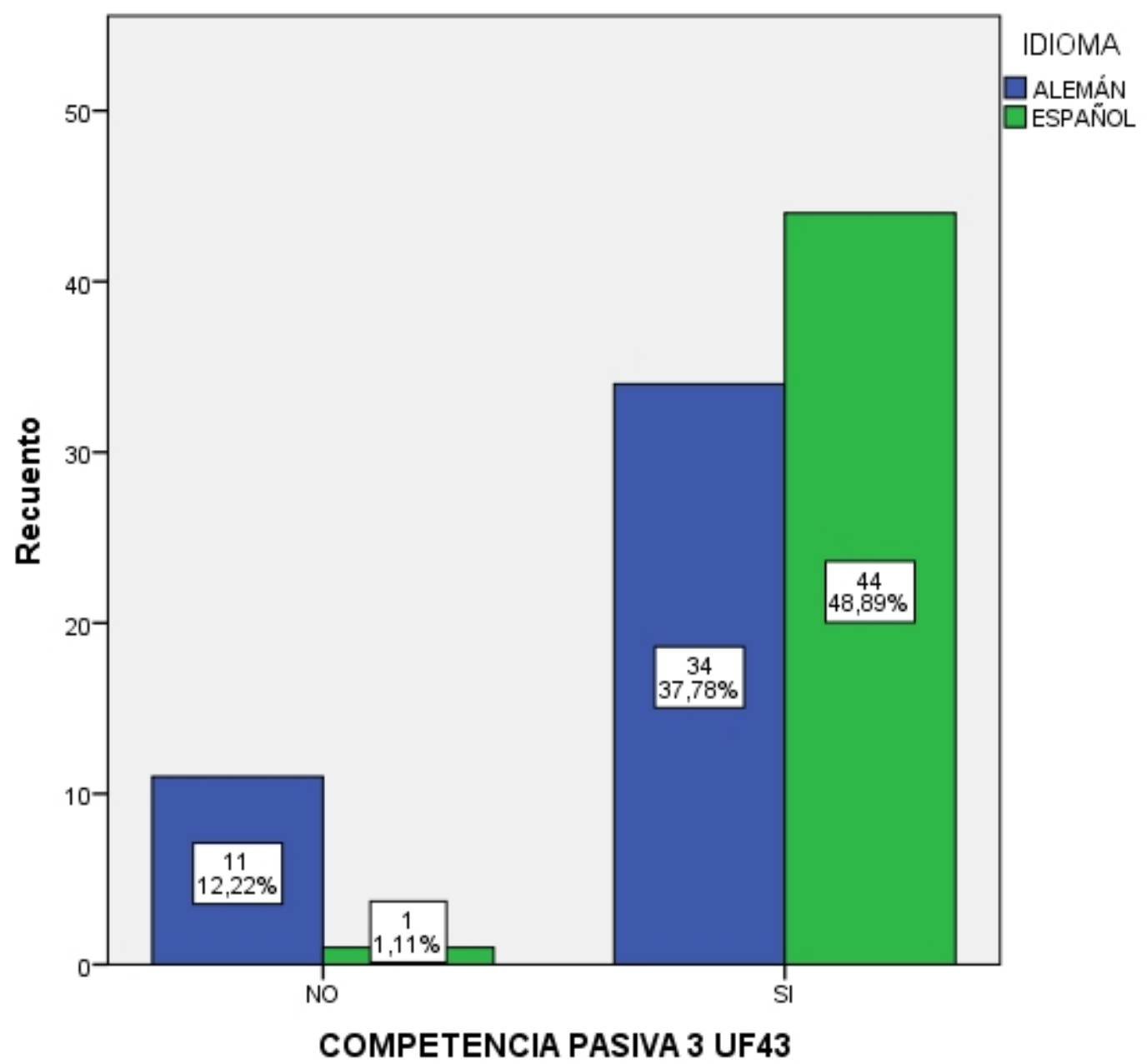

Figura 23. Competencia de la UF43 en español y alemán 
- UF46 ser pobre como una rata arm wie ein Kirchenmaus sein (Figura 24):

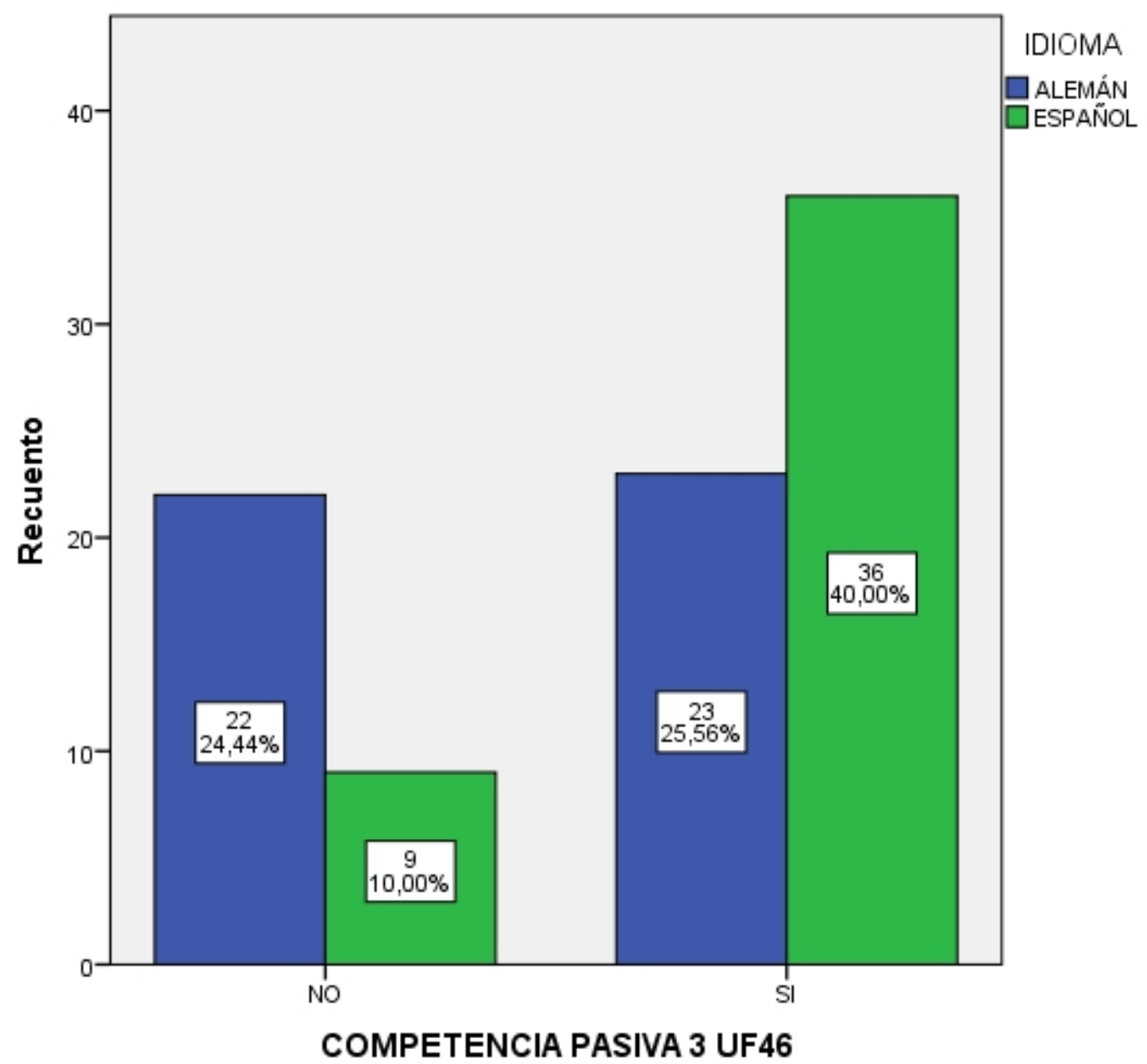

Figura 24. Competencia de la UF46 en español y alemán 
- UF49 meter las narices en todo die Nase in alles stecken (Figura 25):

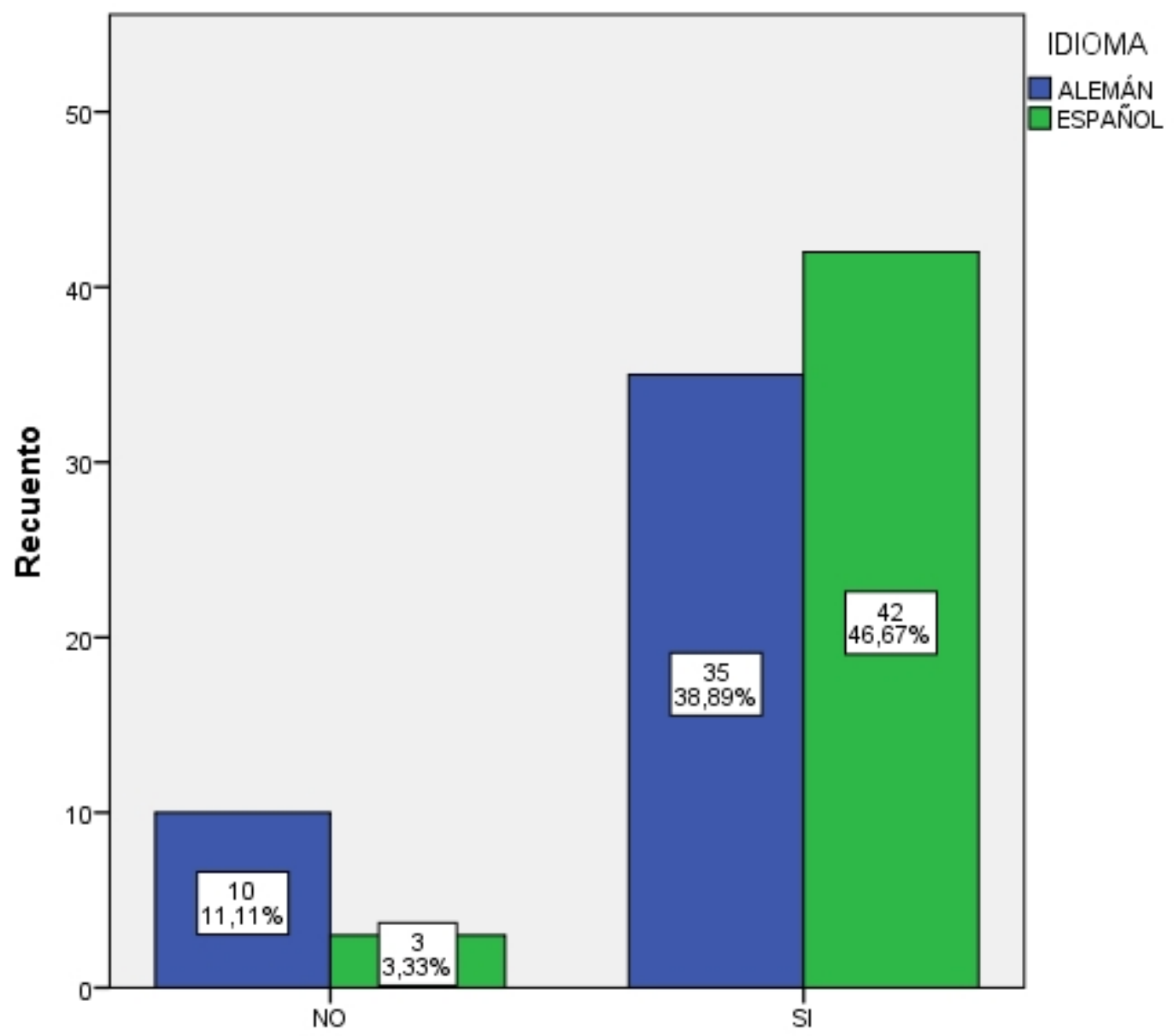

COMPETENCIA PASIVA 3 UF49

Figura 25. Competencia de la UF49 en español y alemán

Como hemos visto, exactamente en la mitad de las UF (25 UF) se aprecian diferencias significativas de competencia entre ambas lenguas, y, de estas, los españoles muestran más competencia en 16 UF y los alemanes en 9.

Por el contrario, en la otra mitad de UF (25 UF) no se aprecian diferencias significativas de competencia entre español y alemán. Se trata de las siguientes UF:

UF4 no tener pelos en la lengua $\approx$ kein Blatt vor den Mund haben

UF5 ponerse los pelos de punta) ₹ jemandem stehen die Haare zu Berge 


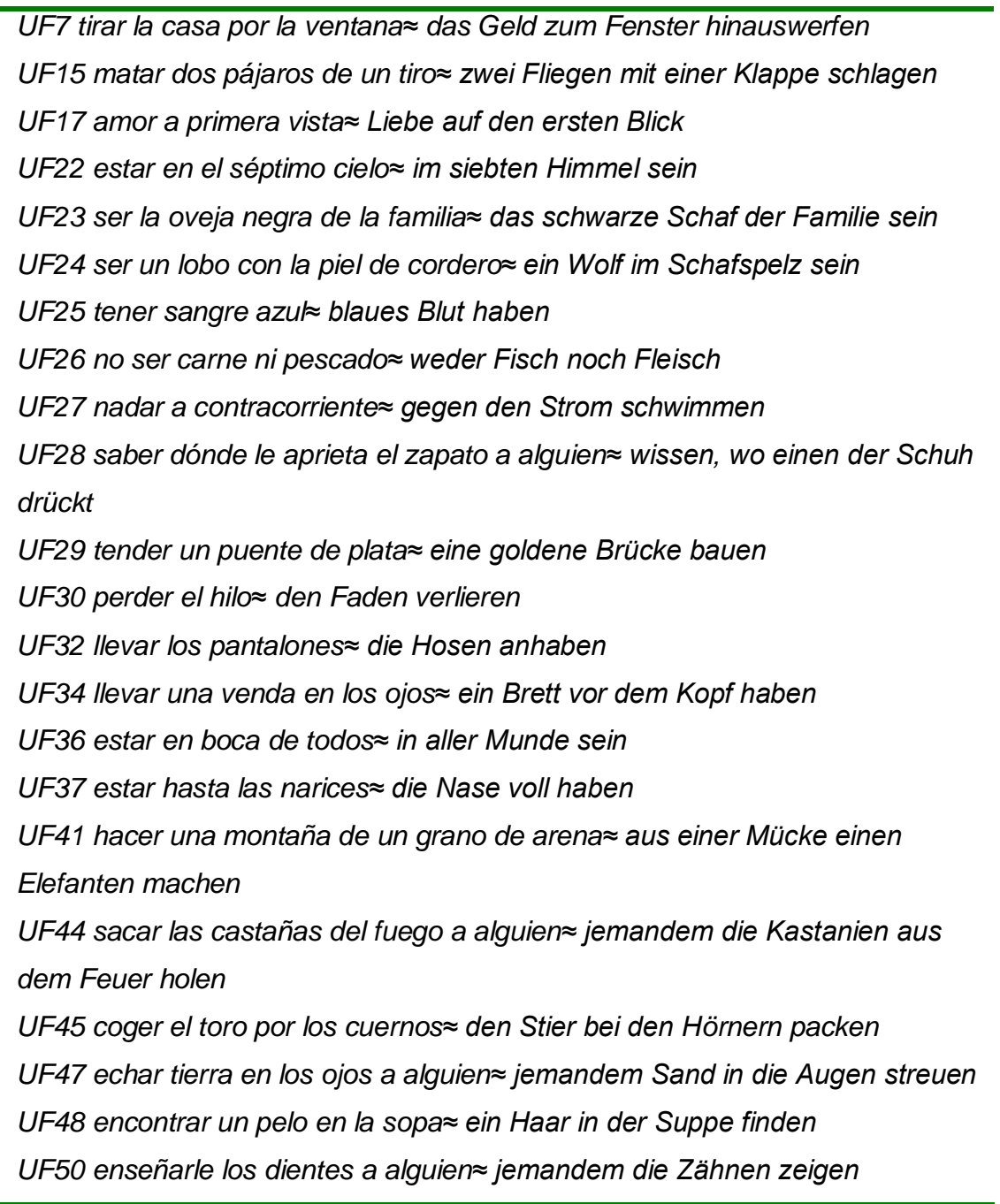

Cuadro 17. UF sin diferencias significativas en español y alemán

Además de las mostradas en el Cuadro 16, también pertenecerían a este grupo de UF en las que no se perciben diferencias significativas de competencia las UF18 y UF41. No obstante, hemos preferido presentarlas aparte por la peculiaridad que manifiestan, ya que presentan una competencia idéntica en las dos lenguas (con un valor de significación 1,00). Se trata de las siguientes UF:

UF18 tener (algo) en la punta de la lengua etwas auf der Zunge liegen UF41 hacer una montaña de un grano de arena aus einer Mücke einen Elefanten machen

Cuadro 18. UF con idéntica competencia en español y alemán 
A modo de resumen, y después de realizar el análisis de los datos de las UF por separado en español y en alemán, destacamos que:

1. en 48 de las 50 UF las medias apuntan hacia una competencia diferente en ambas lenguas, al tiempo que en 2 UF la competencia es idéntica,

2. la mitad de las UF resultan estadísticamente significativas a la luz de la muestra disponible y la otra mitad no lo son.

De la misma manera que se espera que los alumnos españoles y alemanes presenten diferencias de competencia global, también se espera que la competencia por pares de UF equivalentes muestre diferencias significativas. Esta vez los resultados avalan, al menos parcialmente, nuestras hipótesis de partida.

6.1.3. HIPÓTESIS 3: Hay diferencias en el grado de competencia activa y pasiva.

En este punto recordaremos lo comentado sobre del diseño de la encuesta en un apartado anterior (cf. § 5.3.1), y en concreto acerca del tipo de competencia fraseológica medida en cada caso. Como se recordará, la encuesta mide dos tipos de competencia lingüística diferente entre los estudiantes, como son la competencia activa y la competencia pasiva. La competencia fraseológica activa se comprueba a través de los ejercicios 1 y 2 (UF1 a UF20), mientras que la competencia fraseológica pasiva se mide por medio de las respuestas a los ejercicios 3,4 y 5 (UF21 a UF50).

Las unidades fraseológicas asociadas al análisis de la competencia activa son las siguientes:

UF1 poner los cuernos $\approx$ Hörner aufsetzen

UF2 poner la mano en el fuego die Hand ins Feuer legen

UF3 como el perro y el gato wie Hund und Katze 
UF4 no tener pelos en la lengua kein Blatt vor den Mund haben

UF5 ponerse los pelos de punta jemandem stehen die Haare zu Berge

UF6 descubrir la pólvora das Pulver erfunden haben

UF7 tirar la casa por la ventana das Geld zum Fenster hinauswerfen

UF8 sonar a chino $\approx$ jemandem Spanisch vorkommen

UF9 ganz Ohr sein $\approx$ ser todo oídos

UF10 hacerse la boca agua

jemandem das Wasser im Mund zusammenlaufen

UF11 llamar a las cosas por su nombre

die Dinge beim ihrem Namen nennen

UF12 echar leña al fuego $\approx$ Öl ins Feuer giessen

UF13 pagar con la misma moneda mit gleicher Münze heimzahlen

UF14 no tener pies ni cabeza w weder Hand noch Fuss haben

UF15 matar dos pájaros de un tiro z zwei Fliegen mit einer Klappe schlagen

UF16 faltar un tornillo $\approx$ nicht alle Tassen im Schrank haben

UF17 ser amor a primera vista Liebe auf den ersten Blick

UF18 tener algo en la punta de la lengua $\approx$ etwas auf der Zunge liegen

UF19 nadar en la abundancia im Geld schwimmen

UF20 perder hasta la camisa bis aufs Hemd ausziehen

Cuadro 19. UF sobre las que se mide competencia activa

Por su parte, las UF sobre las que se mide la competencia pasiva son estas:

UF21 meter la cuchara seinen Senf dazu geben

UF22 estar en el séptimo cielo im siebten Himmel sein

UF23 ser la oveja negra de la familia das schwarze Schaf der Familie sein

UF24 ser un lobo con la piel de cordero $\approx$ ein Wolf im Schafspelz sein

UF25 tener sangre azu $\approx$ blaues Blut haben

UF26 no ser carne ni pescado $\approx$ weder Fisch noch Fleisch

UF27 nadar a contracorriente $\approx$ gegen den Strom schwimmen

UF28 saber donde le aprieta el zapato a alguien $\approx$ wissen, wo einen der Schuh drückt

UF29 tender un puente de plata eine goldene Brücke bauen

UF30 perder el hilo $\approx$ den Faden verlieren

UF31 jugar con las cartas boca arriba $\approx$ mit offenen Karten spielen

UF32 llevar los pantalones die Hosen anhaben

UF33 hacer la corte a alguien $\approx$ jemandem den Hof machen

UF34 tener una venda en los ojos $\approx$ ein Brett vor dem Kopf haben

UF35 ser el cuento de la lechera eine Milchmädchenrechnung sein

UF36 estar en boca de todos $\approx$ in aller Munde sein

UF37 estar hasta las narices $\approx$ die Nase voll haben

UF38 construir sobre arena a auf Sand bauen 


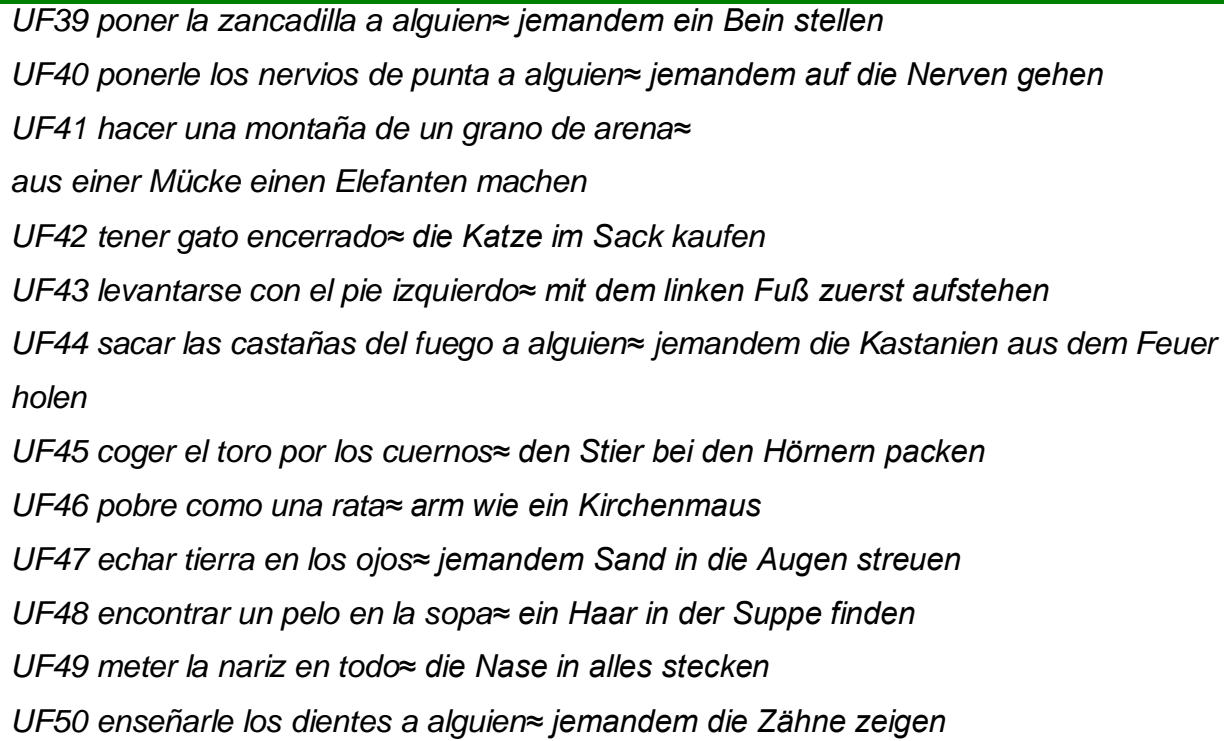

Cuadro 20. UF sobre las que se mide competencia pasiva

En la presente hipótesis se planteaba si el tipo de competencia lingüística medida podía influir en los resultados de los alumnos españoles y alemanes. En este caso, como contamos con el mismo número de sujetos para el estudio de ambas competencias, utlilizamos la T-Student para medidas relacionadas, estadístico que nos revelará si las diferencias son o no significativas. En un primer momento se observan los resultados para cada idioma.

En español observamos las medias que presenta cada tipo de competencia, (Tabla 11). Podemos comprobar que hay una media considerablemente más elevada en la competencia pasiva $(21,07)$ que en la activa $(9,04)$.

Tabla 11. Nivel de competencia activa/pasiva en español: Medias

\begin{tabular}{lccccc}
\hline \multicolumn{2}{c}{ Estadísticos de muestras relacionadas } \\
& & Media & $N$ & \multicolumn{1}{c}{$\begin{array}{c}\text { Desviación } \\
\text { típ. }\end{array}$} & $\begin{array}{c}\text { Error típ. de } \\
\text { la media }\end{array}$ \\
& & & 45 & 3,268 &, 487 \\
Par & COMPETENCIA ACTIVA & 9,04 & 458 &, 746 \\
\hline
\end{tabular}

Para verificar si esa diferencia es significativa en español, se realiza la prueba T-Student, que nos certifica su fiabilidad estadística. En efecto, la competencia 
fraseológica pasiva de los estudiantes españoles es significativamente mayor que la competencia activa $(\mathrm{T}=-20,652$, sig.=,000).

Ahora bien, esta diferencia es todavía mayor en alemán, como podemos comprobar en la Tabla 12, donde se aprecia una distancia más amplia entre los valores elevados de la competencia pasiva $(21,47)$ y los mucho más reducidos del conocimiento fraseológico activo $(6,56)$.

Tabla 12. Nivel de competencia activa/pasiva en alemán: Medias

\begin{tabular}{llcccc}
\hline \multicolumn{2}{c}{ Estadísticos de muestras relacionadas } \\
& & Media & $\mathrm{N}$ & Desviación & Error típ. de \\
& & & & típ. & la media \\
Par & COMPETENCIA ACTIVA & 6,56 & 45 & 2,095 &, 312 \\
1 & COMPETENCIA PASIVA & 21,47 & 45 & 5,146 &, 767 \\
\hline
\end{tabular}

Y, como cabía esperar, esta disparidad de medias también es en alemán estadísticamente significativa $\mathrm{T}=-22,953$, sig.=,000.

A continuación, comparamos los valores obtenidos de cada competencia por idiomas en la siguiente tabla (Tabla 13), donde se pueden consultar las medias.

Tabla 13. Nivel de competencia activa/pasiva en español y alemán: Medias

\begin{tabular}{|c|c|c|c|c|c|}
\hline \multicolumn{6}{|c|}{ Estadísticos de grupo } \\
\hline & IDIOMA & $\mathrm{N}$ & Media & $\begin{array}{c}\text { Desviación } \\
\text { típ. }\end{array}$ & $\begin{array}{c}\text { Error típ. de } \\
\text { la media }\end{array}$ \\
\hline \multirow[t]{2}{*}{ COMPETENCIA ACTIVA } & ALEMÁN & 45 & 6,56 & 2,095 & ,312 \\
\hline & ESPAÑOL & 45 & 9,04 & 3,268 & ,487 \\
\hline \multirow[t]{2}{*}{ COMPETENCIA PASIVA } & ALEMÁN & 45 & 21,47 & 5,146 & ,767 \\
\hline & ESPAÑOL & 45 & 21,07 & 5,002 & ,746 \\
\hline
\end{tabular}

En la tabla anterior (Tabla 13) se observan las medias de competencia obtenidas en cada lengua y puede verse que la diferencia entre las dos lenguas es menor y se encuentra muy próxima si observamos los valores de competencia pasiva, mientras que en activa están más alejados. 
Para ver si estas diferencias son significativas, se ha realizado de nuevo la prueba $T$, que mostramos en la tabla siguiente (Tabla 14). De los datos se deduce que es significativa la diferencia entre español y alemán en la competencia activa, pero no en la pasiva.

Tabla 14. Nivel de competencia activa/pasiva en español y en alemán: T-Student

\begin{tabular}{lrr}
\hline & T-Student & Sig. \\
\hline COMPETENCIA ACTIVA & $-4,301$ &, 000 \\
COMPETENCIA PASIVA &, 374 &, 709 \\
\hline
\end{tabular}

Mostramos a continuación gráficos que ilustran la competencia fraseológica de las UF en el tipo de competencia activa (Figura 26).

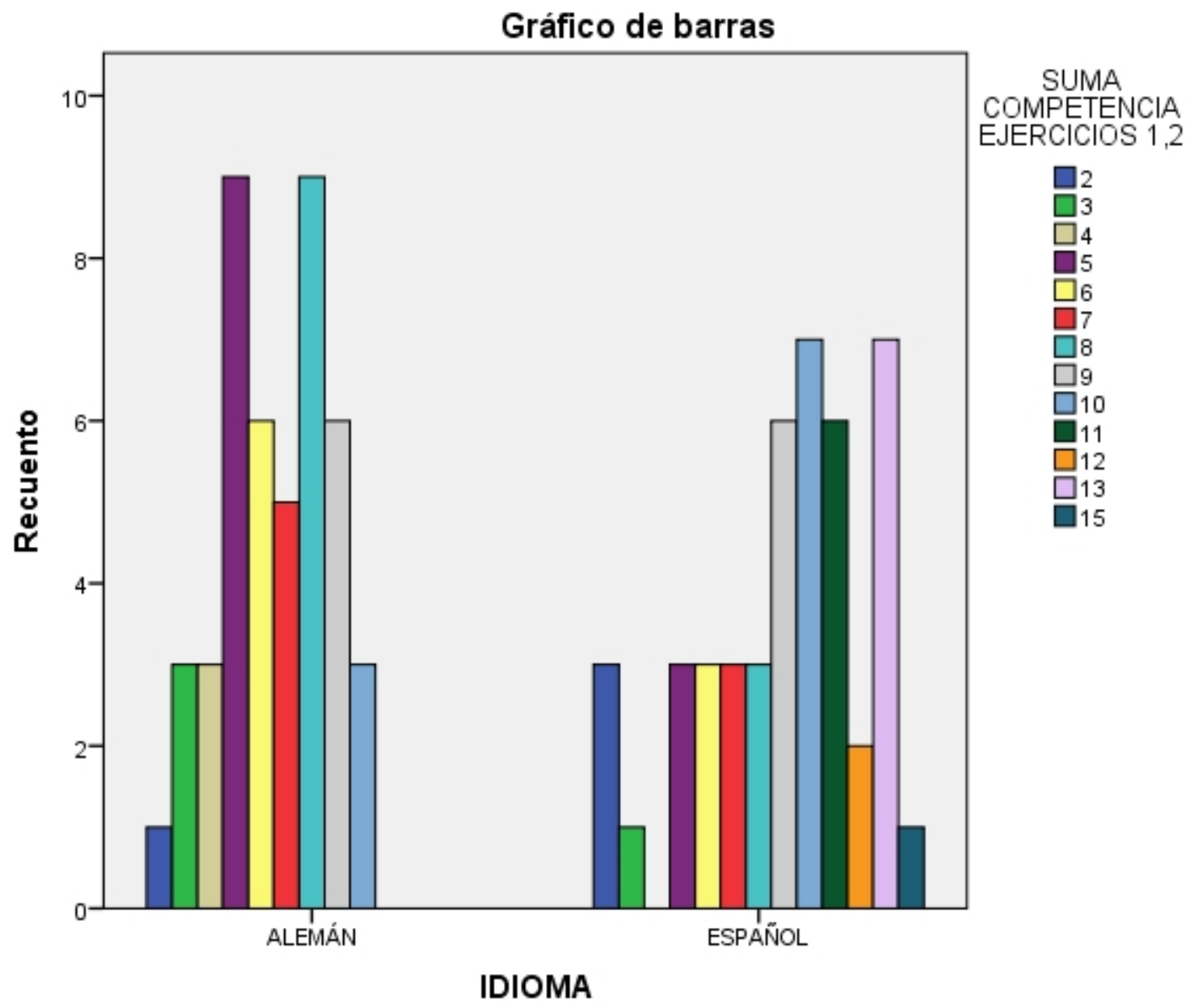

Figura 26. Nivel de competencia activa español/alemán 
En el eje $Y$ están representadas las frecuencias, en este caso el número de estudiantes que coinciden exactamente con el número de respuestas que aciertan; $y$ en el eje $X$ aparece la distribución del número de UF acertadas en cada muestra. El primer gráfico que ofrecemos ilustra la competencia activa, en la que, como se recordará, se responde a 20 UF. Las respuestas en competencia activa pueden alcanzar un máximo de 20 aciertos. Concretamente en alemán han alcanzado un máximo de 10; la mayor frecuencia, concretamente se encuentra en torno a nueve estudiantes, en 5 y 8 aciertos. Puede observarse que la distribución del número de aciertos en este idioma sigue casi una distribución normal donde lo más frecuente son ambas puntuaciones, teniendo a ambos lados, más o menos, frecuencias en aciertos por debajo y por encima. En español, se da en 7 ocasiones las frecuencias de 10 y 13 aciertos. En este caso la distribución de aciertos no sigue una distribución normal, está sesgada hacia la derecha; por tanto, los aciertos tienden hacia los valores más altos. Puede observarse que como máximo en alemán llegan a la puntuación 10 y en español se alcanza hasta el valor 15 . Obviamente son puntuaciones más altas en español que en alemán.

El siguiente gráfico ilustra la competencia fraseológica de las UF según la competencia pasiva, en la que se responde a las 30 UF restantes (Figura 27). Las frases en competencia pasiva pueden alcanzar un máximo de 30 puntos. Concretamente en alemán han alcanzado un máximo de 29; la mayor frecuencia, concretamente se encuentra en torno a cinco estudiantes, en 18, 24 y 27 aciertos. Puede observarse que la distribución del número de aciertos, en conjunto sigue una distribución sesgada hacia la derecha, indicando que mayoritariamente, en alemán, tienden a dar muchas respuestas acertadas. En español, la máxima frecuencia de respuestas se da en 8 estudiantes, con 17 respuestas acertadas, seguido de cinco estudiantes que aciertan en 24 y 27 ocasiones. En este caso la distribución de aciertos tampoco sigue una distribución normal, también está sesgada hacia la derecha; por tanto, los aciertos tienden hacia los valores más altos. En la competencia pasiva, los aciertos en alemán alcanzan una unidad fraseológica más que en español. 


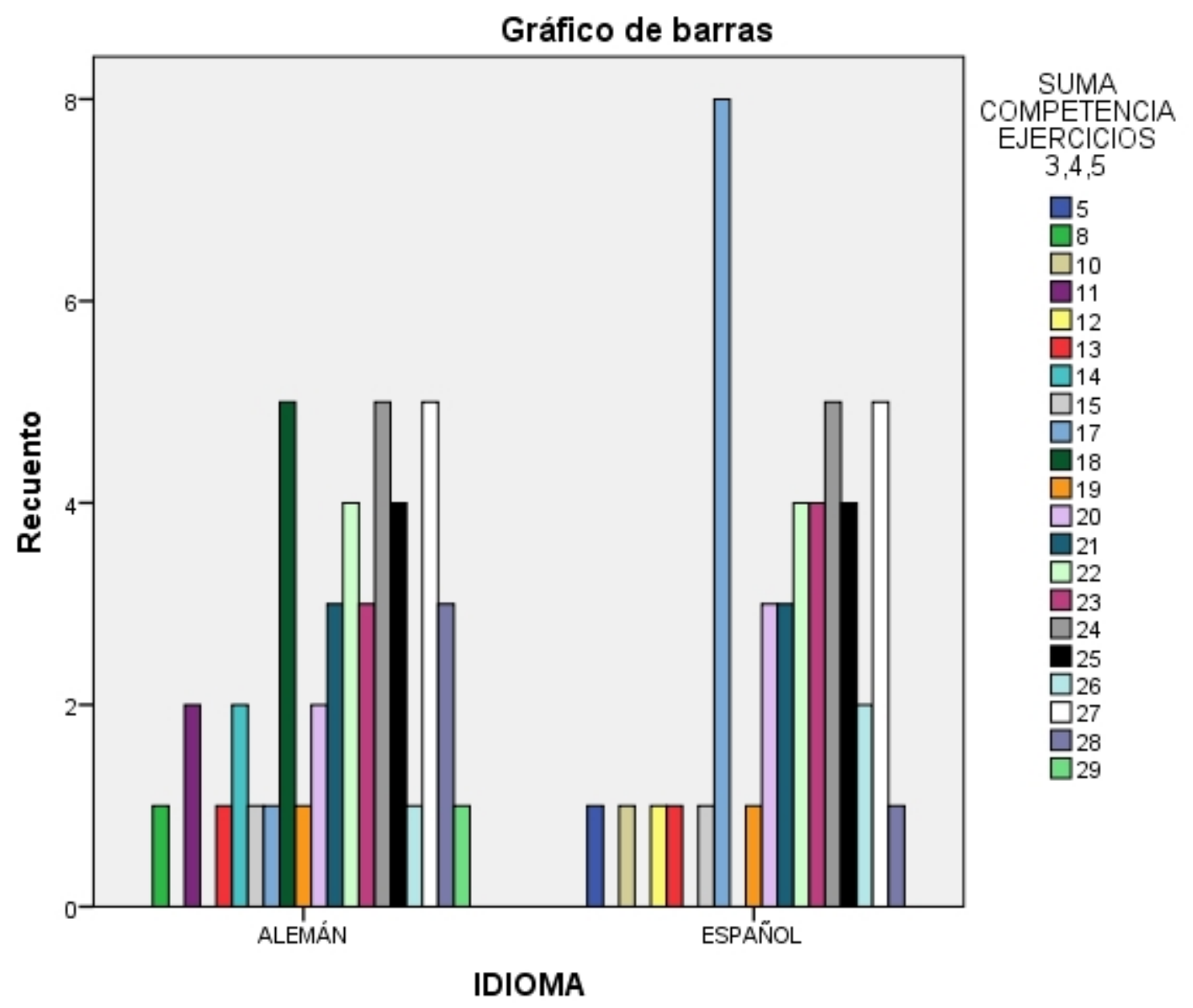

Figura 27. Nivel de competencia activa español/alemán

Como se ha observado existe diferencia de resultados según se mida la competencia activa o pasiva, siendo mejores en las dos muestras los resultados de la competencia pasiva. Esto puede considerarse habitual, pues siempre somos capaces de entender más de lo que somos capaces de producir como hablantes o aprendices de lenguas.

6.1.4. HIPÓTESIS 4: El tipo de ejercicio condiciona la competencia fraseológica que muestran los jóvenes.

Si en el apartado anterior han sido analizadas las diferencias que mostraban la competencia fraseológica activa y pasiva, en el presente apartado se examinarán los valores de competencia fraseológica específicos de cada ejercicio para comprobar si la tipología de estos puede condicionar el conocimiento fraseológico. 
Para confirmar si existen diferencias, y si estas son significativas, se ha realizado un análisis de la varianza para medidas repetidas, ya que hay más de dos grupos, cinco en este caso, y las mediciones las hace el mismo sujeto en diferentes momentos, que corresponden a cada uno de los ejercicios. En la Tabla 15 se pueden comprobar las medias alcanzadas conjuntamente en ambas lenguas en cada ejercicio.

Tabla 15. Nivel de competencia conjunta español-alemán por ejercicios: Medias

\begin{tabular}{|c|c|c|c|}
\hline \multicolumn{4}{|c|}{ Estadísticos descriptivos } \\
\hline & Media & $\begin{array}{c}\text { Desviació } \\
\text { n típica }\end{array}$ & $\mathrm{N}$ \\
\hline COMPETENCIA EJERCICIO 1 & 2,91 & 1,840 & 90 \\
\hline COMPETENCIA EJERCICIO 2 & 4,89 & 1,712 & 90 \\
\hline COMPETENCIA EJERCICIO 3 & 8,92 & 2,024 & 90 \\
\hline COMPETENCIA EJERCICIO 4 & 6,37 & 2,128 & 90 \\
\hline COMPETENCIA EJERCICIO 5 & 5,98 & 2,740 & 90 \\
\hline
\end{tabular}

Recordemos que cada ejercicio preguntaba por $10 \mathrm{UF}$, por lo que el valor máximo en este caso sería 10. Se observa que el primer ejercicio presenta la media de competencia más baja, mientras que el tercero presenta la media más alta.

En relación a las diferencias entre las cinco puntuaciones, la W de Mauchly es significativa $(\mathrm{W}=, 636$, sig. $=, 000)$, sugiriendo que si consideramos esfericidad asumida, la F de Greenhouse-Geisser es de 139,404, sig.=,000, por lo que se deduce que hay diferencias significativas entre algunas de las cinco pruebas.

Concretamente, la Tabla 16 recoge entre qué pares de ejercicios se encuentran diferencias significativas. Así, como podemos ver, las hay entre todas las comparaciones posibles por pares de ejercicios, excepto entre el ejercicio 4 y 5 , que presenta un valor sig.=,228, por tanto no significativo.

Tabla 16. Competencia conjunta por ejercicios español-alemán: Comparación por pares

Comparaciones por pares 


\begin{tabular}{|c|c|c|c|c|c|c|}
\hline \multirow[t]{2}{*}{$\begin{array}{l}\text { Medida: } \\
\text { (I)factor } \\
1\end{array}$} & \multirow[t]{2}{*}{$\begin{array}{c}\text { MEASURE_1 } \\
\text { (J)factor } \\
1\end{array}$} & \multirow[t]{2}{*}{$\begin{array}{l}\text { Diferencia de } \\
\text { medias (I-J) }\end{array}$} & \multirow[t]{2}{*}{$\begin{array}{l}\text { Error } \\
\text { típ. }\end{array}$} & \multirow[t]{2}{*}{ Sig. ${ }^{b}$} & \multicolumn{2}{|c|}{$\begin{array}{l}\text { Intervalo de confianza al } 95 \% \\
\text { para la diferencia }^{\text {b }}\end{array}$} \\
\hline & & & & & Límite inferior & $\begin{array}{l}\text { Límite } \\
\text { superior }\end{array}$ \\
\hline \multirow[t]{4}{*}{1} & 2 & $-1,978^{*}$ & ,200 &, 000 & $-2,376$ & $-1,579$ \\
\hline & 3 & $-6,011^{*}$ & ,261 &, 000 & $-6,529$ & $-5,493$ \\
\hline & 4 & $-3,456^{*}$ & 276 &, 000 & $-4,004$ & $-2,907$ \\
\hline & 5 & $-3,067^{*}$ & 281 &, 000 & $-3,625$ & $-2,509$ \\
\hline \multirow[t]{4}{*}{2} & 1 & $1,978^{*}$ & ,200 &, 000 & 1,579 & 2,376 \\
\hline & 3 & $-4,033^{*}$ & ,210 &, 000 & $-4,450$ & $-3,616$ \\
\hline & 4 & $-1,478^{*}$ & ,254 &, 000 & $-1,983$ &,- 972 \\
\hline & 5 & $-1,089^{*}$ & ,255 & ,000 & $-1,596$ &,- 582 \\
\hline \multirow[t]{4}{*}{3} & 1 & $6,011^{*}$ & ,261 &, 000 & 5,493 & 6,529 \\
\hline & 2 & $4,033^{*}$ & ,210 &, 000 & 3,616 & 4,450 \\
\hline & 4 & $2,556^{*}$ & ,230 &, 000 & 2,098 & 3,013 \\
\hline & 5 & $2,944^{*}$ & ,314 &, 000 & 2,320 & 3,569 \\
\hline \multirow[t]{4}{*}{4} & 1 & $3,456^{*}$ & ,276 &, 000 & 2,907 & 4,004 \\
\hline & 2 & $1,478^{*}$ & ,254 &, 000 & ,972 & 1,983 \\
\hline & 3 & $-2,556^{*}$ & ,230 & ,000 & $-3,013$ & $-2,098$ \\
\hline & 5 & ,389 & ,320 & ,228 &,- 247 & 1,025 \\
\hline \multirow[t]{4}{*}{5} & 1 & $3,067^{\star}$ & ,281 &, 000 & 2,509 & 3,625 \\
\hline & 2 & $1,089^{*}$ & ,255 &, 000 & ,582 & 1,596 \\
\hline & 3 & $-2,944^{*}$ & ,314 &, 000 & $-3,569$ & $-2,320$ \\
\hline & 4 &,- 389 & ,320 & 228 & $-1,025$ & ,247 \\
\hline
\end{tabular}

Basadas en las medias marginales estimadas.

*. La diferencia de medias es significativa al nivel, 05 .

b. Ajuste para comparaciones múltiples: Diferencia menos significativa (equivalente a la ausencia de ajuste).

La Figura 28 muestra la evolución de las medias marginales estimadas para los cinco ejercicios, donde se aprecia de manera muy clara la diferencia de competencia obtenida en cada uno de los ejercicios. 


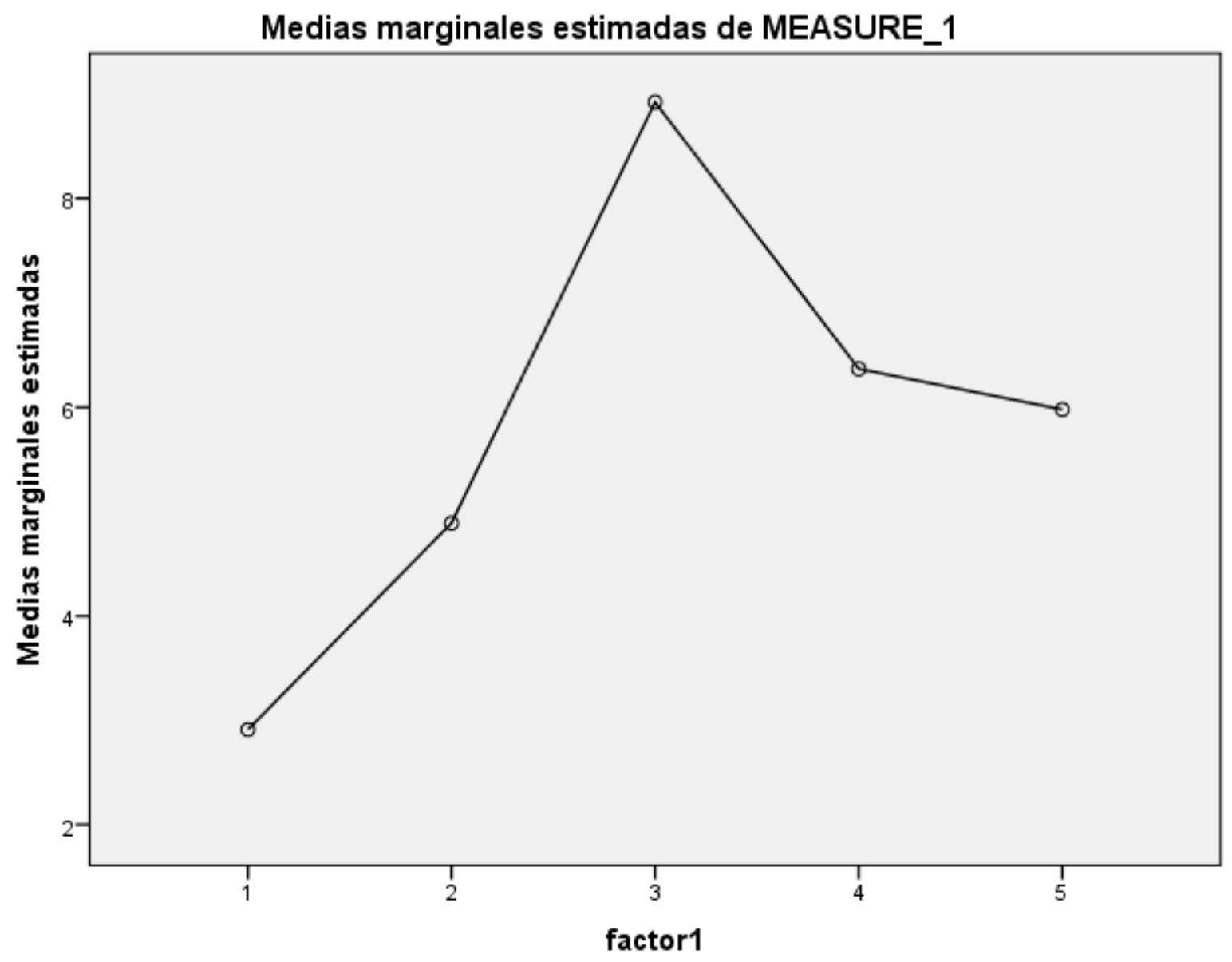

Figura 28. Nivel de competencia conjunta español-alemán por ejercicios: Medias marginales

A continuación procedemos a observar los resultados que obtienen los alumnos por lenguas, primero en español y posteriormente en alemán. Para comprobar si existen diferencias significativas se ha utilizado un análisis de la varianza para medidas repetidas. En la Tabla 17 pueden comprobarse las medias alcanzadas en español.

Tabla 17. Nivel de competencia por ejercicios en español: Medias

\begin{tabular}{lrrr}
\hline \multicolumn{4}{c}{ Estadísticos descriptivos $^{\text {a }}$} \\
& \multicolumn{4}{c}{ Media } & Desviación típica & $\mathrm{N}$ \\
COMPETENCIA EJERCICIO 1 & 3,82 & 1,992 & 45 \\
COMPETENCIA EJERCICIO 2 & 5,22 & 1,882 & 45 \\
COMPETENCIA EJERCICIO 3 & 8,60 & 2,406 & 45 \\
COMPETENCIA EJERCICIO 4 & 5,78 & 2,204 & 45 \\
COMPETENCIA EJERCICIO 5 & 6,69 & 2,076 & 45 \\
a. IDIOMA = ESPAÑOL & & & \\
\hline
\end{tabular}


Al igual que en los resultados conjuntos, observamos que el ejercicio 1 presenta el valor más bajo y el 3 el más alto entre los escolares españoles. Entre ambos valores extremos se encuentran los demás, muy cercanos, como puede verse, entre los ejercicios 2 y 4 , y algo más elevados en el 5 .

En relación con las diferencias entre las cinco puntuaciones en español se observa que la $W$ de Mauchly no es significativa $(W=, 790$, sig.=,352), sugiriendo con ello que no hay esfericidad. A partir de esto, se ha utilizado la prueba $\mathrm{F}$ multivariada, que es de 53,604 , sig. $=, 000$, por lo que se observa que si hay diferencias significativas entre algunas de las cinco pruebas. Concretamente, la Tabla 18 recoge entre qué pares de ejercicios se encuentran diferencias significativas en español entre todas las comparaciones posibles por pares.

Tabla 18. Nivel de competencia por ejercicios en español: Comparación por pares

\begin{tabular}{|c|c|c|c|c|c|c|}
\hline \multicolumn{7}{|c|}{ Comparaciones por pares ${ }^{a}$} \\
\hline \multirow[t]{2}{*}{$\begin{array}{l}\text { Medida: } \\
\text { (I)fact } \\
\text { or1 }\end{array}$} & \multirow[t]{2}{*}{$\begin{array}{l}\text { MEASURE_1 } \\
\text { (J)fact } \\
\text { or1 }\end{array}$} & \multirow[t]{2}{*}{$\begin{array}{c}\text { Diferencia de } \\
\text { medias (I-J) }\end{array}$} & \multirow[t]{2}{*}{ Error típ. } & \multirow[t]{2}{*}{ Sig. $^{\mathrm{c}}$} & \multicolumn{2}{|c|}{$\begin{array}{l}\text { Intervalo de confianza al } 95 \% \text { para } \\
\qquad \text { la diferencia }^{c}\end{array}$} \\
\hline & & & & & Límite inferior & Límite superior \\
\hline \multirow[t]{4}{*}{1} & 2 & $-1,400^{*}$ & ,310 &, 000 & $-2,026$ &,- 774 \\
\hline & 3 & $-4,778^{*}$ & ,366 &, 000 & $-5,516$ & $-4,039$ \\
\hline & 4 & $-1,956^{*}$ & ,350 &, 000 & $-2,660$ & $-1,251$ \\
\hline & 5 & $-2,867^{*}$ & ,369 &, 000 & $-3,610$ & $-2,124$ \\
\hline \multirow[t]{4}{*}{2} & 1 & $1,400^{*}$ & ,310 &, 000 &, 774 & 2,026 \\
\hline & 3 & $-3,378^{*}$ & ,281 &, 000 & $-3,945$ & $-2,811$ \\
\hline & 4 &,- 556 & ,345 &, 114 & $-1,250$ & ,139 \\
\hline & 5 & $-1,467^{*}$ & ,348 &, 000 & $-2,167$ &,- 766 \\
\hline \multirow[t]{4}{*}{3} & 1 & $4,778^{*}$ &, 366 &, 000 & 4,039 & 5,516 \\
\hline & 2 & $3,378^{*}$ & ,281 &, 000 & 2,811 & 3,945 \\
\hline & 4 & $2,822^{*}$ & ,343 &, 000 & 2,131 & 3,513 \\
\hline & 5 & $1,911^{*}$ & ,406 &, 000 & 1,094 & 2,728 \\
\hline \multirow[t]{4}{*}{4} & 1 & $1,956^{*}$ & ,350 & ,000 & 1,251 & 2,660 \\
\hline & 2 &, 556 & ,345 & ,114 &,- 139 & 1,250 \\
\hline & 3 & $-2,822^{*}$ & ,343 & ,000 & $-3,513$ & $-2,131$ \\
\hline & 5 &,$- 911^{*}$ & ,399 & ,027 & $-1,716$ &,- 106 \\
\hline \multirow[t]{2}{*}{5} & 1 & $2,867^{*}$ & ,369 &, 000 & 2,124 & 3,610 \\
\hline & 2 & $1,467^{*}$ & 348 & ,000 & ,766 & 2,167 \\
\hline
\end{tabular}




\begin{tabular}{rrrrrr}
\hline 3 & $-1,911^{*}$ &, 406 &, 000 & $-2,728$ & $-1,094$ \\
4 &, $911^{*}$ &, 399 &, 027 &, 106 & 1,716 \\
\hline
\end{tabular}

Basadas en las medias marginales estimadas.

*. La diferencia de medias es significativa al nivel

a. IDIOMA = ESPAÑOL

c. Ajuste para comparaciones múltiples: Diferencia menos significativa (equivalente a la ausencia de ajuste).

$Y$, en efecto, se observan diferencias significativas en español entre todos los ejercicios, a excepción de los ejercicios 2 y 4, comparación que presenta un valor estadísticamente no significativo (sig.=,114).

A continuación mostramos la representación gráfica de la muestra española (Figura 29):

\section{Medias marginales estimadas de MEASURE_1}

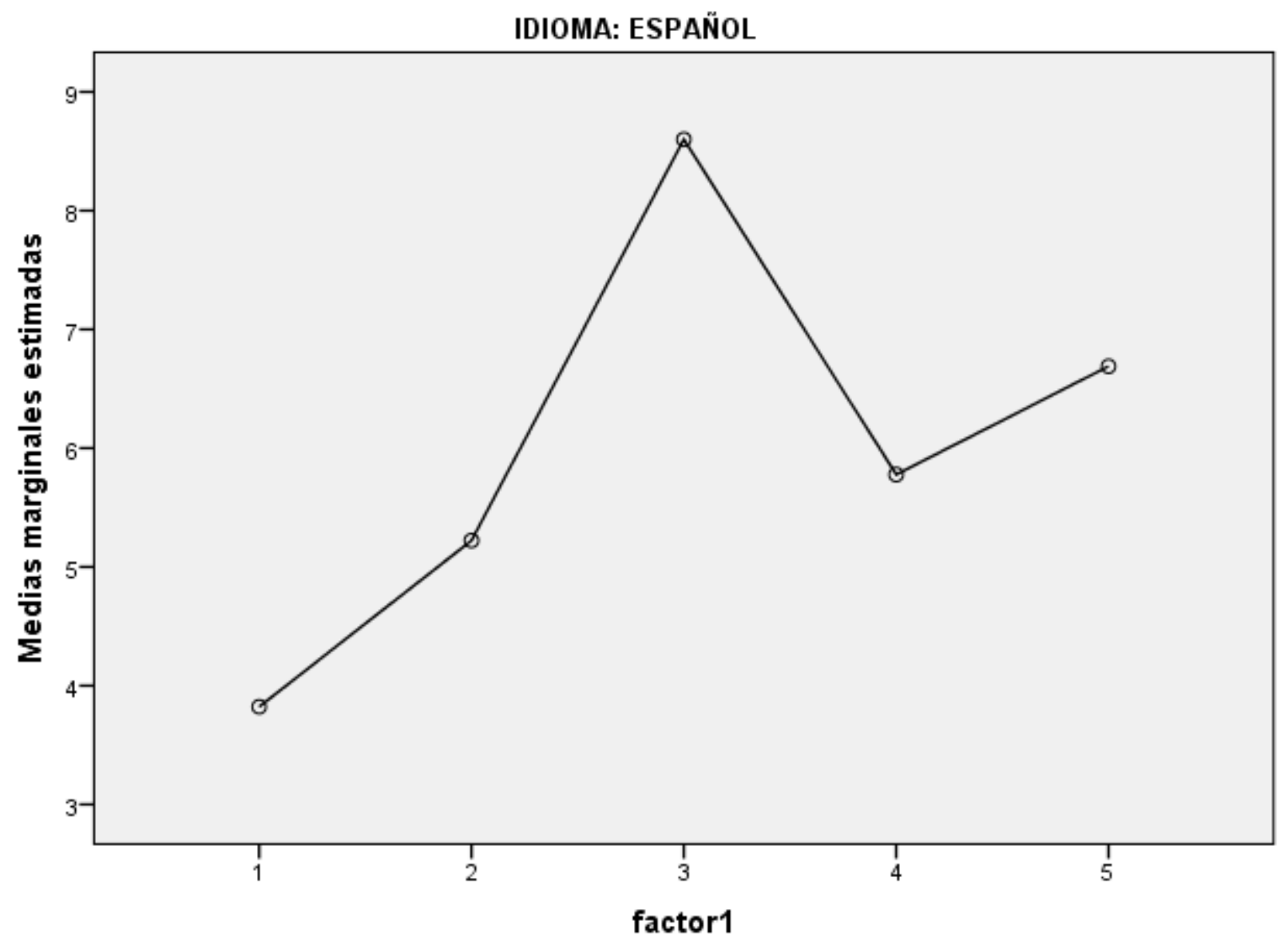

Figura 29. Nivel de competencia en español por ejercicios: Medias marginales 
Como se observa en la Figura 29, los valores de los ejercicios 2 y 4 son los que, efectivamente, se encuentran más cercanos entre sí, y aquellos de los que no hemos obtenido una diferencia significativa en la comunidad española, a diferencia del resto de ejercicios mucho más distanciados entre sí.

Como en el caso español, para la población alemana se ha realizado también un análisis de la varianza para medidas repetidas porque disponemos de más de dos grupos, y las mediciones las hace el mismo individuo en cada ejercicio. En la Tabla 19 pueden comprobarse las medias alcanzadas en esta lengua.

Tabla 19. Nivel de competencia por ejercicios alemán: Medias

\begin{tabular}{lrrr}
\hline \multicolumn{4}{c}{ Estadísticos descriptivos $^{\text {a }}$} \\
& Media & Desviación típica & \\
COMPETENCIA EJERCICIO 1 & 2,00 & 1,087 & 45 \\
COMPETENCIA EJERCICIO 2 & 4,56 & 1,470 & 45 \\
COMPETENCIA EJERCICIO 3 & 9,24 & 1,510 & 45 \\
COMPETENCIA EJERCICIO 4 & 6,96 & 1,894 & 45 \\
COMPETENCIA EJERCICIO 5 & 5,27 & 3,136 & 45 \\
\hline
\end{tabular}

a. IDIOMA = ALEMÁN

Se observa que el ejercicio 1 tiene el valor más bajo y el ejercicio 3 el más alto, tal y como se había observado también en español. Por su parte, los ejercicios 2 y 5 presentan valores cercanos, y el ejercicio 4 se sitúa entre estos y el ejercicio 3.

En relación con las diferencias entre las cinco puntuaciones en alemán, se comprueba que la $W$ de Mauchly es significativa ( $W=, 481$, sig.=,000), sugiriendo que hay esfericidad. En este caso utilizamos la $F$ de GreenhouseGeisser, que es de 1317,662, sig.=,000, por lo que sí hay diferencias significativas entre algunas de las cinco pruebas. Concretamente, la Tabla 20 recoge entre qué pares de ejercicios encuentra diferencias significativas en alemán entre todas las comparaciones posibles por pares. 
Tabla 20. Nivel de competencia por ejercicios alemán: Comparación por pares

\begin{tabular}{|c|c|c|c|c|c|c|}
\hline \multicolumn{7}{|c|}{ Comparaciones por pares ${ }^{a}$} \\
\hline \multirow[t]{2}{*}{$\begin{array}{l}\text { Medida: } \\
\text { (I)fact } \\
\text { or1 }\end{array}$} & \multirow[t]{2}{*}{$\begin{array}{l}\text { MEASURE_1 } \\
\text { (J)fact } \\
\text { or1 }\end{array}$} & \multirow[t]{2}{*}{$\begin{array}{l}\text { Diferencia de } \\
\text { medias (I-J) }\end{array}$} & \multirow[t]{2}{*}{ Error típ. } & \multirow[t]{2}{*}{ Sig. ${ }^{\mathrm{C}}$} & \multicolumn{2}{|c|}{$\begin{array}{l}\text { Intervalo de confianza al } 95 \% \text { para } \\
\text { la diferencia }{ }^{c}\end{array}$} \\
\hline & & & & & Límite inferior & Límite superior \\
\hline \multirow[t]{4}{*}{1} & 2 & $-2,556^{*}$ & ,226 &, 000 & $-3,011$ & $-2,100$ \\
\hline & 3 & $-7,244^{*}$ & ,268 &, 000 & $-7,785$ & $-6,704$ \\
\hline & 4 & $-4,956^{*}$ & 289 &, 000 & $-5,539$ & $-4,372$ \\
\hline & 5 & $-3,267^{*}$ & ,426 &, 000 & $-4,125$ & $-2,409$ \\
\hline \multirow[t]{4}{*}{2} & 1 & $2,556^{*}$ & ,226 &, 000 & 2,100 & 3,011 \\
\hline & 3 & $-4,689^{*}$ & 282 &, 000 & $-5,258$ & $-4,120$ \\
\hline & 4 & $-2,400^{*}$ & ,323 &, 000 & $-3,051$ & $-1,749$ \\
\hline & 5 &,- 711 & ,369 &, 060 & $-1,454$ & ,032 \\
\hline \multirow[t]{4}{*}{3} & 1 & $7,244^{*}$ & ,268 &, 000 & 6,704 & 7,785 \\
\hline & 2 & $4,689^{*}$ & 282 &, 000 & 4,120 & 5,258 \\
\hline & 4 & $2,289^{*}$ & ,306 &, 000 & 1,672 & 2,905 \\
\hline & 5 & $3,978^{*}$ & ,432 &, 000 & 3,108 & 4,848 \\
\hline \multirow[t]{4}{*}{4} & 1 & $4,956^{*}$ & 289 & ,000 & 4,372 & 5,539 \\
\hline & 2 & $2,400^{*}$ & ,323 & ,000 & 1,749 & 3,051 \\
\hline & 3 & $-2,289^{*}$ & ,306 &, 000 & $-2,905$ & $-1,672$ \\
\hline & 5 & $1,689^{*}$ & ,423 &, 000 & ,837 & 2,541 \\
\hline \multirow[t]{4}{*}{5} & 1 & $3,267^{*}$ & ,426 &, 000 & 2,409 & 4,125 \\
\hline & 2 & ,711 & 369 &, 060 &,- 032 & 1,454 \\
\hline & 3 & $-3,978^{*}$ & ,432 &, 000 & $-4,848$ & $-3,108$ \\
\hline & 4 & $-1,689^{*}$ & 423 & ,000 & $-2,541$ &,- 837 \\
\hline
\end{tabular}

Basadas en las medias marginales estimadas.

*. La diferencia de medias es significativa al nivel

a. IDIOMA = ALEMÁN

c. Ajuste para comparaciones múltiples: Diferencia menos significativa (equivalente a la ausencia de ajuste).

Como se puede apreciar en la tabla, en la comunidad alemana se observan diferencias significativas entre todos los ejercicios, a excepción del ejercicio 2 y 5 .

La siguiente figura (Figura 30) representa estos resultados de manera más gráfica: 


\section{Medias marginales estimadas de MEASURE_1}

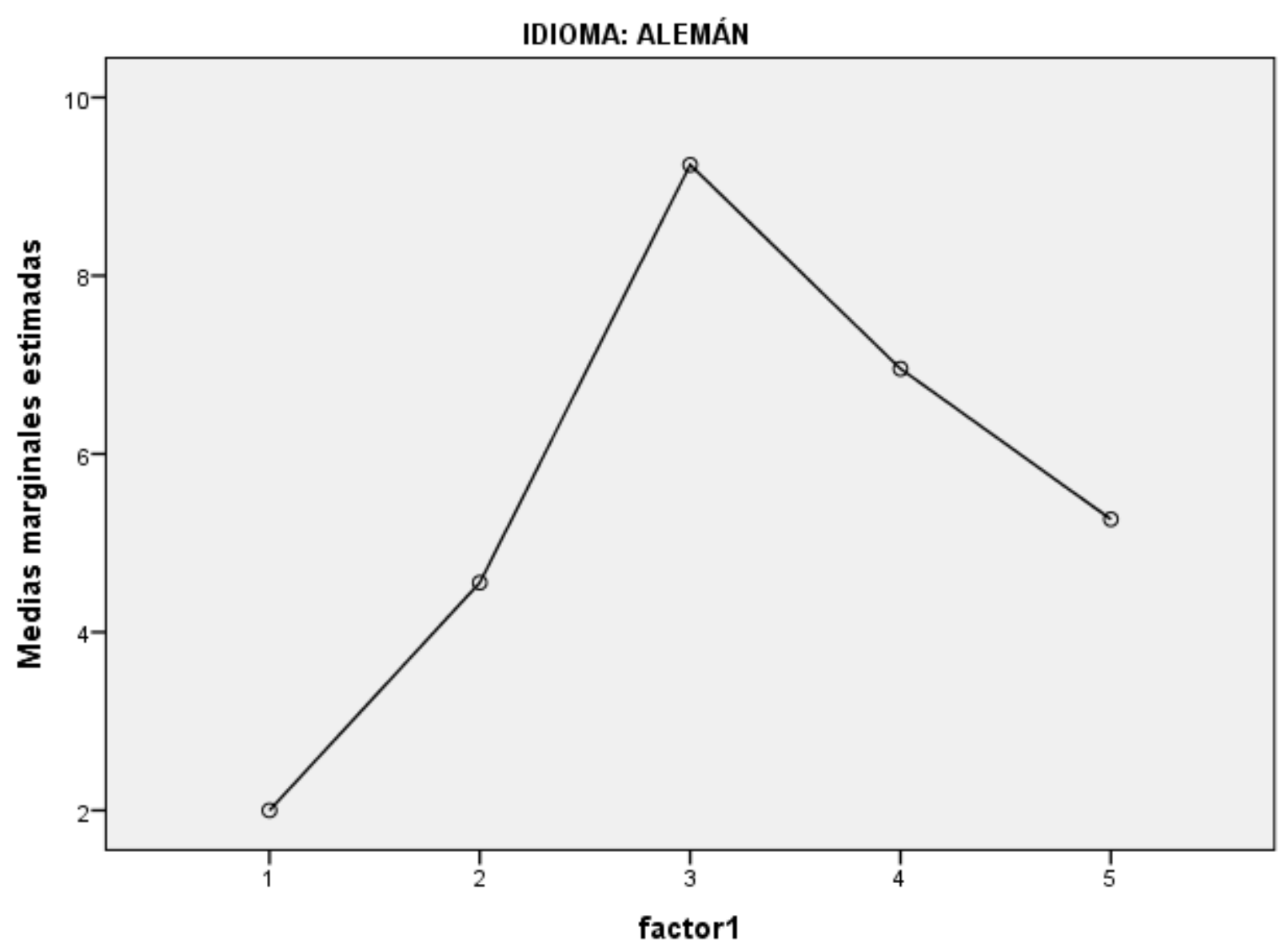

Figura 30: Nivel de competencia en alemán por ejercicios: Medias marginales

Como se observa, los valores correspondientes a los ejercicios 2 y 5 están muy cercanos en alemán, mientras que en español los más cercanos eran los valores de los ejercicios 2 y 4 .

En resumen, de los datos analizados podemos concluir que existen diferencias significativas entre unos ejercicios y otros, tanto en términos generales como por muestras (español y alemán).

6.1.5. HIPÓTESIS 5: la adscripción temática de las UF determina diferencias en la competencia. 
Otro aspecto que nos parecía interesante investigar era el que desarrolla la presente hipótesis, es decir, si el contenido temático o conceptual ${ }^{89}$ de las UF podía influir en la competencia fraseológica que mostraban los jóvenes y si esto se observaba de manera similar en las dos lenguas. Para ello establecimos los siguientes grupos temáticos, formados por un número diferente de UF:
1. otros (1 UF)
2. zoologismos (9 UF)
3. somatismos (19 UF)
4. experiencia humana (16 UF)
5. herencia cultural (5 UF)

A continuación recordaremos las UF que integraban cada uno de los grupos:

1. Otros: En este grupo se encuentra la UF41, por las peculiaridades de equivalencia explicadas anteriormente (cf. $\S 5.2$ ), es decir, debería adscribirse en cada lengua a un grupo diferente de los delimitados aquí, de manera que en español corresponde al grupo de experiencia humana, mientras que en alemán es un zoologismo:

UF41 hacer una montaña de un grano de arena a aus einer Mücke einen Elefanten machen

Cuadro 21. UF por grupos temáticos: Otros

2. Zoologismos: Denominados también zoomorfismos en la fraseología española, se trata de UF referidas a animales o en las que aparece algún elemento del mundo animal. En nuestro corpus son zoologismos las siguientes UF: UF1, UF3, UF15, UF23, UF24, UF26, UF42, UF45 y UF46:

\footnotetext{
${ }^{89}$ Recordemos que la distribución de las UF en los ejercicios se ha hecho de manera aleatoria, sin realizar agrupaciones apriorísticas de ningún tipo. La delimitación de los grupos pretende ser una mera herramienta para comparar si el comportamiento de las dos muestras es similar.
} 
UF1 poner los cuernos $\approx$ Hörner aufsetzen

UF3 como el perro y el gato wie Hund und Katze

UF15 matar dos pájaros de un tiro z zwei Fliegen mit einer Klappe schlagen

UF23 ser la oveja negra de la familia das schwarze Schaf der Familie sein

UF24 ser un lobo con la piel de cordero ein Wolf im Schafspelz sein

UF26 no ser carne ni pescado $\approx$ weder Fisch noch Fleisch

UF42 tener gato encerrado $\approx$ die Katze im Sack kaufen

UF45 coger el toro por los cuernos $\approx$ den Stier bei den Hörnern packen

UF46 ser pobre como una rata arm wie ein Kirchenmaus sein

Cuadro 22. UF por grupos temáticos: Zoologismos

3. Somatismos: Se trata de UF referidas al cuerpo humano. En el corpus son somatismos las UF siguientes: UF2, UF4, UF5, UF9, UF10, UF14, UF18, UF25, UF28, UF32, UF34, UF36, UF37, UF39, UF40, UF43, UF48, UF49 y UF50.

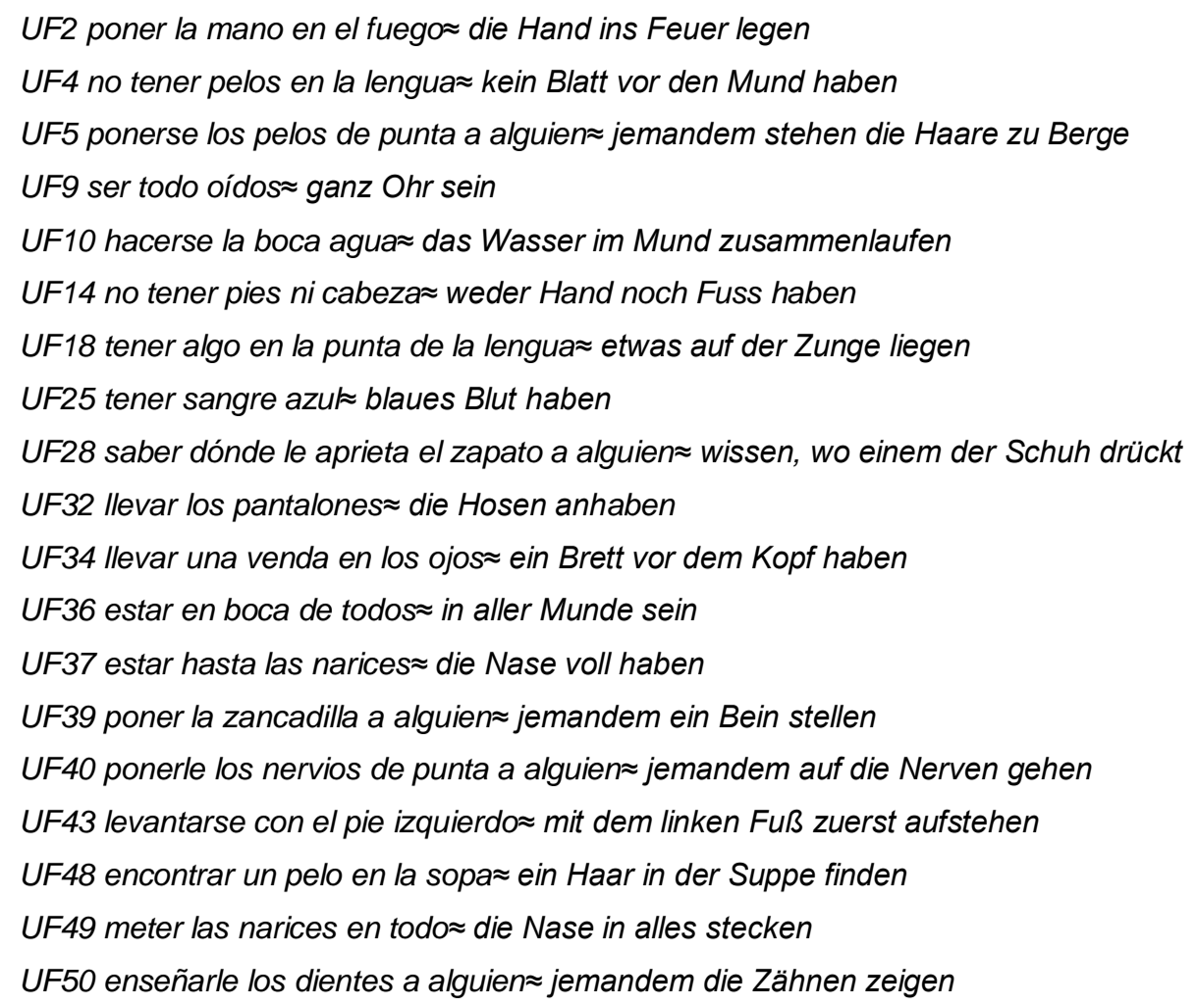

Cuadro 23. UF por grupos temáticos: Somatismos 
4. Experiencia humana: Este grupo está configurado por UF relacionadas con la vida cotidiana, observación de la naturaleza, que hemos denominado experiencia humana en general. Lo integran las UF que siguen: UF7, UF11, UF12, UF13, UF16, UF17, UF19, UF20, UF21, UF22, UF27, UF29, UF31, UF33, UF38 y UF44.

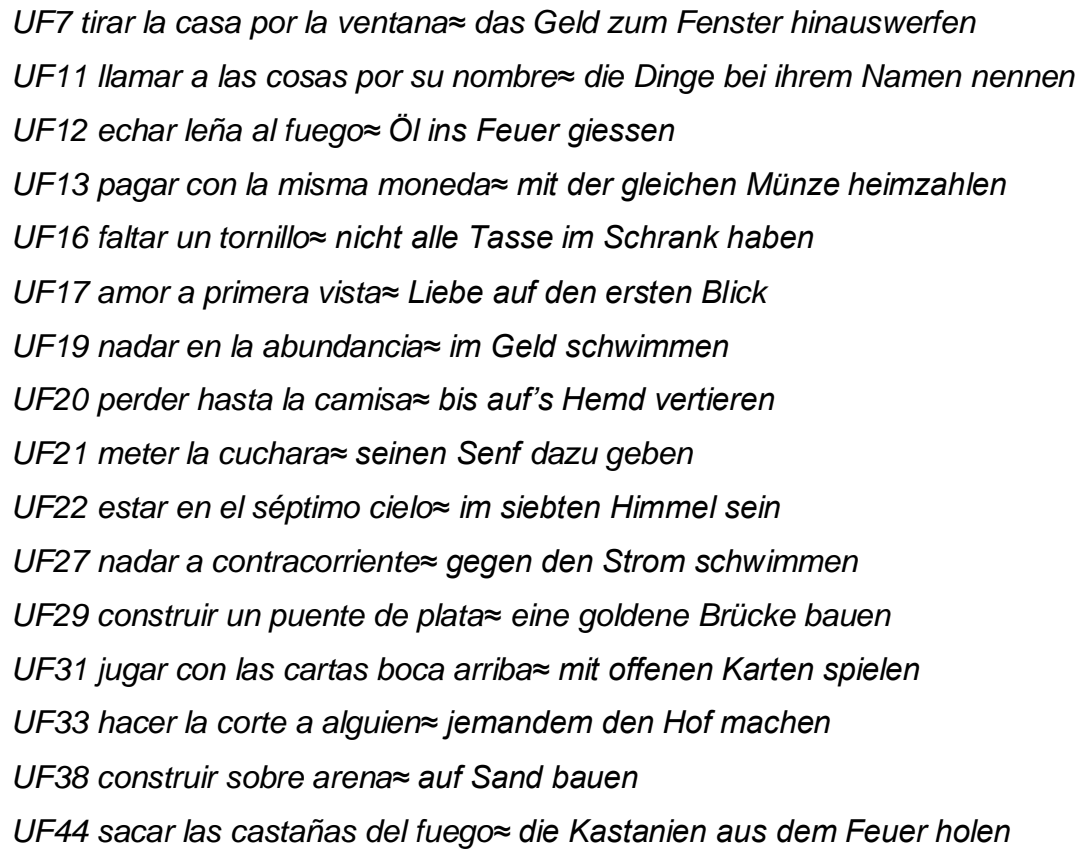

Cuadro 24. UF por grupos temáticos: Experiencia humana

5. Herencia cultural: Se halla formado por UF que tienen raíces culturales (históricas, científicas, literarias, etc.) que, a diferencia de las anteriores, no están relacionadas con la naturaleza intrínsecamente, sino que son más bien el fruto de la creación cultural debida al ser humano. Son las UF6, UF8, UF30, UF35, UF47.

\footnotetext{
UF6 descubrir la pólvora d die Pulver erfunden zu haben

UF8 sonar a chino $\approx$ Spanisch vorkommen

UF30 perder el hilo $\approx$ den Faden verlieren

UF35 ser el cuento de la lechera eine Milchmädchenrechnung sein

UF47 echar tierra en los ojos a alguien $\approx$ jemandem Sand in die Augen streuen
}

Cuadro 25. UF por grupos temáticos: Herencia cultural 
Para ver si la adscripción de las UF a estos grupos temáticos podía determinar la competencia y establecer diferencias, se procede a la comprobación mediante la prueba T-Student para muestras independientes. La Tabla 21 muestra las medias para cada caso considerado. Hemos indicado entre paréntesis al lado de cada grupo el número de UF que lo integran.

Tabla 21. Competencia conjunta español-alemán por grupos temáticos: Medias

\begin{tabular}{|c|c|c|c|c|c|}
\hline \multicolumn{6}{|c|}{ Estadísticos de grupo } \\
\hline & IDIOMA & $\mathrm{N}$ & Media & $\begin{array}{c}\text { Desviación } \\
\text { típ. }\end{array}$ & $\begin{array}{l}\text { Error típ. de } \\
\text { la media }\end{array}$ \\
\hline OTROS (UF41) & ALEMÁN & 45 & 80 & ,405 & ,060 \\
\hline$(T=1)$ & ESPAÑOL & 45 & 80 & ,405 & ,060 \\
\hline ZOOLOGISMOS & ALEMÁN & 45 & 4,4667 & 1,71358 & 25545 \\
\hline$(T=9)$ & ESPAÑOL & 45 & 6,4000 & 1,80151 & ,26855 \\
\hline SOMATISMOS & ALEMÁN & 45 & 11,3333 & 2,79610 & ,41682 \\
\hline$(T=19)$ & ESPAÑOL & 45 & 11,8667 & 3,23756 & ,48263 \\
\hline EXPERIENCIA HUMANA & ALEMÁN & 45 & 9,9778 & 2,35959 & ,35175 \\
\hline$(T=16)$ & ESPAÑOL & 45 & 8,8222 & 2,61368 & ,38962 \\
\hline HERENCIA CULTURAL & ALEMÁN & 45 & 1,4444 & ,72474 & ,10804 \\
\hline$(T=5)$ & ESPAÑOL & 45 & 2,2222 & 1,16558 & , 17375 \\
\hline
\end{tabular}

Como se observa, las medias para español y alemán son distintas en cada unos de los grupos, excepto en el primero (Otros: UF41), en que aparece la misma en las dos muestras.

Para ver si estas diferencias son significativas, observamos el estadístico de contraste a continuación:

Tabla 22. Competencia conjunta español-alemán por grupos temáticos: Prueba T-Student

\begin{tabular}{lrr}
\hline & \multicolumn{1}{c}{ T-Student } & \multicolumn{1}{c}{ Sig. } \\
\hline Otros UF 41 &, 000 & 1,000 \\
Zoologismos & $-5,216$ &, 000 \\
Somatismos &,- 836 &, 405 \\
Experiencia Humana & 2,201 &, 030 \\
Herencia Cultural & $-3,801$ &, 000 \\
\hline
\end{tabular}


Como se advierte en la tabla, las diferencias de competencia entre las muestras no son siempre significativas. Para ello, vamos a retomar cada una de las subhipótesis planteadas para cada grupo y comentaremos los resultados.

Hipótesis 5.1. Las UF del par no adscrito al mismo grupo temático en ambas lenguas presentan un nivel de competencia diferente en las dos lenguas. Por el contrario, comprobamos que en este caso no se muestra diferencia significativa alguna entre las muestras, pues la prueba $T$ ofrece un valor único (sig.=1), lo que significa que la competencia sobre esta UF en español y alemán es idéntica.

Hipótesis 5.2. Los zoologismos presentan un nivel de competencia diferente en las dos lenguas. $Y$, en efecto, esta vez observamos que la diferencia entre las muestras es, efectivamente, significativa (sig.=,000).

Hipótesis 5.3. El grupo de UF denominadas somatismos muestra un nivel de competencia diferente en las dos lenguas. Sin embargo, en este caso, y al igual que ocurriera con la UF41, se observa que la diferencia no es significativa entre la muestra española y la alemana (sig.=,405).

Hipótesis 5.4. Las UF referidas a la experiencia humana presentan un nivel de competencia diferente en las dos lenguas, que resulta significativa (sig.=,030).

Hipótesis 5.5. Las UF que se refieren a la herencia cultural presentan un nivel de competencia diferente en las dos lenguas, lo que viene confirmado por nuestros datos (sig. $=, 000)$.

Así pues, son diferentes y significativos los resultados de los grupos integrados por zoologismos, experiencia humana y herencia cultural. El resto no muestra diferencias significativas.

Si observamos ahora los datos específicos por idioma, obtenemos los siguientes resultados (Tabla 23 ): 
Tabla 23. Competencia en español por grupos temáticos: Medias

\begin{tabular}{lrrr}
\hline \multicolumn{4}{c}{ Estadísticos descriptivos $^{\mathrm{a}}$} \\
& Media & $\begin{array}{c}\text { Desviación } \\
\text { típica }\end{array}$ & $\mathrm{N}$ \\
OTROS (UF41) &, 80 &, 405 & 45 \\
ZOOLOGISMOS & 6,4000 & 1,80151 & 45 \\
SOMATISMOS & 11,8667 & 3,23756 & 45 \\
EXPERIENCIA & 8,8222 & 2,61368 & 45 \\
HUMANA & & & \\
HERENCIA & 2,2222 & 1,16558 & 45 \\
CULTURAL & & & \\
\hline
\end{tabular}

a. IDIOMA = ESPAÑOL

En cuanto a la significación de los datos obtenidos, observamos en los análisis que el estadístico W de Mauchly es significativo (=,239, sig.=,000), por lo que se deduce que sí son reveladoras las diferencias de medias entre los diferentes grupos temáticos en español. Lo confirmamos mediante el estadísco Greenhouse-Geisser y la $F=347,724$, sig.=,000, que también validan el primer resultado.

La comparación más específica entre cada uno de estos gruos se aprecia en la Tabla 24:

Tabla 24. Comparaciones por pares de los grupos en español

\begin{tabular}{|c|c|c|c|c|}
\hline (I)factor & (J)factor & Diferencia de & Error & Sig. $^{\mathrm{c}}$ \\
\hline 1 & 1 & medias (I-J) & típ. & \\
\hline \multirow[t]{4}{*}{1} & 2 & $-5,600^{*}$ & ,251 &, 000 \\
\hline & 3 & $-11,067^{*}$ & ,462 &, 000 \\
\hline & 4 & $-8,022^{*}$ & ,377 &, 000 \\
\hline & 5 & $-1,422^{*}$ & , 170 &, 000 \\
\hline \multirow[t]{4}{*}{2} & 1 & $5,600^{*}$ & ,251 &, 000 \\
\hline & 3 & $-5,467^{*}$ & ,407 & ,000 \\
\hline & 4 & $-2,422^{*}$ & ,312 &, 000 \\
\hline & 5 & $4,178^{*}$ & ,274 &, 000 \\
\hline \multirow[t]{2}{*}{3} & 1 & $11,067^{*}$ & ,462 &, 000 \\
\hline & 2 & $5,467^{*}$ & ,407 &, 000 \\
\hline
\end{tabular}




\begin{tabular}{ccccc}
\hline & 4 & $3,044^{*}$ &, 339 &, 000 \\
& 5 & $9,644^{*}$ &, 423 &, 000 \\
& 1 & $8,022^{*}$ &, 377 &, 000 \\
& 2 & $2,422^{*}$ &, 312 &, 000 \\
& 3 & $-3,044^{*}$ &, 339 &, 000 \\
& 5 & $6,600^{*}$ &, 356 &, 000 \\
& 5 & $1,422^{*}$ &, 170 &, 000 \\
& 1 & $-4,178^{*}$ &, 274 &, 000 \\
& 2 & $-9,644^{*}$ &, 423 &, 000 \\
& 3 & $-6,600^{*}$ &, 356 &, 000 \\
\hline
\end{tabular}

Si comparamos los resultados de todos los grupos entre sí, observamos cómo, en efecto, todos presentan valores significativos (sig.=,000).

A continuación presentamos gráficamente la situación en español donde se aprecian muy bien las diferencias entre los diferentes grupos temáticos (Figura 31):

\section{Medias marginales estimadas de MEASURE_1}

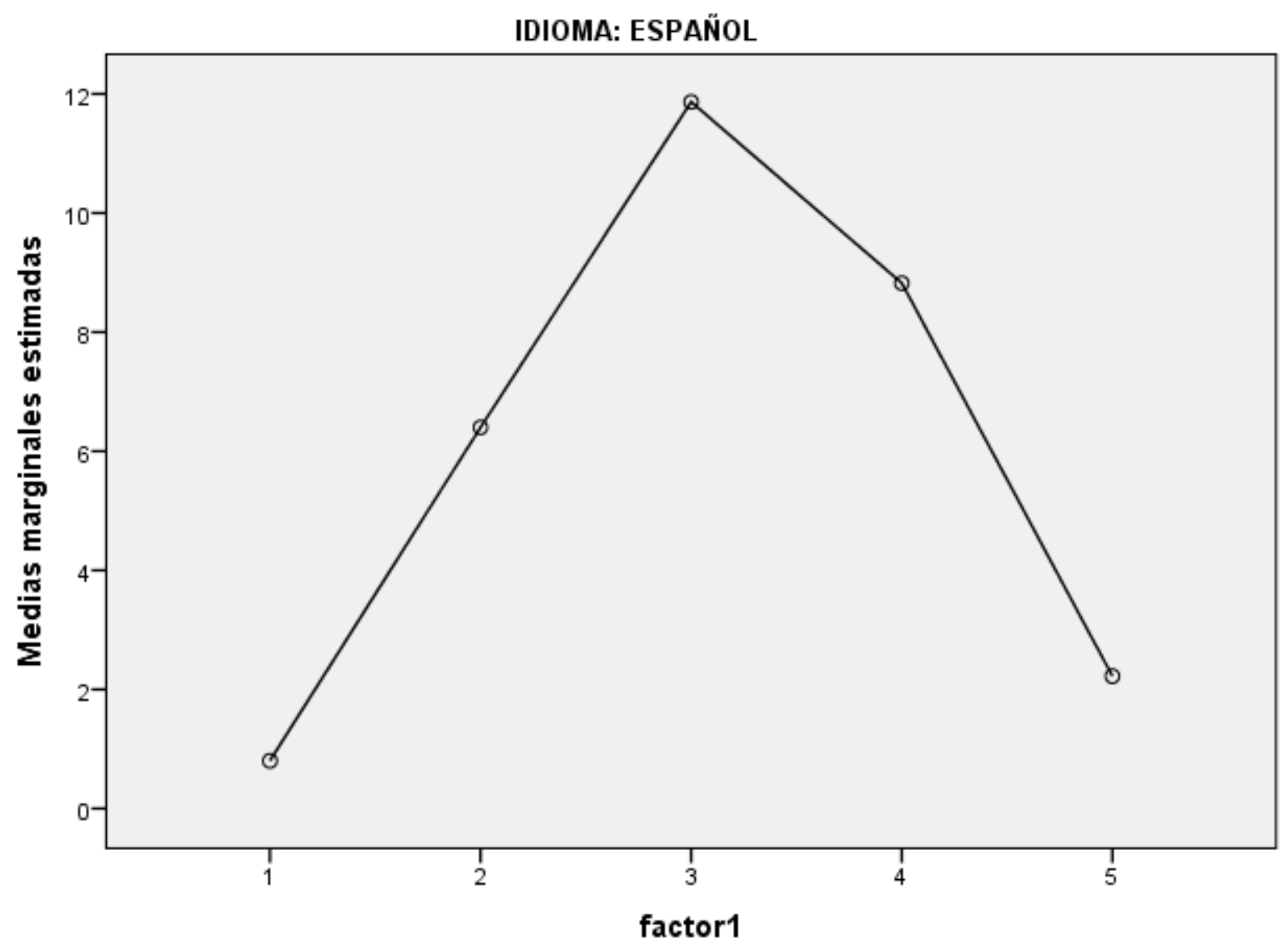

Figura 31. Competencia por grupos temáticos: español 
Finalizaremos el análisis de la hipótesis 5 observando los datos que nos ofrece la muestra alemana. La presentación se inicia con las medias obtenidas en cada uno de los grupos temáticos (Tabla 25):

Tabla 25. Competencia en alemán por grupos temáticos: Medias

\begin{tabular}{lrrr}
\hline \multicolumn{4}{c}{ Estadísticos descriptivos $^{\mathrm{a}}$} \\
& \multicolumn{3}{c}{$\begin{array}{c}\text { Media } \\
\text { Desviación } \\
\text { típica }\end{array}$} \\
OTROS (UF41) &, 80 &, 405 & 45 \\
ZOOLOGISMOS & 4,4667 & 1,71358 & 45 \\
SOMATISMOS & 11,3333 & 2,79610 & 45 \\
EXPERIENCIA HUMANA & 9,9778 & 2,35959 & 45 \\
HERENCIA CULTURAL & 1,4444 &, 72474 & 45 \\
\hline
\end{tabular}

a. IDIOMA = ALEMÁN

Como se observa en la tabla, las medias obtenidas en los distintos grupos son muy diferentes. Coinciden en español y en alemán los resultados que ofrece la UF41, ya comentado también a propósito de la Hipótesis 2. Comprobamos ahora si los resultados son significativos, por medio de los valores que nos ofrecen diversos estadísticos, como la $\mathrm{F}=233$, sig.=,000, y la W de Mauchly $=, 209$, sig. $=, 000$, así como la prueba Greenhouse-Geisser: $F=497,955$, sig.=,000. De todos estos resultados se deduce que sí son significativas las diferencias de medias observadas entre los grupos temáticos en alemán, al igual que lo eran en las comparaciones anteriores en la muestra conjunta español-alemán y español.

A continuación (Tabla 26) ofrecemos las comparaciones intergrupales en la comunidad alemana.

Tabla 26. Comparaciones por pares de los grupos en alemán

\begin{tabular}{|c|c|c|c|c|c|}
\hline \multicolumn{6}{|c|}{ Comparaciones por pares ${ }^{a}$} \\
\hline $\begin{array}{l}\text { (I)factor } \\
1\end{array}$ & $\begin{array}{l}\text { (J)factor } \\
1\end{array}$ & $\begin{array}{l}\text { Diferencia de } \\
\text { medias (I-J) }\end{array}$ & $\begin{array}{c}\text { Error } \\
\text { típ. }\end{array}$ & Sig. ${ }^{\mathrm{C}}$ & $\begin{array}{c}\text { Intervalo de confianza al } 95 \% \\
\text { para la diferencia }{ }^{c}\end{array}$ \\
\hline
\end{tabular}




\begin{tabular}{|c|c|c|c|c|c|c|}
\hline & & & & & Límite inferior & $\begin{array}{l}\text { Límite } \\
\text { superior }\end{array}$ \\
\hline \multirow[t]{4}{*}{1} & 2 & $-3,667^{*}$ & ,236 &, 000 & $-4,142$ & $-3,192$ \\
\hline & 3 & $-10,533^{*}$ & ,385 &, 000 & $-11,309$ & $-9,758$ \\
\hline & 4 & $-9,178^{*}$ & ,323 &, 000 & $-9,829$ & $-8,527$ \\
\hline & 5 &,$- 644^{*}$ & ,120 &, 000 &,- 885 &,- 403 \\
\hline \multirow[t]{4}{*}{2} & 1 & $3,667^{*}$ & ,236 &, 000 & 3,192 & 4,142 \\
\hline & 3 & $-6,867^{*}$ & ,323 &, 000 & $-7,519$ & $-6,215$ \\
\hline & 4 & $-5,511^{*}$ & ,294 &, 000 & $-6,104$ & $-4,918$ \\
\hline & 5 & $3,022^{*}$ & ,245 &, 000 & 2,528 & 3,516 \\
\hline \multirow[t]{4}{*}{3} & 1 & $10,533^{*}$ & ,385 &, 000 & 9,758 & 11,309 \\
\hline & 2 & $6,867^{*}$ & ,323 &, 000 & 6,215 & 7,519 \\
\hline & 4 & $1,356^{*}$ & ,334 &, 000 & ,683 & 2,028 \\
\hline & 5 & $9,889^{*}$ & ,393 &, 000 & 9,096 & 10,682 \\
\hline \multirow[t]{4}{*}{4} & 1 & $9,178^{*}$ & ,323 &, 000 & 8,527 & 9,829 \\
\hline & 2 & $5,511^{*}$ & ,294 &, 000 & 4,918 & 6,104 \\
\hline & 3 & $-1,356^{*}$ & ,334 &, 000 & $-2,028$ &,- 683 \\
\hline & 5 & $8,533^{*}$ & ,317 &, 000 & 7,894 & 9,173 \\
\hline \multirow[t]{4}{*}{5} & 1 & $644^{*}$ & ,120 &, 000 & ,403 & ,885 \\
\hline & 2 & $-3,022^{*}$ & 245 &, 000 & $-3,516$ & $-2,528$ \\
\hline & 3 & $-9,889^{*}$ & ,393 &, 000 & $-10,682$ & $-9,096$ \\
\hline & 4 & $-8,533^{*}$ & ,317 & ,000 & $-9,173$ & $-7,894$ \\
\hline
\end{tabular}

Basadas en las medias marginales estimadas. ${ }^{a}$

*. La diferencia de medias es significativa al nivel ,05.

a. IDIOMA = ALEMÁN

c. Ajuste para comparaciones múltiples: Diferencia menos significativa (equivalente a la ausencia de ajuste).

Como se observa a partir de la comparación de los resultados de los grupos temáticos en alemán, todas las diferencias son significativas.

Para finalizar esta hipótesis 5, ofrecemos el gráfico (Figura 32), en el que se pueden visualizar las diferencias entre cada uno de los grupos temáticos: 


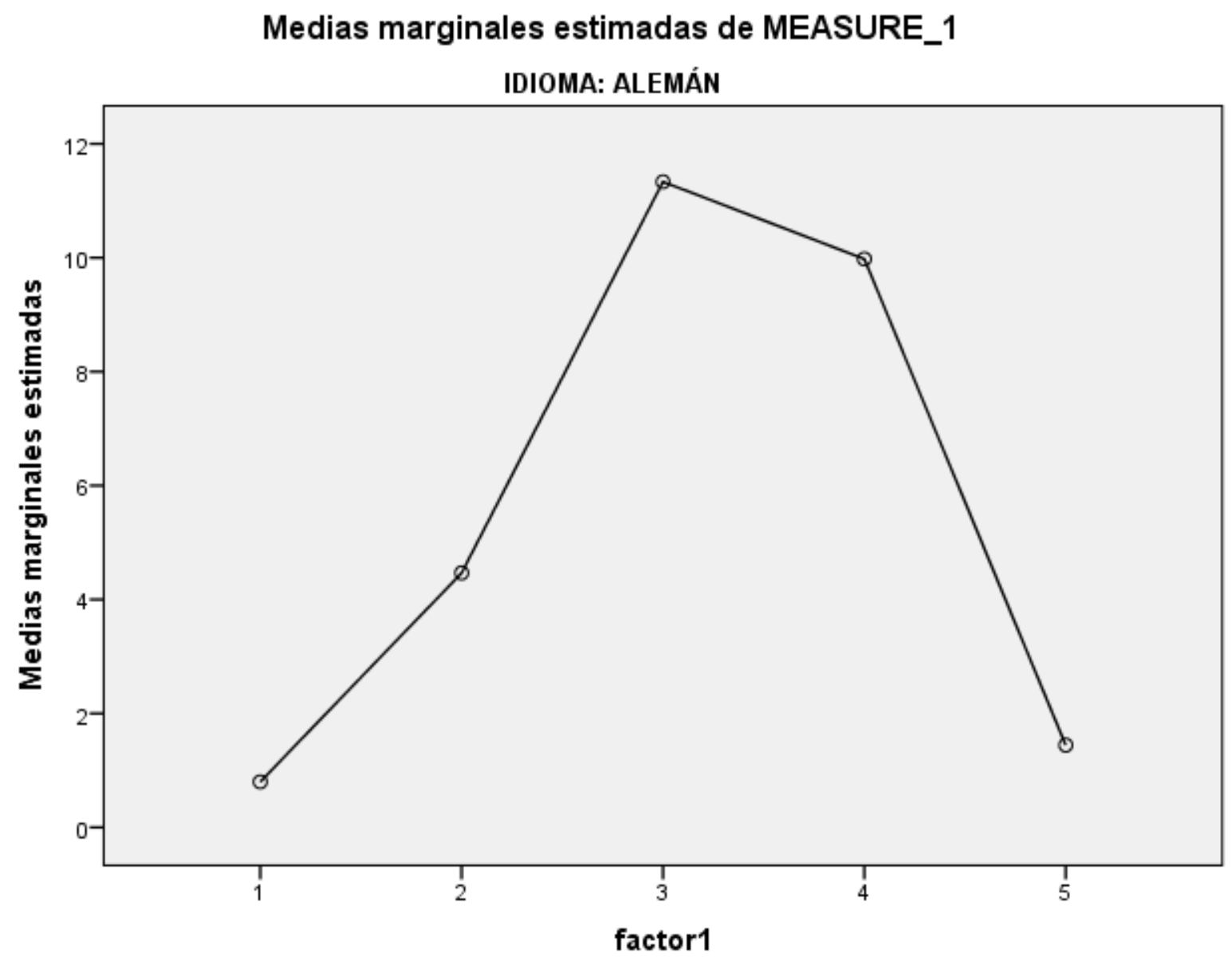

Figura 32. Competencia por grupos temáticos: alemán

En conclusión, el análisis de la hipótesis 5 nos ha permitido comprobar que existen diferencias significativas entre los grupos temáticos tanto en la muestra general como en cada una de las poblaciones analizadas, pero en especial en los relativos a zoologismos, experiencia humana y herencia cultural.

\subsection{FASE II: NIVEL SOCIOLINGÜÍSTICO}

Como se ha comentado más arriba, en el presente estudio se pretende comprobar si algunos factores sociales podían influir en la competencia fraseológica de los estudiantes, como habíamos intuido en anteriores estudios. Por ello, en esta investigación se ha dedicado una parte del estudio de campo a recabar datos sobre la adscripción social de los alumnos a través del modelo de cuestionario diseñado a tal efecto (Anexo II). 
6.2.1. HIPÓTESIS 6: La competencia fraseológica está condicionada por diversos factores sociales.

La primera hipótesis que planteábamos en la fase sociolingüística es si la competencia podía estar condicionada por diversos factores extralingüísticos. Los factores sociales que se han tenido en cuenta son cuatro: edad de los alumnos, sexo, si eran bilingües o no y el entorno familiar, medido en las horas que pasaban a la semana con sus abuelos. Cada uno de estos factores se ha analizado en una subhipótesis que desarrollamos a continuación.

Hipótesis 6.1: Las diferencias de edad se reflejan en la competencia fraseológica de los jóvenes.

Nos interesaba observar si la comparación de estas dos variables, la competencia fraseológica (variable dependiente) y la edad (variable independiente) se hallan relacionadas. Recordamos que los alumnos encuestados tenían edades que oscilaban entre los 14 años a los 17 años.

Para comprobar si existe relación entre ambas variables, se ha procedido inicialmente a realizar correlaciones tomando en conjunto ambas muestras. Los resultados nos indican que esta es significativa de acuerdo con el índice de Correlación de Pearson =,212, sig.=,045. Esto significa que la edad está relacionada con la competencia fraseológica: el coeficiente de Pearson positivo indica que esa relación es positiva y que aumenta la competencia con la edad. No obstante, la relación podría calificarse de débil, por el valor obtenido, cercano a 0,05, límite máximo generalmente aceptado en las ciencias sociales.

Ahora bien, un análisis por lenguas demuestra que las cosas son bien diferentes entre una comunidad y otra. En español, las cifras del índice correlación de Pearson son =,066, sig.=,669, lo que indica claramente que no hay relación entre la edad y competencia fraseológica, y que ambas variables son independientes, al menos con la muestra disponible. 
Por el contrario, el alemán, sí muestra una relación significativa, a partir de la Correlación de Pearson, que es =,363, sig.=,014. En definitva, en esta comunidad lingüística parece confirmarse que la competencia fraseológica en alemán aumenta con la edad, a diferencia de la muestra española.

Hipótesis 6.2: Chicos y chicas muestran diferencias significativas en el conocimiento de las UF.

En este apartado observaremos si hay diferencias en la competencia fraseológica cuando consideramos el sexo de los jóvenes. Comprobamos esta hipótesis con la prueba T.

Teniendo en cuenta los resultados globales, sin segmentar de momento por idiomas, los resultados muestran, mayor media en la competencia por parte de las mujeres que de los hombres (Tabla 27). Además, esta diferencia resulta estadísticamente significativa: $T=-2,191$, sig.=,031, lo que indica que, en líneas generales, las mujeres muestran un mayor conocimiento fraseológico que los hombres.

Tabla 27. Variables sexo y competencia: Medias español-alemán

\begin{tabular}{llrrrr}
\hline & \multicolumn{5}{c}{ Estadísticos de grupo } \\
& SEXO & $N$ & Media & $\begin{array}{c}\text { Desviación } \\
\text { típ. }\end{array}$ & $\begin{array}{r}\text { Error típ. de la } \\
\text { media }\end{array}$ \\
TOTAL & hombre & 44 & 27,43 & 8,097 & 1,221 \\
COMPETENCIA & mujer & 46 & 30,63 & 5,579 &, 823 \\
ESPAÑOL & hombre & 24 & 28,21 & 8,314 & 1,697 \\
& mujer & 21 & 32,29 & 5,892 & 1,286 \\
ALEMÄN & hombre & 20 & 26,50 & 7,937 & 1,775 \\
& mujer & 25 & 29,24 & 5,002 & 1,000 \\
\hline
\end{tabular}

Ahora bien, realizada la Prueba T por idiomas comprobamos que no hay ahora diferencias significativas por sexo, ni en español, ni en alemán. El español ofrece unos índices más cercanos a la significación positiva ( $T=-1,872$, sig.=,068), pero se queda fuera, y todavía más lo hace el grupo de escolares alemanes $(T=-1,413$, sig. $=, 165)$. Con todo, cabe suponer que los resultados 
podrían variar con una muestra más amplia, al menos en el caso español, ya que los resultados obtenidos en la población global apuntan hacia esas diferencias generolectales.

Hipótesis 6.3: La competencia fraseológica está condicionada por la adscripción lingüística y el grado de bilingüismo de los hablantes.

En el presente estudio, también se pretende comprobar si la condición de bilingües de los jóvenes podía influir en la competencia. La Tabla 28 muestra las medias de competencias según el grado de bilingüismo.

Tabla 28. Variables bilingüismo y competencia: Medias español-alemán

\begin{tabular}{|c|c|c|c|c|c|}
\hline \multicolumn{6}{|c|}{ Estadísticos de grupo } \\
\hline & BILINGÜISMO & $\mathrm{N}$ & Media & $\begin{array}{c}\text { Desviación } \\
\text { estándar }\end{array}$ & $\begin{array}{c}\text { Media } \\
\text { de } \\
\text { error } \\
\text { estánd } \\
\text { ar }\end{array}$ \\
\hline TOTAL COMPETENCIA & NO BILINGÜE & 61 & 29,59 & 6,556 & ,839 \\
\hline FRASEOLÓGICA & BILINGÜE & 29 & 27,97 & 8,060 & 1,497 \\
\hline ESPAÑOL COMPETENCIA & NO BILINGÜE & 26 & 30,19 & 7,250 & 1,422 \\
\hline FRASEOLÓGICA & BILINGÜE & 19 & 30,00 & 8,014 & 1,839 \\
\hline ALEMÁN COMPETENCIA & NO BILINGÜE & 35 & 29,14 & 6,059 & 1,024 \\
\hline FRASEOLÓGICA & BILINGÜE & 10 & 24,10 & 6,951 & 2,198 \\
\hline
\end{tabular}

Tomando las medias de las muestras en conjunto, parece que los no bilingües muestran más competencia fraseológica. La misma situación encontramos en español y en alemán separadamente, aunque la diferencia es menor en español que en alemán. Ahora bien, tras realizar la prueba $T$, podemos confirmar que tanto en el conjunto de la muestra $(T=1,019$, sig.=,311) como en en español ( $T=, 084$, sig.=,933), las diferencias observadas entre bilingües y no bilingües no son significativas. Por el contrario, sí lo son en alemán ( $T=2,248$, sig.=,030), en el sentido apuntado arriba: los no bilingües muestran un nivel más alto de competencia. 
Respecto al bilingüismo, recordamos en este punto que hay ligeros matices diferentes entre las muestras. En el grupo español, de los 20 estudiantes que se definen bilingües, 9 son de procedencia extranjera, debido a la inmigración, mientras que 11 son alumnos que viven una situación de lenguas en contacto con el español y el catalán como lenguas de uso cotidiano en Castellón. En la muestra española, las lenguas maternas diferentes al español son: árabe (3 estudiantes), rumano (4 estudiantes), polaco (1 estudiante) y marroquí (1 estudiante). Por el contrario, en la muestra alemana, todos los estudiantes que se declaran bilingües (11 estudiantes) son de procedencia extranjera, puesto que Hamburgo pertenece a un país monolingüe. Las lenguas maternas de estos alumnos son: turco (3 estudiantes), dari (3 estudiantes), farsi (1 estudiante), inglés (1 estudiante), serbio (1 estudiante), polaco (1 estudiante) y español (1 estudiante).

Aunque apenas hay, pues, diferencia entre el número de estudiantes extranjeros en una y otra muestra (españoles 9 / alemanes 11), las divergencias encontradas podrían obedecer a que, en la comunidad española, los hablantes bilingües autóctonos viven en una situación de intenso bilingüismo social e individual, lo que favorecería una mayor competencia fraseológica en español, con independencia de cuál sea la lengua nativa de los estudiantes.

Hipótesis 6.4: El entorno familiar de los jóvenes influye en el nivel de competencia fraseológica.

Para dar respuesta a esta hipótesis hemos utilizado de nuevo el índice de correlación de Pearson, que nos ofrece un valor =-,096, sig.=,369, lo que demuestra que no es significativa la correlación si tenemos en cuenta conjuntamente las dos muestras: el entorno familiar no parece influir en la competencia. Lo mismo se advierte en el análisis específico de cada lengua, tanto en español $(-, 108$, sig.=,482), como en alemán $(-, 186$, sig.=,221).

6.2.2. HIPÓTESIS 7: Algunos cruces entre los factores sociales reseñados inciden también significativamente en el grado de competencia fraseológica. 
En este apartado nos planteamos si una combinación de variables independientes puede explicar los resultados obtenidos en torno a los niveles de competencia fraseológica global en los jóvenes. ${ }^{90}$ Así pues, realizamos un análisis de regresión con interacción y vemos en qué medida este puede pronosticar la variable dependiente, esto es, la competencia fraseológica. Para ello, esta hipótesis se divide en diversas subhipótesis, que estudian la interacción entre cada uno de los pares de factores sociales considerados.

Las subhipótesis planteadas son las siguientes:

Hipótesis 7.1. La interacción entre las variables edad y sexo son significativas para explicar la competencia.

Hipótesis 7.2. La interacción entre las variables edad y bilingüismo son significativas para explicar la competencia.

Hipótesis 7.3. La interacción entre las variables edad y entorno familiar son significativas para explicar la competencia.

Hipótesis 7.4. La interacción entre las variables sexo y bilingüismo son significativas para explicar la competencia.

Hipótesis 7.5. La interacción entre las variables sexo y entorno familiar son significativas para explicar la competencia.

Hipótesis 7.6. La interacción entre las variables bilingüismo y entorno familiar son significativas para explicar la competencia.

Hipótesis 7.1 La interacción entre las variables edad y sexo son significativas para explicar la competencia.

El modelo de regresión utilizado arroja resultados significativos $(F=5,095$, sig.=,003), lo que indica que es posible pronosticar adecuadamente las competencias desde las variables independientes propuestas. Concretamente, el hecho de incluir la interacción de variables resulta ser un cambio significativo, respecto de no ponerlo ( $F=5,017$, sig.=,028), por tanto, explicamos el pronóstico contando con dicha interacción. Los coeficientes del modelo se

${ }^{90}$ En esta hipótesis hemos considerado solo la competencia fraseológica global de los jóvenes. 
encuentran en la Tabla 29, donde se puede comprobar que la interacción sexoedad resulta significativa e indica que para uno de los dos sexos y una edad determinada se producen unos valores de competencia fraseológica distintos a los de otros cruces.

Tabla 29. Coeficientes de la ecuación de regresión

\begin{tabular}{lrrrr}
\hline Modelo & \multicolumn{3}{c}{ Coeficientes no } \\
& \multicolumn{2}{c}{ estandarizados } \\
& B & \multicolumn{1}{c}{$\begin{array}{c}\text { Error } \\
\text { estándar }\end{array}$} & \multicolumn{1}{c}{ T } & Sig. \\
& & & & \\
(Constante) & $-23,333$ & 16,059 & $-1,453$ &, 150 \\
SEXO & 52,083 & 21,803 & 2,389 &, 019 \\
EDAD & 3,354 & 1,059 & 3,167 &, 002 \\
COMPUTE sexXEdad=SEXO * EDAD & $-3,229$ & 1,442 & $-2,240$ &, 028 \\
\hline
\end{tabular}

La Figura 33 nos muestra el comportamiento de la competencia fraseológica pronosticada desde la interacción de las variables: 


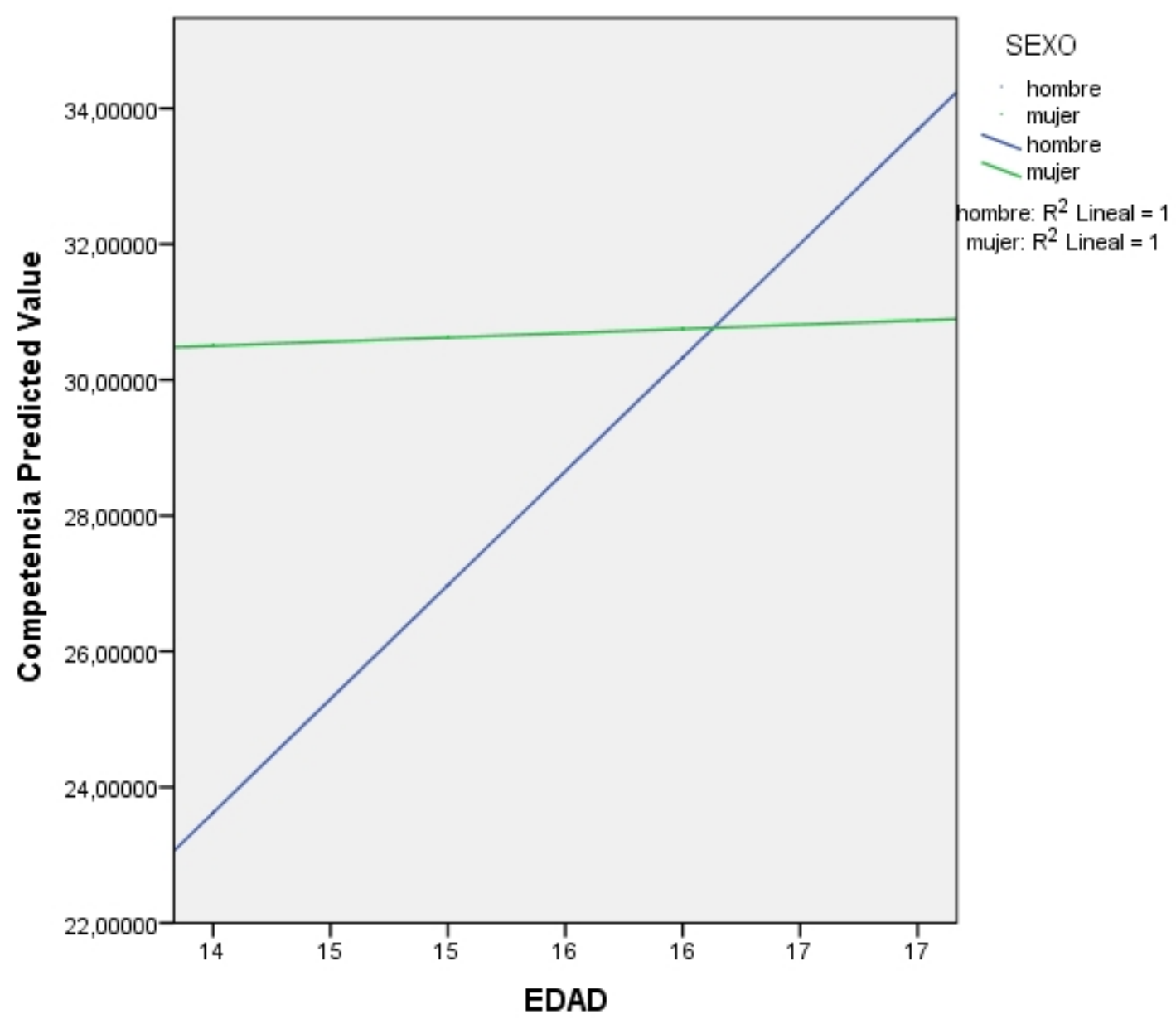

Figura 33. Interacción de las variables edad y sexo en la competencia

Resulta muy gráfico comprobar en la figura cómo la interacción de estas dos variables independientes influyen en la competencia fraseológica: mientras que los chicos parten de una menor competencia a los 14 años y evolucionan in crescendo, las chicas tienen una madurez fraseológica adquirida ya a los 14 años y similar a la de los 16-17 años, manteniéndose, pues, estables en el período de la educación pre-universitaria.

Hipótesis 7.2. La interacción entre las variables edad y bilingüismo son significativas para explicar la competencia.

En la regresión realizada para analizar la interacción entre las variables bilingüismo y edad, comprobamos que esta no influye significativamente en la variable dependiente $(F=2,182$, sig. $=, 096)$. No hay, por tanto, diferencias en la competencia si consideramos el bilingüismo y la edad conjuntamente, pues los índices de significación son superiores al 0,05. 
Tabla 30. Coeficientes de la ecuación de regresión

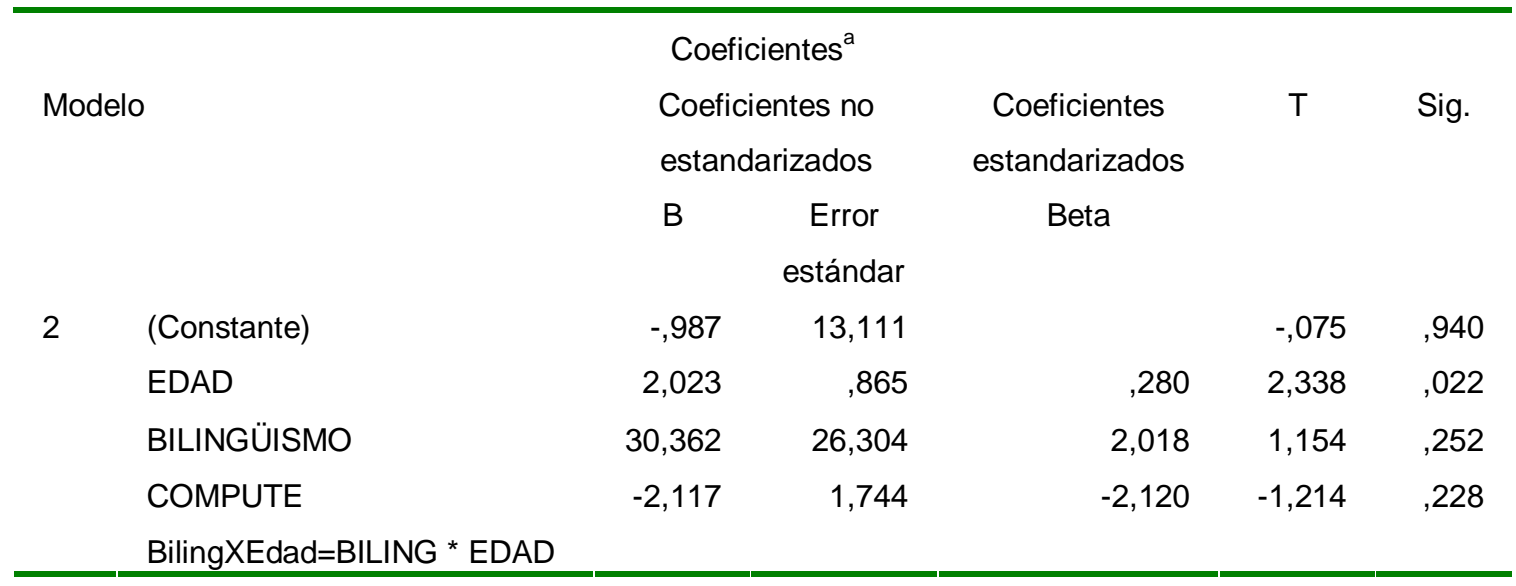

a. Variable dependiente: TOTAL COMPETENCIA FRASEOLÓGICA

Hipótesis 7.3. La interacción entre las variables edad y entorno familiar son significativas para explicar la competencia.

Tabla 31. Coeficientes de la ecuación de regresión

\begin{tabular}{|c|c|c|c|c|c|c|}
\hline \multicolumn{7}{|c|}{ Coeficientes $^{\mathrm{a}}$} \\
\hline \multirow{4}{*}{\multicolumn{2}{|c|}{ Modelo }} & \multirow{2}{*}{\multicolumn{2}{|c|}{$\begin{array}{l}\text { Coeficientes no } \\
\text { estandarizados }\end{array}$}} & Coeficientes & $\mathrm{T}$ & Sig. \\
\hline & & & & estandarizados & & \\
\hline & & B & Error & Beta & & \\
\hline & & & estándar & & & \\
\hline \multirow[t]{4}{*}{2} & (Constante) & 23,225 & 14,832 & & 1,566 & ,121 \\
\hline & EDAD & ,422 & ,981 & 058 & ,430 & ,668 \\
\hline & ENTORNO FAMILIAR & $-13,294$ & 7,545 & $-2,804$ & $-1,762$ & ,082 \\
\hline & Ent_famXEdad & 857 &, 501 & 2,720 & 1,709 & ,091 \\
\hline
\end{tabular}

a. Variable dependiente: TOTAL COMPETENCIA FRASEOLÓGICA

En este caso, tampoco es significativa $(F=2,631$, sig. $=, 055)$ para la competencia fraseológica la interacción entre las variables edad y entorno familiar.

Hipótesis 7.4. La interacción entre las variables sexo y bilingüismo son significativas para explicar la competencia. 
En este caso la ecuación de regresión sí indica significación $(F=3,189$, sig.=,028), pero cuando miramos la Tabla 32 comprobamos que esa significación no se debe a la interacción de las variables tal como postulábamos, pues se observa un valor sig.=,089.

Tabla 32. Coeficientes de regresión: sexo y bilingüismo

\begin{tabular}{|c|c|c|c|c|c|}
\hline \multicolumn{6}{|c|}{ Coeficientes $^{a}$} \\
\hline \multirow[t]{2}{*}{ Modelo } & \multicolumn{2}{|c|}{$\begin{array}{l}\text { Coeficientes no } \\
\text { estandarizados }\end{array}$} & $\begin{array}{l}\text { Coeficientes } \\
\text { estandarizados }\end{array}$ & $\mathrm{T}$ & Sig. \\
\hline & B & $\begin{array}{c}\text { Error } \\
\text { estánd } \\
\text { ar }\end{array}$ & Beta & & \\
\hline (Constante) & 28,781 & 1,206 & & 23,860 & ,000 \\
\hline BILINGÜISMO & $-4,948$ & 2,310 &,- 329 & $-2,142$ & ,035 \\
\hline SEXO & 1,702 & 1,749 & ,121 & ,973 & ,333 \\
\hline COMPUTE & 5,348 & 3,111 & ,298 & 1,719 & ,089 \\
\hline BilingXsexo=BIL & & & & & \\
\hline
\end{tabular}

a. Variable dependiente: TOTAL COMPETENCIA FRASEOLÓGICA

Hipótesis 7.5. La interacción entre las variables sexo y entorno familiar son significativas para explicar la competencia.

En este caso, tampoco se observa un modelo significativo $(F=1,792$, sig. $=, 155)$ cuando ponemos a prueba la interacción entre las variables independientes sexo y entorno familiar.

Tabla 33. Coeficientes de regresión: sexo y entorno familiar

\begin{tabular}{|c|c|c|c|c|c|c|}
\hline \multicolumn{7}{|c|}{ Coeficientes $^{\mathrm{a}}$} \\
\hline \multirow{2}{*}{\multicolumn{2}{|c|}{ Modelo }} & \multicolumn{2}{|c|}{$\begin{array}{l}\text { Coeficientes no } \\
\text { estandarizados }\end{array}$} & $\begin{array}{l}\text { Coeficientes } \\
\text { estandarizad }\end{array}$ & $T$ & Sig. \\
\hline & & B & $\begin{array}{c}\text { Error } \\
\text { estándar }\end{array}$ & Beta & & \\
\hline 2 & (Constante) & 28,119 & 1,417 & & 19,84 & ,000 \\
\hline
\end{tabular}




\begin{tabular}{lrrrrr}
\hline & & & & 5 & \\
ENTORNO FAMILIAR &,- 480 &, 663 &,- 101 &,- 724 &, 471 \\
SEXO & 2,840 & 1,983 &, 202 & 1,432 &, 156 \\
Ent_famXSexo &, 215 & 1,002 &, 035 &, 214 &, 831 \\
\hline
\end{tabular}

a. Variable dependiente: TOTAL COMPETENCIA FRASEOLÓGICA

Hipótesis 7.6. La interacción entre las variables bilingüismo y entorno familiar son significativas para explicar la competencia.

Este modelo que pone a prueba la interacción bilingüismo y entorno familiar tampoco resulta significativa ( $F=1,118$, sig.=,346).

Tabla 34. Coeficientes de regresión: bilingüismo y entorno familiar

\begin{tabular}{|c|c|c|c|c|c|c|}
\hline \multicolumn{7}{|c|}{ Coeficientes $^{a}$} \\
\hline \multicolumn{2}{|c|}{ Modelo } & \multicolumn{2}{|c|}{$\begin{array}{l}\text { Coeficientes no } \\
\text { estandarizados }\end{array}$} & $\begin{array}{l}\text { Coeficientes } \\
\text { estandarizad }\end{array}$ & $\mathrm{T}$ & Sig. \\
\hline & & B & $\begin{array}{l}\text { Error } \\
\text { estándar }\end{array}$ & Beta & & \\
\hline \multirow[t]{4}{*}{2} & (Constante) & 30,969 & 1,291 & & 23,992 & ,000 \\
\hline & ENTORNO FAMILIAR &,- 895 & ,598 &,- 189 & $-1,495$ & , 138 \\
\hline & BILINGÜISMO & $-3,249$ & 2,043 &,- 216 & $-1,590$ & ,115 \\
\hline & Ent_famXBiling & 1,169 & 1,158 & 143 & 1,010 & ,316 \\
\hline
\end{tabular}

a. Variable dependiente: TOTAL COMPETENCIA FRASEOLÓGICA

En resumen, de lo visto en este apartado en relación con la hipótesis 7 y sus diferentes subhipótesis, que estudiaban la influencia en la competencia fraseológica global de dos factores sociales, se deduce que solo resulta significativa en el caso de la edad y el sexo. El resto de interacciones no han dado resultados significativos. 



\section{CONCLUSIONES}

La fraseología puede considerarse en estos momentos como una disciplina plenamente consolidada, no solo en líneas generales, sino también en aquello que se refiere más específicamente a los estudios contrastivos, objeto del presente estudio. La denominada fraseología contrastiva puede observarse desde dos vertientes: interlingüística o intralingüística. Cualquiera de los dos ámbitos de investigación atrae la atención de los lingüistas y esto se refleja en las numerosas publicaciones y congresos dedicados a la investigación sobre la fraseología de los últimos tiempos, especialmente en el ámbito interlingüístico.

Esta incesante actividad alrededor de la fraseología en general, y la fraseología contrastiva en particular, pone de manifiesto, a nuestro entender, otra característica de la disciplina en la actualidad, como es el talante cooperativo e internacionalizador de los investigadores. Ahora el foco de interés se centra en aspectos diversos de los estudios fraseológicos, fundamentalmente en los de carácter aplicado, lejos ya de las discusiones terminológicas de los primeros momentos que tendían a la introspección. De manera que se puede considerar completamente superada esa fase inicial, puramente teórica (Castillo, 2015).

La investigación sobre fraseología contrastiva se basa, por lo general, en corpus $^{91}$ extraídos de obras literarias y sus respectivas traducciones. Ello hace que el trabajo parta de muestras textuales que podría calificarse de ajenas, en las que el investigador se convierte en poco más que un mero observador de unos y otros, escritores y traductores. Los estudios que han surgido a partir de una obra y de su traducción son numerosos, y en ellos se analiza las UF en la $L 1$ y la $L 2$, y se verifica el tratamiento que se les ha dado. Sirvan como ejemplo los trabajos contrastivos español-alemán de Segura (1998) o López (2002). También suelen ser frecuentes los estudios que se basan en agrupaciones conceptuales o temáticas de UF, como el de Larreta sobre somatismos (1998/2001).

\footnotetext{
${ }^{91}$ Respecto al número de expresiones que deben contener los corpus relacionados con la fraseología, se hace alusión muchas veces a 'mínimos', pero especialmente referido a los 'mínimos paremiológicos' (Tarnowska, 2014; Bauer y Chlosta, 1996a, 1996b, Mieder, 1993).
} 
Sin embargo, la presente investigación, no pretendía estudiar la fraseología dada en este tipo de corpus, sino que quería analizar in vivo la competencia fraseológica que poseen los jóvenes españoles y alemanes en la actualidad, es decir, realizar un estudio descriptivo de la situación real acerca del conocimiento de estas expresiones. Por ello, a diferencia de los estudios mencionados, el corpus no venía dado externamente por otros agentes, sino que se ha creado ad hoc. Se trata de un corpus bilingüe español-alemán de UF que presentaba ciertos requisitos de equivalencia.

Además de este criterio previo para la comparación interlingüística españolalemán, consideramos que un material de estas características debía cumplir otros requisitos, en concreto los dos siguientes:

1. representatividad: debían ser UF conocidas ampliamente por los hablantes nativos jóvenes en cada una de las muestras,

2. adecuación: puesto que la forma externa de la UF no venía dada con antelación en un texto fijado, era necesario una verificación de la misma para garantizar el rigor de la investigación.

La representatividad de las UF se decidió a partir de estudios previos, en los que se verificó un grado de conocimiento superior al $50 \%,{ }^{92}$ un dato respaldado además por la experiencia y el conocimiento de ambas lenguas objeto de estudio por parte de la investigadora. Por su parte, la adecuación de la forma elegida se verificó a partir del cotejo de diferentes fuentes fraseográficas, comprobando que la variante elegida por nosotros fuera la forma más usual o 'canónica', según denominación de Conca y Guia (2014).

Delimitado así el corpus de UF, se procedió al diseño de la encuestacuestionario, que constaba de dos partes, una lingüística y otra sociológica. En

\footnotetext{
92 Tarnovska (2004) ha considerado también este porcentaje como un buen nivel de competencia paremiológica. Al igual que ocurre en nuestro trabajo, Tarnovska desarrollo su investigación empírica por medio de encuestas, a fin de delimitar un refranero básico español (unas 250 paremias). Este trabajo lo completa con el análisis contrastivo de otras unidades fraseológicas equivalentes en ruso y ucraniano. La finalidad de este trabajo consiste acercar las paremias al estudiante de español como lengua extranjera, estableciendo un mínimo paremiológico español.
} 
la parte lingüística pretendíamos averiguar cuál era el nivel de conocimiento o competencia que los informantes tenían de las unidades fraseológicas elegidas. Para ello se consultaron diferentes manuales relacionados con la didáctica de fraseología. ${ }^{93}$ En la parte sociolingüística nos interesaba el análisis de ciertos datos sociológicos de los informantes y el modo en que estos, bien de forma aislada, bien en interacción, podrían afectar a dicho conocimiento.

Así pues, se partió de diversas premisas teóricas y metodológicas para realizar el diseño de la investigación, que tuvo las siguientes fases: 1) elaboración del corpus, 2) redacción de la encuesta, 3) selección de informantes, y 4) recogida de datos. A continuación, se procedió al análisis estadístico y a su posterior interpretación, en relación con las hipótesis planteadas previamente.

Repasamos a continuación las principales conclusiones que se derivan de los datos analizados en el apartado anterior y procedemos a la validación o refutación de las hipótesis planteadas.

HIPÓTESIS 1: La competencia fraseológica global de los jóvenes de las comunidades lingüísticas española y alemana presenta diferencias significativas. Como vimos en el apartado anterior, a pesar de que las medias globales de ambas muestras fueron diferentes, estas resultaron ser escasas y estadísticamente no significativas, por lo que esta primera hipótesis queda refutada: La competencia fraseológica global de los jóvenes de las comunidades lingüísticas española y alemana no presenta diferencias significativas.

HIPÓTESIS 2: Determinadas UF son más conocidas en una lengua que en otra. Se observó que, excepto en dos casos, en que la competencia fue idéntica, en la mayoría de las comparaciones sí hubo diferencias, aunque de estas solo resultaron significativas en 25 UF, no así en el resto. Podemos decir

\footnotetext{
93 En ambas lenguas se encuentran ya hace tiempo manuales sobre la didáctica de fraseología. Entre otros, cabe destacar en alemán entre los pioneros de B. Wotjak (1996), Baur y Chlosta (1996a, 1996b), Elorduy y Fandrich (1996) o Kühn (1996), que acuñó el término de Phraseodidaktik. En español podemos destacar los manuales de Ortega y Rochel (1995) o Domínguez y otros (1995).
} 
que la hipótesis 2 queda validada: Determinadas UF son más conocidas en una lengua que en otra.

HIPÓTESIS 3: Hay diferencias en el grado de competencia activa y pasiva. En este caso se verificó la significación de las diferencias tanto interlingüística como intralingüísticamente. En la comparación interlingüística, las diferencias apreciadas entre español y alemán en competencia activa sí fueron significativas, pero las diferencias en la competencia pasiva, no. Por otro lado, observando cada una de estas facetas de la competencia fraseológica en el seno de una misma lengua, tanto el español como el alemán arrojaron valores distintos, y esa diferencia sí era muy significativa. Por tanto, queda validada la hipótesis 3: Hay diferencias en el grado de competencia activa y pasiva.

HIPÓTESIS 4: El tipo de ejercicio condiciona la competencia que muestran los jóvenes. Esta hipótesis pretendía demostrar que, independientemente del tipo de competencia lingüística que esté en juego (activa o pasiva), el planteamiento de los ejercicios plantea retos y dificultades diferentes, hasta el punto de que estos pueden condicionar los resultados. Y de los obtenidos para evaluar esta hipótesis, se deriva que, para la comparación interlingual españolalemán, se encuentran diferencias significativas en todos los ejercicios, excepto en los datos obtenidos en el ejercicio 4 y 5 , los dos referidos a competencia pasiva.

En la comparación intralingual, en español se encuentran diferencias significativas en todos los ejercicios excepto entre el 2 y el 4, pertenecientes cada uno a un tipo de competencia (activa y pasiva, respectivamente). En alemán se encuentran diferencias significativas entre todos, menos entre el 2 y el 5, pertenecientes también cada uno a un tipo de competencia (activa y pasiva, respectivamente). Por ello, podemos concluir que sí existen diferencias significativas, pero no en todos los casos, por lo que queda validada solo parcialmente la hipótesis: El tipo de ejercicio condiciona la competencia que muestran los jóvenes. 
HIPÓTESIS 5: La adscripción temática de las UF determina diferencias en la competencia fraseológica. Esta hipótesis pretendía verificar si la diferencia conceptual o temática influía en la competencia. Para ello se realizaron agrupaciones de UF, que estaban dispuestas al azar a lo largo de todos los ejercicios. Veamos las subhipótesis una por una.

Hipótesis 5.1: Las UF no adscritas a grupos determinados presentan un nivel de competencia diferente. En este caso se trataba de una sola UF que no podía asociarse a ningún grupo por presentar cierta singularidad semántica. Presentaba una competencia idéntica en las dos lenguas, por lo que esta hipótesis queda refutada: Las UF no adscritas a grupos determinados no presentan un nivel de competencia diferente.

Hipótesis 5.2 Los zoologismos presentan un nivel de competencia diferente en las dos lenguas. En este caso, en una y otra lengua se presenta un nivel de competencia significativamente diferente, por lo que la hipótesis queda validada: Los zoologismos presentan, en efecto, un nivel de competencia diferente en ambas lenguas.

Hipótesis 5.3: El grupo de UF denominadas somatismos presentan un nivel de competencia diferente en las dos lenguas. En este caso no se aprecian diferencias significativas, por lo que la hipótesis queda refutada: El grupo de UF denominadas somatismos no presentan un nivel de competencia diferente en las dos lenguas.

Hipótesis 5.4: Las UF referidas a la experiencia humana presentan un nivel de competencia diferente en las dos lenguas. Las UF referidas a la experiencia humana presentan un nivel de competencia significativamente diferente en las dos comunidades lingüísticas, por lo que queda validada la hipótesis: Las UF referidas a la experiencia humana presentan un nivel de competencia diferente en las dos lenguas.

Hipótesis 5.5: Las UF que se refieren a la herencia cultural presentan un nivel de competencia diferente en las dos lenguas. Estas UF muestran diferencias 
significativas de competencia en ambas lenguas, por lo que la hipótesis queda igualmente validada: Las UF que se refieren a la herencia cultural presentan un nivel de competencia diferente en las dos lenguas.

Las hipótesis que siguen a continuación ( 6 y 7) aúnan elementos lingüísticos con factores sociales, y pretendían comprobar si alguno de estos puede incidir en la competencia fraseológica, tanto si los tomamos de manera individualizada como si analizamos el cruce entre ellos. A continuación resumimos las principales conclusiones derivadas del análisis de las hipótesis 6 y 7 con sus respectivas subhipótesis.

HIPÓTESIS 6: La competencia fraseológica está condicionada por diversos factores sociales. Puesto que los factores sociales son diferentes, hemos dividido esta presunción en una serie de subhipótesis.

Hipótesis 6.1: Las diferencias de edad se reflejan en la competencia fraseológica de los jóvenes. Respecto a si la edad es significativa, se ha comprobado que, tomadas ambas muestras en su conjunto, se aprecia una correlación débil, aunque positiva: es decir, conforme a lo esperado, a mayor edad de los estudiantes, mayor también el grado de conocimiento fraseológico alcanzado. Ahora bien, en el análisis aislado de cada comunidad lingüística con una muestra, consiguientemente, reducida a la mitad- los resultados son dispares: en español no resulta significativo el factor, mientras que en alemán lo es y, además, en un sentido positivo: la edad y el nivel de competencia se hallan, efectivamente, relacionados. Por tanto, sólo es validada parcialmente la hipótesis, pues las diferencias de edad no se reflejan en todos los casos en la competencia fraseológica de los jóvenes, sino solo cuando se observan las muestras conjuntamente y específicamente, también, en el caso alemán.

Hipótesis 6.2: Chicos y chicas muestran diferencias significativas en el conocimiento de las UF. Si tomamos la muestra en su conjunto, sin distinguir por idioma, observamos que el sexo es una variable que arroja resultados significativos en la competencia, pues las mujeres presentan más conocimiento 
fraseológico que los hombres, lo que está en consonancia con los resultados obtenidos desde hace décadas por la sociolingüística, y en los que se ha puesto de relieve el mayor repertorio verbal de las primeras en relación con los segundos (Chambers, 2005; Blas Arroyo, 2005). Ahora bien, cuando las muestras se reducen a la mitad, como sucede cuando tomamos los casos español y alemán aisladamente, el resultado no es significativo. Aunque ello no significa que mediante el concurso de un corpus más extenso y representativo las cosas no pudieran ser de otra manera, lo cierto es que, con los datos disponibles del presente estudio, la hipótesis solo puede ser validada parcialmente, pues se observan resultados significativos solo en la muestra conjunta.

Hipótesis 6.3: La competencia fraseológica está condicionada por la adscripción lingüística y el grado de bilingüismo de los hablantes. Comprobamos en esta hipótesis si el bilingüismo individual y social podía incidir en el grado de competencia fraseológica, y se ha comprobado que para la muestra en su conjunto no es significativo, para el español tampoco, pero para el alemán sí lo es: los alumnos bilingües de la muestra alemana tienen menos competencia fraseológica que los que tienen el alemán como única lengua, pues como se ha comentado anteriormente (cf. $\S 6.2 .1$, Hipótesis 6.3), su bilingüismo proviene del hecho de ser inmigrantes y poseer una lengua materna diferente. En el caso del español, se daba tanto esta circunstancia como la de un bilingüismo social e individual intenso con la otra lengua de la comunidad, el catalán. De todo esto, queda validada parcialmente la hipótesis, pues la competencia fraseológica no está siempre condicionada por la adscripción lingüística y el grado de bilingüismo de los hablantes, sino solo en la muestra alemana.

Hipótesis 6.4: El entorno familiar de los jóvenes influye en el nivel de competencia fraseológica. Respecto a esta variable, hay que destacar que en otras ocasiones había resultado significativa (Andúgar, 2010), lo cual no es de extrañar si tenemos en cuenta que la mayoría de los estudiosos erigen a las 
generaciones mayores ${ }^{94}$ como las más competentes en esta esfera léxica y las transmisoras, en definitiva, del saber fraseológico. Sin embargo, con los datos disponibles en esta investigación, no podemos decir que sea significativa en ningún caso, ni en la muestra conjunta, ni por idiomas. Por tanto, queda refutada la hipótesis, pues, al menos con nuestras muestras de población, el entorno familiar de los jóvenes no parece guardar mucha relación con el nivel de conocimiento fraseológico alcanzado.

Seguimos a continuación con la última hipótesis del trabajo, que intentaba verificar si una interacción entre variables sociales podía ser determinante para explicar el grado de competencia fraseológica alcanzado por los escolares españoles y alemanes, considerado en esta ocasión de manera conjunta. A partir de esta hipótesis, se derivan subhipótesis, que enunciamos a continuación.

HIPÓTESIS 7: La interacción entre algunas variables son significativas para explicar la competencia fraseológica.

Hipótesis 7.1: La interacción entre las variables edad y sexo es significativa para explicar la competencia. Ambas muestran una interacción significativa, pues mientras que las mujeres presentan un nivel de competencia estable y similar en todas las edades analizadas, los hombres parten de una menor competencia inicial y la adquisición de UF es más lenta y progresiva con respecto a las mujeres de la misma edad. Así pues, queda validada la hipótesis acerca de la interacción entre las variables edad y sexo para explicar la competencia.

El resto de hipótesis que aunaban dos factores sociales $(7.2,7.3,7.4,7.5$ y 7.6$)$ no han dados resultados significativos, como se muestra a continuación.

Hipótesis 7.2: La interacción entre las variables edad y bilingüismo es significativa para explicar la competencia. La interacción entre estas variables

${ }^{94}$ Schemann y otros (2013) o Sevilla (2010). 
independientes no resulta significativa, por lo que se refuta la hipótesis, la interacción entre las variables edad y bilingüismo no es significativa para explicar la competencia.

Hipótesis 7.3: La interacción entre las variables edad y entorno familiar es significativa para explicar la competencia. La interacción de estas variables no es significativa para la competencia, por lo que se refuta la hipótesis, la interacción entre las variables edad y entorno familiar no se muestra significativa para explicar la competencia.

Hipótesis 7.4: La interacción entre las variables sexo y bilingüismo es significativa para explicar la competencia. Por el contrario, se ha comprobado que las diferencias entre los correspondientes subgrupos no son estadísticamente significativas, por lo que se refuta igualmente la hipótesis, la interacción entre las variables sexo y bilingüismo tampoco es significativa para explicar la competencia.

Hipótesis 7.5: La interacción entre las variables sexo y entorno familiar es significativa para explicar la competencia queda igualmente refutada al no hallarse diferencias significativas entre los subgrupos correspondientes a las variables sexo y entorno familiar.

Hipótesis 7.6: La interacción entre las variables bilingüismo y entorno familiar es significativa para explicar la competencia. De nuevo se refuta la hipótesis, al no hallar significación estadística en la interacción entre ambas variables, bilingüismo y entorno familiar.

Vistos los resultados, del estudio se derivan algunas conclusiones generales:

1. Los jóvenes españoles y alemanes no muestran diferencias significativas de competencia. En principio, se esperaba que las diferencias fuesen mayores y que la muestra alemana diera cuenta de un mayor conocimiento fraseológico, puesto que en el entorno alemán la fraseología en general y la paremiología en particular no 
han estado tradicionalmente tan estigmatizadas como en el entorno español. Sin embargo, la competencia demostrada por los jóvenes de ambas lenguas es prácticamente idéntica.

2. La competencia o 'subcompetencia fraseológica' (Corpas, 2001: 68) que muestran los jóvenes es bastante más alta de lo que se esperaba, pues supera el $50 \%$, cifra que algunos autores califican para los adultos como aceptable (Tarnowska, 2004). Así pues, nuestra visión es más positiva que la apuntada por García Sebastià (2014: 43) en su estudio:

A hores d'ara, els joves presenten dèficits notables quant al coneixement i l'ús dels fraseologismes. I és que molt sovint tenen dificultats per a comprendre'ls.

3. Es relevante la distinción entre competencia activa y pasiva, así como el tipo de ejercicio que se utiliza para su medición. Generalmente, en los manuales se utilizan ejercicios que miden tan solo la competencia pasiva, por lo que esos datos, en el mejor de los casos, serían solo parciales.

4. La adscripción conceptual de las UF ofrece diferencias de competencia, que, sin embargo, no siempre resultan estadísticamente significativas. Si, tal como postula Ďurčo (1994a: 18), las UF son el «resultado de una actividad de nominación que siempre se deriva de una primera imagen (Bild) de la realidad», sería previsible encontrar esas diferencias en todos los casos. Parece ser que, más allá de esta conceptualización primera, las diferencias entre lenguas se deben más a influencias culturales. ${ }^{95}$ Así, partiendo de un posible "desglose conceptual diferente en cada lengua», según Yaguello (1983: 99), cada vez más gana adeptos una «corriente universalista, que postula, bajo diferencias de superficie, operaciones mentales idénticas».

\footnotetext{
${ }^{95}$ En el presente trabajo, no hemos abundado en las fuentes, objeto de investigación en sí mismo que exigiría de otros trabajos.
} 
5. Los hablantes de las lenguas- en el presente caso, los jóvenes españoles y alemanes- deben ser el centro de interés cuando se trata de realizar una investigación lingüística: si las lenguas son el vehículo, ellos son los sujetos indispensables, variados y diferentes, que moldean y definen las características reales de las lenguas. En el presente estudio, hemos querido conferirles el protagonismo que merecen como sujetos de la investigación por medio de la encuesta. Como afirma Yaguello: «El hablante [...] largo tiempo ausente de la lingüística, ha sido introducido recientemente en ella por los sociolingüistas» (Yaguello, 1983: 14). De la visión de la competencia a través de ellos, se ha observado que factores como la edad, el sexo o el bilingüismo pueden determinar en parte la competencia.

6. La interacción entre algunos factores sociales es determinante para la competencia: como se ha visto en nuestro estudio, la interacción entre la edad y el sexo parece afectar al conocimiento fraseológico, mientras que aisladamente no ofrecían resultados tan significativos.

A partir de las conclusiones obtenidas en la presente investigación, surgen diferentes retos de cara al futuro y nuevas exigencias en el estudio empírico de la competencia fraseológica, como es la necesidad de contar con muestras de población más amplias, así como profundizar en diferentes aspectos teóricos y metodológicos.

Por otro lado, los resultados obtenidos pueden tener una influencia directa en la fraseología aplicada y en sus diferentes vertientes, como es la didáctica de la fraseología, y en particular en el campo que nos interesa, la enseñanza del alemán a hispanohablantes jóvenes como los analizados en el presente estudio. Tal como afirma Sagban (2010):

Una buena enseñanza de la fraseología española a extranjeros exige un estudio contrastivo de la fraseología de la lengua meta (L2) y de la lengua nativa (L1) de los estudiantes» (Sagban, 2010: 170). 
Es necesario realizar estudios contrastivos previos, y tal como el de Sagban analiza el par español-árabe para la enseñanza del español, nuestro trabajo tendría especialmente validez para la docencia del alemán a españoles.

En definitiva, consideramos que un planteamiento de didáctica de la fraseología alemana dirigida a hispanohablantes debería partir, a nuestro juicio, del establecimiento de un corpus de UF que cumpliera tres premisas:

1. Equivalencia: las expresiones que queremos enseñar deben tener equivalente fraseológico en español-alemán,

2. Frecuencia: deben ser expresiones usuales y conocidas, verificado en el estudio empírico,

3. Actualidad: deben ser expresiones en uso en la lengua meta que queremos enseñar, el alemán, también verificado en el estudio.

A partir de estas premisas, la didáctica de la UF en la clase de alemán se podría realizar desde un primer momento teniendo en cuenta estos requisitos (Andúgar, 2008: 791):

1. Conectar con el momento de aprendizaje

2. Delimitar las estategias a utilizar

3. Ajustar el nivel de dificultad de la actividad

En suma, no creemos que haya que postergar necesariamente el inicio del aprendizaje de la fraseología en el aula de alemán hasta adquirir un buen nivel en el idioma, tal y como mantienen otros autores (Ruiz Gurillo, 2000), sino que este puede tener lugar desde las primeras etapas de dicho aprendizaje. De hecho, tal como sostiene Torrent-Lenzen (2008), incluso a los propios hablantes de una lengua les supone una dificultad delimitar el significado de las UF:

Está claro que el valor comunicativo o significado completo de muchas unidades fraseológicas no es determinable sin más ni más, ni siquiera por el hablante nativo, que las usa aplicando su saber lingüístico más intuitivo (Torrent-Lenzen, 2008: 1435). 
Así pues, se puede y aun se debe enseñar fraseología desde un primer momento, y propiciar que los estudiantes se familiaricen en la L2 también con el uso de estas expresiones que, como pueden comprobar, existen y usan también en su propia lengua nativa. De esta manera, induciremos a un aprendizaje real y más completo de la lengua, y propiciaremos la sensibilidad idiomática, «cuando una palabra llama obligatoriamente a otra» (Yaguello, 1983: 44). Como también dice Millás, personaje de la novela del autor del mismo nombre en su visita al psicoanalista:

- [...] Ahora no me pasa nada, nada especialmente patológico al menos, y me apetece disfrutar de un análisis en estas condiciones. Es un regalo que me hago.

Frente al silencio de la analista, Millás siguió hablando, dijo que tras pronunciar la palabra «regalo», le habían dado ganas de decir «envenenado», «regalo envenenado».

- No porque se trate de un regalo envenenado- aclaró-, sino por una cuestión de orden mecánico. Ya sabe, hay palabras que llaman a otras (Millás, 2014: 107).

'Palabras que llaman a otras' continuamente. En esto consiste, en definitiva, el juego que es el lenguaje y las elecciones que realizan los hablantes en cada momento.

Queda mucho por hacer y la presente investigación pretende ser solo un paso más en la tarea de la divulgación fraseológica. Hacemos nuestras las palabras de Eco cuando afirma:

Lo importante es hacer las cosas con gusto. [...] La tesis puede vivirse como un juego, como una apuesta, como una búsqueda del tesoro (Eco, 1977: 265-266).

Sin duda, como un tesoro la hemos concebido nosotros, y un tesoro queesperamos- tenga consecuencias positivas en el aprendizaje del alemán por parte de nuestros alumnos. 



\section{BIBLIOGRAFÍA}

ABRAHAM, W. (1989): «Idioms in contrastive and in universally based typological research: towards distinctions of relevance», en Everaert, M. y E.- J. Van der (eds.): Proceedings of the first Tilburg workshop on idioms, ITK, Tilburg (1989: $1-22)$.

AbRAmov, N. (1915): Slovar' russkix sinonimov i sxodnyx po smyslu vyraženij, Izdanie četvertoe, Petrograd.

AGost, R. (2007a): «El concepto de equivalencia traductora: Perspectiva histórica», Revista de la Facultad de Humanidades y Lenguas Modernas, 10, Diciembre, Universidad Ricardo Palma, Lima, 75-86.

- (2007b): «Traductología actual: Nuevas formas de abordar la relación entre original y traducción", Revista de la Facultad de Humanidades y Lenguas Modernas, 10, Diciembre, Universidad Ricardo Palma, Lima, 87-102.

AGRICOLA, E. (1962): Wörter und Wendungen. Wörterbuch zum deutschen Sprachgebrauch, Bibliographisches Institut, Mannheim.

AGRICOLA, J. (1529): Drey hundert Gemeyner Sprichwörter/der wir Deutschen uns gebrauchen/und doch nicht wissen woher sie kommen, Haganow.

AKTAŞ, A. (2010): «Eine kontrastive Darstellung der deutschen und türkischen Geld-Phraseologismen», en Korhonen, J. y otros (eds.) (2010a: 301-308).

ALESSANDRO, A. Y P. ZAMORA (2011): «Un análisis lingüístico y traductológico de algunos enunciados pragmáticos en una perspectiva contrastiva españolitaliano», en Pamies, A. y otros (eds.) (2011b: 139-146). 
AlMELA, R. y otros (eds.) (2005): Fraseología contrastiva con ejemplos tomados del alemán, español, francés e italiano, Universidad de Murcia, Murcia.

Amigot CAStILLO, L. (2011): «Fórmulas rutinarias con forma interrogativa y fuerza ilocutiva expresiva: análisis contrastivo alemán-español y problemas equivalencia», en Pamies, A. y otros (eds.) (2011b: 205-214).

Amosova, N. N. (1963): Osnovy anglijskoj frazeologii, Izdatel'stvo Leningradskogo universiteta, Leningrad.

ANDÚGAR ANDREU, I. (2008): "Introducción de la fraseología en la clase de alemán», en Blas Arroyo, J. L. y otros (2008: 781-791).

- (2010): Análisis de la competencia fraseológica de los jóvenes: estudio contrastivo español-alemán (Trabajo de Investigación, inédito).

- (2010): «Antiredensarten in der spanischen Pop-Musik der 80er Jahre. ,Gabinete Caligari' als Modell der menschlichen Weisheit», en Korhonen, J. y otros (eds.) (2010b: 217-225).

ANIČKov, I. E. (1964): «Idiomatika idiom i idiomatica idiomatizmov», en Aničkov (1997: 147-165).

— (1997): Trudy po jazykoznaniju, Nedjalkov, Sankt-Peterburg.

ApRESJAN, J. D. (2004): "O semantičeskoj nepustote i motivirovannosti leksičeskix funkcij glagolov», en Problema russkoj leksikografii. Tesizy dokladov meždunarodnoj konferencii Šestye Šmelevskie čtenija 24-26 fevralja 2004 g., Moskua (4-10).

ARRIVÉ, M. (2007): Lingüística y psicoanálisis, Siglo XXI Editores, Madrid. 
ARSENT'EVA, E. F. (1993): Sopostavitel'nyj analiz frazeologičeskix edidnic, semantičeski orientirovannyx na čeloveka, $v$ russkom i anglijskom jazykax $i$ voprosy sozdanija russko-anglijskogo slovarja, Diss. Kazan', KGU.

ARSENTEVA, E. (2011): «The main problems of multilingual phraseological dictionary compilation», en Pamies, A. y otros (eds.) (2011b: 81-88).

BAKER, M. (1992): In Other Words. A Coursebook on Traslation, Routledge London/Nueva York.

BALly, C. (1951/1909): Traité de stylistique française, Klincksieck.

BalzeR, B. (2012): «"Wenn du mich fragst...": hypotaktische Phraseotexteme deutsch und spanisch», en Pamies, A. y otros (eds.) (2012: 111-121).

BALzeR, B. y M. RADERS (2004): «Aus der Küche geplaudert und Wein auf Bier, das rat ich dir: Methodologische Bemerkungen und empirische Befunde zur kontrastiven interkulturellen Phraseologie und Parömiologie», en Estudios Filológicos Alemanes 5, 307-333.

BALZER, B. y otros (2005): "Lug und Trug: Interkulturelle Untersuchungen zu den Wortfeldern "Lüge“ und "Betrug" in deutschen und spanischen Phraseologismen», en Heine, A. y otros (eds.): Deutsch als Fremdsprache. Konturen und Perspektiven eines Faches. Festschrift für Barbara Wotjak zum 65. Geburstag, München, 167-180.

BAPTISTA, J. y D. CATALÀ (2012): «What glues idioms together may not be just statistics alter all? The case for compound adverbs in Portuguese and Spanish», en Pamies, A. y otros (eds.) (2012: 19-27). 
Baranov, A. N. y D. O. Dobrovol'skiJ (1998): «Vnutrennjaja forma idiom i problema tolkovanija», Izvestija RAN, serija literatura i jazyka 1 (Tom 57), 3644.

BauR, S. R. y C. Chlosta (eds.) (1995): Von der Einwortmetapher zur Satzmetapher, Universitätsverlag Dr. N. Brockmeyer, Bochum.

- (1996a): «Sprichwörter: ein Problem für Fremdsprachenlehrer wie lerner?!», en Deutsch als Fremdsprache, 2, 91-102.

— (1996b): «Welche Übung macht den Meister? Von der Sprichwortforschung zur Sprichwortdidaktik», en Fremdsprache Deutsch, 15, Goethe- Institut, Klett Verlag, 16-24.

BEINHAUER, W. (1978): Stilistisch-phraseologisches Wörterbuch SpanischDeutsch, Hueber, München.

BERTHEMET, E. (2010): «"Phraseological Equivalence" in digital multilingual diccionaries», en Korhonen, J. y otros (eds.) (2010a: 351-358).

- (2011): «Prototype of a digital multilingual phraseological dictionary», en Pamies, A. y otros (eds.: 2011b: 71-80).

Blas Arroyo, J. L. (2005): Sociolingüística del español. Desarrollo y perspectivas en el estudio de la lengua española en contexto social, Cátedra, Madrid.

- (1997): «Valenciano y castellano. Actitudes lingüísticas en la sociedad valenciana», disponible en http://www.cervantesvirtual.com/obra-visor/hispania-19/html/025685ca-82b2-11df-acc7-002185ce6064_5.html\#27 (julio 2015). 
Blas Arroyo, J. L. y otros (2008): Discurso y Sociedad II. Nuevas contribuciones al estudio de la lengua en un contexto social, Universitat Jaume I, Castelló.

Bock, B. (2010): «Kann man indogermanische Phraseologismen systematisch rekonstruiren?», en Korhonen, J. y otros (eds.) (2010a: 129-135).

BuRgeR, H. (1973): Idiomatik des Deutschen, Niemeyer, Tübingen.

- (1977): «Probleme einer historischen Phraseologie des Deutschen», en Beiträge zur Geschichte der deutschen Sprache und Literatur, 99, Tübingen, 124.

- (1998): Phraseologie: eine Einführung am Beispiel des Deutschen, Erich Schmidt, Berlin.

- (1999): «Phraseologie- Die Situation des Faches aus germanistischer Perspektive», en Revista de Filología Alemana 7, 185-207.

- (2001): «Helvetismen in der Phraseologie- Vorkommen und stilistische Funktionen», en Hartmann, D. (ed.) (2001: 49-80).

BURGER, H. y A. BUHOFER (1981): «Phraseologie als Indikator für Text und Stiltypen», en WW6/81, 377-398.

BURGER, H. Y P. ZÜRRER (2010): «Französische und Italienische Einflüsse auf die deutsche Phraseologie- Wann es sie gab und ob es sie heute noch gibt», en Korhonen, J. y otros (eds.) (2010a: 73-90).

BuRgeR, H. y otros (eds.) (1982): Handbuch der Phraseologie, Walter de Gruyter, Berlin/Nueva York. 
Burger, H. y otros (eds.) (2007): Phraseologie: Ein internationales Handbuch Zeitgenössicher Forschung= Phraseology: an International Handbook of Contemporary Research, Walter de Gruyter, Berlin/ New York.

BUITRAGO, A. (2008): Diccionario de dichos y frases hechas, Espasa, Madrid.

Bustos PlAZA, A. (2005): «Poner en movimiento/in Bewegung setzen: ¿Verbos pseudocopulativos españoles frente a verbos funcionales alemanes?», en Almela, R. y otros (eds.) (2005: 185-195).

CALeRo, J. A. (2011): «La fuerza ilocutiva socialmente reprochable en el léxico: análisis contrastivo checo-español», en Pamies, A. y D. Dobrovol'skij (eds.) (2011: 179-187).

CANDÓn, M. y M. BONET (1994): A buen entendedor... Diccionario de frases hechas de la lengua castellana, $5^{\mathfrak{a}}$ ed., Anaya/Mario Muchnik, Madrid.

CARnEAdO, Z. y A. M. TRISTÁ (1985): Estudios de Fraseología, Instituto de las ciencias de Cuba, La Habana.

Cartagena, N. y M. Gauger (1989): Vergleichende Grammatik SpanischDeutsch, Dudenverlag, Manheim/Wien/Zürich.

CASARES, J. (1950/1992): Introducción a la lexicografía moderna, CSIC, Madrid.

Castillo Carballo, M. A. (2015): De la investigación fraseológica a las decisiones fraseográficas, Academia del hispanismo, Vigo.

ČERMAK, F. (1978): «Idiomatika, frazeologie a lexikografie», Slovo a slovesnost, 39, 40-54.

— (1982): Idiomatika a frazeologie češtiny, Universita Karlova (učebný text). 
ČERNIŠEVA, I. I. (1970): Frazeologija sovremennogo nemeckogo jazyka, Moskua.

- (1976): «Tektobrazujuščije potencii frazeologičeskich jedinic (na materiale nemeckoj frazeologii)», en Sbornik naučnych trudov MGPIIJa, 103, Lingvistika teksta, Moskua, 256-263.

- (1981a): «Das phraseologische System und seie semantischen Kategorien (an deutschem Material)», Reader zur sowjetischen Phraseologie, 29-50.

- (1981b): «Zum Problem der phraseologischen Semantik», en Untersuchungen zur deutsche Phraseologie, 424-429.

— (1986): «Phraseologie», en Stepanova, M. D. y I. I. Černiševa: Lexikologie der deutschen Gegenwartssprache, Vysšaja Škola, Moskau, 175-230.

ČennIŠEVA, I. I. y M. D. Stepanova (eds.) (1975): Lexikologie der Deutschen Gegenwartssprache, Vysšaja Škola, Hochschule, Moscú.

ChlostA, C. y otros (eds.) (1994): Sprachbilder zwischen Theorie und Praxis, Brockmeyer, Bochum.

ConCA, M. (1987/1990): Paremiologia, Biblioteca lingüística catalana, Univ. Valencia, Valencia.

Conca, M. y J. GuIA (2014): La fraseologia. Principis, mètodes i aplicacions, Bromera, Valencia.

CORPAS PASTOR, G. (1994): Un estudio paralelo de los sistemas fraseológicos del inglés y del español, Universidad Complutense de Madrid, Madrid (ed. microficha, Universidad de Málaga 1995) (Tesis doctoral). 
—(1996): Manual de fraseología española, Gredos, Madrid.

- (2000): «Acerca de la (in)traducibilidad de la fraseología», en Corpas Pastor, G. (ed.) (2000: 483-522).

- (2001): «La creatividad fraseológica: efectos semántico-pragmáticos y estrategias de traducción», Paremia 10, Madrid, 67-78.

- (2003): Diez años de investigación en fraseología: Análisis sintácticossemánticos, contrastivos y traductológicos, Iberoamericana, Madrid.

Corpas PAstor, G. (ed.) (2000): Las lenguas de Europa: Estudios de fraseología, fraseografía y traducción, Comares, Granada.

CoSERIU, E. (1966): «Structure lexicale et enseignement du vocabulaire», en Actes du premier colloque international de linguistique appliquée, 175-217.

— (1977): Principios de semántica estructural, Gredos, Madrid.

Cox, L. (1993): Phraseologische Wendungen im Vergleich Spanisch-Deutsch. eine textuell-pragmatische Untersuchung, Fabricio Impresores, Santiago de Chile (Tesis doctoral 1991).

Crida Álvarez, C. A. (2011): «La sangre en las unidades fraseológicas y paremias del español y del griego. Estudio comparativo y propuesta de uso práctico», en PAMIES, A. y otros (eds.) (2011a: 119-128).

DIADECHKO, L. (2010): «Winged words as a nation consolidating factor», en Korhonen, J. y otros (eds.) (2010a: 137-142). 
DoBROVOL'SKIJ, D. (1981): «Semanalyse bei der Untersuchung der phraseologischen Semantik», en Wissenschaftliche Zeitschrift der Karl-MarxUniversität Leipzig, Gessellschaftliche Reihe 30/5, 444-448.

- (1982): «Zum Problem der phraseologisch gebundenen Bedeutung», en Beiträge zur Erforschung der deutschen Sprache (Halle) 2, 52-67.

- (1987): «Texbildende Potenz von Phraseologismen», en Linguistische Studien, Reihe A, 164, 69-85.

- (1988): Phraseologie als Objekt der Universalienlinguistik, VEB Verlag Enzyklopädie, Leipzig.

- (1992): «Phraseologie und sprachliches Weltbild», en C. Földes (ed.), Deutsche Phraseologie in Sprachsystem und Sprachverwendung, Praesens, Wien, 171-195.

- (1995): Kognitive Aspekte der Idiom-Semantik: Studien zum Thesaurus deutscher Idiome, Günter Narr, Tübingen.

- (1998): «Russian and German idioms from a contrastive perspective», en Weigand, E. (ed.): Constrastive lexical semantics, Benjamins (=Series IVCurrent issues in linguistic theory, vol. 171), Amsterdam/Philadelphia, 227-242.

- (1999): «Kulturelle Spezifik in der Phraseologie: allgemeine Probleme und kontrastive Aspekte», en A. Sabban (ed.): Phraseologie und Übersetzen. Phrasemata II, Aisthesis Verlag, Biefield, 41-58.

— (2001): «Zur Motivation in der Idiomatik», en Häcki Buhofer, A. y otros (eds.) (2001: 89-98). 
- (2011): «Cross linguistic equivalence of idioms: does it really exist?», en Pamies, A. y D. Dobrovol'skij (eds.) (2011: 7-24).

Dobrovol'SkIJ, D. y E. PilRaInen (1997): Symbole in Sprache und Kultur: Studien zur Phraseologie aus kultursemiotischer Perspektive, Brockmeyer, Bochum.

DoBRovol'SKIJ, D. y T. FILIPENKO (2007): «Russian Phraseology», en Burger, H. y otros (eds.) (2007: 714-727).

Dobrovol'SKIJ, D. y otros (2010): «Phraseologie im „Neuen DeutschRussischen Großwörterbuch“», en Korhonen, J. y otros (eds.) (2010a: 247-253).

DomíngueZ, P. y otros (1995): El español idiomático. Frases y modismos del español, Ariel Lenguas Modernas, Ariel, Barcelona.

Doval HueCAS, G. (1995): Del hecho al dicho, Ediciones del Prado, Madrid.

Drosdowski, G. y W. SCHOLZE-STUBENRECHT (1992/2002): Redewendungen und sprichwörtliche Redensarten, Band 11, Duden, Mannheim.

ĎURČo, P. (1994a): Probleme der allgemeinen und kontrastiven Phraseologie am Beispiel Deutsch und Slowakisch, Julius Groos, Heidelberg.

- (1994b): «Das Wort als phraseologische Konstituente. Zur Beziehung der linguistischen und psycholinguistischen Standpunkte», en Sandig, B. (ed.): (1994: 67-90).

— (2007): «Slovak Phraseology», en Burger, H. y otros (eds.) (2007: 728-736). 
- (2001): «Bekannheit, Häufigkeit und lexikographische Erfassung von Sprichwörtern. Zu parömiologischen Minima für DaF», en Häcki Buhofer, A. y otros (eds.). (2001: 99-106).

- (2010): «WICOL- Deutsch-Slowakisches Kollokationswörterbuch», en J. Korhonen y otros (eds.) (2010a: 255-260).

Eco, U. (1977): Como se hace una tesis, Gedisa, México D. F.

ECKERT, R. (1979): «Akpekte der konfrontativen Phrasaeologie», Linguistische Studien, Reihe A 56 (74-80).

EISMANN, W. (1989): «Zum Problem der Äquivalenz von Phraseologismen», en G. Gréciano (ed.) (1989: 83-93).

- (1994): «Nationales Stereotyp uns sprachliches Klischee. Deutsche und Slawen im Lichte ihrer Phraseologie und Parömiologie», en Sandig, B. (ed.): (1994: 81-107).

- (1995): «Pragmatik und kulturelle Spezifik als Problem der Äquivalenz von Phraseologismen», en Baur, S. R. y C. Chlosta (eds.) (1995: 95-119).

- (2001): «Jenseits der Weltbild-Phraseologie. Vergessene psychoanalytische Perspektiven in der Phraseologie», en Häcki Buhofer, A. y otros (eds.) (2001: 107-121).

- (2010): «Remarks on Russian phrasemes in European languages", en Korhonen, J. y otros (eds.) (2010a: 61-72).

ELORDUY, E. y C. FANDRYCH (1996): «Seltsame Vergleiche, komische Wendungen. Idiomatische Wendungen und Wortbildungen im Deutschunterricht in Mexiko", en Fremdsprache Deutsch, 15, Goethe- Institut, Klett Verlag, 42-46. 
ESPUNYES, J. (2007): Dites, locucions i frases fetes, Proa, Barcelona.

ETTINGER, S. (1982): «Formación de palabras y fraseología en la lexicografía», en Haensch, G. y otros (1982: 233-258).

FEdorov, A. I. (1980): Sibirskaja dialektnaja fraszeologija, Novosibirsk.

Fernández Bravo, N. (2001): «Rhetorik und Phraseologie im Text "Das Lied von der großkapitulation (in Bertold Brechts ,Mutter Courage und ihre Kinder')“"», en Häcki Buhofer, A. y otros (eds.) (2001: 135-149).

FIEDLER, S. (2010): «"Am Ende des Tages zählt die Performance“ - Der Einfluss des Englischen auf die Phraseologie der deutschen Gegenwartsprache», en Korhonen, J. y otros (eds.) (2010a: 163-172).

FIRTH, J. R. (1957): Papers in Linguistics 1934-1951, Oxford University Press, London.

FIX, U. (1971): Das Verhältnis von Syntax und Semantik im Wortgruppenlexem. Versuch einer objektivierten Klassifizierung und Definition des Wortgruppenlexems, Diss. A., Leipzig.

FLEISCHER, W. (1982): Phraseologie der deutschen Gegenwartssprache, Bibliographisches Institut, Leipzig.

- (1997): Phraseologie der deutschen Gegenwartssprache, Max Niemeyer, Tübingen.

FÖLDES, C. (1989): "Onymische Phraseologismen als Objekt des Sprachvergleichs», en Gréciano, G. (ed.) (1989: 127-140). 
- (1992): «Feste verbale Vergleiche im Deutschen, Russischen und Ungarischen", en Untersuchungen zur Phraseologie des Deutschen und anderer Sprachen, 61-78.

- (2010): «Auswirkungen des Deutschen auf die Phraseologie seiner östlichen Nachbarsprachen», en Korhonen, J. y otros (eds.) (2010a: 91-107).

Fontanillo Merino, E. (ed.) (1993): Larousse diccionario práctico de locuciones, Larousse Planeta, Barcelona.

FRASER, B. (1970): «Idioms within a Transformational Grammar», Foundations of Language 6, 22-42.

FRIEDRICH, W. (1993/1976): Moderne deutsche Idiomatik, Hueber, Ismaning.

GAK, V. G. (1975): «Frazeologičeskije jedinicy v svete asimetrii jazykovogo znaka», en Voprosy frazeologii VII, Samarkand, 5-13.

GARCíA-PAGE, M. (2008): Introducción a la fraseología española, Anthropos, Barcelona.

GARCía SebAStiÀ, J. V. (2014): «Inferència i subjectivació en la interpretació dels fraseologismes. Un estudi qualitatiu en l'àmbit de l'ensenyament secundari», Revista Internacional d' Humanitats, 31 (maig-agost 2014), CEM OrOc-Feusp, Universitat Autònoma de Barcelona, 43- 54.

GautieR, L. (2001): “„Es machte dem Auersberger Spaß, seine Schwiegermutter, wie in Österreich gesagt wird, aus dem Häuschen zu bringen“. Zur Verwendung (nicht nur) österreichischer Phraseme in österreichischen literarischen Texten», en Häcki Buhofer, A. y otros (eds.) (2001: 151-161). 
GECK, S. (2011): «Guten Appetit! Routineformeln und das Script der Mahlzeit aus interkultureller Perspektive (deutsch-spanisch)», en Pamies, A. y D. Dobrovol'skij (eds.) (2011), 341-348.

GLÄSER, R. (1978): «Syntaktische und semantische Aspekte der Klassifizierung von Phraseologismen», en Neubert, A. (ed.), Zur lexikalische Semantik des Englischen, Akademie, Berlin (1978: 78-98).

— (1986): Phraseologie der englischen Sprache, Niemeyer, Tübingen.

- (2010): «Ländliches Sprichwortgut (Bauer- und Wetterregeln) im Deutschen und Englischen», en Korhonen, J. y otros (eds.) (2010b: 344-354).

GONDEK, A. (2010): «Unterschiedliche Aspekte der Menschenbewertung in der deutschen und polnischen Phraseologie (am lexikografischen Material)», en Korhonen, J. y otros (eds.) (2010b: 305-314).

GontČAROVA, N. (1981): «Antonymische Phraseologismen unter kommunikativen Aspekt», Untersuchungen zur deutsche Phraseologie, 478483.

GonZÁlez ReY, I. (2005): «La noción de "hápax” en el sistema fraseológico francés y español», en Almela, R. y otros (eds.) (2005: 313-327).

GonzÁlez Royo, C. y P. MogorRón Huerta (eds.) (2008): Estudios y análisis de fraseología contrastiva: lexicografía y traducción, Universidad de Alicante, Alicante.

GRÉCIANO, G. (1978): «A propos de la sémantique des expressions idiomatiques en allemand», en Verbum I, 2, 87-110. 
- (1982): «Zur Semantik der deutschen Idiomatik», Zeitschrift für germanistische linguistik, 10, 295-316.

- (ed.) (1989): EUROPHRAS 88: Phraseologie contrastive. Actes du Colloque International Klingenthal-Strasbourg, 12-16 Mai 1988, Université des Sciences Humaines, Département d'Etudes Allemandes, Strasbourg.

GRIEsbach, H. y D. Schulz (2000/1961): 1000 deutsche Redensarten, Langenscheidt, Berlin.

GULAWSKA- GaWKOWSKA, M. (2010): «Emotionale und somatische Konzepte im Deutschen und Polnischen am Beispiel der Phraseologismen mit der Konstituente Nase», en Korhonen, J. y otros (eds.) (2010b: 315-324).

GüNTER, K. (1990): «Äquivalenzbeziehungen in der Phraseologie», Zeitschrift für Slawistik, 35 (4), 505-509.

HÄCKI BUHOFER, A. (1987): «Alltägliche Verstehens- und Erklärungsstrategien bei Phraseologismen», en Burger, H. y R. Zett (eds.): Aktuelle Probleme der Phraseologie, Zürcher Germanistische Studien 9, Bern/Frankfurt a. M., 59-77.

- (1989): «Psycholinguistische Aspekte in der Bildhaftigkeit der Phraseologismen», en Gréciano, G. (ed.) (1989: 165-185).

HÄCKI BuHOFER, A. y otros (eds.) (2001): Phraseologiae Amor. Aspekte europäischer Phraseologie, Schneider, Hohengehren.

HAENSCH, G. y otros (1982): La lexicografía. De la lingüística teórica a la lexicografía práctica, Gredos, Madrid.

HaLLIDAY, M. A. K. (1966): «Lexis as a linguistic Level», en C. E. Bazell y otros (eds.), In Memory of John Firth, Longmans, London, 148-162. 
HARTMAnN, D. (ed.) (2001): „Das geht auf keine Kuhhaut" Arbeitsfelder der Phraseologie, Universitätsverlag Dr. N. Brockmeyer, Bochum.

HATIM, B. y I. MASON (1990): Discourse and the Translator, Longman, London.

HäUSERMANN, J. (1977): Phraseologie: Hauptprobleme der deutschen Phraseologie auf der Basis sotwjetischer Forschungsergebnisse, Tübingen.

HeINEMANN, W. (1981): «Phraseologismen mit neg-Konstituenten und NEGPhraseologismen in der deutschen Gegenwartssprache», en Untersuchungen zur deutschen Phraseologie, Wissenschaftliche Zeitschrift der Karl-MarxUniversität Leipzig, Gesellschafts- und Sprachwissenschaftliche Reihe, 30, 470477.

HeRnÁndez Campoy, J. M. y M. Almeida (2005): Metodología de la investigación sociolingüística, Comares, Granada.

HERZOG, A. y otros (1993): Idiomatische Redewendungen von A-Z. Ein Übungsbuch für Anfänger und Fortgeschrittene, Langenscheidt, Leipzig.

HESSKY, R. (1980): «Zur kontrastiven Untersuchung idiomatischer Wendungen», en Juhasz, J. y G. Szepe: Kontrastive Studien UngarischDeutsch, Akademici Kiadó, 65-76.

- (1989): «Psycholinguistische Aspekte in der Bildhaftigkeit der Phraseologismen», en Gréciano, G. (ed.) (1989: 195-204).

— (1992): «Phraseolexeme als harte Nuß für die zweisprachige Lexikographie», en Földes, C. (ed.): Deutsche Phraseologie in Sprachsystem und Sprachverwendung, Praesens, Wien, 107-124. 
- (1999): «Vermitlungsinstanz zwischen Sprachsystem und Sprachverwendung», en Fernández Bravo, N. y otros (eds.): Phraseme und typisierte Rede, Stauffenburg, Tübingen, 233-241.

- (2001): «Das euphemistische Idiom- eine Problemskizze», en Häcki Buhofer, A. y otros (eds.) (2001: 107-121).

HolzINGER, H. (1993): «Probleme der kontrastiven Phraseologie deutschspanisch am Beispiel somatischer Phraseologismen», en Revista de Filología Alemana, 1, 155-167.

- (1994): «Phraseologismen im Deutschunterricht für Spanischsprechende», en DaF aus spanischer Sicht. Primeres Jornades sobre l'Ensenyament de l'Alemany en Contextos Hispànics: Perspectives Metodològiques, Institut de Ciències de l'Educació de la Universitat Autònoma de Barcelona, Barcelona, 98-112.

- (1996): «Transgression als Norm? Zum „falschen“ Gebrauch von Phraseologismen in bestimmten Textsorten», en Millet, V. (ed.) (1996): Norm und Transgression in deutscher Sprache und Literatur, ludicium, München, 218229.

- (1998a): «Kontrastive Phraseologie und Deutsch als Fremdsprache für Spanischsprechende", en Eismann, W. (ed.): EUROPHRAS 95. Europäische Phraseologie im Vergleich: Gemeinsames Erbe und kulturelle Vielfalt, Bochum (1998: 337-350).

- (1998b): «¿Ni pies ni cabeza? Apuntes sobre sobre la utilización de fraseologismos somáticos en textos de prensa», en Jirku, B. E. y otros (eds.) (1998): El cuerpo en la lengua y literatura alemanas: ein weites Feld, Anejo $\mathrm{n}^{\circ}$ XXX de la Revista Cuadernos de Filología, Universitat de València, Valencia 81-108. 
IÑEsta MenA, E. M. y A. Pamies Beltrán (2002): Fraseología y metáfora: aspectos tipológicos y cognitivos, Granada, Granada lingvistica,

IRIBAREN, J. M. (1994): El porqué de los dichos. Sentido, origen y anécdota de los dichos, modismos y frases proverbiales de España con otras muchas curiosidades, Gobierno de Navarra, Departamento de Educación y Cultura y Turismo, Pamplona.

IRIBAREN, J. M. (1955/2005): El porqué de los dichos. Gobierno de Navarra, Dep. de Cultura y Turismo, Institución Príncipe de Viana, Pamplona.

JAKSCHE, H. y otros (1982): Reader sowjetischer Phraseologie, Walter de Gruyter, Berlin/New York.

JAKOBSON, R. (1981): Ensayos de lingüística general, Seix Barral.

JUNCEDA, L. (2006): Diccionario de refranes, dichos y proverbios, Espasa, Madrid.

JUSKA-BACHER, B. Y S. MEIER (2012): «Die areale Verbreitung sog. phraseologischer "Helvetismen"», en Pamies, A. y otros (eds.) (2012: 257-266).

KEINÄSTÖ, K. (2010): «Arme Ritter zwischen Baum und Borke? Phraseologismen deutscher Herkunft im hohen Norden», en Korhonen, J. y otros (eds.) (2010a: 109-120).

KLAPPENBACH, R. (1968): Probleme der Phraseologie, en Wissenschaftliche Zeitschrift der Kart-Marx-Universität Leipzig, Gesselschafts- und Sprachwissenschaftliche Reihe 17, 221-227.

KLIMASZWESKA, Z. (1991): «Die Phraseologie auf kulturhistorischem Hintergrund am Beispiel des Deutschen, Niederländischen und Polnischen», en Akten des 
VIII Internationalen Germanistenkongresses, Bd. 4, ludicium, München, 362369.

KoČETOVA, T. (1978): «Probleme der phraseologischen Antonymie», Beiträge zur Geschichte der deutschen Sprache und Literatur, 99, 304-315.

KolleR, W. (2007): «Probleme der Übersetzung von Phraseme», en Burger, H. y otros (eds.): Phaseologie: Ein internationales Handbuch zeitgenössicher Forschung, Mouton de Gruyter, Berlin/Nueva York (2007: 605-613).

KöNIG, W. (1998): Dtv-Atlas Deutsche Sprache, Deutscher Taschenbuch Verlag, München.

KORHONEN, J. (1991): «Kontrastive Idiomatik Deutsch-Finnisch. Ein Forschungsbericht», en Korhonen, J. (ed.) (1991: 37-66).

- (2002): «Typologien der Phraseologismen: ein Überblick», en Cruse, D. A. y otros (eds.): Lexikologie: ein Internationales Handbuch zur Natur und Struktur von Wörtern und Wörtschätzen, Walter de Gruyter, Berlin/ Nueva York (2002: 402-407).

- (2007): «Probleme der kontrastiven Phraseologie», en Burger, H. y otros (eds.) (2007: 579-589).

KORHONEN, J. (1987) (ed.): Beiträge zur allgemeinen und germanistischen Phraseologieforschung, Veröffentlichungen des Germanistischen Instituts 7, Oulu.

- (1991) (ed.): Beiträge zur allgemeinen und germanistischen Phraseologie, Westdeutscher Verlag, Opladen. 
- (1992) (ed.): Untersuchungen zur Phraseologie des Deutschen und anderer Sprachen: einzelspezifisch-kontrastiv-vergleichend, Peter Lang, Frankfurt a. M.

KoRHONEN, J. y B. WOTJAK (2001): «Kontrastivität in der Phraseologie», en Helbig, G. y otros (ed.): Deutsch als Fremdsprache. Ein internationales Handbuch, Walter de Gruyter, Berlin/New York (2001: 224-235).

KoRHONEN, J. y otros (eds.) (2010a): Phraseologie global-areal-regional, Akten der Konferenz Europhras 2008 vom 13.-16.08.2008 in Helsinki, Narr, Tübingen.

KORHONEN, J. y otros (eds.) (2010b): EUROPHRAS 2008. Beiträge zur internationalen Phraseologiekonferenz 13.-16.08.2008 in Helsinki, Universität Helsinki, Institut für moderne Sprachen, Germanistik, disponible en http://homepage.univie.ac.at/beata.trawinski/publications/europhras_08.pdf (agosto, 2015).

KRÜGER-LORENZEN, K. (2002): Deutsche Redensarten und was dahintersteckt, Heyne, München.

KüHN, P. (1996): «Redewendungen nur im Kontext!», en Fremdsprache Deutsch, 15, Goethe- Institut, Klett Verlag, 10-16.

- (2007): «Phraseologie des Deutschen: zur Forschungsgeschichte», en Burger, H. y otros (eds.) (2007: 617-643).

KUnIN, A. V. (1970): Anglijskaja fraszeologija, Vysšaja škola, Moskua.

KYRYAKOVA-DinIEVA, T. (2011): «Zwillingsformeln aus der Bibel auf deutsch und bulgarisch- kulturelle Aspekte», en Pamies, A. y D. Dobrovol'skij (eds.) (2011: 137-145). 
LAKKOF, G. y M. JOHNSON (1980): Metaphors we live by, University of Chicago Press, Chicago/London.

LARRETA ZULATEGUI, J. P. (1998): «Fraseología contrastiva alemán-español: hacia un estudio onomasiológico/ideográfico», en Tradición e innovación en los estudios de lengua, literatura y cultura alemanas en España, Sevilla, Kronos Universidad, 461-472.

- (1998/2001): Fraseología contrastiva del alemán y el español, Peter Lang, Frankfurt.

LÁzARO CarReter, F. (1957/1984): Diccionario de términos filológicos, Gredos, Madrid.

Leiva RoJo, J. y G. CORPAS PASTOR (2011): «Placing Italian idioms in a foreign milieu: a case study», Pamies, A. y otros (eds.) (2011b: 289-298).

LÓPEZ LEÓN, J. M. (2013): Introducción a la fraseología y su aplicación a la didáctica: corpus del poniente almeriense, Universidad de Almería. TFM, disponible en http://repositorio.ual.es:8080/jspui/bitstream/10835/2343/1/Trabajo.pdf

LóPEZ MORales, H. (1994): Métodos en investigación lingüística, Ediciones Colegio de España, Salamanca.

LÓPEZ RolG, C. (2001): Aspectos de Fraseología Contrastiva (Alemán-Español) en el Sistema y en el Texto, Universidad de Valencia, Valencia (Tesis doctoral).

- (2002): Aspectos de Fraseología (alemán-español) en el sistema y en el texto, Peter Lang, Frankfurt a. M. 
LUQUe DuRÁN, J. D. D. y L. LUQUe NADAL (2010): «Cómo las metáforas recurren a conocimientos ontológicos y culturales. Fundamentos teóricos del Diccionario Intercultural e Interlingüístico», en Korhonen, J. y otros (eds.) (2010a: 359-366).

LUQUe DuRÁN, J. D. D. y otros (1998): El Arte del Insulto: estudio lexicográfico. Península (col. Atalaya), Barcelona.

MAKKAI, A. (1972): Idiom Structure in English, Mouton, The Hague/Paris.

MANSILLA, A. (2003): «Das Symbol in Sprache und Kultur. Untersuchungen zur deutsch-spanischen Phraseologie», en Burger, H. y otros (eds.): Flut von Texten- Vielfalt der Kulturen. Ascona 2001 zur Methodologie und Kulturspezifisch der Phraseologie, Baltmannsweiler, 219-228.

Marcos García, M. J. (2012): «Los complementos del verbo en las locuciones verbales fijas. Estudio contrastivo en inglés y en español», en Pamies, A. y otros (eds.) (2012: 133-141).

MARTí SOLANO, R. (2012): «The current world economic crisis: phraseological equivalents and variants in English, Spanish and French», en Pamies, A. y otros (eds.) (2012: 133-141).

MARTínet, A. (1985): Sintaxis general, Gredos, Madrid.

MARTínez De SouzA, J. (2003): Manuel de estilo de la lengua española, 2. a ed., Trea, Gijón.

MARTínez LóPeZ, J. A. (1996): La fraseología del español. Acercamiento morfosintáctico, semántico y pragmático, Universidad de Granada, Granada (Tesis doctoral). 
MARTínez MARíN, J. (1996): Estudios de fraseología española, Librería Ágora, Málaga.

MEJRI, S. (2007): «French Phraseology», en Burger, H. y otros (eds.) (2007: 682-691).

MeL'ČUK, I. A. (1960): "O terminach "ustojčivost i idiomatičnost”», Voprosy jazykoznanija 4, 73-80.

- (1974): «Niveles de representación de enunciados y composición del modelo lingüístico "Sentido ↔ Texto"», Prohemio 5, 5-42.

— (1995): «Phrasemes in language and phraseology in linguistics», en Everaert y otros (eds.): Idioms: structural and psychological perspectives, Hillsdale, $\mathrm{NJ} /$ Hove, LEA, UK, 167-232.

Mellado Blanco, C. (2004): Fraseologismos somáticos del alemán, Peter Lang, Frankfurt a. M.

- (2007): «Die Frage der Äquivalenzkriterien in der kontrastiven Phraseologie», en Santana, B. y otros (eds.): Puente entre dos mundos: Últimas tendencias en la investigación traductológica alemán-español, Ediciones Universidad de Salamanca, Salamanca, 261-272.

- (ed.) (2014): Kontrastive phraseologie deutsch-spanisch, Edition Julius Groos, Stauffenburg, Tübingen.

MELONI, I. (2011): «Zur Versprachlichung mimisch-gestischer Zeichen. Kinegramme im Deutschen und im Italienischen», en Pamies, A. y D. Dobrovol'skij (eds.) (2011: 157-166). 
Mena Martínez, F. M. (2002): La desautomatización de las paremias inglesas por sustitución: un estudio cognitivo, Universidad de Murcia, Murcia (Tesis doctoral).

MendiviL GiRó, J. L. (1999): Las palabras disgregadas. Sintaxis de las expresiones idiomáticas y los predicados complejos, Prensas Universitarias de Zaragoza, Zaragoza.

MIEDER, W. (1975): «Sprichwörter im modernen Sprachgebrauch», en Muttersprache 85 (65-88).

- (1979): Deutsche Sprichwörter und Redensarten. Arbeitstexte für den Unterricht, Philipp Reclam jun., Stuttgart.

— (1983): «Sprichwörter unterm Hakenkreuz», en Muttersprache, 1-30.

- (1985a): Deutsche Sprichwörter und Redensarten, Philipp Reclam jun., Stuttgart.

- (1985b): Sprichwort, Redensart, Zitat. Tradierte Formelsprache in der Moderne, Peter Lang, Bern.

- (1992): Sprichwort- Wahrwort? Studien zur Geschichte, Bedeutung und Funktion deutscher Sprichwörter, Peter Lang, Frankfurt.

- (1993): «Deutsche Sprichwörter im amerikanischen Sprachunterricht», Die Unterrichtpraxis 26,1, 13-21.

MigLA, I. (2010): «Phraseologismen mit einem Personennamen im Deutschen, Russischen und Lettischen», en Korhonen, J. y otros (eds.) (2010b: 282-290).

MILLÁs, J. J. (2014): La mujer loca, Seix Barral, Barcelona. 
MiRA ÁLVAREZ, G. D. (2011): «La equivalencia en la traducción de las unidades fraseológicas. Un estudio empírico", en Íkala: revista de lenguaje y cultura, 16, 27 , disponible en

http://aprendeenlinea.udea.edu.co/revistas/index.php/ikala/article/view/8657/79 83 (julio, 2015).

MISIEK, D. (2010): «Phraseologismen in deutschen und polnischen Meldungen, Berichten und Kommentaren. Eine quantitative Analyse", en Korhonen, J. y otros (eds.) (2010b: 325-333).

MoHR-ELFALD, S. (2010): «Zum phraseologischen Ausdruck von Temporalität im deutsch-französischen Vergleich», en J. Korhonen y otros (eds.) (2010a: 381388).

MOLINER, M. (1984): Diccionario de uso del español, Gredos, Madrid.

MolotKov, A. I (1967): «Frazeologyzmy russkogo jazyka i principy ich leksikografičeskogo opisanija», en Frazeologičeskij slovar' russkogo jazyka, Sovjetskaja Enciklopedija, Moskua (7-23).

— (1977): Osnovy frazeologii russkogo jazyka, Nauka, Leningrad.

MORENO FERnÁNDEZ, F. (1990): Metodología sociolingüística, Gredos, Madrid.

Moreta LaRA, M. y F. Álvarez CuRiel (1995): Los andaluces en el refranero, Arguval, Málaga.

MORIENKO, V. M. (1980): Slavjanskaja frazeologija, Moskva.

Nedwed, S. y C. Romeu (2009): Diccionario de fraseología del español y alemán, Ediciones del Serbal S.A., Barcelona (E-Book). 
Neubert, A. y G. M. Shreve (1992): Translation as Text, The Kent State University Press, Kent/Ohio/London.

NORRICK, N. R. (2007): «English Phraseology», en Burger, H. y otros (eds.) (2007: 615-619).

ORTEGa y Gasset, J. (1964): El hombre y la gente, Revista de Occidente, II, Madrid.

Ortega OJedA, G. y M. I. GonzÁlez AguiAR (2000): Diccionario de expresiones y refranes del español de Canarias, Cabildo Insular de Gran Canaria, Las Palmas de Gran Canaria.

Ortega, G. y G. Rochel (1995): Dificultades del español, Ariel Lenguas Modernas, Barcelona.

OzHEGov, S. I. (1974): Lexicología. Lexicografía. Cultivo del lenguaje, Moscú.

PALM, C. (1991) (ed.): EUROPHRAS 90, Almqvist \& Wiksell International, Uppsala.

— (1992): «"Umgekehrt wird ein Schuh draus". Idiomatizität und Konnotation im Phrasem», en C. Földes (ed.): Deutsche Phraseologie in Sprachsystem und Sprachverwendung, Praesens, Wien (89-106).

- (1994): «Habent sua fata idiomata. Beobachtungen zur Polysemie von Phraseologismen», en Sandig, B. (ed.): EUROPHRAS 92. Tendenzen der Phraseologieforschung, (1994: 431-446).

— (1997): Phraseologie. Eine Einführung, Günter Narr, Tübingen. 
- (2010): «Implementación lexicográfica de los símbolos desde un enfoque multilingüe transcultural», en Korhonen, J. y otros (eds.) (2010a: 339-349).

PAMIES, A. y O. POTÁPOVA (2005): «Metaphoric competence and the recognition of idioms: an experimental approach», en Almela, R. y otros (eds.) (2005: 259281).

Pamies, A. y D. Dobrovol'SkIJ (eds.) (2011): Linguo-Cultural Competence and Phraseological Motivation, Schneider, Baltmannsweiler (Actas de la conferencia internacional EUROPHRAS 2010, Granada).

PAMIES, A. y otros (eds.) (2011a): Paremiología y herencia cultural, Granada Lingvistica / Educatori, Granada (Actas de la conferencia internacional EUROPHRAS 2010, Granada).

PAMIES, A. y otros (eds.) (2011b): Multi-Lingual Phraseography: Second Language Learning and Translation Applications, Schneider Verlag Hohengehren, Baltmannsweiler (Actas de la conferencia internacional EUROPHRAS 2010, Granada).

Pamies, A y otros (eds.) (2012): Phraseology and Discourse: Cross Linguistic and Corpus-based Approaches, Schneider Verlag Hohengehren, Baltmannsweiler (Actas de la conferencia internacional EUROPHRAS 2010, Granada).

PÀMIES I RIUDOR, V. (2008): Vocabulari de paremiologia [en línia], Wordpress, Vallromanes, disponible en http://refranys.wordpress.com/vocabulari-deparemiologia (agosto, 2015).

PAscual LóPez, X. (2003): Fraseologia espanyola d' origen llatí i motiu grecorromà (Tesis doctoral). 
PAVIČ PINTARIČ, A. (2010): «Das deutsche Element in der kroatischen Phraseologie», en Korhonen, J. y otros (eds.) (2010a: 173-178).

PAzos, J. M. (2005): Detección automatizada de fraseologismos, Universidad. de Granada, Granada, disponible en http://hera.ugr.es/tesisugr/15476935.pdf (Tesis doctoral) (julio, 2015).

PEJovic, A. (2011): «Las comparaciones estereotipadas en la fraseología española y serbia: análisis contrastivo», en Pamies, A. y otros (eds.) (2011b: 157-166).

Pellen, R. (2001): «Phraséologie et phraséographie en espagnol. De la typologie à l'inventaire de resources», en Bulletin Hispanique 2 (607-673).

PIIRAINEN, E (2000): Phraseologie der westmünsterländischen Mundart. Teil I: Semantische, kulturelle und pragmatische Aspekte dialektaler Phraseologismen. Teil 2: Lexikon der westmünsterländischen Redensarten, Baltmannsweiler.

- (2010): "Common features in the phraseology of European languages: Cultural and areal perspectives», en Korhonen, J. y otros (eds.) (2010a: 15-27).

PILZ, K. D. (1981): Phraseologie, Metzler, Stuttgart.

— (1983): «Zur Terminologie der Phraseologie», en Muttersprache 5-6 (336350).

PIÑEL, R. (2003): «Der Tod und das Sterben in der deutschen und spanischen Phraseologie. Ein interkultureller Vergleich» en Burger, H. y otros (eds.): Flut von Texten- Vielfalt der Kulturen. Ascona 2001 zur Methodologie und Kulturspezifisch der Phraseologie, Baltmannsweiler, 229-238. 
- (2011): «La imagen del Diablo en la fraseología española y alemana» en Pamies, A. y D. Dobrovol'skij (eds.) (2011), 125-135.

RAE (1992): Diccionario de la lengua española, 21. ed., Espasa Calpe, Madrid (DRAE)

RAJXŠTEJN, A. D. (1980): Sopostavitel'nyj analiz nemeckoj i russkoj frazeologii, Moskva.

REGaLES, A. (1988): "Sobre el valor de algunos de los verbos más frecuentes en los giros idiomáticos del alemán y del español», en Wotjak, G. (ed.), Linguistische Studien/ Reihe A. Studien zur Sprachkonfrontation. Materialien der I. Internationalen Arbeitstagung zum Romanisch-Deutschen Sprachvergleich, Berlin (72-87).

RIUTORT I RIUTORT, M. (2011): «Fraseología y refranes en las Sagas de islandeses y su traducción al español», en Pamies, A. y otros (eds.) (2011a: 203-211).

RöHRICH, L. (1989): «Alemannische Sprichwörter. Form und Funktion», en G. Gréciano (ed.) (1989: 357-370).

- (2003/1973): Lexikon der sprichwörtlichen Redensarten (3 Bände), Herder, Freiburg.

RÖHRICH, L. y W. MIEDER (1977): Sprichwort, Metzler, Stuttgart.

RoJZENZON, L. I. y J. J. AVALIANI (1967): «Sovremennye aspekty izučenija frazeologii», en Problema frazeologii $i$ zadači ee izučenija $v$ vysšej škole, Vologda (68-81). 
RotHKEgeL, A. (1973): Feste Syntagmen. Grundlagen, Strukturbeschreibungen und automatische Analyse, Max Niemeyer, Tübingen.

Ruiz GuRILLo, L. (1997): Aspectos de fraseología teórica española, Cuadernos de Filología, XXIV, Universidad de Valencia, Valencia.

- (1998): «Una clasificación no discreta de las unidades fraseológicas del español», en Wotjak, G. (ed.) (1998: 13-37).

- (2000): «Un enfoque didáctico de la fraseología española para extranjeros» (1), Especulo, Universidad Complutense de Madrid, Madrid, disponible en http://www.edinumen.es/index.php?option=com_content\&view=article\&id=90\&c atid=13\&ltemid=51 \&lang=es (agosto, 2015).

- (2000): «Un enfoque didáctico de la fraseología española para extranjeros», en Coperías, M. J. y otros (eds.) (2000): Aprendizaje y enseñanza de una segunda lengua, Cuadernos de Filología, Universitat de València, Valencia.

SABbAN, A. y J. WIRRER (eds.) (1991): Sprichwörter und Redensarten im interkulturellen Vergleich, Westdeutschen Verlag, Opladen.

SAGBAN, M. K. (2010): La fraseología comparada del español y el árabe de Irak: su aplicación a la enseñanza de las unidades fraseológicas en el aula de ELE, Universidad de Granada, Granada, disponible en http://hera.ugr.es/tesisugr/18754582.pdf (Tesis doctoral) (septiembre 2015).

Salvador Liern, V. y A. Piquer Vidal (eds.) (2000): El discurs prefabricat. Estudis de fraseologia teòrica i aplicada (Actes de les Jornades de Fraseologia Comparada), Universitat Jaume I, Castelló.

SANCHO CRemades, P. (1999): Introducció a la fraseologia. Aplicació al valencià col.loquial, Denes, Paiporta (València). 
SANDIG, B. (ed.) (1994): EUROPHRAS 92. Tendenzen der Phraseologieforschung. Studien zur Phraseologie und Parömiologie, Universitätsverlag Dr. N. Brockmeyer, Bochum.

ŠANSKIJ, N. M. (1963): Frazeologija sovremennogo russkogo jazyka, Moskua.

SANTAMARía PÉREZ, M. I. (2000): Tratamiento de las unidades fraseológicas en la lexicografía bilingüe español-catalán, Universidad de Alicante. (Tesis doctoral).

SARDELLI, M. A. (2010): «La envidia en los refranes españoles, italianos e ingleses», en Korhonen, J. y otros (eds.) (2010b: 291-304).

Sarmiento Reyes, Y. y L. Alfaro Echevarría (2011): "Coincidencias fraseológicas entre Cuba y Canarias», Paremia 20, 211-219.

SAUSSURE, F. (1981): Curso de lingüística general, Akal.

Schmale, G. (2010): «nun di Die isch han de Flämm- Französische Einflüsse auf phraseologische Ausdrücke des Rheinfränkischen», en Korhonen, J. y otros (eds.) (2010a: 185-193).

SCHEMANN, H. (1989): «Das phraseologische Wörterbuch», en Hausmann y otros (eds.), Wörterbücher. Diccionaries. Diccionaires. Ein internationales Handbuch zur Lexikographie, 2 Bände, Berlin (1019-1032).

Schemann, H. y otros (2013): Idiomatik Deutsch-Spanisch, Buske, Hamburg.

SCHILLING, M. L. (2012): «Nur über meine Leiche! ¡Por encima de mi cadáver! Enunciados fraseológicos alemanes y españoles que expresan recusación», en Pamies, A. y otros (eds.) (2012: 421-429). 
ScHMITT, C. y B. WotJAK (2005) (eds.): Studien zur romanisch-deutschen und innerromanischen Sprachvergleich. Actas del V Congreso de Lingüística Contrastiva Interrománica y con el Alemán en Leipzig, Bonn, Romanistischer Verlag.

SECo, M. y otros (2005): Diccionario fraseológico documentado del español actual. Locuciones y modismos españoles, Aguilar Lexicografía, Madrid.

Segura García, B. (1998): Kontrastive Idiomatik: Deutsch-Spanisch, Peter Lang, Frankfurt a. M.

SEVILLA MUÑOZ, J. (1988): Hacia una aproximación conceptual de las paremias francesas y españolas, Editorial Complutense, Universidad Complutense de Madrid, Madrid.

- (1993): «Las paremias españolas: clasificación, definición y correspondencia francesa», Paremia 2, 15-20.

- (1996): «Sobre la paremiología española», disponible en http://www.euskaltzaindia.eus/dok/euskera/49699.pdf, 641-672 (julio, 2015).

- (1998): «Fernando Lázaro Carreter y las manifestaciones folclóricas del lenguaje literal», en Paremia 7, 7-9.

- (2000): «La sinonimia en el proceso traductológico de paremias francesas al español (II) », en M. L. Casal Silva y otros (eds.), La lingüística francesa en España camino del siglo XXI (2000: 995-1004) disponible en FILE://G:/SEVILLA\%20SINONIMIA\%20PAREMIAS.PDF (julio, 2015).

- (2004): “O concepto "correspondencia" na traduccíon paremiológica», en Cadernos de fraseoloxía galega, 6, 2004, 221-230. 
(2010): «La competencia paremiológica en la generación española de más de 65 años», en Korhonen, J. y otros (eds.) (2010b: 151-158).

- Sevilla, J. y J. Cantera Ortiz de URBina (2001): 1001 refranes españoles con sus correspondencias en alemán, árabe, francés, inglés, italiano, polaco, provenzal y ruso, EIUNSA, Madrid.

- (2004): Diccionario temático de locuciones francesas con su correspondencia española, Gredos, Madrid.

Sierra Soriano, A. (2005): «Rôle du nom prope dans la traduction françaisespagnole des expressions imagées», en Almela, R. y otros (eds.) (2005: 329344).

SMELEY, D. N. (2003/1977): «Sovremennyj russkij jazyk», Leksika 2-e izd, Moskva.

SOLODUB, J. P. (2003): «Sovremennyj russkij jazyk», Leksika i fraseologija, Moskva.

SoloduXo, E. M. (1982): Problemy internacianalizacii frazeologii: na materiale jazykov slavjanskoj, germanskoj i romanskoj grupp, KGU, Kazan.

StantCHeVA, D. (1996): Körperteile als Grundelemente von Phraseologismen und deren Darstellung in einsprachigen synkronischen Bedeutungswörterbüchern des Deutschen und Spanischen. Ein Vergleich, Marburg.

StavtSeVA, A. (2011): «Semantic and functional peculiarities of English and German phraseological units denoting human intellectual abilities», en Pamies, A. y D. Dobrovol'skij (eds.) (2011: 167-172). 
SzCZĘK, J. (2010): «Eine kleine Schweinerei gefällig? Zum sprachlichen Bild des Schweins in der deutschen und polnischen Phraseologie», en Korhonen, J. y otros (eds.) (2010b: 334-343).

SZCZEPANIAK, R. y URBAN, A. (2011): «Hunting for idiomatic functional equivalents in Polish, English and German: a cross linguistic study of selected idioms from the semantic field of deception", en Pamies, A. y otros (eds.) (2011b: 251-264).

TABARES PlasenciA, E. (2010): «Ausgewählte Übersetzungsprobleme der juristischen Fachphraseologie. Vergleich Deutsch-Spanisch», en J. Korhonen y otros (eds.) (2010a), 285-291.

Tabares Plasencia, E. y J. J. Batista RodríGuez (2005): "Notas sobre fraseología jurídica comparada español-alemán», en Almela, R. y otros (eds.) (2005: 345-356).

TARNOVSKA, O. (2004): Refranero básico español con correspondencias en ruso y ucraniano, Logos, Kiev

TELIJA, V. N. (1966): Čto takoe frazeologija?, Moskva.

- (1981): «Zur Variabilität von Wort und Idiom», en Jaksche y otros (eds.): Reader zur sowjetischen Phraseologie, Walter de Gruyter, Berlin/New York, 91112.

- (1986): Konnotativnyj aspekt semantiki nominativnych jedinic, Nauka, Moskua.

TORRENT-LenZeN, A. (2008): «Aspectos de fraseografía bilingüe españolalemán: la equivalencia frente a la definición», en Bernal, E. y J. De Cesaris (eds.): Proceedings of the XIII Euralex International Congress, Barcelona, 2008, 
Institut Universitari de Lingüística Aplicada, Universitat Pompeu Fabra, Barcelona, CD-ROM (1433-1443), disponible en http://www.euralex.org/proceedings-toc/euralex_2008/ (julio, 2015).

- (2010): «Aspekte der spanisch-deutschen Phraseographie. Die Definition der Phraseologismen und ihr semantischer Mehrwert», en Korhonen, J. y otros (eds.) (2010b: 365-375).

Thun, H. (1978): Probleme der Phraseologie, Max Niemeyer, Tübingen.

TRISTÁ PÉREZ, M. A. (1988): Fraseología y contexto, Editorial de Ciencias Sociales, La Habana.

UMBORG, V. (2010): «Deutsche Feste Wortverbindungen in Fachtexten im Vergleich mit ihren estnischen und russischen Entsprechungen», en Korhonen, J. y otros (eds.) (2010a), 239-245.

VALLI, A. y otros (2012): "Comprendre les métaphores ontologiques dans l'espace roman: le cas du français vers l'espagnol et l'italien», en Pamies, A. y otros (eds.) (2012: 91-99).

VAN LAWICK, H. (2010): "Phraseologismen in der Minderheitensprache Katalanisch: Global, areal oder dialektal? Ein korpuslinguistisch gestützte Untersuchung von Übersetzungen», en Korhonen, J. y otros (eds.) (2010a: 293299).

VARELA, F. y H. KUBARTH (1994): Diccionario fraseológico del español moderno, Gredos, Madrid.

VeLÁZQUez PUERTO, K. (2015): Análisis fraseológico contrastivo español-alemán y su aplicación a ELE. Una propuesta didáctica para la enseñanza-aprendizaje 
de las unidades fraseológicas desde una perspectiva cognitiva, Universidad Complutense de Madrid (UCM), Madrid (Tesis doctoral).

VINOGRADOV, V. V. (1946): «Osnovnyje poňatija russkoj frazeologii kak lin gvitičeskoj discipliny», en Trudy jubilejnoj sesii LGU, Sekcija filologičeskaja, Leningrad.

— (1947): «Ob osnovnych tipach frazeologičeskich jedinic v russkom jazyke», en Sbornik A. A. Šachmatov. Trudy Komisii po istorii Akademi nauk SSSR, Vyp. 3, Moskua/Leningrad.

WAHRIG, G (1994): Deutsches Wörterbuch, Bertelsmann Lexikon, Gütersloch.

WEINRICH, U. (1969): «Problems in the Analysis of Idioms», in Puhvel, J. (ed.): Substance and Structure of Language, University of California Press, Los Ángeles, 23-81.

WOTJAK, B. (1987): «Aspekte einer konfrontativen Beschreibung von Phraseolexemen: deutsch-spanisch», en Linguistische Arbeitsbereiche 59, 86100.

- (1989): «Ansatz eines modular-integrativen Beschreibungsmodells für verbale Phraseolexeme (PL)», en Gréciano, G. (ed.) (1989: 469-483).

- (1992): Verbale Phraseolexeme in System und Text, Max Niemeyer, Tübingen.

— (1996): «Redewendungen und Sprichwörter. Ein Buch mit sieben Siegeln? Einführung in den Themenschwerpunkt», en Fremdsprache Deutsch, 15, Goethe- Institut, Klett Verlag, 4-9. 
WotJAK, B. y M. RICHTER (1988): Sage und Schreibe. Deutsche Phraseologismen in Theorie und Praxis, Langenscheidt, Leipzig.

WOTJAK, G. (1983): «En torno a la traducción de unidades fraseológicas (con ejemplos tomados del español y el alemán)», LAB 40, 56-80.

- (1986): «Zur Bedeutung ausgewählter verbaler Phraseologismen des Deutschen», en Zeitschrift für Germanistik 2, 183-200.

- (1989): «Übereinzelsprachliches und Einzelsprachspezifisches bei Phraseolexeme», en Gréciano, G. (ed.) (1989: 469-483).

- (2000): «No hay que estarse con los brazos cruzados. Algunas observaciones acerca del significado de expresiones idiomáticas verbales del español actual, en Corpas Pastor, G. (ed.) (2000: 185-196).

- (ed.) (1988): Linguistische Studien/ Reihe A. Studien zur Sprachkonfrontation. Materialien der I. Internationalen Arbeitstagung zum Romanisch-Deutschen Sprachvergleich, Berlin.

- (ed.) (1992): Estudios de lexicografía y metalexicografía del español actual, Max Niemeyer, Tübingen.

-. (ed.) (1998): Estudios de fraseología y fraseografía del español actual, Tübingen.

Yaguello, M. (1983): Alicia en el país del lenguaje, Mascarón, Madrid.

ŽÁRSKÁ, M. (2011): «Die Entstehungsgeschichte des deutsch-tschechischen Wörterbuchs der Phraseologismen und festgeprägten Wendungen: ein Berich», en Pamies, A. y otros (eds.) (2011b: 245-250). 
ZAYNULDINOV, A. (2010): «La referencia temática como un factor de la evaluación emocional en la fraseología rusa y española», en Korhonen, J. y otros (eds.) (2010b: 381-390).

Zholobova, A. (2011): «Uso actual de los bibleísmos fraseológicos en español y ruso», en Palies, A. y D. Dobrovol'skij (eds.) (2011: 101-109).

ZULUAGA, A. (1975): «La fijación fraseológica», en Thesaurus, Boletín del Instituto Caro y Cuervo, 225-248.

— (1980): Introducción al estudio de las expresiones fijas, Lang, Frankfurt a. M.

- (1992): «Spanisch: Phraseologie», en Holtus, G., M. Metzelin y C. Schmitt (eds.): Lexikon der Romanistischen Linguistik, Bd. 6 (1992: 125-131).

- (1998): «Análisis y traducción de unidades fraseológicas desautomatizadas», PhiN 16/2001: 67-84, Tübingen.

- (2002): «Los "enlaces frecuentes" de María Moliner. Observaciones sobre las Ilamadas colocaciones», PhiN 22/2002, Tübingen, 56-74.

ZURDO, M. T. (1993): «Motivación situacional del léxico de los Refranes/Sprichwörter. Contribución a un análisis intercultural», en Revista de Filología Alemana I, 197-215.

- (1999): «Sobre la adecuación del método contrastivo para el análisis interlingüístico de fraseologismos», en Eggelte, B. y otros (coords.): La lengua alemana y sus literaturas en el contexto europeo. Siglos XIX y XX, Salamanca, 354-365.

- (2001): «Andere Zeiten, andere Texte?: efectos del paso del tiempo en la tipología, función y forma de los textos de gramáticas y métodos de alemán 
para extranjeros», en FERER MORA, H. y otros (eds.): Metodología y didáctica del alemán como lengua extranjera en el contexto hispánico, Valencia, 53-71.

- (2002): «En torno a la modificación por expansión en fraseologismos de núcleo verbal alemanes y españoles», en Estudios Filológicos Alemanes I, 131149.

- (2003): «La amistad a través de las paremias de ocho lenguas europeas (Alemán, español, francés, griego moderno, inglés, italiano, polaco y portugués)», en Eslavística Complutense 3, 173-198.

- (2005): «Panorama sobre los estudios fraseológicos en Alemania», en Almela, R. y otros (eds.) (2005: 39-63).

— (2007): «Phraseologie des Spanischen«, en Burger, H. y otros (eds.) (2007: 703-713). 



\section{ANEXOS}

\section{ANEXO I. DOCUMENTACIÓN FRASEOGRÁFICA DEL CORPUS}

\section{Unidad fraseológica 1}

\begin{tabular}{|c|c|c|}
\hline \multicolumn{3}{|c|}{ UF1 poner los cuernos $\approx$ Hörner aufsetzen } \\
\hline \multirow[t]{3}{*}{$\begin{array}{l}\text { Niveles de } \\
\text { equivalencia }\end{array}$} & Formal & $\begin{array}{l}\text { Las dos UF presentan la misma estructura }(\mathrm{V} .+\mathrm{CD})^{96} \\
\text { Destacaremos la ausencia de artículo en alemán }\end{array}$ \\
\hline & Léxica & Coincidente el campo léxico utilizado en ambas lenguas \\
\hline & Idiomática & $\begin{array}{l}\text { Responden las dos al mismo significado fraseológico: ser } \\
\text { infiel }\end{array}$ \\
\hline \multirow{3}{*}{$\begin{array}{l}\text { Consulta } \\
\text { fraseográfica }\end{array}$} & Español & Seco (2005: 349); Buitrago (2008: 552) \\
\hline & Alemán & Schemann (2013: 433) \\
\hline & Bilingüe & Nedwed (2009: 50) \\
\hline \multirow[t]{2}{*}{ Páginas web } & Español & $\begin{array}{l}\text { http://es.wiktionary.org/wiki/poner_los_cuernos (julio, 2014) } \\
\text { http://www.blogolengua.com/2010/07/poner-los-cuernos.html }\end{array}$ \\
\hline & Alemán & $\begin{array}{l}\text { http://www.redensarten- } \\
\text { index.de/suche.php?suchbegriff=jemandem\%20H\%C3\%B6rn } \\
\text { er\%20aufsetzen\&bool=relevanz\&suchspalte[]=rart_ou (julio, } \\
\text { 2014) }\end{array}$ \\
\hline $\begin{array}{l}\text { Forma } \\
\text { ampliada }\end{array}$ & \multicolumn{2}{|c|}{ Poner los cuernos (a alguien)= (jemandem) Hörner aufsetzen } \\
\hline Comentarios & \multicolumn{2}{|c|}{$\begin{array}{l}\text { Hay que destacar en esta UF, al igual que otras muchas, que puede aparecer } \\
\text { catalogada y también en el imaginario de los hablantes tanto en su forma } \\
\text { breve, como en su forma extendida. Esta puede constar solo de forma verbal y } \\
\text { complementos indispensables y prescindir del Cl (la persona beneficiada o } \\
\text { perjudicada por la acción verbal), que sí se actualiza en su forma } \\
\text { contextualizada. En otros casos, puede tratarse de otras funciones. Así pues, } \\
\text { ofreceremos también en cada UF esta forma ampliada con este complemento } \\
\text { que se actualiza en contexto entre paréntesis: poner los cuernos (a alguien)= } \\
\text { (jemandem) Hörner aufsetzen. }\end{array}$} \\
\hline
\end{tabular}

\footnotetext{
${ }_{97}^{96}$ Las abreviaturas y siglas están consignadas en el inicio del trabajo.

97 Larreta (1998/2001: 117) aboga por incluir en los equivalentes totales aquellas estructuras que tienen diferencias gramaticales de este tipo, e incluso a las expresiones con diferencia de componente externo como C Prep. frente a Cl.
} 


\section{Unidad fraseológica 2}

\section{UF2 poner la mano en el fuego die Hand ins Feuer legen}

\begin{tabular}{|c|c|c|}
\hline \multirow{3}{*}{$\begin{array}{l}\text { Niveles de } \\
\text { equivalencia }\end{array}$} & Formal & Coinciden la estructura de las dos UF (V. + CD + CCL) \\
\hline & Léxica & También en este nivel coinciden \\
\hline & Idiomática & $\begin{array}{l}\text { Las dos presentan el mismo significado fraseológico: } \\
\text { arriesgarse ayudando (a alguien) }\end{array}$ \\
\hline \multirow{3}{*}{$\begin{array}{l}\text { Consulta } \\
\text { fraseográfica }\end{array}$} & Español & Seco (2005: 619); Buitrago (2008: 546) \\
\hline & Alemán & Schemann (2013: 362) \\
\hline & Bilingüe & Nedwed (2009: 97) \\
\hline \multirow[t]{2}{*}{ Páginas web } & Español & $\begin{array}{l}\text { http://www.fraseshechas.net/poner-la-mano-en-el-fuego/(julio, } \\
\text { 2014) }\end{array}$ \\
\hline & Alemán & $\begin{array}{l}\text { http://www.redensarten- } \\
\text { index.de/suche.php?suchbegriff= fuer\%20jemanden\%20die } \\
\% 20 \text { Hand\%20ins\%20Feuer\%20legen\&suchspalte[]=rart_ou } \\
\text { (julio, 2014). }\end{array}$ \\
\hline $\begin{array}{l}\text { Forma } \\
\text { ampliada }\end{array}$ & \multicolumn{2}{|c|}{ Poner la mano en el fuego por alguien $\approx$ für jemanden die Hand ins Feuer legen } \\
\hline Comentarios & \multicolumn{2}{|c|}{$\begin{array}{l}\text { Puede aparecer el beneficiario de la acción verbal, por alguien (en español es } \\
\mathrm{Cl} / \text { /für jemandem (en alemán S prep.): tanto en las catalogaciones en español } \\
\text { como en alemán aparecen indistintamente la forma extendida, como la } \\
\text { reducida }\end{array}$} \\
\hline
\end{tabular}




\section{Unidad fraseológica 3}

\begin{tabular}{|c|c|c|}
\hline & \multicolumn{2}{|c|}{ UF3 como el perro y el gato $\approx$ wie Hund und Katze } \\
\hline \multirow[t]{3}{*}{$\begin{array}{l}\text { Niveles de } \\
\text { equivalencia }\end{array}$} & Formal & $\begin{array}{l}\text { Presentan equivalencia de esquemas funcionales ( } P \text {. } \\
\text { comparativa + Sust. + Conj. + Sust. ). En alemán destaca la } \\
\text { ausencia del artículo }\end{array}$ \\
\hline & Léxica & Mismo léxico \\
\hline & Idiomática & Mismo significado fraseológico: pelearse continuamente \\
\hline \multirow{3}{*}{$\begin{array}{l}\text { Consulta } \\
\text { fraseográfica }\end{array}$} & Español & Seco (2005: 777); Buitrago (2008: 112) \\
\hline & Alemán & Schemann (2013: 439) \\
\hline & Bilingüe & Nedwed (2009: 125) \\
\hline \multirow[t]{2}{*}{ Páginas web } & Español & $\begin{array}{l}\text { http://erasmusv.wordpress.com/2008/03/01/llevarse-como-el- } \\
\text { perro-y-el-gato/ (julio, 2014) }\end{array}$ \\
\hline & Alemán & $\begin{array}{l}\text { Wie Hund und Katze: http://www.redensarten- } \\
\text { index.de/suche.php?suchbegriff=wie\%20Hund\%20und\%20Ka } \\
\text { tze\&bool=relevanz\&suchspalte[]=rart_ou (julio, 2014) }\end{array}$ \\
\hline $\begin{array}{l}\text { Forma } \\
\text { ampliada }\end{array}$ & \multicolumn{2}{|c|}{ Ser/estar como el perro y el gato $\approx$ wie Hund und Katze sein } \\
\hline Comentarios & \multicolumn{2}{|c|}{$\begin{array}{l}\text { Aparece en su forma extendida generalmente, con verbo copulativo, tanto en } \\
\text { español como en alemán }\end{array}$} \\
\hline
\end{tabular}




\section{Unidad fraseológica 4}

\section{UF4 no tener pelos en la lenguaz kein Blatt vor den Mund haben}

\begin{tabular}{|c|c|c|}
\hline \multirow{3}{*}{$\begin{array}{l}\text { Niveles de } \\
\text { equivalencia }\end{array}$} & Formal & Estructura sintáctica similar (V. + CD + CCL) \\
\hline & Léxica & $\begin{array}{l}\text { Divergencia léxica: en alemán dice literalmente no llevar una } \\
\text { hoja ante la boca }{ }^{98} \text {, mientras que en español los sustantivos } \\
\text { utilizados son pelos y lengua }\end{array}$ \\
\hline & Idiomática & Ambas significan hablar sin tapujos. \\
\hline \multirow{3}{*}{$\begin{array}{l}\text { Consulta } \\
\text { fraseográfica }\end{array}$} & Español & Seco (2005: 766); Buitrago (2008: 501) \\
\hline & Alemán & Schemann $(2013: 100)$ \\
\hline & Bilingüe & Nedwed (2009: 124) \\
\hline \multirow[t]{2}{*}{ Páginas web } & Español & $\begin{array}{l}\text { http://sigificadoyorigen.wordpress.com/2010/05/10/no-tener- } \\
\text { pelos-en-la-lengua/ (julio, 2014) }\end{array}$ \\
\hline & Alemán & $\begin{array}{l}\text { http://www.redensarten- } \\
\text { index.de/suche.php?suchbegriff=kein+Blatt+vor+den+Mund+n } \\
\text { ehmen\&bool=relevanz\&suchspalte[]=rart_ou (julio, 2014) }\end{array}$ \\
\hline $\begin{array}{l}\text { Forma } \\
\text { ampliada }\end{array}$ & \multicolumn{2}{|c|}{ La forma usual es la mostrada } \\
\hline \multirow[t]{2}{*}{ Comentarios } & \multicolumn{2}{|c|}{$\begin{array}{l}\text { Por un lado, queríamos destacar el modo de negación: cada lengua expresa de } \\
\text { una manera9 }{ }^{9} \text { la negación en esta UF (en esp. se niega el verbo; en al. el } \\
\text { sustantivo en el caso que sea indeterminado). }\end{array}$} \\
\hline & \multicolumn{2}{|c|}{$\begin{array}{l}\text { Por otro, a pesar de cierta divergencia de léxico empleado, hay que destacar } \\
\text { que no solo ambas hacen referencia al cuerpo humano (boca/lengua), sino que } \\
\text { es evidente la relación de cercanía entre estos términos }\end{array}$} \\
\hline
\end{tabular}

\footnotetext{
${ }^{98}$ Ponemos entre comillas para indicar que es únicamente una traducción literal con la finalidad de facilitar la comprensión de ambas lenguas.

99 No comparamos sistemas lingüísticos, tan diferentes uno de otro y con todo lo que ello supone: el alemán es una lengua de origen sincrético, que está evolucionando a analítica, pero manteniendo estructuras; el español, por su parte, lengua analítica.
} 


\section{Unidad fraseológica 5}

\section{UF5 ponerse los pelos de puntaz jemandem stehen die Haare zu Berge}

\begin{tabular}{|c|c|c|}
\hline \multirow[t]{3}{*}{$\begin{array}{l}\text { Niveles de } \\
\text { equivalencia }\end{array}$} & Formal & $\begin{array}{l}\text { Similares estructuras, con alguna diferencia entre ambas } \\
\text { lenguas: en español el verbo es reflexivo, a diferencia del } \\
\text { alemán, y el modificador verbal (CCM) está expresado de } \\
\text { diferente manera: en español de punta y en alemán zu Berge } \\
\text { (lit. hacia la montaña) }\end{array}$ \\
\hline & Léxica & $\begin{array}{l}\text { Utiliza vocabulario diferente para expresar el CCM: de punta } \\
\text { frente a zu Berge (lit. hacia la montaña) }\end{array}$ \\
\hline & Idiomática & $\begin{array}{l}\text { Equivalentes a nivel fraseológico, que denotan una acción de } \\
\text { asustarse }\end{array}$ \\
\hline \multirow{3}{*}{$\begin{array}{l}\text { Consulta } \\
\text { fraseográfica }\end{array}$} & Español & Seco (2005: 767); Buitrago (2008: 554) \\
\hline & Alemán & Schemann (2013: 345) \\
\hline & Bilingüe & Nedwed (2009: 123) \\
\hline \multirow[t]{2}{*}{ Páginas web } & Español & $\begin{array}{l}\text { http://es.thefreedictionary.com/poner+los+pelos+de+punta } \\
\text { (marzo, 2013) }\end{array}$ \\
\hline & Alemán & $\begin{array}{l}\text { http://www.redensarten- } \\
\text { index.de/suche.php?suchbegriff= jemandem\%20stehen\%20 } \\
\text { die\%20Haare\%20zu\%20Berge\&suchspalte[]=rart_ou (marzo, } \\
\text { 2013) }\end{array}$ \\
\hline $\begin{array}{l}\text { Forma } \\
\text { ampliada }\end{array}$ & \multicolumn{2}{|c|}{ Ponérsele los pelos de punta a alguien $\approx$ jemandem stehen die Haare zu Berge } \\
\hline Comentarios & \multicolumn{2}{|c|}{$\begin{array}{l}\text { Mientras que la UF en español puede aparecer en su versión reducida o } \\
\text { ampliada, en alemán suele aparecer siempre con el } \mathrm{Cl} \text { (jemandem). En este } \\
\text { caso, las dos UF coinciden también en que tiene expresado el Sujeto (Ios } \\
\text { pelos/die Haare), y la parte que se actualiza en contexto es el Cl }\end{array}$} \\
\hline
\end{tabular}




\section{Unidad fraseológica 6}

\section{UF6 descubrir la pólvora das Pulver erfunden haben}

\begin{tabular}{|c|c|c|}
\hline \multirow{3}{*}{$\begin{array}{l}\text { Niveles de } \\
\text { equivalencia }\end{array}$} & Formal & Nivel estructural básico similar (V. + CD) \\
\hline & Léxica & Vocabulario similar en ambas lenguas \\
\hline & Idiomática & $\begin{array}{l}\text { Mismo significado fraseológico: (tener la creencia de) haber } \\
\text { descubierto algo nuevo que ya hace tiempo que existe }\end{array}$ \\
\hline \multirow{3}{*}{$\begin{array}{l}\text { Consulta } \\
\text { fraseográfica }\end{array}$} & Español & Seco (2005: 818); Buitrago (2008: 208) \\
\hline & Alemán & Schemann (2013: 734) \\
\hline & Bilingüe & Nedwed (2009: 132) \\
\hline \multirow[t]{2}{*}{ Páginas web } & Español & $\begin{array}{l}\text { http://www.linguee.es/espanol- } \\
\text { ingles/traduccion/descubrir+la+p\%C3\%B3lvora.html } \\
\text { (septiembre, 2014) }\end{array}$ \\
\hline & Alemán & $\begin{array}{l}\text { http://www.redensartenindex.de/suche.php?suchbegriff= da } \\
\text { s\%20Pulver\%20/\%20Schiesspulver\%20nicht\%20erfunden\%2 } \\
\text { Ohaben\&suchspalte[]=rart_ou (julio, 2014) }\end{array}$ \\
\hline $\begin{array}{l}\text { Forma } \\
\text { ampliada }\end{array}$ & \multicolumn{2}{|c|}{ La forma usual es la mostrada } \\
\hline Comentarios & \multicolumn{2}{|c|}{$\begin{array}{l}\text { Destaca el infinitivo de perfecto en alemán (lit. haber descubierto) frente a la } \\
\text { forma de presente en español }\end{array}$} \\
\hline
\end{tabular}




\section{Unidad fraseológica 7}

\section{UF7 tirar la casa por la ventana das Geld zum Fenster hinauswerfen}

\begin{tabular}{|c|c|c|}
\hline \multirow[t]{3}{*}{$\begin{array}{l}\text { Niveles de } \\
\text { equivalencia }\end{array}$} & Formal & $\begin{array}{l}\text { Sintaxis similar (V.+ CD }+ \text { CCL), con los matices } \\
\text { preposicionales propios de cada lengua }\end{array}$ \\
\hline & Léxica & $\begin{array}{l}\text { En alemán lo que tiran es das Geld (el dinero), mientras que } \\
\text { en español es la casa }\end{array}$ \\
\hline & Idiomática & $\begin{array}{l}\text { Similar significado fraseológico: derrochar, aunque con } \\
\text { matices negativos en alemán, positivos en español }\end{array}$ \\
\hline \multirow{3}{*}{$\begin{array}{l}\text { Consulta } \\
\text { fraseográfica }\end{array}$} & Español & Seco (2005: 260); Buitrago (2008: 735) \\
\hline & Alemán & Schemann (2013: 287) \\
\hline & Bilingüe & Nedwed (2009: 232) \\
\hline \multirow[t]{2}{*}{ Páginas web } & Español & $\begin{array}{l}\text { http://origenlenguaje.blogspot.com.es/2012/02/origen-de-la- } \\
\text { expresion-tirar-la-casa.html (julio, 2014) }\end{array}$ \\
\hline & Alemán & $\begin{array}{l}\text { http://www.redensarten.index.de/suche.php?suchbegriff= da } \\
\text { s\%20Geld\%20zum\%20Fenster\%20herauswerfen\%20\%2F\%2 } \\
\text { 0hinauswerfen\%20\%2F\%20hinausschmeissen\%3B\%20das\% } \\
\text { 20Geld\%20\%28mit\%20vollen\%20Haenden\%29\%20aus\%20d } \\
\text { em\%20Fenster\%20werfen\&bool=relevanz\&suchspalte[]=rart_ } \\
\text { ou (julio, 2014) }\end{array}$ \\
\hline $\begin{array}{l}\text { Forma } \\
\text { ampliada }\end{array}$ & \multicolumn{2}{|c|}{ La forma usual es la mostrada } \\
\hline Comentarios & \multicolumn{2}{|c|}{$\begin{array}{l}\text { En alemán aparece la forma sin el CCL (zum Fenster), pero también la } \\
\text { extendida: das Geld (zum Fenster) hinauswerfen. Por el contrario, en español } \\
\text { solo hemos encontrado la forma extendida tirar la casa por la ventana }\end{array}$} \\
\hline
\end{tabular}




\section{Unidad fraseológica 8}

\section{UF8 sonar a chino jemandem Spanisch vorkommen}

\begin{tabular}{|c|c|c|}
\hline \multirow[t]{3}{*}{$\begin{array}{l}\text { Niveles de } \\
\text { equivalencia }\end{array}$} & Formal & $\begin{array}{l}\text { Similar teniendo en cuenta particularidades de cada lengua } \\
(\mathrm{V} .+\mathrm{CV})\end{array}$ \\
\hline & Léxica & $\begin{array}{l}\text { Diferente, teniendo en cuenta particularidades culturales }{ }^{100} \text { de } \\
\text { cada ámbito lingüístico: en alemán aparece Spanisch } \\
\text { (español) la lengua extraña, mientras que en español es el } \\
\text { chino }\end{array}$ \\
\hline & Idiomática & Mismo significado fraseológico: no entender \\
\hline \multirow{3}{*}{$\begin{array}{l}\text { Consulta } \\
\text { fraseográfica }\end{array}$} & Español & Seco (2005: 275); Buitrago (2008: 695) \\
\hline & Alemán & Schemann (2013: 1076) \\
\hline & Bilingüe & Nedwed (2009: 306) \\
\hline \multirow[t]{2}{*}{ Páginas web } & Español & $\begin{array}{l}\text { http://forum.wordreference.com/showthread.php?t=78794 (to } \\
\text { be all Greek for someone) (marzo, 2013) }\end{array}$ \\
\hline & Alemán & $\begin{array}{l}\text { http://www.spanien-treff.de/threads/1145-Redewendung-Das- } \\
\text { kommt-mir-Spanisch-vor-esto-me-suena-a-chino (marzo, } \\
\text { 2013) }\end{array}$ \\
\hline $\begin{array}{l}\text { Forma } \\
\text { ampliada }\end{array}$ & \multicolumn{2}{|c|}{ Sonar a chino a alguien $\approx$ jemandem Spanisch vorkommen } \\
\hline Comentarios & \multicolumn{2}{|c|}{$\begin{array}{l}\text { En el nivel formal, matizaremos que en alemán se trata de un predicativo, } \\
\text { mientras que en español de un complemento preposicional, no obstante } \\
\text { complementos sintácticos necesarios en ambos casos de los verbos }\end{array}$} \\
\hline
\end{tabular}

${ }^{100}$ Rastrear diacrónicamente las fuentes es tarea difícil en algunos casos, pero no en todos. Sin duda la versión alemana de esta expresión tiene que ver con nuestro pasado común español-alemán. Puesto que Carlos $\mathrm{V}$ tenía origen español, introdujo costumbres y modas que llamaban la atención y producían estrañeza. Así lo atestigua Röhrich, que viene a decir esto mismo:

Als Kart V (1519-56), ein Spanier seiner Abstammung und Erziehung nach, die dt.[deutsche] Kaiserkrone trug, fanden manche span. [spanische] Sitten, Moden, Glaubenssatzungen, die den Deutschen bis dahin unerhört waren, in Dtl. [deutsche Literatur] Eingang. Damals wird die Rda. [Redensart] aufgekommen sein, bezeichnend für ein- wenn auch geringes- bewußtes Fühlen der eigenen Art gegenüber aufgedrängtem fremden Brauch (Röhrich, 2010: 1493-1494). 


\section{Unidad fraseológica 9}

\begin{tabular}{|c|c|c|}
\hline \multicolumn{3}{|c|}{ UF9 ganz Ohr sein $\approx$ ser todo oídos } \\
\hline \multirow{3}{*}{$\begin{array}{l}\text { Niveles de } \\
\text { equivalencia }\end{array}$} & Formal & Similar (V. + Atr.), en ambos casos atributos del verbo ser \\
\hline & Léxica & $\begin{array}{l}\text { Similar, teniendo en cuenta el singular en alemán (Ohr) frente } \\
\text { al plural en español (oídos), y expresión de la intensidad en } \\
\text { alemán mediante ganz (lit. completamente, todo), en español } \\
\text { con todo }\end{array}$ \\
\hline & Idiomática & Mismo significado fraseológico: escuchar con atención \\
\hline \multirow[t]{3}{*}{$\begin{array}{l}\text { Consulta } \\
\text { fraseográfica }\end{array}$} & Español & $\begin{array}{l}\text { Seco (2005: 700); no aparece en Buitrago (2008); sí en } \\
\text { Junceda (2009: 552) }\end{array}$ \\
\hline & Alemán & Schemann (2013: 692) \\
\hline & Bilingüe & Nedwed (2009: 273) \\
\hline \multirow[t]{2}{*}{ Páginas web } & Español & $\begin{array}{l}\text { http://erasmusv.wordpress.com/2007/02/20/ser-todo-oidos-o- } \\
\text { ser-toda-oidos/ (marzo, 2013) }\end{array}$ \\
\hline & Alemán & $\begin{array}{l}\text { http://www.duden.de/suchen/dudenonline/ganz+Ohr+sein } \\
\text { (marzo, 2013) }\end{array}$ \\
\hline $\begin{array}{l}\text { Forma } \\
\text { ampliada }\end{array}$ & \multicolumn{2}{|c|}{ La forma usual es la mostrada } \\
\hline Comentarios & \multicolumn{2}{|c|}{ Destacamos la ausencia de artículo en ambas lenguas } \\
\hline
\end{tabular}




\begin{tabular}{|c|c|c|}
\hline \multicolumn{3}{|r|}{ UF10 hacerse la boca agua } \\
\hline \multicolumn{3}{|c|}{ jemandem das Wasser im Mund zusammenlaufen } \\
\hline \multirow[t]{3}{*}{$\begin{array}{l}\text { Niveles de } \\
\text { equivalencia }\end{array}$} & Formal & $\begin{array}{l}\text { Presentan estructuras diferentes y utilizan el mismo léxico: en } \\
\text { alemán das Wasser (el agua), es el sujeto de la UF, mientras } \\
\text { que Mund (boca) es el CCL (im Mund). En el caso español, } \\
\text { boca es el sujeto y agua es predicativo. La sintaxis verbal } \\
\text { también es diferente: en alemán es intransitivo, en español es } \\
\text { reflexivo }\end{array}$ \\
\hline & Léxica & Mismo léxico \\
\hline & Idiomática & $\begin{array}{l}\text { El significado fraseológico de ambas estructuras es similar: } \\
\text { estar ávido (de algo), generalmente en el campo léxico de la } \\
\text { alimentación }\end{array}$ \\
\hline \multirow{3}{*}{$\begin{array}{l}\text { Consulta } \\
\text { fraseográfica }\end{array}$} & Español & Seco (2005: 192); Buitrago (2008: 354) \\
\hline & Alemán & Schemann (2013: 1093) \\
\hline & Bilingüe & Nedwed (2009: 132) \\
\hline \multirow[t]{2}{*}{ Páginas web } & Español & $\begin{array}{l}\text { http://erasmusv.wordpress.com/2007/03/28/hacerse-la-boca- } \\
\text { agua/ (marzo, 2013) }\end{array}$ \\
\hline & Alemán & $\begin{array}{l}\text { http://www. woxikon.es/wort/das\%20Wasser\%20im\%20Mund } \\
\text { \%20zusammenlaufen\%20lassen.php (marzo, 2013) }\end{array}$ \\
\hline $\begin{array}{l}\text { Forma } \\
\text { ampliada }\end{array}$ & \multicolumn{2}{|c|}{$\begin{array}{l}\text { Hacerse la boca agua a alguien } \approx \text { jemandem das Wasser im Mund } \\
\text { zusammenlaufen }\end{array}$} \\
\hline Comentarios & \multicolumn{2}{|c|}{$\begin{array}{l}\text { En ambas lenguas se dan las UF en su versión ampliada o reducida } \\
\text { indistintamente }\end{array}$} \\
\hline
\end{tabular}


11. Unidad fraseológica 11

\begin{tabular}{|c|c|c|}
\hline \multicolumn{3}{|c|}{ UF11 Ilamar a las cosas por su nombre } \\
\hline \multicolumn{3}{|c|}{ die Dinge bei ihrem Namen nennen } \\
\hline \multirow{3}{*}{$\begin{array}{l}\text { Niveles de } \\
\text { equivalencia }\end{array}$} & Formal & Similar en ambos casos (V. $+C D+C$ prep.) \\
\hline & Léxica & Identidad léxica destacable \\
\hline & Idiomática & Mismo significado fraseológico: hablar sin eufemismos \\
\hline \multirow{3}{*}{$\begin{array}{l}\text { Consulta } \\
\text { fraseográfica }\end{array}$} & Español & Seco (2005: 326); Buitrago (2008: 413) \\
\hline & Alemán & Schemann (2013: 151) \\
\hline & Bilingüe & Nedwed (2009: 46) \\
\hline \multirow[t]{2}{*}{ Páginas web } & Español & $\begin{array}{l}\text { http://www.wordreference.com/definicion/llamar\%20a\%20las } \\
\% 20 \text { cosas\%20por\%20su\%20nombre (julio, 2014) }\end{array}$ \\
\hline & Alemán & $\begin{array}{l}\text { http://www.dict.cc/?s=die+Dinge+beim+Namen+nennen (julio, } \\
\text { 2014) }\end{array}$ \\
\hline $\begin{array}{l}\text { Forma } \\
\text { ampliada }\end{array}$ & \multicolumn{2}{|c|}{ La forma usual es la mostrada } \\
\hline Comentarios & \multicolumn{2}{|c|}{ No hay comentarios en esta UF } \\
\hline
\end{tabular}




\begin{tabular}{|c|c|c|}
\hline \multicolumn{3}{|c|}{ UF12 echar leña al fuego Öl ins Feuer giessen } \\
\hline \multirow{3}{*}{$\begin{array}{l}\text { Niveles de } \\
\text { equivalencia }\end{array}$} & Formal & Estructura similar $(\mathrm{V} .+\mathrm{CD}+\mathrm{CCL})$ \\
\hline & Léxica & $\begin{array}{l}\text { Alguna diferencia destacable: en alemán dice Öl (esp. aceite), } \\
\text { en lugar de leña }\end{array}$ \\
\hline & Idiomática & $\begin{array}{l}\text { Similar valor fraseológico, que se resumiría en hacer algo que } \\
\text { tiende a empeorar las cosas }\end{array}$ \\
\hline \multirow{3}{*}{$\begin{array}{l}\text { Consulta }^{101} \\
\text { fraseográfica }\end{array}$} & Español & Seco (2005: 579); Buitrago (2008: 222) \\
\hline & Alemán & Schemann (2013: 697) \\
\hline & Bilingüe & Nedwed (2009: 91) \\
\hline \multirow[t]{2}{*}{ Páginas web } & Español & $\begin{array}{l}\text { http://www.linguee.es/espanol- } \\
\text { ingles/traduccion/echar+le\%C3\%B1a+al+fuego.html (julio, } \\
\text { 2014) }\end{array}$ \\
\hline & Alemán & $\begin{array}{l}\text { http://www.redensarten.index.de/suche.php?suchbegriff=Oel+ } \\
\text { ins+Feuer+giessen\&bool=relevanz\&suchspalte[]=rart_o (julio, } \\
\text { 2014) }\end{array}$ \\
\hline $\begin{array}{l}\text { Forma } \\
\text { ampliada }\end{array}$ & \multicolumn{2}{|c|}{ La forma usual es la mostrada } \\
\hline Comentarios & \multicolumn{2}{|c|}{$\begin{array}{l}\text { Cabe destacar que la variante echar aceite al fuego está catalogada en obras } \\
\text { clásicas españolas }\end{array}$} \\
\hline
\end{tabular}

\footnotetext{
${ }^{101}$ Como se ha comentado anteriormente, la inclusión de estas unidades en las obras fraseográficas presenta mucha heterogeneidad. Por ejemplo, en la obra de Iribaren (2005), la UF12 echar leña al fuego (2005: 102) se puede localizar en el índice de expresiones a través de tres palabras diferentes: echar (2005: 393), de leña (2005: 401) y de fuego (2005: 397). En este caso la valoración debe ser positiva, pues las tres remiten a una misma entrada y por tanto facilita al lector la localización de la expresión.
} 
13. Unidad fraseológica 13

\begin{tabular}{|c|c|c|}
\hline \multicolumn{3}{|c|}{ 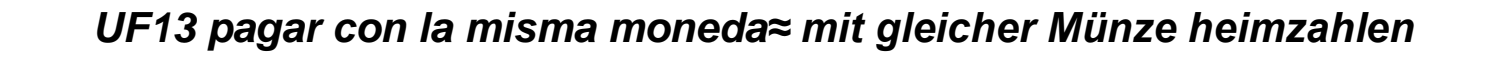 } \\
\hline \multirow{3}{*}{$\begin{array}{l}\text { Niveles de } \\
\text { equivalencia }\end{array}$} & Formal & Misma estructura sintáctica (V. + C prep.) \\
\hline & Léxica & Mismo léxico \\
\hline & Idiomática & Mismo significado fraseológico: tratar como se es tratado \\
\hline \multirow{3}{*}{$\begin{array}{l}\text { Consulta } \\
\text { fraseográfica }\end{array}$} & Español & Seco (2005: 660); Buitrago (2008: 512) \\
\hline & Alemán & Schemann (2013: 649) \\
\hline & Bilingüe & Nedwed (2009: 104) \\
\hline \multirow[t]{2}{*}{ Páginas web } & Español & $\begin{array}{l}\text { http://sigificadoyorigen.wordpress.com/2010/05/10/pagar-con- } \\
\text { la-misma-moneda/ (julio, 2014) }\end{array}$ \\
\hline & Alemán & $\begin{array}{l}\text { http://www.redensarten- } \\
\text { index.de/suche.php?suchbegriff= etwas+mit+gleicher+Muen } \\
\text { ze+heimzahlen\&suchspalte[]=rart_ou) (julio, 2014) }\end{array}$ \\
\hline $\begin{array}{l}\text { Forma } \\
\text { ampliada }\end{array}$ & \multicolumn{2}{|c|}{ La forma usual es la mostrada } \\
\hline Comentarios & \multicolumn{2}{|c|}{$\begin{array}{l}\text { También se encuentra en alemán la versión con el artículo determinado, frente } \\
\text { a la que presenta ausencia del mismo: mit der gleichen Münze heimzahlen }\end{array}$} \\
\hline
\end{tabular}


14. Unidad fraseológica 14

\begin{tabular}{|c|c|c|}
\hline \multicolumn{3}{|c|}{ UF14 no tener pies ni cabeza weder Hand noch Fuss haben } \\
\hline \multirow[t]{3}{*}{$\begin{array}{l}\text { Niveles de } \\
\text { equivalencia }\end{array}$} & Formal & $\begin{array}{l}\text { Estructura sintáctica parecida (Conj. + Sust. + Conj. + Sust. + } \\
\text { V.), con los matices de orden oracional propios cada } \\
\text { lengua }{ }^{102}\end{array}$ \\
\hline & Léxica & $\begin{array}{l}\text { En este nivel hay que diferenciar algunos matices. En primer } \\
\text { lugar, el sentido negativo de las conjunciones en la versión } \\
\text { española. En segundo lugar, los sustantivos utilizados: en } \\
\text { alemán utilizan Hand, Fuss (mano, pie), frente al español pies } \\
\text { (pl.) y cabeza }\end{array}$ \\
\hline & Idiomática & Similar significado fraseológico: no tener sentido \\
\hline \multirow{3}{*}{$\begin{array}{l}\text { Consulta } \\
\text { fraseográfica }\end{array}$} & Español & Seco (2005: 792); Buitrago (2008: 501) \\
\hline & Alemán & Schemann (2013: 362) \\
\hline & Bilingüe & Nedwed (2009: 128) \\
\hline \multirow[t]{2}{*}{ Páginas web } & Español & $\begin{array}{l}\text { http://www.esacademic.com/dic.nsf/sp_sp_dichos_refranes/1 } \\
\text { 568/no (julio, 2014) }\end{array}$ \\
\hline & Alemán & $\begin{array}{l}\text { http://de.wiktionary.org/wiki/weder_Hand_noch_Fu\%C3\%9F_ } \\
\text { haben }\end{array}$ \\
\hline $\begin{array}{l}\text { Forma } \\
\text { ampliada }\end{array}$ & \multicolumn{2}{|c|}{ La forma usual es la mostrada } \\
\hline Comentarios & \multicolumn{2}{|c|}{$\begin{array}{l}\text { En español es usual también la forma con otro ni: no tener ni pies ni cabeza. } \\
\text { Destacamos la ausencia de artículo en alemán. }\end{array}$} \\
\hline
\end{tabular}




\section{UF15 matar dos pájaros de un tiro zwei Fliegen mit einer Klappe schlagen}

Niveles de Formal equivalencia

Léxica

Idiomática

Consulta

fraseográfica

Español

Alemán

Bilingüe

Páginas web

Español

Alemán
Parecida estructura sintáctica (V. + CD + C prep.), donde ese Cprep está expresado en cada lengua de un modo

Algunas divergencias léxicas: en alemán el CD son zwei Fliegen, esp. dos moscas, a diferencia de los dos pájaros de la UF española. Por otro lado, la versión alemana expresa con mit einer Klappe, esp. con una paleta (matamoscas) la forma de acabar con los insectos schlagen, esp. aplastar. La versión española utiliza un lenguaje más directo, pues habla de matar y de un tiro

\section{Similar significado fraseológico: cumplir un doble objetivo}

Seco (2005: 720); Buitrago (2008: 446)

Schemann (2013: 236), versión zwei Fliegen mit einer Klappe schlappen

Nedwed (2009: 214)

http://erasmusv.wordpress.com/lista-de-expresionesespanolas/ (marzo, 2013)

http://www.ebay.de/itm/Gastehausschuhe-HausschuheFilzpantoffeln-Filz-Pantoffeln-Latschen-Schlappen/360544074641 (marzo, 2013)

Forma

ampliada

Comentarios
La forma usual es la mostrada

Puede aparecer la forma mostrada o bien la versión con el verbo diferente: zwei Fliegen mit einer Klappe schlappen 


\section{UF16 faltar un tornillo nicht alle Tassen im Schrank haben}

\begin{tabular}{|c|c|c|}
\hline \multirow[t]{3}{*}{$\begin{array}{l}\text { Niveles de } \\
\text { equivalencia }\end{array}$} & Formal & $\begin{array}{l}\text { Estructuras anisomórficas, esto es, distintas: la UF alemana } \\
\text { tiene una estructura (V. + CD + CCL), mientras que la UF } \\
\text { española presenta una estructura más simple (Suj. + V.). } \\
\text { Además, mientras que en la alemana se actualiza el Sujeto } \\
\text { en contexto, en la española será el Cl. También cabe decir } \\
\text { que la versión alemana presenta negación, mientras que la } \\
\text { española es afirmativa }\end{array}$ \\
\hline & Léxica & $\begin{array}{l}\text { Divergencia léxica: los campos semánticos son } \\
\text { completamente diferentes en las UF. La UF alemana se } \\
\text { podría traducir lit. no tener todas las tazas en la estantería, } \\
\text { mientras que la versión española presenta un campo } \\
\text { semántico distinto }\end{array}$ \\
\hline & Idiomática & $\begin{array}{l}\text { El significado fraseológico, que es en definitiva lo que nos } \\
\text { interesa en el presente trabajo, es similar: no estar cabal, y es } \\
\text { la forma que tiene cada lengua para expresar ese concepto } \\
\text { fraseológicamente }\end{array}$ \\
\hline \multirow{3}{*}{$\begin{array}{l}\text { Consulta } \\
\text { fraseográfica }\end{array}$} & Español & Seco (2005: 984); Buitrago (2008: 317) \\
\hline & Alemán & Schemann (2013: 968) \\
\hline & Bilingüe & Nedwed (2009: 316) \\
\hline \multirow[t]{2}{*}{ Páginas web } & Español & $\begin{array}{l}\text { http://es.thefreedictionary.com/faltar+un+tornillo (marzo, } \\
\text { 2013) }\end{array}$ \\
\hline & Alemán & $\begin{array}{l}\text { http://www.redensarten- } \\
\text { index.de/suche.php?suchbegriff= nicht\%20alle\%20Tassen } \\
\text { \%20im\%20Schrank\%20haben\&bool=relevanz\&suchspalte[]=r } \\
\text { art_ou (marzo, 2013) }\end{array}$ \\
\hline $\begin{array}{l}\text { Forma } \\
\text { ampliada }\end{array}$ & \multicolumn{2}{|c|}{$\begin{array}{l}\text { La UF española aparece ampliada con el } \mathrm{Cl} \text {, faltar un tornillo (a alguien), que } \\
\text { es el elemento a actualizar en contexto, mientras que en la alemana el } \\
\text { elemento que falta es el sujeto }\end{array}$} \\
\hline Comentarios & \multicolumn{2}{|c|}{$\begin{array}{l}\text { El par de UF presenta estructuras muy diferentes, tanto sintácticamente como } \\
\text { en su composición léxica, y evidentemente, lo que nos interesa es su } \\
\text { significado fraseológico, que es idéntico }\end{array}$} \\
\hline
\end{tabular}


17. Unidad fraseológica 17

\section{UF17 ser amor a primera vista $\approx$ Liebe auf den ersten Blick}

\begin{tabular}{|c|c|c|}
\hline \multirow{3}{*}{$\begin{array}{l}\text { Niveles de } \\
\text { equivalencia }\end{array}$} & Formal & Similares a nivel estructural (Atrib. + C prep.) \\
\hline & Léxica & Muy similares, con la ausencia de artículo en ambas \\
\hline & Idiomática & Mismo significado fraseológico: enamorarse repentinamente \\
\hline \multirow{3}{*}{$\begin{array}{l}\text { Consulta } \\
\text { fraseográfica }\end{array}$} & Español & Seco (2005: 1043); no aparece en Buitrago (2008) \\
\hline & Alemán & Schemann (2013: 568) \\
\hline & Bilingüe & No aparece en Nedwed (2009) \\
\hline \multirow[t]{2}{*}{ Páginas web } & Español & $\begin{array}{l}\text { http://inciclopedia.wikia.com/wiki/Amor_a_Primera_Vista } \\
\text { (julio, 2014) }\end{array}$ \\
\hline & Alemán & $\begin{array}{l}\text { http://es.bab.la/diccionario/aleman-espanol/liebe-auf-den- } \\
\text { ersten-blick (julio, 2014) }\end{array}$ \\
\hline $\begin{array}{l}\text { Forma } \\
\text { ampliada }\end{array}$ & \multicolumn{2}{|c|}{ Ser amor a primera vista $\approx$ Liebe auf den ersten Blick sein } \\
\hline Comentarios & \multicolumn{2}{|c|}{ No hay comentarios adicionales } \\
\hline
\end{tabular}


18. Unidad fraseológica 18

\section{UF18 tener algo en la punta de la lengua etwas auf der Zunge liegen}

\begin{tabular}{|c|c|c|}
\hline \multirow[t]{3}{*}{$\begin{array}{l}\text { Niveles de } \\
\text { equivalencia }\end{array}$} & Formal & $\begin{array}{l}\text { Encontramos diferencias en cuanto a la estructura sintáctica, } \\
\text { que en la UF española es }(V .+C D+C C L) \text {, y en la UF } \\
\text { alemana es (Suj. }+V .+C C L) \text {, lit. algo está en/ sobre la } \\
\text { lengua }\end{array}$ \\
\hline & Léxica & $\begin{array}{l}\text { En español está más extendido el CCL en la punta de la } \\
\text { lengua }\end{array}$ \\
\hline & Idiomática & $\begin{array}{l}\text { Mismo significado fraseológico: tener algo en mente que no } \\
\text { se acierta a verbalizar }\end{array}$ \\
\hline \multirow{3}{*}{$\begin{array}{l}\text { Consulta } \\
\text { fraseográfica }\end{array}$} & Español & Seco (2005: 842); Buitrago (2008: 700) \\
\hline & Alemán & Schemann (2013: 1189) \\
\hline & Bilingüe & Nedwed (2009: 345) \\
\hline \multirow[t]{2}{*}{ Páginas web } & Español & http://www.spanishdict.com/translate/lengua (marzo, 2013) \\
\hline & Alemán & $\begin{array}{l}\text { http://www.redensarten- } \\
\text { index.de/suche.php?suchbegriff=es+liegt+mir+auf+der+zunge } \\
\text { \&bool=relevanz\&gawoe=an\&suchspalte[]=rart_ou (marzo, } \\
\text { 2013) }\end{array}$ \\
\hline
\end{tabular}

Forma La forma usual es la mostrada

ampliada

Comentarios Como se ha comentado anteriormente, hay diferencias a nivel estructural: en español la función sintáctica omitid, actualizable en discurso, es el sujetopersona, y la estructura idiomática es (V. + CD + CCL), es decir, alguien tiene algo en la punta de la lengua; por el contrario en alemán el elemento omitido es el sujeto-cosa y la estructura idiomática es (Suj. + V + CCL), lit. esp. algo está sobre la lengua para alguien.

Larreta (1998/2001: 112) pone a esta UF, entre otras, como ejemplo de unidad fraseológica con mayor expansión en una lengua que en otra, y observa al respecto que «la ampliación del componente léxico constituía a menudo únicamente una variante facultativa: tener una persona. algo en (la punta de) la lengua». En cualquier caso, el autor menciona continuamente la dificultad de establecer límites nítidos, como no podía ser de otra manera. 
19. Unidad fraseológica 19

\begin{tabular}{|c|c|c|}
\hline \multicolumn{3}{|c|}{ UF19 nadar en la abundancia im Geld schwimmen } \\
\hline \multirow{3}{*}{$\begin{array}{l}\text { Niveles de } \\
\text { equivalencia }\end{array}$} & Formal & Similares sintácticamente $(\mathrm{V} .+\mathrm{CCL})$ \\
\hline & Léxica & $\begin{array}{l}\text { A nivel léxico encontramos breves matices: a diferencia del } \\
\text { español, en alemán dice lit. nadar en dinero }\end{array}$ \\
\hline & Idiomática & Coinciden ambas UF: tener mucho dinero \\
\hline \multirow{3}{*}{$\begin{array}{l}\text { Consulta } \\
\text { fraseográfica }\end{array}$} & Español & Seco (2005: 109); Buitrago (2008: 468) \\
\hline & Alemán & Schemann (2013: 286) \\
\hline & Bilingüe & Nedwed (2009: 10) \\
\hline \multirow[t]{2}{*}{ Páginas web } & Español & http://es.thefreedictionary.com/abundancia (julio, 2014) \\
\hline & Alemán & $\begin{array}{l}\text { http://www.redensarten- } \\
\text { index.de/suche.php?suchbegriff= im+Geld+schwimmen\&su } \\
\text { chspalte[]=rart_ou (julio, 2014). }\end{array}$ \\
\hline $\begin{array}{l}\text { Forma } \\
\text { ampliada }\end{array}$ & \multicolumn{2}{|c|}{ La forma usual es la mostrada } \\
\hline Comentarios & \multicolumn{2}{|c|}{ No hay comentarios adicionales } \\
\hline
\end{tabular}


20. Unidad fraseológica 20

\section{UF20 perder hasta la camisa bis aufs Hemd ausziehen}

\begin{tabular}{|c|c|c|}
\hline \multirow{3}{*}{$\begin{array}{l}\text { Niveles de } \\
\text { equivalencia }\end{array}$} & Formal & Misma estructura sintáctica (V. + C prep.) \\
\hline & Léxica & Se mueven ambas en el mismo entorno léxico \\
\hline & Idiomática & Mismo valor fraseológico sufrir una gran pérdida económica \\
\hline \multirow{3}{*}{$\begin{array}{l}\text { Consulta } \\
\text { fraseográfica }\end{array}$} & Español & Seco (2005: 235); no aparece en Buitrago (2008) \\
\hline & Alemán & Schemann (2013: 389) \\
\hline & Bilingüe & Nedwed (2009: 31) \\
\hline \multirow[t]{2}{*}{ Páginas web } & Español & http://es.thefreedictionary.com/camisa (marzo, 2013) \\
\hline & Alemán & $\begin{array}{l}\text { http://www.redensarten- } \\
\text { index.de/suche.php?suchbegriff=f\%C3\%BCr\%20jemanden\% } \\
\text { 20das\%20letzte\%20Hemd\%20hergeben\&bool=relevanz\&suc } \\
\text { hspalte[]=rart_ou (marzo, 2013) }\end{array}$ \\
\hline $\begin{array}{l}\text { Forma } \\
\text { ampliada }\end{array}$ & \multicolumn{2}{|c|}{ La forma usual es la mostrada } \\
\hline Comentarios & \multicolumn{2}{|c|}{ No hay comentarios adicionales } \\
\hline
\end{tabular}




\section{Unidad fraseológica 21}

\begin{tabular}{|c|c|c|}
\hline \multicolumn{3}{|c|}{ UF21 meter la cuchara seinen Senf dazu geben } \\
\hline \multirow[t]{3}{*}{$\begin{array}{l}\text { Niveles de } \\
\text { equivalencia }\end{array}$} & Formal & $\begin{array}{l}\text { Cierto parecido en las estructuras }(V .+C D) \text {, aunque el léxico } \\
\text { utilizado difiere }\end{array}$ \\
\hline & Léxica & $\begin{array}{l}\text { El léxico mostrado en ambas UF tanto en el } \mathrm{V} \text {. como en el CD } \\
\text { es distinto, aunque pertenecen a campos léxicos cercanos. A } \\
\text { diferencia del verbo español, en alemán dice dar, ofrecer, } \\
\text { proporcionar. En el CD, dentro del campo léxico de la comida/ } \\
\text { cocina, el alemán dice lit. su mostaza }\end{array}$ \\
\hline & Idiomática & $\begin{array}{l}\text { Ambas UF tienen un valor fraseológico similar: inmiscuirse en } \\
\text { algo }\end{array}$ \\
\hline \multirow{3}{*}{$\begin{array}{l}\text { Consulta } \\
\text { fraseográfica }\end{array}$} & Español & Seco (2005: 340); Buitrago (2008: 452) \\
\hline & Alemán & Schemann (2013: 878) \\
\hline & Bilingüe & Nedwed (2009: 31) \\
\hline \multirow[t]{2}{*}{ Páginas web } & Español & $\begin{array}{l}\text { http://es.thefreedictionary.com/meter+la+cuchara } \quad \text { (marzo, } \\
\text { 2013) }\end{array}$ \\
\hline & Alemán & $\begin{array}{l}\text { http://de.wiktionary.org/wiki/seinen_Senf_dazugeben; } \\
\text { http://www.dict.cc/deutsch- } \\
\text { englisch/seinen+Senf+dazugeben.html (julio, 2014) }\end{array}$ \\
\hline $\begin{array}{l}\text { Forma } \\
\text { ampliada }\end{array}$ & \multicolumn{2}{|c|}{$\begin{array}{l}\text { Meter la cuchara (en algo) } \approx \text { seinen Senf (dazu) geben, en ambas lenguas se } \\
\text { puede desarrollar el CCL }\end{array}$} \\
\hline Comentarios & \multicolumn{2}{|c|}{$\begin{array}{l}\text { Sin duda se trata de una UF enraizada con el acervo cultural: la cocina de } \\
\text { cuchara es muy habitual en el contexto hispánico, mientras que en el } \\
\text { germánico lo es la mostaza como ingrediente culinario }\end{array}$} \\
\hline
\end{tabular}


22. Unidad fraseológica 22

\section{UF22 estar en el séptimo cielo i im siebten Himmel sein}

\begin{tabular}{|c|c|c|}
\hline \multirow{3}{*}{$\begin{array}{l}\text { Niveles de } \\
\text { equivalencia }\end{array}$} & Formal & Ambas UF comparten la misma estructura (V. + CCL) \\
\hline & Léxica & En el nivel de vocabulario utilizado, también son idénticas \\
\hline & Idiomática & El significado fraseológico es el mismo: estar pletórico \\
\hline \multirow{3}{*}{$\begin{array}{l}\text { Consulta } \\
\text { fraseográfica }\end{array}$} & Español & Seco (2005: 281); Buitrago (2008: 296) \\
\hline & Alemán & Schemann (2013: 412) \\
\hline & Bilingüe & No aparece en Nedwed (2009) \\
\hline \multirow[t]{2}{*}{ Páginas web } & Español & $\begin{array}{l}\text { http://diccionario.sensagent.com/estar+en+el+s\%C3\%A9ptim } \\
\text { o+cielo/es-es/ (julio, 2014) }\end{array}$ \\
\hline & Alemán & $\begin{array}{l}\text { http://de.wiktionary.org/wiki/im_siebten_Himmel_sein } \\
\text { 2014) }\end{array}$ \\
\hline $\begin{array}{l}\text { Forma } \\
\text { ampliada }\end{array}$ & \multicolumn{2}{|c|}{ La forma usual es la mostrada } \\
\hline Comentarios & \multicolumn{2}{|c|}{ No hay comentarios adicionales } \\
\hline
\end{tabular}


23. Unidad fraseológica 23

UF23 ser la oveja negra de la familia das schwarze Schaf der Familie sein

\begin{tabular}{|c|c|c|}
\hline \multirow{3}{*}{$\begin{array}{l}\text { Niveles de } \\
\text { equivalencia }\end{array}$} & Formal & Misma estructura sintáctica (V. + Atrib. + [CN] ) \\
\hline & Léxica & Idénticos campos léxicos, tanto a nivel nominal, como verb \\
\hline & Idiomática & Mismo significado: destacar negativamente \\
\hline \multirow{3}{*}{$\begin{array}{l}\text { Consulta } \\
\text { fraseográfica }\end{array}$} & Español & Seco (2005: 716); Buitrago (2008: 396) \\
\hline & Alemán & Schemann (2013: 808) \\
\hline & Bilingüe & Nedwed (2009: 294) \\
\hline \multirow[t]{2}{*}{ Páginas web } & Español & $\begin{array}{l}\text { http://erasmusv.wordpress.com/2007/03/08/ser-la-oveja- } \\
\text { negra/ (julio, 2014) }\end{array}$ \\
\hline & Alemán & http://de.wikipedia.org/wiki/Schwarzes_Schaf (julio, 2014) \\
\hline $\begin{array}{l}\text { Forma } \\
\text { ampliada }\end{array}$ & \multicolumn{2}{|c|}{ La forma usual es la mostrada } \\
\hline Comentarios & \multicolumn{2}{|c|}{ No hay comentarios adicionales } \\
\hline
\end{tabular}


24. Unidad fraseológica 24

\section{UF24 ser un lobo con la piel de cordero $\approx$ ein Wolf im Schafspelz sein}

\begin{tabular}{|c|c|c|}
\hline \multirow[t]{3}{*}{$\begin{array}{l}\text { Niveles de } \\
\text { equivalencia }\end{array}$} & Formal & $\begin{array}{l}\text { Comparten la misma estructura oracional (V. + Atrib. + [C } \\
\text { prep.] ) }\end{array}$ \\
\hline & Léxica & Mismo vocabulario \\
\hline & Idiomática & $\begin{array}{l}\text { Mismo significado fraseológico: tener una apariencia dulce } \\
\text { que es falsa }\end{array}$ \\
\hline \multirow{3}{*}{$\begin{array}{l}\text { Consulta } \\
\text { fraseográfica }\end{array}$} & Español & Seco (2005: 592); Buitrago (2008:657) \\
\hline & Alemán & Schemann (2013: 1142) \\
\hline & Bilingüe & Nedwed (2009: 338) \\
\hline \multirow[t]{2}{*}{ Páginas web } & Español & http://mitosyleyendascr.com/fabulas/fabula50/ (julio, 2014) \\
\hline & Alemán & $\begin{array}{l}\text { http://www.duden.de/suchen/dudenonline/ein\%20Wolf\%20im } \\
\text { \%20Schafspelz\%20sein (julio, 2014) }\end{array}$ \\
\hline $\begin{array}{l}\text { Forma } \\
\text { ampliada }\end{array}$ & \multicolumn{2}{|c|}{ La forma usual es la mostrada } \\
\hline Comentarios & \multicolumn{2}{|c|}{ No hay comentarios adicionales } \\
\hline
\end{tabular}


25. Unidad fraseológica 25

\begin{tabular}{|c|c|c|}
\hline \multicolumn{3}{|c|}{ UF25 tener sangre azul blaues Blut haben } \\
\hline \multirow[t]{3}{*}{$\begin{array}{l}\text { Niveles de } \\
\text { equivalencia }\end{array}$} & Formal & $\begin{array}{l}\text { Misma estructura sintáctica (V. + CD). Coinciden además en } \\
\text { la ausencia del artículo }\end{array}$ \\
\hline & Léxica & Mismo campo léxico \\
\hline & Idiomática & Mismo significado fraseológico: ser de ascendencia noble \\
\hline \multirow{3}{*}{$\begin{array}{l}\text { Consulta } \\
\text { fraseográfica }\end{array}$} & Español & Seco (2005: 911); Buitrago (2008: 608) \\
\hline & Alemán & Schemann (2013: 108) \\
\hline & Bilingüe & Nedwed (2009: 150) \\
\hline \multirow[t]{2}{*}{ Páginas web } & Español & http://es.wikipedia.org/wiki/Sangre_azul (julio, 2014) \\
\hline & Alemán & http://de.wikipedia.org/wiki/Blaues_Blut (julio, 2014) \\
\hline $\begin{array}{l}\text { Forma } \\
\text { ampliada }\end{array}$ & \multicolumn{2}{|c|}{ La forma usual es la mostrada } \\
\hline Comentarios & \multicolumn{2}{|c|}{ No hay comentarios adicionales } \\
\hline
\end{tabular}


26. Unidad fraseológica 26

\section{UF26 no ser carne ni pescado $\approx$ weder Fisch noch Fleisch}

\begin{tabular}{|c|c|c|}
\hline \multirow[t]{3}{*}{$\begin{array}{l}\text { Niveles de } \\
\text { equivalencia }\end{array}$} & Formal & $\begin{array}{l}\text { Estructuras sintácticas similares (Conj. + Sust. + Conj. + Sust. } \\
+ \text { V.) }\end{array}$ \\
\hline & Léxica & Coincide el vocabulario empleado en ambas UF \\
\hline & Idiomática & Similar significado fraseológico: ser ambiguo, no claro \\
\hline \multirow{3}{*}{$\begin{array}{l}\text { Consulta } \\
\text { fraseográfica }\end{array}$} & Español & Seco (2005: 254); Buitrago (2008: 470) \\
\hline & Alemán & Schemann (2013: 233) \\
\hline & Bilingüe & Nedwed (2009: 36) \\
\hline \multirow[t]{2}{*}{ Páginas web } & Español & $\begin{array}{l}\text { http://www.wordreference.com/definicion/no\%20ser\%20ni\%20 } \\
\text { carne\%20ni\%20pescado (julio, 2014) }\end{array}$ \\
\hline & Alemán & $\begin{array}{l}\text { http://www.duden.de/suchen/dudenonline/weder\%20Fisch\%2 } \\
\text { Onoch\%20Fleisch (julio, 2014) }\end{array}$ \\
\hline $\begin{array}{l}\text { Forma } \\
\text { ampliada }\end{array}$ & \multicolumn{2}{|c|}{$\begin{array}{l}\text { La versión alemana también aparece en su versión actualizada en contexto con } \\
\text { el verbo copulativo como en español, weder Fisch noch Fleisch sein }\end{array}$} \\
\hline Comentarios & \multicolumn{2}{|c|}{$\begin{array}{l}\text { Repiten esquema de otra UF analizada anteriormente, la UF14 weder Hand } \\
\text { noch Fuss haben } \approx \text { no tener pies ni cabeza }\end{array}$} \\
\hline
\end{tabular}


27. Unidad fraseológica 27

\begin{tabular}{|c|c|c|}
\hline \multicolumn{3}{|c|}{ UF27 nadar a contracorriente $\approx$ gegen den Strom schwimmen } \\
\hline \multirow{3}{*}{$\begin{array}{l}\text { Niveles de } \\
\text { equivalencia }\end{array}$} & Formal & Estructuras sintácticas similares (V. + C prep.) \\
\hline & Léxica & Léxico idéntico \\
\hline & Idiomática & $\begin{array}{l}\text { Mismo significado fraseológico: enfrentarse a un statu quo/ a } \\
\text { una situación en la que se tiene oposición de la mayoría }\end{array}$ \\
\hline \multirow{3}{*}{$\begin{array}{l}\text { Consulta } \\
\text { fraseográfica }\end{array}$} & Español & Seco (2005: 313); Buitrago (2008: 363) \\
\hline & Alemán & Schemann (2013: 945) \\
\hline & Bilingüe & Nedwed (2009: 46) \\
\hline \multirow[t]{2}{*}{ Páginas web } & Español & $\begin{array}{l}\text { http://www.1diccionario.com/buscar/contracorriente (julio, } \\
\text { 2014) }\end{array}$ \\
\hline & Alemán & $\begin{array}{l}\text { http://www.zitate-online.de/literaturzitate/allgemein/18538/wer- } \\
\text { zur-quelle-will-muss-gegen-den-strom-schwimmen.html (julio, } \\
\text { 2014) }\end{array}$ \\
\hline $\begin{array}{l}\text { Forma } \\
\text { ampliada }\end{array}$ & \multicolumn{2}{|c|}{ La forma usual es la mostrada } \\
\hline Comentarios & \multicolumn{2}{|c|}{ No hay comentarios adicionales } \\
\hline
\end{tabular}


28. Unidad fraseológica 28

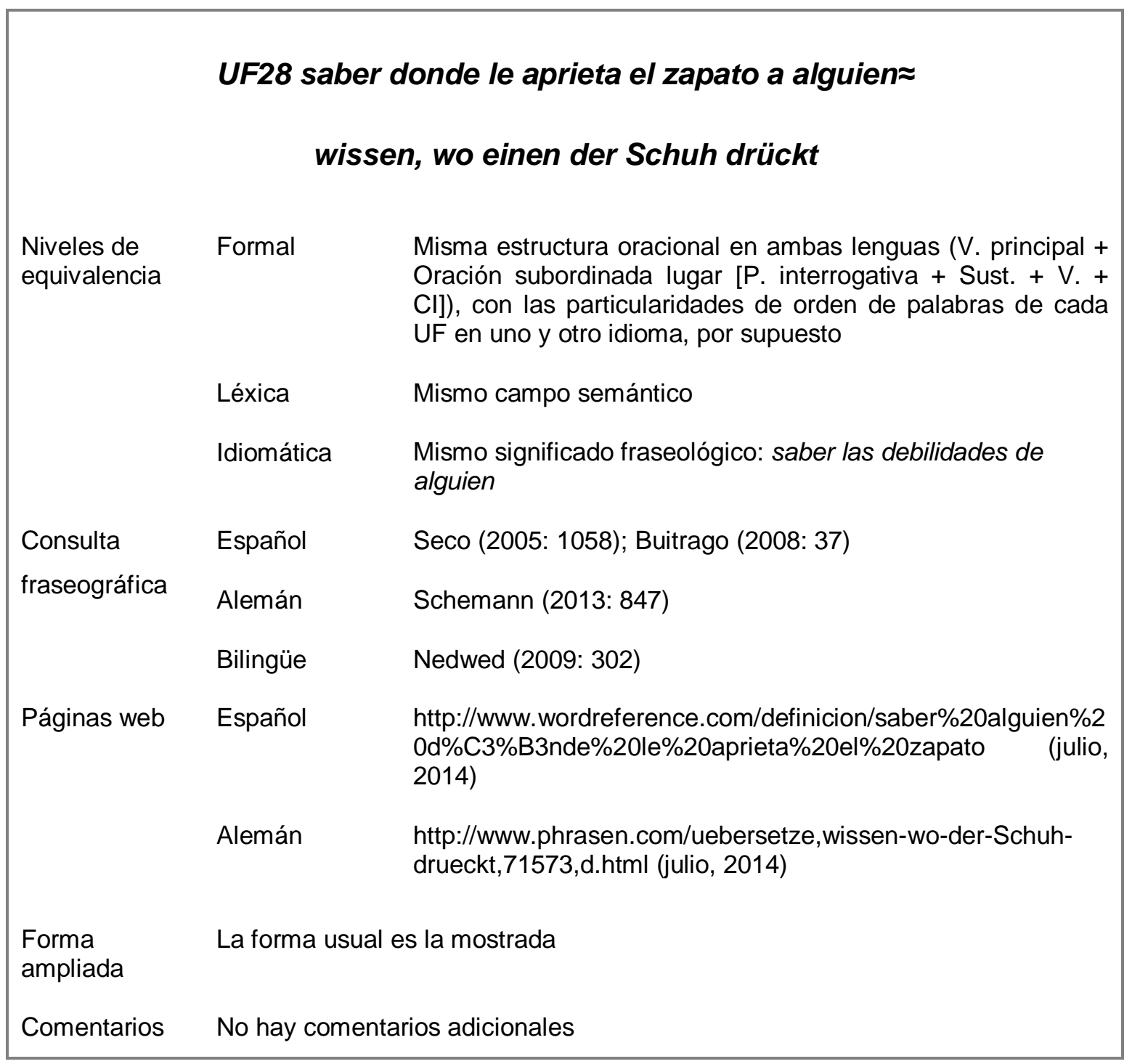


29. Unidad fraseológica 29

\section{UF29 tender un puente de plata eine goldene Brücke bauen}

\begin{tabular}{|c|c|c|}
\hline \multirow[t]{3}{*}{$\begin{array}{l}\text { Niveles de } \\
\text { equivalencia }\end{array}$} & Formal & $\begin{array}{l}\text { La estructura presenta isomorfía o paralelismo sintáctico, es } \\
\text { decir, son iguales (V. }+\mathrm{CD}+[\mathrm{CN} / \mathrm{Adj} .] \text { ), teniendo en cuenta } \\
\text { preferencia expresiva de cada lengua, que en español se } \\
\text { decanta por un } \mathrm{CN} \text {, mientras que en alemán presenta un } \\
\text { adjetivo atributivo (goldene) }\end{array}$ \\
\hline & Léxica & $\begin{array}{l}\text { Léxicamente presenta alguna diferencia, pues en español } \\
\text { dice de plata, y en alemán goldene Brücke, lit. puente de oro }\end{array}$ \\
\hline & Idiomática & $\begin{array}{l}\text { Mismo significado: facilitar el camino de marcha a alguien } \\
\text { (que resulta embarazoso o molesto) }\end{array}$ \\
\hline \multirow[t]{3}{*}{$\begin{array}{l}\text { Consulta } \\
\text { fraseográfica }\end{array}$} & Español & $\begin{array}{l}\text { No aparece en Seco (2005). Catalogada en Buitrago (2008 } \\
\text { 7), bajo la forma: A enemigo que huye, puente de plata }\end{array}$ \\
\hline & Alemán & Schemann (2013: 124) \\
\hline & Bilingüe & Nedwed (2009: 135) \\
\hline \multirow[t]{2}{*}{ Páginas web } & Español & http://es.thefreedictionary.com/puente \\
\hline & Alemán & $\begin{array}{l}\text { http://de.wikipedia.org/wiki/Goldene_Br\%C3\%BCcke (julio, } \\
\text { 2014) }\end{array}$ \\
\hline $\begin{array}{l}\text { Forma } \\
\text { ampliada }\end{array}$ & \multicolumn{2}{|c|}{ La forma usual es la mostrada } \\
\hline Comentarios & \multicolumn{2}{|c|}{ No hay comentarios adicionales } \\
\hline
\end{tabular}




\begin{tabular}{|c|c|c|}
\hline \multicolumn{3}{|c|}{ UF30 perder el hilo $\approx$ den Faden verlieren } \\
\hline \multirow{3}{*}{$\begin{array}{l}\text { Niveles de } \\
\text { equivalencia }\end{array}$} & Formal & Isomorfía estructural: misma forma oracional (V. + CD) \\
\hline & Léxica & Congruencia léxica: mismo léxico \\
\hline & Idiomática & Mismo significado fraseológico: quedarse en blanco \\
\hline \multirow{3}{*}{$\begin{array}{l}\text { Consulta } \\
\text { fraseográfica }\end{array}$} & Español & Seco (2005: 526); Buitrago (2008: 532) \\
\hline & Alemán & Schemann (2013: 208) \\
\hline & Bilingüe & Nedwed (2009: 211) \\
\hline \multirow[t]{2}{*}{ Páginas web } & Español & $\begin{array}{l}\text { http://forum.wordreference.com/showthread.php?t=143995 } \\
\text { (marzo, 2013) }\end{array}$ \\
\hline & Alemán & $\begin{array}{l}\text { http://www.gymnasium- } \\
\text { zwettl.ac.at/LEHRER/sprachprojekt/contentfiles/Sprachenproj } \\
\text { ekt_Faden_verlieren.pdf (marzo, 2013) }\end{array}$ \\
\hline $\begin{array}{l}\text { Forma } \\
\text { ampliada }\end{array}$ & \multicolumn{2}{|c|}{ La forma usual es la mostrada } \\
\hline \multirow[t]{2}{*}{ Comentarios } & \multicolumn{2}{|c|}{$\begin{array}{l}\text { En general es difícil rastrear las fuentes de la Fraseología, excepto aquellas UF } \\
\text { que se sustentan en referentes culturales comunes, como es en el caso de } \\
\text { esta UF, cuya fuente es la Mitología grecolatina. En estos casos, la } \\
\text { coincidencia de las UF en todos los planos de la comparación interlingüística } \\
\text { es mucho mayor, pues se trata de calcos de una fuente común. Lo mismo } \\
\text { ocurre con las que deben su origen a los libros sagrados de las religiones. }\end{array}$} \\
\hline & \multicolumn{2}{|c|}{$\begin{array}{l}\text { A este tipo de UF también se las ha denominado europeísmos, frente a los } \\
\text { internacionalismos, denominación con la que se suelen referir a aquellas UF } \\
\text { que tienen que ver con sentimientos, sensaciones físicas, etc. supuestamente } \\
\text { compartidas por una población más amplia, que no necesariamente comparten } \\
\text { un contexto cultural común }\end{array}$} \\
\hline
\end{tabular}




\section{Unidad fraseológica 31}

\begin{tabular}{|c|c|c|}
\hline \multicolumn{3}{|c|}{ UF31 jugar con las cartas boca arribaz mit offenen Karten spielen } \\
\hline \multirow{3}{*}{$\begin{array}{l}\text { Niveles de } \\
\text { equivalencia }\end{array}$} & Formal & Misma estructura sintáctica (V. + S prep.) \\
\hline & Léxica & $\begin{array}{l}\text { Leves matices diferentes, pues en alemán dice lit. con cartas } \\
\text { abiertas, prescindiendo del artículo }\end{array}$ \\
\hline & Idiomática & $\begin{array}{l}\text { Mismo significado fraseológico: ser franco o transparente en } \\
\text { las intenciones }\end{array}$ \\
\hline \multirow[t]{3}{*}{$\begin{array}{l}\text { Consulta } \\
\text { fraseográfica }\end{array}$} & Español & $\begin{array}{l}\text { Seco (2005: 258), con la versión descubrir/poner las cartas } \\
\text { boca arriba. Catalogada en Buitrago (2008: 403) }\end{array}$ \\
\hline & Alemán & $\begin{array}{l}\text { Schemann (2013: 463), aparece la versión die Karten offen } \\
\text { ausspielen (lit. jugar con las cartas abiertas). También die } \\
\text { Karten offen auf den Tisch legen (lit. poner las cartas abiertas } \\
\text { sobre la mesa) }\end{array}$ \\
\hline & Bilingüe & Nedwed (2009: 35) \\
\hline \multirow[t]{2}{*}{ Páginas web } & Español & $\begin{array}{l}\text { http://www.wordmagicsoft.com/diccionario/es- } \\
\text { en/poner\%20las\%20cartas\%20boca\%20arriba.php (julio, } \\
\text { 2014) }\end{array}$ \\
\hline & Alemán & $\begin{array}{l}\text { http://www.redensarten- } \\
\text { index.de/suche.php?suchbegriff= mit+offenen+Karten+spiel } \\
\text { en\&suchspalte[]=rart_ou (julio, 2014) }\end{array}$ \\
\hline $\begin{array}{l}\text { Forma } \\
\text { ampliada }\end{array}$ & \multicolumn{2}{|c|}{ La forma usual es la mostrada } \\
\hline Comentarios & \multicolumn{2}{|c|}{ No hay comentarios adicionales } \\
\hline
\end{tabular}


32. Unidad fraseológica 32

\begin{tabular}{|c|c|c|}
\hline \multicolumn{3}{|c|}{ UF32 Ilevar los pantalones $\approx$ die Hosen anhaben } \\
\hline \multirow{3}{*}{$\begin{array}{l}\text { Niveles de } \\
\text { equivalencia }\end{array}$} & Formal & Mismo esquema sintáctico ( V. + CD) \\
\hline & Léxica & Campos semánticos similares \\
\hline & Idiomática & Mismo significado fraseológico: mandar, tener el mando \\
\hline \multirow{3}{*}{$\begin{array}{l}\text { Consulta } \\
\text { fraseográfica }\end{array}$} & Español & Seco (2005: 731); Buitrago (2008:418) \\
\hline & Alemán & Schemann (2013: 434) \\
\hline & Bilingüe & Nedwed (2009: 118) \\
\hline \multirow[t]{2}{*}{ Páginas web } & Español & $\begin{array}{l}\text { http://www.wordreference.com/definicion/llevar\%20los\%20pa } \\
\text { ntalones (julio, 2014) }\end{array}$ \\
\hline & Alemán & $\begin{array}{l}\text { http://www.phrasen.com/uebersetze, die-Hosen- } \\
\text { anhaben,1363,d.html (julio, 2014) }\end{array}$ \\
\hline $\begin{array}{l}\text { Forma } \\
\text { ampliada }\end{array}$ & \multicolumn{2}{|c|}{ La forma usual es la mostrada } \\
\hline Comentarios & \multicolumn{2}{|c|}{ No hay comentarios adicionales } \\
\hline
\end{tabular}


33. Unidad fraseológica 33

\section{UF33 hacer la corte a alguien $\approx$ jemandem den Hof machen}

\begin{tabular}{|c|c|c|}
\hline \multirow{3}{*}{$\begin{array}{l}\text { Niveles de } \\
\text { equivalencia }\end{array}$} & Formal & Misma estructura sintáctica $(V .+C D+C l)$ \\
\hline & Léxica & Comparten mismo léxico \\
\hline & Idiomática & Mismo significado fraseológico: cortejar \\
\hline \multirow{3}{*}{$\begin{array}{l}\text { Consulta } \\
\text { fraseográfica }\end{array}$} & Español & Seco (2005: 324); no aparece en Buitrago (2008) \\
\hline & Alemán & Schemann (2013: 426) \\
\hline & Bilingüe & Nedwed (2009: 46) \\
\hline \multirow[t]{2}{*}{ Páginas web } & Español & $\begin{array}{l}\text { http://www.wordreference.com/definicion/hacer\%20la\%20cort } \\
\text { e (julio, 2014) }\end{array}$ \\
\hline & Alemán & $\begin{array}{l}\text { http://www.redensarten- } \\
\text { index.de/suche.php?suchbegriff= jemandem+den+Hof+mac } \\
\text { hen\&suchspalte[]=rart_ou (julio, 2014) }\end{array}$ \\
\hline $\begin{array}{l}\text { Forma } \\
\text { ampliada }\end{array}$ & \multicolumn{2}{|c|}{ La forma usual es la mostrada } \\
\hline Comentarios & \multicolumn{2}{|c|}{ No hay comentarios adicionales } \\
\hline
\end{tabular}


34. Unidad fraseológica 34

\section{UF34 tener una venda en los ojos ein Brett vor dem Kopf haben}

\begin{tabular}{|c|c|c|}
\hline \multirow{3}{*}{$\begin{array}{l}\text { Niveles de } \\
\text { equivalencia }\end{array}$} & Formal & Estructura sintáctica similar (V. + CD + CCL) \\
\hline & Léxica & $\begin{array}{l}\text { Vocabulario distinto, pues en la UF alemana aparece com } \\
\text { CD ein Brett, lit. una tabla; y como CCL presenta el sintagm } \\
\text { vor dem Kopf, lit. delante de la cabeza. No obstante, amba } \\
\text { UF muestran campos léxicos similares relacionados co } \\
\text { somatismos }\end{array}$ \\
\hline & Idiomática & $\begin{array}{l}\text { A pesar de las diferencias léxicas, su significado fraseológic } \\
\text { es similar: ser incapaz de ver objetivamente las cosas }\end{array}$ \\
\hline \multirow{3}{*}{$\begin{array}{l}\text { Consulta } \\
\text { fraseográfica }\end{array}$} & Español & Seco (2005: 1017); no aparece en Buitrago (2008) \\
\hline & Alemán & Schemann (2013: 119) \\
\hline & Bilingüe & Nedwed (2009: 196) \\
\hline \multirow[t]{2}{*}{ Páginas web } & Español & http://es.thefreedictionary.com/ojo (julio, 2014) \\
\hline & Alemán & $\begin{array}{l}\text { http://de.wiktionary.org/wiki/ein_Brett_vor_dem_Kopf_haben } \\
\text { (julio, 2014) }\end{array}$ \\
\hline $\begin{array}{l}\text { Forma } \\
\text { ampliada }\end{array}$ & \multicolumn{2}{|c|}{ La forma usual es la mostrada } \\
\hline Comentarios & \multicolumn{2}{|c|}{ No hay comentarios adicionales } \\
\hline
\end{tabular}


35. Unidad Fraseológica 35

\begin{tabular}{|c|c|c|}
\hline \multicolumn{3}{|c|}{ UF35 ser el cuento de la lechera eine Milchmädchenrechnung sein } \\
\hline \multirow[t]{3}{*}{$\begin{array}{l}\text { Niveles de } \\
\text { equivalencia }\end{array}$} & Formal & $\begin{array}{l}\text { Misma estructura sintáctica (V. + Atrib.), si bien el Atributo es } \\
\text { desarrollado con los mecanismos disponibles en cada lengua: } \\
\text { en español utiliza el CN, en alemán la composición (Milch + } \\
\text { mädchen + rechnung) }\end{array}$ \\
\hline & Léxica & Mismo vocabulario \\
\hline & Idiomática & $\begin{array}{l}\text { Mismo significado fraseológico: no ser realista u objetivo, es } \\
\text { decir, ver las cosas excesivamente positivas sin tener motivos } \\
\text { para ello }\end{array}$ \\
\hline \multirow{3}{*}{$\begin{array}{l}\text { Consulta } \\
\text { fraseográfica }\end{array}$} & Español & Seco (2005: 346); Buitrago (2008: 236) \\
\hline & Alemán & Schemann (2013: 633) \\
\hline & Bilingüe & Nedwed (2009: 49) \\
\hline \multirow[t]{2}{*}{ Páginas web } & Español & $\begin{array}{l}\text { http://www.materialesdelengua.org/LITERATURA/TEXTOS_LI } \\
\text { TERARIOS/CUENTOS/contar/lechera.htm (julio, 2014) }\end{array}$ \\
\hline & Alemán & $\begin{array}{l}\text { eine Milchmädchenrechnung sein: } \\
\text { http://www.redensarten.net/Milchmaedchen.html (julio, 2014) }\end{array}$ \\
\hline $\begin{array}{l}\text { Forma } \\
\text { ampliada }\end{array}$ & \multicolumn{2}{|c|}{ La forma usual es la mostrada } \\
\hline Comentarios & \multicolumn{2}{|c|}{ No hay comentarios adicionales } \\
\hline
\end{tabular}


36. Unidad fraseológica 36

\begin{tabular}{|c|c|c|}
\hline \multicolumn{3}{|c|}{ UF36 estar en boca de todos $\approx$ in aller Munde sein } \\
\hline \multirow[t]{3}{*}{$\begin{array}{l}\text { Niveles de } \\
\text { equivalencia }\end{array}$} & Formal & $\begin{array}{l}\text { Básicamente iguales en cuanto a su estructura sintáctica ( } \mathrm{V} \text {. } \\
+\mathrm{CCL} \text { ), solucionando el modificador según los recursos de } \\
\text { cada lengua, con un } \mathrm{CN} \text { de nuevo en español (de todos), con } \\
\text { un genitivo en alemán (aller) }\end{array}$ \\
\hline & Léxica & Mismo vocabulario en ambas UF \\
\hline & Idiomática & Mismo significado fraseológico: ser pública una cosa \\
\hline \multirow[t]{3}{*}{$\begin{array}{l}\text { Consulta } \\
\text { fraseográfica }\end{array}$} & Español & $\begin{array}{l}\text { Seco (2005: 191). No aparece en Buitrago (2008), ni Junceda } \\
\text { (2009); sí aparece en Varela (1994: 36) }\end{array}$ \\
\hline & Alemán & Schemann (2013: 648) \\
\hline & Bilingüe & Nedwed (2009: 22) \\
\hline \multirow[t]{2}{*}{ Páginas web } & Español & $\begin{array}{l}\text { http://diccionario.reverso.net/espanol- } \\
\text { ingles/est\%C3\%A1\%20en\%20boca\%20de\%20todos (julio, } \\
\text { 2014) }\end{array}$ \\
\hline & Alemán & $\begin{array}{l}\text { http://www.redensarten- } \\
\text { index.de/suche.php?suchbegriff= in\%20aller\%20Munde\%2 } \\
\text { Osein\&suchspalte[]=rart_ou (julio, 2014) }\end{array}$ \\
\hline $\begin{array}{l}\text { Forma } \\
\text { ampliada }\end{array}$ & \multicolumn{2}{|c|}{ La forma usual es la mostrada } \\
\hline Comentarios & \multicolumn{2}{|c|}{ No hay comentarios adicionales } \\
\hline
\end{tabular}




\begin{tabular}{|c|c|c|}
\hline \multicolumn{3}{|c|}{ UF37 estar hasta las narices $\approx$ die Nase voll haben } \\
\hline \multirow[t]{3}{*}{$\begin{array}{l}\text { Niveles de } \\
\text { equivalencia }\end{array}$} & Formal & $\begin{array}{l}\text { Este par de UF presenta anisomorfía sintáctica. La UF } \\
\text { española presenta una estructura (V. + CCL), que no suele } \\
\text { ser productiva excepto en el ámbito fraseológico (hasta los } \\
\text { codos, etc.). Por su parte, la UF alemana presenta el } \\
\text { esquema (V. + CD + C pred.) }\end{array}$ \\
\hline & Léxica & $\begin{array}{l}\text { Similar vocabulario con desarrollo morfosintáctico diferente en } \\
\text { una y otra UF. Especialmente diferentes a nivel verbal: en } \\
\text { español estar (intransitivo), en alemán aparece el verbo } \\
\text { haben (lit. tener) }\end{array}$ \\
\hline & Idiomática & Coinciden en el significado fraseológico: estar harto \\
\hline \multirow{3}{*}{$\begin{array}{l}\text { Consulta } \\
\text { fraseográfica }\end{array}$} & Español & Seco (2005: 682); en Buitrago (2008: 306) \\
\hline & Alemán & Schemann (2013: 666) \\
\hline & Bilingüe & Nedwed (2009: 108) \\
\hline \multirow[t]{2}{*}{ Páginas web } & Español & $\begin{array}{l}\text { http://diccionario.reverso.net/espanol- } \\
\text { ingles/estar\%20hasta\%20las\%20narices (julio, 2014). }\end{array}$ \\
\hline & Alemán & http://de.wiktionary.org/wiki/die_Nase_voll_haben (julio, 2014) \\
\hline $\begin{array}{l}\text { Forma } \\
\text { ampliada }\end{array}$ & \multicolumn{2}{|c|}{ La forma usual es la mostrada } \\
\hline Comentarios & \multicolumn{2}{|c|}{$\begin{array}{l}\text { En la UF del alemán aparece el sustantivo en singular (Nase), a diferencia de } \\
\text { la UF española, que aparece con la forma en plural (narices), especialmente } \\
\text { productiva a nivel fraseológico }\end{array}$} \\
\hline
\end{tabular}


38. Unidad fraseológica 38

\begin{tabular}{|c|c|c|}
\hline \multicolumn{3}{|c|}{ UF38 construir sobre arena $\approx$ auf Sand bauen } \\
\hline \multirow{3}{*}{$\begin{array}{l}\text { Niveles de } \\
\text { equivalencia }\end{array}$} & Formal & misma estructura sintáctica $(\mathrm{V} .+\mathrm{CCL})$ \\
\hline & Léxica & comparten mismos campos léxicos \\
\hline & Idiomática & $\begin{array}{l}\text { mismo significado fraseológico: no tener una base } 10 \\
\text { suficientemente sólida }\end{array}$ \\
\hline \multirow{3}{*}{$\begin{array}{l}\text { Consulta } \\
\text { fraseográfica }\end{array}$} & Español & $\begin{array}{l}\text { Seco (2005: 153), versión edificar sobre arena; Buitrago } \\
\text { (2008: 130) }\end{array}$ \\
\hline & Alemán & Schemann (2013: 802) \\
\hline & Bilingüe & Nedwed (2009: 16) \\
\hline \multirow[t]{2}{*}{ Páginas web } & Español & http://www.aguasvivas.cl/revistas/70/05.htm (julio, 2014) \\
\hline & Alemán & $\begin{array}{l}\text { http://www.redensarten- } \\
\text { index.de/suche.php?suchbegriff= auf\%20Sand\%20bauen\& } \\
\text { bool=relevanz\&suchspalte[]=rart_ou (julio, 2014) }\end{array}$ \\
\hline $\begin{array}{l}\text { Forma } \\
\text { ampliada }\end{array}$ & \multicolumn{2}{|c|}{ La forma usual es la mostrada } \\
\hline Comentarios & \multicolumn{2}{|c|}{ No hay comentarios adicionales } \\
\hline
\end{tabular}


39. Unidad fraseológica 39

\section{UF39 poner la zancadilla a alguieñ jemandem ein Bein stellen}

\begin{tabular}{|c|c|c|}
\hline \multirow{3}{*}{$\begin{array}{l}\text { Niveles de } \\
\text { equivalencia }\end{array}$} & Formal & Misma estructura sintáctica (V. + CD + Cl) \\
\hline & Léxica & $\begin{array}{l}\text { Cabe destacar el uso del indeterminado en alemán (ein) } \\
\text { frente al determinado en español (la). También destacaremo } \\
\text { la escasa productividad del sustantivo español zancadilla } \\
\text { fuera de contextos fraseológicos, mientras que la palabra } \\
\text { alemana es usual, Bein, lit. pierna }\end{array}$ \\
\hline & Idiomática & $\begin{array}{l}\text { Mismo significado fraseológico: molestar, impedir a alguien } \\
\text { hacer algo }\end{array}$ \\
\hline \multirow[t]{3}{*}{$\begin{array}{l}\text { Consulta } \\
\text { fraseográfica }\end{array}$} & Español & $\begin{array}{l}\text { Seco (2005: 1058). No aparece catalogada en Buitrago, sí er } \\
\text { Junceda (2009: 459) }\end{array}$ \\
\hline & Alemán & $\begin{array}{l}\text { Schemann (2013: } 78) \text {. Aparece también la versión afirmativa } \\
\text { y con diminutivo jemandem ein Beinchen stellen y la negativa } \\
\text { kein Bein stellen }\end{array}$ \\
\hline & Bilingüe & Nedwed (2009: 191) \\
\hline \multirow[t]{2}{*}{ Páginas web } & Español & http://www.spanishdict.com/traductor/zancadilla (julio, 2014) \\
\hline & Alemán & http://www.duden.de/rechtschreibung/Bein (julio, 2014) \\
\hline $\begin{array}{l}\text { Forma } \\
\text { ampliada }\end{array}$ & \multicolumn{2}{|c|}{ En ambas lenguas son usuales las formas ampliadas con el $\mathrm{Cl}$} \\
\hline Comentarios & \multicolumn{2}{|c|}{ No hay comentarios adicionales } \\
\hline
\end{tabular}


40. Unidad fraseológica 40

\section{UF40 ponerle los nervios de punta a alguien jemandem auf die Nerven gehen}

\begin{tabular}{|c|c|c|}
\hline \multirow[t]{3}{*}{$\begin{array}{l}\text { Niveles de } \\
\text { equivalencia }\end{array}$} & Formal & $\begin{array}{l}\text { Diferente estructura sintáctica, pues en alemán aparece el } \\
\text { esquema }(V .+C l+C C L) \text {, mientras que en español el } \\
\text { esquema es }(V+C D+C C M+C l)\end{array}$ \\
\hline & Léxica & $\begin{array}{l}\text { Similares campos léxico-semánticos, algo más extensa la UF } \\
\text { española, que matiza con el sintagma preposicional de punta, } \\
\text { no presente en alemán }{ }^{103}\end{array}$ \\
\hline & Idiomática & Mismo significado fraseológico: poner muy nervioso, enervar \\
\hline \multirow{3}{*}{$\begin{array}{l}\text { Consulta } \\
\text { fraseográfica }\end{array}$} & Español & Seco (2005: 685); Buitrago (2008: 552) \\
\hline & Alemán & Schemann (2013: 673) \\
\hline & Bilingüe & Nedwed (2009: 109) \\
\hline \multirow[t]{2}{*}{ Páginas web } & Español & http://www.spanishdict.com/traductor/zancadilla (julio, 2014) \\
\hline & Alemán & $\begin{array}{l}\text { http://www.woxikon.de/wort/jemandem\%20auf\%20die\%20ner } \\
\text { ven\%20gehen.php (julio, 2014) }\end{array}$ \\
\hline $\begin{array}{l}\text { Forma } \\
\text { ampliada }\end{array}$ & \multicolumn{2}{|c|}{ La forma usual es la mostrada } \\
\hline Comentarios & \multicolumn{2}{|c|}{ No hay comentarios adicionales } \\
\hline
\end{tabular}

${ }^{103}$ La preposición auf implica en alemán un movimiento hacia arriba. 


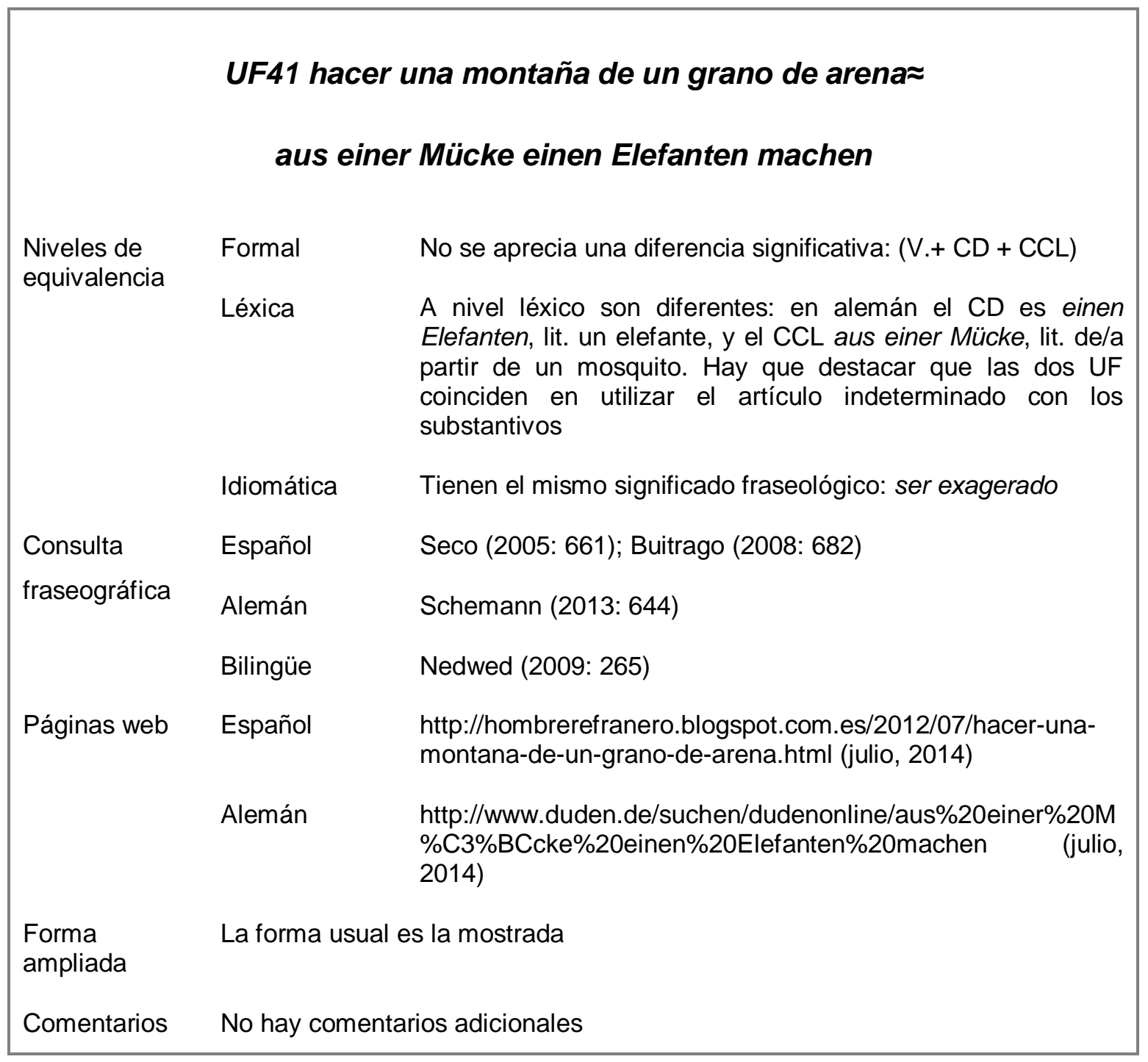




\section{UF42 tener gato encerrado die Katze im Sack kaufen}

\begin{tabular}{|c|c|c|}
\hline \multirow[t]{3}{*}{$\begin{array}{l}\text { Niveles de } \\
\text { equivalencia }\end{array}$} & Formal & $\begin{array}{l}\text { Algo diferentes: en alemán la UF presenta la estructura }(\mathrm{V} .+ \\
C D+C C) \text {, mientras que la versión española presenta la } \\
\text { estructura }(V .+C D+C \text { pred.) }\end{array}$ \\
\hline & Léxica & $\begin{array}{l}\text { Léxicamente son similares, aunque como hemos visto, } \\
\text { expresados de manera diferente. En alemán dice lit. comprar } \\
\text { el gato en el saco, con lo que es evidente el parecido con el } \\
\text { campo léxico de la expresión en español. El uso de los } \\
\text { artículos difiere, pues en alemán utiliza el determinado die, } \\
\text { mientras que en español no presenta artículo }\end{array}$ \\
\hline & Idiomática & $\begin{array}{l}\text { Mismo significado fraseológico: no ser clara una situación, es } \\
\text { decir, encerrar algo una sorpresa desagradable }\end{array}$ \\
\hline \multirow[t]{3}{*}{$\begin{array}{l}\text { Consulta } \\
\text { fraseográfica }\end{array}$} & Español & $\begin{array}{l}\text { Seco (2005: 491); Buitrago (2008: 53), con la variante haber } \\
\text { gato encerrado }\end{array}$ \\
\hline & Alemán & Schemann (2013: 466) \\
\hline & Bilingüe & Nedwed (2009:72) \\
\hline \multirow[t]{2}{*}{ Páginas web } & Español & $\begin{array}{l}\text { http://www.lasfrasesparahoy.com/rec/frorigen005.htm } \\
\text { 2014) }\end{array}$ \\
\hline & Alemán & $\begin{array}{l}\text { http://de.wiktionary.org/wiki/die_Katze_im_Sack_kaufen (julio, } \\
\text { 2014) }\end{array}$ \\
\hline $\begin{array}{l}\text { orma } \\
\text { mpliada }\end{array}$ & \multicolumn{2}{|c|}{ La forma usual es la mostrada } \\
\hline Comentarios & \multicolumn{2}{|c|}{$\begin{array}{l}\text { En infinitivo presentará esta estructura }(C D+C C+V .) \text {, por lo comentado } \\
\text { anteriormente- la disposición en alemán del infinitivo al final de frase en las } \\
\text { estructuras de infinitivo-, pero en su forma conjugada aparecerá así }(V .+C D+ \\
C C L)\end{array}$} \\
\hline
\end{tabular}


43. Unidad fraseológica 43

\section{UF43 levantarse con el pie izquierdo $\approx$ mit dem linken Fuß zuerst aufstehen}

\begin{tabular}{|c|c|c|}
\hline \multirow[t]{3}{*}{$\begin{array}{l}\text { Niveles de } \\
\text { equivalencia }\end{array}$} & Formal & $\begin{array}{l}\text { Estructura morfosintáctica muy similar en ambas } \\
\text { construcciones ( } V \text {. + CCInstrumento), con el matiz de que en } \\
\text { alemán aparece un adverbio temporal (zuerst, lit. en primer } \\
\text { lugar), y que el verbo en español es reflexivo, mientras que } \\
\text { en alemán no }\end{array}$ \\
\hline & Léxica & $\begin{array}{l}\text { Similar en ambas expresiones, con las salvedades ya } \\
\text { avanzadas. Utiliza en los dos casos el artículo determinado } \\
\text { con el sustantivo el pie/dem (linken) Fuß }\end{array}$ \\
\hline & Idiomática & Mismo significado fraseológico: tener un mal día \\
\hline \multirow{3}{*}{$\begin{array}{l}\text { Consulta } \\
\text { fraseográfica }\end{array}$} & Español & Seco (2005: 792); Buitrago (2008: 410) \\
\hline & Alemán & Schemann (2013: 256) \\
\hline & Bilingüe & Nedwed (2009: 127) \\
\hline \multirow[t]{2}{*}{ Páginas web } & Español & $\begin{array}{l}\text { http://diccionario.reverso.net/espanol- } \\
\text { ingles/levantarse\%20con\%20el\%20pie\%20izquierdo } \\
\text { 2014) }\end{array}$ \\
\hline & Alemán & $\begin{array}{l}\text { http://www.redensarten- } \\
\text { index.de/suche.php?suchbegriff= mit dem linken \%2F } \\
\text { falschen \%2F verkehrten Fuss \%2F Bein (zuerst) } \\
\text { aufstehen\%2F aufgestanden (julio, 2014) }\end{array}$ \\
\hline $\begin{array}{l}\text { Forma } \\
\text { ampliada }\end{array}$ & \multicolumn{2}{|c|}{ La forma usual es la mostrada } \\
\hline Comentarios & \multicolumn{2}{|c|}{ No hay comentarios adicionales } \\
\hline
\end{tabular}


44. Unidad fraseológica 44

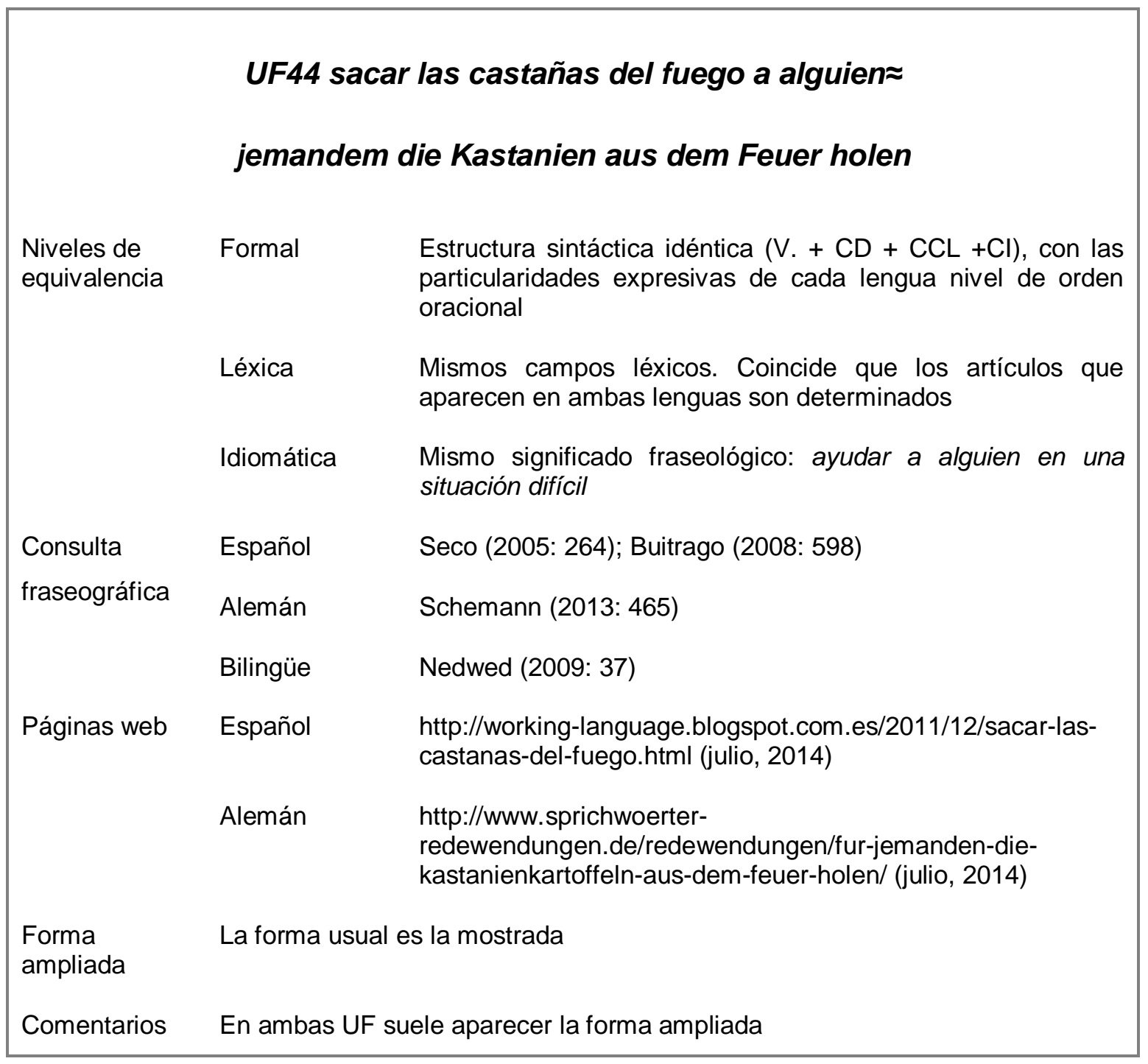


45. Unidad fraseológica 45

\begin{tabular}{|c|c|c|}
\hline \multicolumn{3}{|c|}{ UF45 coger el toro por los cuernos $\approx$ den Stier bei den Hörnern packen } \\
\hline \multirow{3}{*}{$\begin{array}{l}\text { Niveles de } \\
\text { equivalencia }\end{array}$} & Formal & Misma estructura sintáctica $(\mathrm{V} .+\mathrm{CD}+\mathrm{CCL})$ \\
\hline & Léxica & $\begin{array}{l}\text { Mismos campos léxicos. Coinciden también en que los } \\
\text { artículos de los substantivos en ambas lenguas son } \\
\text { determinados }\end{array}$ \\
\hline & Idiomática & Mismo significado fraseológico: afrontar una situación \\
\hline \multirow{3}{*}{$\begin{array}{l}\text { Consulta } \\
\text { fraseográfica }\end{array}$} & Español & Seco (2005: 984); Buitrago (2008: 101) \\
\hline & Alemán & Schemann (2013: 931) \\
\hline & Bilingüe & Nedwed (2009: 162) \\
\hline \multirow[t]{2}{*}{ Páginas web } & Español & $\begin{array}{l}\text { http://dictionary.reverso.net/spanish- } \\
\text { english/coger\%20el\%20toro\%20por\%20los\%20cuernos (julio, } \\
\text { 2014) }\end{array}$ \\
\hline & Alemán & $\begin{array}{l}\text { http://www.phraseo.de/phrase/den-stier-bei-den-hoernern- } \\
\text { packen/ (julio, 2014) }\end{array}$ \\
\hline $\begin{array}{l}\text { Forma } \\
\text { ampliada }\end{array}$ & \multicolumn{2}{|c|}{ La forma usual es la mostrada } \\
\hline Comentarios & \multicolumn{2}{|c|}{ No hay comentarios adicionales } \\
\hline
\end{tabular}


46. Unidad fraseológica 46

\section{UF46 pobre como una rata arm wie ein Kirchenmaus}

\begin{tabular}{|c|c|c|}
\hline \multirow[t]{3}{*}{$\begin{array}{l}\text { Niveles de } \\
\text { equivalencia }\end{array}$} & Formal & $\begin{array}{l}\text { Las dos UF presentan la misma estructura ( } P \text {. comparativa+ } \\
\text { [V]), que se actualiza con el verbo copulativo en ambos casos }\end{array}$ \\
\hline & Léxica & $\begin{array}{l}\text { Mismo léxico. Además ambas UF presentan artículos } \\
\text { indeterminados precediendo al substantivo. Se destaca que } \\
\text { en alemán añade connotaciones: Kirchenmaus, lit. ratón de } \\
\text { iglesia }\end{array}$ \\
\hline & Idiomática & Mismo significado fraseológico: ser muy pobre \\
\hline \multirow{3}{*}{$\begin{array}{l}\text { Consulta } \\
\text { fraseográfica }\end{array}$} & Español & Seco (2005: 863); Buitrago (2008: 440) \\
\hline & Alemán & Schemann (2013: 476) \\
\hline & Bilingüe & Nedwed (2009: 40) \\
\hline \multirow[t]{2}{*}{ Páginas web } & Español & $\begin{array}{l}\text { http://es.thefreedictionary.com } / \mathrm{m} \% \mathrm{C} 3 \% \mathrm{~A} 1 \mathrm{~s}+\text { pobre+que+una+ } \\
\text { rata (marzo, 2013) }\end{array}$ \\
\hline & Alemán & $\begin{array}{l}\text { http://www.eudict.com/?lang=gereng\&word=arm\%20wie\%20e } \\
\text { ine\%20Kirchenmaus (marzo, 2013) }\end{array}$ \\
\hline $\begin{array}{l}\text { Forma } \\
\text { ampliada }\end{array}$ & \multicolumn{2}{|c|}{ Ser pobre como una rata $\approx$ arm wie ein Kirchenmaus sein } \\
\hline Comentarios & \multicolumn{2}{|c|}{$\begin{array}{l}\text { En español también aparece la versión más pobre que una rata, que presenta } \\
\text { algunas diferencias a partir de esa estructura común (V. + Atrib.), pues } \\
\text { desarrolla el Atributo mediante un comparativo de superioridad con un segundo } \\
\text { término de la comparación (más pobre que) }\end{array}$} \\
\hline
\end{tabular}


47. Unidad fraseológica 47

\begin{tabular}{|c|c|c|}
\hline \multicolumn{3}{|c|}{ UF47 echar tierra en los ojos $\approx$ jemandem Sand in die Augen streuen } \\
\hline \multirow{3}{*}{$\begin{array}{l}\text { Niveles de } \\
\text { equivalencia }\end{array}$} & Formal & Idéntica estructura sintáctica (V. + CD + Cl + CCL) \\
\hline & Léxica & Mismo léxico empleado en ambas UF \\
\hline & Idiomática & Mismo significado fraseológico: importunar (para vencer) \\
\hline \multirow{3}{*}{$\begin{array}{l}\text { Consulta } \\
\text { fraseográfica }\end{array}$} & Español & $\begin{array}{l}\text { No aparece en las obras consultadas: Seco (2005); Buitrago } \\
\text { (2008); Junceda (2009); Domínguez (1995); Varela (1994) }\end{array}$ \\
\hline & Alemán & Schemann (2013: 802) \\
\hline & Bilingüe & Nedwed (2009: 293) \\
\hline \multirow[t]{2}{*}{ Páginas web } & Español & $\begin{array}{l}\text { http://es.thefreedictionary.com/echar+tierra; } \\
\text { http://www.speakinglatino.com/word/echar-tierra-en-los-ojos/ } \\
\text { (marzo, 2013) }\end{array}$ \\
\hline & Alemán & http://www.redensarten.net/Sand.html (marzo, 2013) \\
\hline $\begin{array}{l}\text { Forma } \\
\text { ampliada }\end{array}$ & \multicolumn{2}{|c|}{ La forma usual es la mostrada } \\
\hline Comentarios & \multicolumn{2}{|c|}{ No hay comentarios adicionales } \\
\hline
\end{tabular}


48. Unidad fraseológica 48

\begin{tabular}{|c|c|c|}
\hline \multicolumn{3}{|c|}{ UF48 encontrar un pelo en la sopa $\approx$ ein Haar in der Suppe finden } \\
\hline \multirow{3}{*}{$\begin{array}{l}\text { Niveles de } \\
\text { equivalencia }\end{array}$} & Formal & Misma estructura sintáctica (V. + CD + CCL) \\
\hline & Léxica & $\begin{array}{l}\text { Mismo léxico, igual uso de los artículos también en ambas UF } \\
\text { (en el CD: indeterminado; en el CCL: determinado) }\end{array}$ \\
\hline & Idiomática & $\begin{array}{l}\text { Mismo significado fraseológico: encontrar los defectos a algo, } \\
\text { es decir, hacer un descubrimiento desagradable }\end{array}$ \\
\hline \multirow[t]{3}{*}{$\begin{array}{l}\text { Consulta } \\
\text { fraseográfica }\end{array}$} & Español & $\begin{array}{l}\text { No aparece catalogada en las obras consultadas: Seco } \\
\text { (2005); Buitrago; (2008); Junceda (2009); Domínguez (1995); } \\
\text { Varela (1994) }\end{array}$ \\
\hline & Alemán & Schemann (2013: 345) \\
\hline & Bilingüe & Nedwed (2009: 227) \\
\hline \multirow[t]{2}{*}{ Páginas web } & Español & $\begin{array}{l}\text { http://forum.wordreference.com/showthread.php?t=1763835\&I } \\
\text { angid=24 (julio, 2014). }\end{array}$ \\
\hline & Alemán & http://uli.söhnel.info/redewendungen/haar.php (julio, 2014) \\
\hline $\begin{array}{l}\text { Forma } \\
\text { ampliada }\end{array}$ & \multicolumn{2}{|c|}{ La forma usual es la mostrada } \\
\hline Comentarios & \multicolumn{2}{|c|}{ No hay comentarios adicionales } \\
\hline
\end{tabular}


49. Unidad fraseológica 49

\section{UF49 meter la nariz en todo die Nase in alles stecken}

\begin{tabular}{|c|c|c|}
\hline \multirow{3}{*}{$\begin{array}{l}\text { Niveles de } \\
\text { equivalencia }\end{array}$} & Formal & Misma estructura sintáctica $(V .+C D+[C C L])$ \\
\hline & Léxica & $\begin{array}{l}\text { Mismo vocabulario, teniendo en cuenta que el alemán utiliza } \\
\text { la forma en singular (Nase), y en español aparece la forma en } \\
\text { plural (narices). }\end{array}$ \\
\hline & Idiomática & Mismo significado fraseológico: inmiscuirse \\
\hline \multirow{3}{*}{$\begin{array}{l}\text { Consulta } \\
\text { fraseográfica }\end{array}$} & Español & Seco (2005: 682); Buitrago (2008: 453) \\
\hline & Alemán & Schemann (2013: 666) \\
\hline & Bilingüe & Nedwed (2009: 269) \\
\hline \multirow[t]{2}{*}{ Páginas web } & Español & $\begin{array}{l}\text { http://www.collinsdictionary.com/dictionary/spanish- } \\
\text { english/meter-las-narices-en-algo (marzo, 2013) }\end{array}$ \\
\hline & Alemán & http://www.duden.de/rechtschreibung/Nase (marzo, 2013) \\
\hline $\begin{array}{l}\text { Forma } \\
\text { ampliada }\end{array}$ & \multicolumn{2}{|c|}{$\begin{array}{l}\text { Se actualiza generalmente en la versión extendida meter las narices en todo } \\
\approx \text { die Nase in alles stecken, aunque también se utiliza en la breve, sin el CCL }\end{array}$} \\
\hline Comentarios & \multicolumn{2}{|c|}{$\begin{array}{l}\text { La forma en plural narices es especialmente productiva a nivel fraseológico y } \\
\text { apenas usada fuera de él, como se ha comentado más arriba, a propósito de } \\
\text { otra UF (UF37) }\end{array}$} \\
\hline
\end{tabular}


50. Unidad fraseológica 50

\begin{tabular}{|c|c|c|}
\hline \multicolumn{3}{|c|}{ UF50 enseñarle los dientes a alguieñ jemandem die Zähne zeigen } \\
\hline \multirow{3}{*}{$\begin{array}{l}\text { Niveles de } \\
\text { equivalencia }\end{array}$} & Formal & Misma estructura sintáctica $(V .+C D+C l)$ \\
\hline & Léxica & $\begin{array}{l}\text { Mismo léxico en ambas UF, incluso coinciden los artículos, } \\
\text { siendo determinados en ambos casos }\end{array}$ \\
\hline & Idiomática & Mismo significado fraseológico: tener una actitud amenazante \\
\hline \multirow{3}{*}{$\begin{array}{l}\text { Consulta } \\
\text { fraseográfica }\end{array}$} & Español & Seco (2005: 394); Buitrago (2008: 271) \\
\hline & Alemán & Schemann (2013: 1161) \\
\hline & Bilingüe & Nedwed (2009: 343) \\
\hline \multirow[t]{2}{*}{ Páginas web } & Español & $\begin{array}{l}\text { http://www.esacademic.com/dic.nst/sp_sp_dichos_refranes/8 } \\
\text { 81/ense\%C3\%B1ar (marzo, 2013) }\end{array}$ \\
\hline & Alemán & $\begin{array}{l}\text { http://www.duden.de/suchen/dudenonline/die\%2BZ\%C3\%A4h } \\
\text { ne\%2Bzeigen (marzo, 2013) }\end{array}$ \\
\hline $\begin{array}{l}\text { Forma } \\
\text { ampliada }\end{array}$ & \multicolumn{2}{|c|}{ La forma usual es la mostrada } \\
\hline Comentarios & \multicolumn{2}{|c|}{ No hay comentarios adicionales } \\
\hline
\end{tabular}




\section{ANEXO II. ENCUESTAS}

ENCUESTA ESPAÑOL

COMPETENCIA ACTIVA. EJERCICIO 1

Completa las siguientes frases con las expresiones que consideres oportunas.

Ejemplo:

Las presiones que sufre el director son tanto por parte de los clientes, como de los proveedores. Difícil solución, se diría que

Solución: está entre dos fuegos

1. Ana se ve con otro, y no es sólo una buena amistad. Lo siento por su novio, pero creo que le

2. No estoy del todo seguro de la honestidad de Esteban, y más en estos tiempos de corrupción. Yo por él hoy no

3. Juan y Pedro no paran de discutir todo el día, están siempre

4. Pedro dice siempre lo que piensa, aunque pueda ofender a alguien. Desde luego, de él se puede decir claramente que no

5. La historia que contó era para a cualquiera: si me pasa a mí, me muero de miedo.

6. Ahora dicen que conducir suavemente reduce el consumo... ¡Vaya novedad!, se creerán que han

7. La comunión de la niña les está suponiendo muchos gastos: se empeñaron en que fuera diferente a todas y están

8. El profesor hablaba y hablaba, pero no entendíamos nada, todo aquello nos

9. Por fin acabé el trabajo y puedo sentarme contigo. Cuéntame con detalle eso que me decías, soy

10. No sigas hablando de los deliciosos platos que degustaste en la cenamaridaje, no puedo más, se me 


\section{ENCUESTA ESPAÑOL}

COMPETENCIA ACTIVA. EJERCICIO 2

Ahora haz lo mismo con estas otras frases:

1. A María no le gusta utilizar eufemismos como 'pompis' o 'trasero'. Si tiene que decir 'culo', esa es la palabra que utiliza. Defiende que hay que llamar

2. Déjalo ya estar, no lo empeores más. La situación ya es bastante crítica, no hace falta que eches

3. Nunca hace nada por nadie. Si algún día necesita algo, que no se extrañe si le pagan

4. Juan nos ha contado una historia que no tiene ningún sentido. Vamos, que no tiene

5. Al periodista le pidieron que redactase un cuento en conmemoración del aniversario de la revista. En él dejó entrever el ambiente laboral que se respiraba en ese momento. Inmejorable ocasión, pensó, para matar

6. Lo conozco bien, y no es que esté ahora trastornado por su situación actual, es de siempre. A veces parece que le falte

7. En cuanto la conoció, supo que era su chica. Desde luego aquello fue amor

8. ¿Cómo era el título de la película? Estoy todo el día dándole vueltas, y el caso es que lo tengo en

9. No te preocupes, Juan puede aportar la cantidad exigida como fianza sin problemas, pues dicen que en estos momentos él nada

10. Esther no hace más que invertir en negocios sin calcular demasiado los resultados. A este paso, me temo que perderá 


\section{ENCUESTA ESPAÑOL}

\section{COMPETENCIA PASIVA. EJERCICIO 3}

Relaciona estas expresiones con las frases que aparecen a continuación:

Meter la cuchara

Estar en el séptimo cielo

Ser la oveja negra de la familia

Ser un lobo con piel de cordero

Tener sangre azul

No ser ni carne ni pescado

Nadar a contracorriente

Saber dónde le aprieta el zapato a alguien

Tender un puente de plata

Perder el hilo

1. Cuando se lleva la falda larga, Ester utiliza minifalda. Cuando se lleva la minifalda, ella se pone falda larga. Le gusta

2. Pedro parece muy amable y dulce, pero procura no tener problemas con él; como dice Ana, es

3. En casa de María ya no saben qué hacer con él: ni estudia, ni trabaja, y siempre con problemas. Desde luego ya dice la propia María que su hermano

4. En mitad de su conferencia, en el momento en que estaba haciendo un análisis de la situación internacional, se calló de repente, de lo que estaba diciendo, y ya no pudo seguir adelante.

5. ¡Cómo se estaba en Punta Cana! Todo el día de la playa a la piscina del hotel, y por la noche fiesta siempre. Vamos, que esos días

6. Al principio, no decía nada, pero conforme fue avanzando la reunión aprovechó cualquier ocasión para

7. A mí la música de ese grupo no me acaba de gustar: no es exactamente ni rock, ni pop, ni música indi. Vamos, que

8. Ya nos causó bastantes problemas en el pasado. Si ahora se quiere marchar de la empresa, adelante, Como se suele decir:

9. No te preocupes, déjamelo a mí, que lo conozco bien: hemos pasado muchas juntas, buenas y malas, como si lo hubiera criado yo:

10. Según dicen, su familia es de ascendencia noble. ¿Quién nos iba a decir que nuestra amiga ? 


\section{ENCUESTA ESPAÑOL}

\section{COMPETENCIA PASIVA. EJERCICIO 4}

Elige la expresión que consideres más adecuada para finalizar las siguientes frases:

A. Desde el principio, Ana nos ha dicho bien claro por qué se queda con nosotros. Ella siempre...

1. juega con las cartas boca arriba.

2. juega con cartas marcadas.

3. es muy clara.

B. Pedro hace en su casa lo que quiere. Está bien claro quien...

1. lleva la corbata.

2. manda.

3. Ileva los pantalones.

C. Carlos está colado por Diana. Por su manera de actuar, se ve bien claro que...

1. quiere conquistarla.

2. le está haciendo la ronda.

3. le está haciendo la corte.

D. Javier no sabe dónde se mete, parace que ....

1. esté ciego.

2. lleve una venda en los ojos.

3. lleve una venda en la cabeza.

E. Alberto está siempre haciendo planes de cómo va a invertir esto, y luego esto en aquello, pero las cosas no le salen bien, es lo mismo de siempre:

1. hace mal las cuentas.

2. el cuento de la lechera.

3. el cuento de nunca acabar.

F. Todos han sabido ya del escándalo. El acontecimiento está ...

1. muy extendido.

2. en boca de cualquiera.

3. en boca de todos.

G. No puedo soportar más su intolerable comportamiento. En verdad, estoy ...

1. bastante cansado de él.

2. hasta las narices de él.

3. hasta los codos de él.

H. Sus planes no tienen fundamento, no le va a salir bien la venta: de nuevo ...

1. construye sobre arena.

2. construye sobre hierba.

3. hace mal los cálculos.

I. No le importunes más en su trabajo, deja de ....

1. ponerle la zancadilla.

2. molestarle.

3. ponerle la pierna.

J. Ella no soporta más a Pedro, siempre consigue ...

1. ponerle los pelos de punta

2. ponerla de mal humor.

3. ponerle los nervios de punta. 


\section{ENCUESTA ESPAÑOL}

COMPETENCIA PASIVA. EJERCICIO 5

Utiliza las siguientes expresiones en un contexto determinado o con una explicación.

Expresión: Quien hambre tiene, sopas sueña

CONTEXTO: Juan no suele ligar. Para colmo, cada vez que alguna mujer le mira, cree que está interesada en él. Ya se sabe: quien hambre tiene, sopas sueña.

EXPLICACIÓN: El que desea mucho algo, piensa que continuamente se está aludiendo a ello.

1. Hacer una montaña de un grano de arena $\rightarrow$

2. Tener gato encerrado $\rightarrow$

3. Levantarse con el pie izquierdo $\rightarrow$

4. Sacar las castañas del fuego a alguien $\rightarrow$

5. Coger el toro por los cuernos $\rightarrow$

6. Ser pobre como una rata $\rightarrow$

7. Echar tierra a los ojos $\rightarrow$

8. Encontrar un pelo en la sopa $\rightarrow$

9. Meter las narices en todo $\rightarrow$

10. Enseñar los dientes a alguien $\rightarrow$ 
ENCUESTA ESPAÑOL. DATOS SOCIOLÓGICOS

DATOS PERSONALES

A. INFORMANTE

1. EDAD

\begin{tabular}{|l|l|}
\hline año nacimiento & edad \\
\hline
\end{tabular}

2. SEXO

\begin{tabular}{|l|l|}
\hline mujer & hombre \\
\hline
\end{tabular}

3. LENGUA MATERNA LENGUA HABITUAL

\begin{tabular}{ll|l}
\hline castellano & valenciano & otra ¿cuál?) \\
\hline
\end{tabular}

4. LUGAR RESIDENCIA

Población

5. NIVEL DE ESTUDIOS ALCANZADO

B. FAMILIA

FORMACIÓN

- PADRES (formación que tienen)

\begin{tabular}{|l|c|}
\hline & NIVEL DE ESTUDIOS ALCANZADO \\
\hline MADRE & \\
\hline PADRE & \\
\hline
\end{tabular}

TRABAJO

- PADRES (ocupación que tienen/ tuvieron)

\begin{tabular}{|l|l|l|l|l|}
\hline & \multicolumn{2}{|c|}{ ACTIVO } & $\begin{array}{c}\text { OCUPACION } \\
\text { HABITUAL }\end{array}$ & OTRAS ESPECIFICACIONES \\
\hline MADRE & SI & NO & & \\
\hline PADRE & SI & NO & & \\
\hline
\end{tabular}

C. TIEMPO DE VIDA EN FAMILIA (horas compartidas con otros miembros de la familia por semana)

- CON LOS ABUELOS

\begin{tabular}{|c|c|c|c|c|c|c|}
\hline Maternos & 0 horas & $1-5$ & $6-10$ & $11-15$ & $16-20$ & +20 \\
\hline & & & & & & \\
\hline
\end{tabular}

\begin{tabular}{|c|c|c|c|c|c|c|}
\hline Paternos & 0 horas & $1-5$ & $6-10$ & $11-15$ & $16-20$ & +20 \\
\hline & & & & & & \\
\hline
\end{tabular}




\section{ENCUESTA ALEMÁN}

COMPETENCIA ACTIVA. EJERCICIO 1

Ergänzen Sie die Sätze mit den Ausdrücken, die Sie für korrekt halten .

Beispiel:

Karl war angeblich sehr traurig, aber es ist nicht wahr: er hat

Lösung: Krokodilstränen geweint

1. Björn betrügt seine Frau. Ich finde das nicht richtig, dass er

2. Ich traue ihm, er ist ein ehrlicher Kerl. Ich würde für ihn meine Hand

3. Sie streiten immer noch. Sie sind wie

4. Ute sagt immer, was sie meint, auch wenn sie jemanden beleidigen könnte. Sie

5. Seine Erzählung war so spannend, dass mir

6. Die Idee des Direktors ist nicht ganz neu, aber er tut so, als hätte er das

7. Jens kauft sich jeden Tag Dinge, die er gar nicht braucht. Er

8. Der Chemielehrer sprach ununterbrochen mehr als zwei Stunden, ich verstand überhaupt nichts. Der Vortrag

9. Erzähle mir von deinem Problem. Ich

10. Hör bitte auf! Ich bin hungrig und du sprichst nur übers Essen. Mir 


\section{ENCUESTA ALEMÁN}

COMPETENCIA ACTIVA. EJERCICIO 2

Ergänzen Sie weiter diese Sätze mit den Ausdrücken, die Sie für korrekt halten.

1. Petra redet nicht um den heißen Brei herum. Sie die Dinge

2. Sie haben schon einen großen Streit. Sag ihnen nichts, kein

3. Sie hat ihn schlecht behandelt. Sie darf sich nicht wundern, wenn er ihr es heimzahlt.

4. Die Geschichte von Johannes ergibt keinen Sinn. Sie hat weder

5. Du bist bei deiner Chefin zur Party eingeladen: wenn du gehst, wirst du Spaß haben und die Beziehung mit ihr verbessern. So schlägst du

6. Seine Mutter benimmt sich ständig komisch. Die Leute sagen, sie hat nicht alle

7. Als sie inn kennenlernte, wusste sie sofort, dass er ihr Typ war. Es war

8. Ich komme gerade nicht darauf. Es liegt

9. Sie hat im Lotto gewonnen. Jetzt schwimmt

10. Beim Poker hat er alles verloren. Seine Mitspieler haben ihn bis aufs 


\section{ENCUESTA ALEMÁN \\ COMPETENCIA PASIVA. EJERCICIO 3}

Jede Redewendung passt zu einem Satz. Ergänzen Sie bitte:

gegen den Strom schwimmen

seinen Senf dazu geben

im siebten Himmel sein

den Faden verlieren

weder Fisch noch Fleisch

das schwarze Schaf der Familie sein

ein Wolf im Schafspelz sein

blaues Blut haben

wissen, wo einen der Schuh drückt

eine goldene Brücke bauen

1. Sie glaubt, über jedes beliebige Thema Bescheid zu wissen. Immer muss sie

2. Ich bin total verliebt. Ich bin

3. Seine Eltern wissen nicht, was sie mit inm machen sollen: Er arbeitet nicht und bereitet innen immer Sorgen. Er ist

4. Stephan sieht sehr nett und höflich aus, aber er ist ganz anders. Er ist

5. Der Volksmund sagt, dass Adelige

6. Entweder man ist dafür oder dagegen. Dieses Verfahren ist

7. Wenn lange Röcke in Mode kommen, zieht Simone sich einen kurzen Rock an. Wenn kurze Röcke Mode sind, zieht sie sich einen langen Rock an. Ihr gefällt es, gegen

8. Er spricht nie über seine Probleme, aber ich weiß, wo

9. Die Professorin ist sehr beliebt. Wenn die Studenten nicht auf die Lösung kommen,

10. Ich wusste genau, was ich sagen wollte. Aber durch die Unterbrechung 


\section{ENCUESTA ALEMÁN}

COMPETENCIA PASIVA. EJERCICIO 4

Jeder Satz passt zu einem Ausdruck. Ergänzen Sie bitte.

A. Anja hat uns ganz deutlich gesagt, warum sie bei uns bleibt, sie...

1. spielt mit offenen Karten.

2. spielt mit gezinkten Karten.

3. hat die besseren Karten.

B. Klaus macht zu Hause immer, was er will. Er...

1. zieht den Hut tief ins Gesicht.

2. hat eine weiße Weste.

3. hat die Hosen an.

C. Dieter ist in Diana verliebt, er...

1. fegt für sie den Hof.

2. singt unter ihrem Fenster im Hof.

3. macht ihr den Hof.

D. Karl weiß nicht mehr, was er tut.

1. Er ist ein kluger Kopf.

2. Er hat ein Brett vor dem Kopf.

3. Er hat den Kopf verloren.

E. Ihre Rechnung geht nicht auf.

1. Sie hat die Rechnung ohne den Wirt gemacht.

2. Das ist eine Milchmädchenrechnung.

3. Das ist eine Blumenmädchenrechnung.

F. Alle haben bereits von dem Skandal gehört. Das Ereignis ist...

1. auf allen Plätzen.

2. in allen Straßen.

3. in aller Munde.

G. Ich kann sein unanständiges Benehmen nicht mehr ertragen. Ich ...

1. habe das Auge voll.

2. habe die Nase voll.

3. habe den Kopf voll.

H. Seine Pläne sind sehr riskant. Er...

1. baut auf Sand.

2. baut auf sicherem Grund.

3. baut vor.

I. Lass inn seine Arbeit beenden und behindere inn nicht dabei.

1) Stell ihm kein Bein.

2) Leg inm keine Steine vor die Füße.

3) Leg inm keine Steine in den Weg.

J. Sie kann Paul nicht mehr aushalten. Er...

1) geht mit ihr laufen.

2) geht nicht weg.

3) geht ihr auf die Nerven. 


\section{ENCUESTA ALEMÁN}

COMPETENCIA PASIVA. EJERCICIO 5

Erklären Sie, was diese Ausdrücke bedeuten. Sie können auch Synonyme benutzen.

Ausdruck: um den heißen Brei herumgehen

KONTEXT: Anja fühlt sich sehr unwohl, aber sie will nicht darüber sprechen.

Sie geht um das Problem herum, wie die Katze um den heißen Brei.

ERKLÄRUNG: etwas Unangenehmes vermeiden

1. aus einer Mücke einen Elefanten machen $\rightarrow$

2. die Katze im Sack kaufen $\rightarrow$

3. mit dem linken Fuß zuerst aufstehen $\rightarrow$

4. jemandem die Kastanien aus dem Feuer holen $\rightarrow$

5. den Stier bei den Hörnern packen $\rightarrow$

6. arm wie eine Kirchenmaus sein $\rightarrow$

7. jemandem Sand in die Augen streuen $\rightarrow$

8. ein Haar in der Suppe finden $\rightarrow$

9. die Nase in alles stecken $\rightarrow$

10. jemandem die Zähne zeigen $\rightarrow$ 
ENCUESTA ALEMÁN. DATOS SOCIOLÓGICOS

PERSONALIEN

A. TEILNEHMER/ IN

1. ALTER

2. GESCHLECHT

3. MUTTERSPRACHE

2. HÄUFIGSTE SPRACHE

4. WOHNORT

5. AKADEMISCHER GRAD ODER SCHULABSCHLUSS

\begin{tabular}{|l|l|}
\hline GEBOREN IN & ALTER \\
\hline FRAU & MANN \\
\hline
\end{tabular}

\begin{tabular}{|l|l|l|}
\hline DEUTSCH & ANDERE & welche? \\
\hline DEUTSCH & ANDERE & welche? \\
\hline
\end{tabular}

\begin{tabular}{|l|l|}
\hline STADT & \\
\hline
\end{tabular}

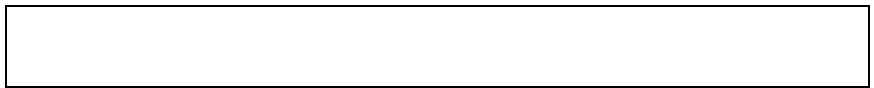

B. FAMILIE

AUSBILDUNG

- ELTERN

\begin{tabular}{|l|c|}
\hline & AKADEMISCHER GRAD ODER SCHULABSCHLUSS \\
\hline MUTTER & \\
\hline VATTER & \\
\hline
\end{tabular}

ARBEIT

\section{- ELTERN}

\begin{tabular}{|l|l|l|l|l|}
\hline & \multicolumn{2}{|l|}{ BERUFSTÄTIG } & $\begin{array}{c}\text { STÄNDIGER } \\
\text { JOB }\end{array}$ & ANMERKUNGEN \\
\hline MUTTER & JA & NEIN & & \\
\hline VATTER & JA & NEIN & & \\
\hline
\end{tabular}

C. ZUSAMMENLEBEN

Wie viel Zeit verbringst du gewöhnlich pro Woche mit anderen Mitgliedern deiner Familie?

- MIT DEN GROßELTERN

\begin{tabular}{|c|c|c|c|c|c|c|}
\hline \multirow{2}{*}{$\begin{array}{c}\text { ELTERN DER } \\
\text { MUTTER }\end{array}$} & O Stunden & $1-5$ & $6-10$ & $11-15$ & $16-20$ & +20 \\
\hline & & & & & & \\
\hline $\begin{array}{c}\text { ELTERN DES } \\
\text { VATERS }\end{array}$ & O Stunden & $1-5$ & $6-10$ & $11-15$ & $16-20$ & +20 \\
\hline
\end{tabular}




\section{ANEXO III. DOCUMENTACIÓN ESTADÍSTICA}

\section{Archivo SPSS. Pantalla de variables}

\begin{tabular}{|c|c|c|c|c|c|c|c|c|c|c|}
\hline Nombre & Tipo & Anchura & Decimales & Etiqueta & Valores & Perdidos & Columnas & Alineación & Medida & Ro \\
\hline SEXO & Numérico & 8 & 0 & SEXO & $\{0$, hombre $\} \ldots$ & Ninguna & 8 & Derecha & $\&$ Nominal & $\searrow$ Entra \\
\hline EDAD & Numérico & 8 & 0 & EDAD & $\{13,13$ aก̃ก $\ldots$ & Ninguna & 8 & 豆 Derecha & $\&$ Escala & $\searrow$ Entra \\
\hline IDIOMA & Cadena & 8 & 0 & IDIOMA & \{A, ALEMÁ & Ninguna & 8 & 豆 Derecha & $\&$ Nominal & $\searrow$ Entra \\
\hline BILING & Numérico & 8 & 0 & BILINGÜISMO & $\{0$, NO BILI... & Ninguna & 8 & Derecha & $\$$ Nominal & $\searrow$ Entra \\
\hline TCONVAB & Numérico & 8 & 0 & CONVIVENCIA & $\{0,0$ HORA $\ldots$ & Ninguna & 8 & Derecha & Ordinal & $\searrow$ Entra \\
\hline HCONV & Numérico & 8 & 0 & CONVIVENCIA & $\{0,0$ horas $\} \ldots$ & Ninguna & 8 & 軍 Derecha & Ordinal & $\searrow$ Entra \\
\hline UF1 & Numérico & 8 & 0 & COMPETENCl... & $\{0, N O\} \ldots$ & Ninguna & 8 & Derecha & $\infty$ Nominal & $\searrow$ Entra \\
\hline UF2 & Numérico & 8 & 0 & COMPETENCI... & $\{0, N O\} \ldots$ & Ninguna & 8 & Derecha & $\$$ Nominal & $\searrow$ Entra \\
\hline UF3 & Numérico & 8 & 0 & COMPETENCI... & $\{0, N O\} \ldots$ & Ninguna & 8 & 至 Derecha & $\&$ Nominal & $\searrow$ Entra \\
\hline UF4 & Numérico & 8 & 0 & COMPETENCI... & $\{0, N O\} \ldots$ & Ninguna & 8 & Derecha & $\infty$ Nominal & $\searrow$ Entra \\
\hline UF5 & Numérico & 8 & 0 & COMPETENCI... & $\{0, N O\} \ldots$ & Ninguna & 8 & 至 Derecha & $\$$ Nominal & $\searrow$ Entra \\
\hline UF6 & Numérico & 8 & 0 & COMPETENCI... & $\{0, N O\} \ldots$ & Ninguna & 8 & 豆 Derecha & $\&$ Nominal & $\searrow$ Entra \\
\hline UF7 & Numérico & 8 & 0 & COMPETENCI... & $\{0, N O\} \ldots$ & Ninguna & 8 & Derecha & $\&$ Nominal & $\searrow$ Entra \\
\hline UF8 & Numérico & 8 & 0 & COMPETENCI... & $\{0, N O\} \ldots$ & Ninguna & 8 & 害 Derecha & $\&$ Nominal & $\searrow$ Entra \\
\hline UF9 & Numérico & 8 & 0 & COMPETENCI... & $\{0, N O\} \ldots$ & Ninguna & 8 & Derecha & $\&$ Nominal & $\searrow$ Entra \\
\hline UF10 & Numérico & 8 & 0 & COMPETENCI... & $\{0, N O\} \ldots$ & Ninguna & 8 & Derecha & $\infty$ Nominal & $\searrow$ Entra \\
\hline UF11 & Numérico & 8 & 0 & COMPETENCI... & $\{0, N O\} \ldots$ & Ninguna & 8 & 害 Derecha & $\$$ Nominal & $\searrow$ Entra \\
\hline UF12 & Numérico & 8 & 0 & COMPETENCI... & $\{0, N O\} \ldots$ & Ninguna & 8 & 豆 Derecha & $\&$ Nominal & $\searrow$ Entra \\
\hline UF13 & Numérico & 8 & 0 & COMPETENCI... & $\{0, N O\} \ldots$ & Ninguna & 8 & Derecha & $\infty$ Nominal & $\searrow$ Entra \\
\hline UF14 & Numérico & 8 & 0 & COMPETENCI... & $\{0, N O\} \ldots$ & Ninguna & 8 & 軍 Derecha & $\$$ Nominal & $\searrow$ Entra \\
\hline UF15 & Numérico & 8 & 0 & COMPETENCI... & $\{0, N O\} \ldots$ & Ninguna & 8 & Derecha & $\$$ Nominal & $\searrow$ Entra \\
\hline UF16 & Numérico & 8 & 0 & COMPETENCI... & $\{0, N O\} \ldots$ & Ninguna & 8 & Derecha & $\infty$ Nominal & $\searrow$ Entra \\
\hline UF17 & Numérico & 8 & 0 & COMPETENCI... & $\{0, N O\} \ldots$ & Ninguna & 8 & 軍 Derecha & $\$$ Nominal & $\searrow$ Entra \\
\hline UF18 & Numérico & 8 & 0 & COMPETENCI... & $\{0, N O\} \ldots$ & Ninguna & 8 & Derecha & $\&$ Nominal & $\searrow$ Entra \\
\hline
\end{tabular}


2. Archivo SPSS. Pantalla de datos de alumnos españoles

\begin{tabular}{|c|c|c|c|c|c|c|c|c|c|c|}
\hline SEXO & EDAD & IDIOMA & BILING & TCONVAB & HCONV & UF1 & UF2 & UF3 & UF4 & UF5 \\
\hline 0 & 15 & E & 0 & 5 & 2 & 0 & 0 & 0 & 0 & 0 \\
\hline 0 & 14 & E & 1 & 0 & 0 & 0 & 0 & 0 & 0 & 0 \\
\hline 0 & 16 & $E$ & 1 & 0 & 0 & 1 & 0 & 0 & 0 & 0 \\
\hline 0 & 15 & $E$ & 0 & 0 & 0 & 0 & 0 & 0 & 0 & 0 \\
\hline 0 & 14 & $E$ & 0 & 3 & 2 & 0 & 1 & 1 & 0 & 0 \\
\hline 0 & 14 & $E$ & 0 & 3 & 2 & 0 & 0 & 0 & 0 & 0 \\
\hline 0 & 16 & $E$ & 1 & 1 & 1 & 0 & 0 & 1 & 0 & 0 \\
\hline 0 & 14 & $E$ & 0 & 4 & 2 & 1 & 0 & 0 & 0 & 0 \\
\hline 0 & 15 & $E$ & 0 & 1 & 1 & 1 & 0 & 0 & 0 & 0 \\
\hline 0 & 16 & $E$ & 1 & 2 & 1 & 0 & 1 & 1 & 1 & 0 \\
\hline 0 & 16 & $E$ & 1 & 0 & 0 & 1 & 0 & 0 & 0 & 0 \\
\hline 0 & 14 & $E$ & 0 & 2 & 1 & 1 & 0 & 0 & 1 & 0 \\
\hline 0 & 16 & E & 0 & 4 & 2 & 0 & 0 & 0 & 0 & 0 \\
\hline 0 & 14 & $E$ & 1 & 0 & 0 & 1 & 1 & 0 & 0 & 0 \\
\hline 0 & 15 & $E$ & 1 & 4 & 2 & 0 & 0 & 0 & 0 & 0 \\
\hline 0 & 15 & $E$ & 0 & 5 & 2 & 1 & 0 & 0 & 1 & 0 \\
\hline 0 & 15 & $E$ & 0 & 2 & 1 & 0 & 0 & 0 & 1 & 0 \\
\hline 0 & 15 & $E$ & 0 & 0 & 0 & 1 & 0 & 1 & 1 & 0 \\
\hline 0 & 16 & $E$ & 0 & 2 & 1 & 1 & 0 & 1 & 1 & 0 \\
\hline 0 & 17 & $E$ & 0 & 0 & 0 & 0 & 0 & 1 & 0 & 0 \\
\hline 0 & 16 & $E$ & 0 & 0 & 0 & 1 & 0 & 1 & 1 & 0 \\
\hline 0 & 16 & $E$ & 0 & 2 & 1 & 1 & 0 & 0 & 1 & 0 \\
\hline 0 & 16 & $E$ & 0 & 4 & 2 & 1 & 1 & 1 & 0 & 0 \\
\hline
\end{tabular}


3. Archivo SPSS. Pantalla de datos de alumnos alemanes

\begin{tabular}{|c|c|c|c|c|c|c|c|c|c|c|}
\hline SEXO & EDAD & IDIOMA & BILING & TCONVAB & HCONV & UF1 & UF2 & UF3 & UF4 & UF5 \\
\hline 0 & 14 & A & 0 & 3 & 2 & 0 & 0 & 0 & 0 & 0 \\
\hline 0 & 15 & A & 1 & 1 & 1 & 0 & 1 & 0 & 0 & 0 \\
\hline 0 & 15 & A & 0 & 1 & 1 & 0 & 0 & 0 & 0 & 0 \\
\hline 0 & 15 & A & 1 & 4 & 2 & 0 & 1 & 0 & 0 & 0 \\
\hline 0 & 14 & A & 0 & 0 & 0 & 0 & 1 & 0 & 0 & 0 \\
\hline 0 & 14 & A & 0 & 1 & 1 & 0 & 1 & 0 & 0 & 0 \\
\hline 0 & 15 & A & 0 & 3 & 2 & 0 & 1 & 0 & 0 & 0 \\
\hline 0 & 15 & A & 0 & 0 & 0 & 0 & 1 & 0 & 0 & 0 \\
\hline 0 & 15 & A & 1 & 0 & 0 & 0 & 1 & 0 & 1 & 0 \\
\hline 0 & 14 & A & 1 & 0 & 0 & 0 & 1 & 0 & 0 & 0 \\
\hline 0 & 14 & A & 0 & 2 & 1 & 0 & 1 & 0 & 0 & 0 \\
\hline 0 & 17 & A & 0 & 2 & 1 & 0 & 1 & 0 & 0 & 1 \\
\hline 0 & 17 & A & 0 & 0 & 0 & 0 & 1 & 0 & 0 & 0 \\
\hline 0 & 14 & A & 1 & 0 & 0 & 0 & 1 & 0 & 1 & 0 \\
\hline 0 & 15 & A & 0 & 0 & 0 & 0 & 1 & 0 & 1 & 0 \\
\hline 0 & 15 & A & 0 & 0 & 0 & 0 & 1 & 0 & 1 & 0 \\
\hline 0 & 17 & A & 0 & 0 & 0 & 0 & 1 & 0 & 0 & 1 \\
\hline 0 & 14 & A & 0 & 0 & 0 & 0 & 1 & 0 & 0 & 0 \\
\hline 0 & 15 & A & 0 & 1 & 1 & 0 & 1 & 0 & 1 & 0 \\
\hline 0 & 16 & A & 0 & 0 & 0 & 1 & 0 & 0 & 0 & 0 \\
\hline 1 & 15 & A & 1 & 2 & 1 & 0 & 1 & 0 & 0 & 0 \\
\hline 1 & 15 & A & 1 & 1 & 1 & 0 & 1 & 0 & 0 & 0 \\
\hline 1 & 15 & A & 0 & 2 & 1 & 0 & 1 & 0 & 0 & 0 \\
\hline
\end{tabular}


4. Archivo SPSS. Pantalla de datos de competencia de UF40 a UF50 de alumnos españoles

\begin{tabular}{|c|c|c|c|c|c|c|c|c|c|c|}
\hline UF40 & UF41 & UF42 & UF43 & UF44 & UF45 & UF46 & UF47 & UF48 & UF49 & UF50 \\
\hline 0 & 0 & 1 & 1 & 1 & 0 & 0 & 0 & 1 & 1 & 1 \\
\hline 0 & 0 & 0 & 1 & 1 & 0 & 1 & 1 & 0 & 1 & 0 \\
\hline 0 & 1 & 0 & 0 & 0 & 1 & 1 & 0 & 0 & 1 & 0 \\
\hline 1 & 1 & 1 & 1 & 1 & 1 & 1 & 1 & 0 & 1 & 0 \\
\hline 0 & 0 & 0 & 1 & 1 & 1 & 1 & 0 & 0 & 1 & 0 \\
\hline 0 & 1 & 0 & 1 & 1 & 1 & 1 & 1 & 0 & 1 & 1 \\
\hline 0 & 0 & 1 & 1 & 1 & 1 & 1 & 1 & 0 & 1 & 1 \\
\hline 0 & 0 & 1 & 1 & 1 & 1 & 1 & 0 & 0 & 1 & 1 \\
\hline 1 & 0 & 0 & 1 & 0 & 0 & 0 & 0 & 0 & 1 & 1 \\
\hline 1 & 1 & 0 & 1 & 1 & 0 & 1 & 0 & 0 & 1 & 1 \\
\hline 0 & 0 & 0 & 1 & 0 & 1 & 1 & 0 & 0 & 1 & 0 \\
\hline 1 & 1 & 1 & 1 & 0 & 1 & 0 & 0 & 0 & 0 & 0 \\
\hline 0 & 1 & 1 & 1 & 1 & 1 & 1 & 1 & 1 & 1 & 1 \\
\hline 1 & 1 & 1 & 1 & 1 & 1 & 1 & 1 & 1 & 1 & 1 \\
\hline 0 & 1 & 1 & 1 & 1 & 1 & 1 & 0 & 0 & 1 & 1 \\
\hline 0 & 0 & 1 & 1 & 1 & 0 & 1 & 0 & 0 & 1 & 0 \\
\hline 0 & 1 & 1 & 1 & 1 & 0 & 0 & 0 & 0 & 0 & 0 \\
\hline 1 & 1 & 1 & 1 & 1 & 1 & 1 & 0 & 0 & 1 & 0 \\
\hline 0 & 1 & 0 & 1 & 1 & 1 & 1 & 1 & 1 & 1 & 1 \\
\hline 0 & 1 & 1 & 1 & 1 & 1 & 1 & 0 & 1 & 1 & 1 \\
\hline 0 & 1 & 1 & 1 & 1 & 1 & 1 & 0 & 1 & 1 & 1 \\
\hline 1 & 1 & 0 & 1 & 0 & 0 & 0 & 0 & 0 & 0 & 0 \\
\hline 1 & 1 & 1 & 1 & 1 & 1 & 1 & 1 & 1 & 1 & 1 \\
\hline
\end{tabular}


5. Archivo SPSS. Pantalla de datos de competencia de UF40 a UF50 de alumnos alemanes

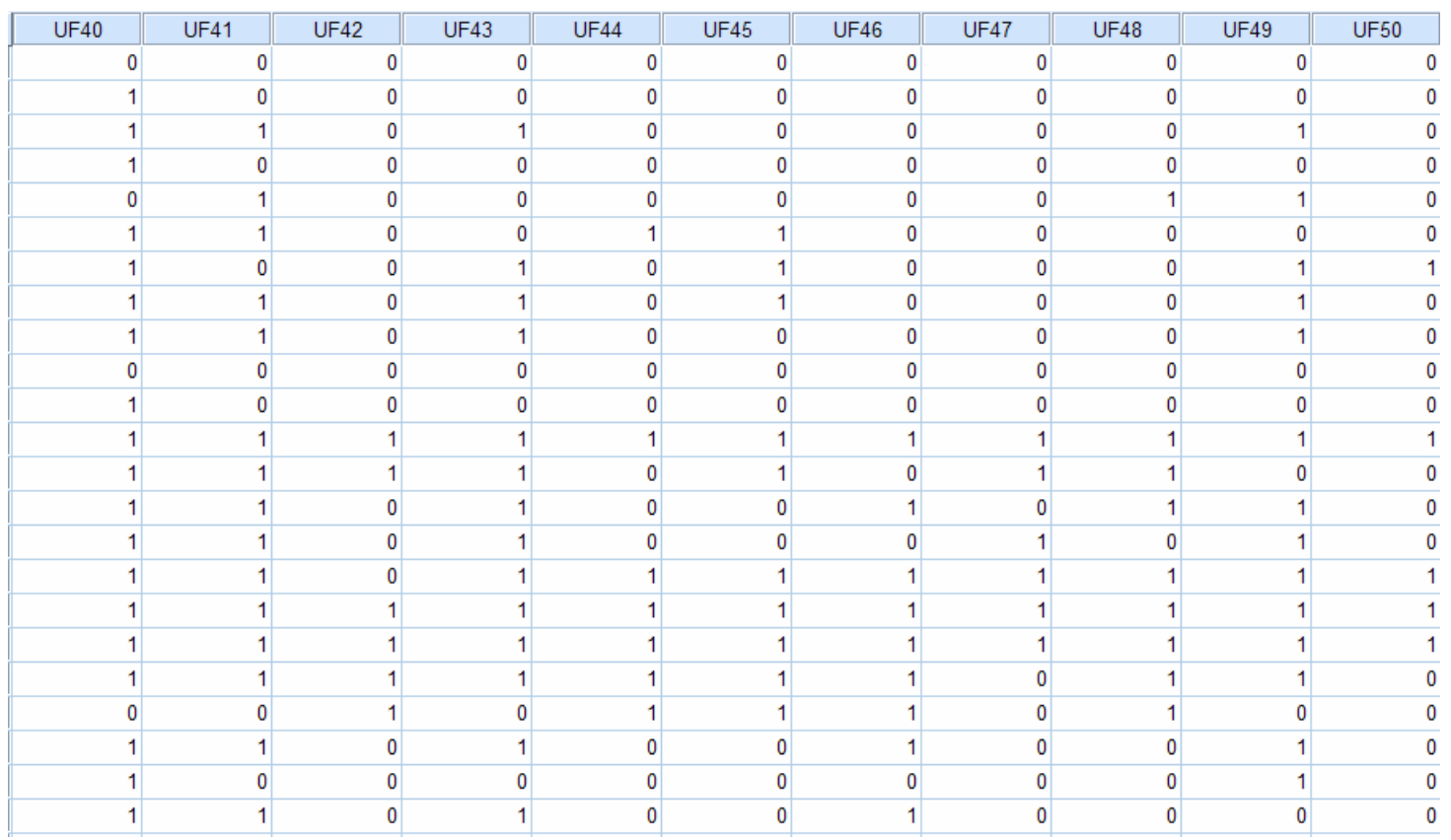

353 